\title{
A CRITICAL RATIONALIST INQUIRY OF MANAGERIAL EPISTEMOLOGY
}

TOWARD THE CONFRONTATION OF THE UNAWARENESS

PROBLEM 
Graduation committee:

Prof. Dr. P.J.J.M. van Loon (chairperson)

Prof. Dr. C.W.A.M. Aarts

Prof. Dr. S. Carlsson

Prof. Dr. U. Frank

Prof. Dr. A.J. Groen

Prof. Dr. S. Kuhlmann

Prof. Dr. B. Nooteboom

Dr. A.B.J.M. Wijnhoven
University of Twente

University of Twente

Lund University

University of Duisburg-Essen

University of Twente

University of Twente

Tilburg University

University of Twente

Printed in the Netherlands

ISBN: 978-90-365-3145-0

Copyright (C) 2011 by Doron Faran

ALL RIGHTS RESERVED. Any unauthorized reprint or use of this material is prohibited. No part of this book may be reproduced or transmitted in any form or by any means, electronic or mechanical, including photocopying, recording, or by any information storage and retrieval system without express written permission from the author / publisher. 


\title{
A CRITICAL RATIONALIST INQUIRY OF MANAGERIAL EPISTEMOLOGY \\ TOWARD THE CONFRONTATION OF THE UNAWARENESS \\ PROBLEM
}

\section{DISSERTATION}

\author{
to obtain \\ the degree of doctor at the University of Twente, \\ on the authority of the rector magnificus, \\ prof. dr. H. Brinksma, \\ on account of the decision of the graduation committee, \\ to be publicly defended \\ on Friday, February $4^{\text {th }}, 2011$ at $12: 45$
}

by

\section{Doron Faran}

born on 8 August 1956

in Haifa, Israel 
This dissertation has been approved by:

prof. dr A.J. Groen (promotor)

dr. A.B.J.M. Wijnhoven (assistant promotor)

This dissertation is dedicated with love to my late wife, Aliza, who gave me the courage to start the enterprise and is so missing when it ends 


\section{Table of Contents}

Synopsis ................................................................................................................ 1

1. The Practical Problem and the State of Unawareness .......................... 5

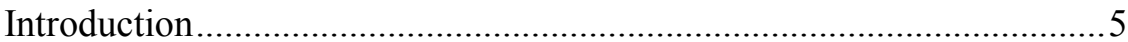

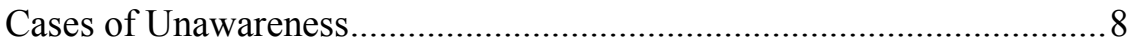

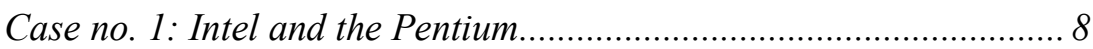

Case no. 2: The American car industry and the Japanese competition 9

Case no. 3: Theory change in two railroad companies ...................... 12

Cross-case analysis..................................................................... 14

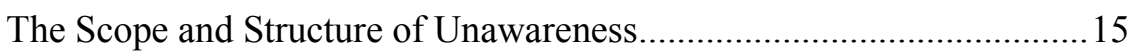

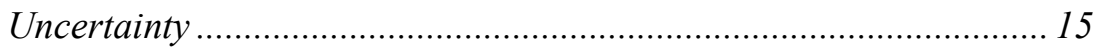

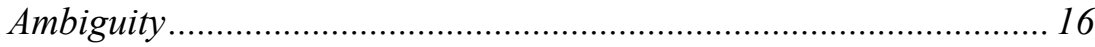

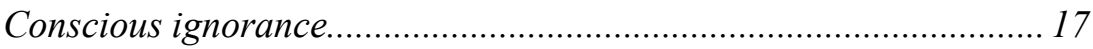

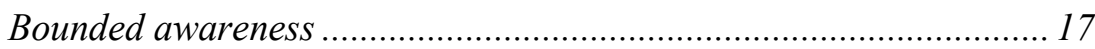

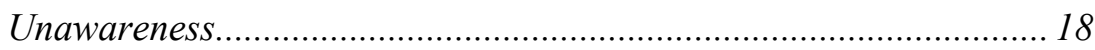

Alignment with the decision-making process.................................... 19

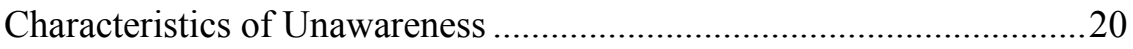

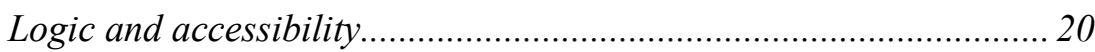

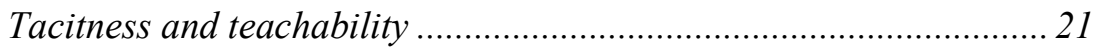

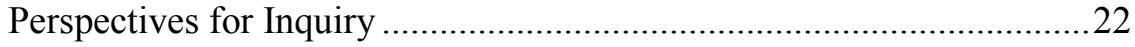

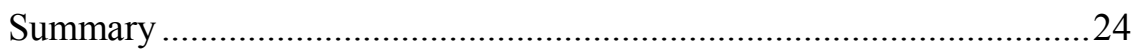

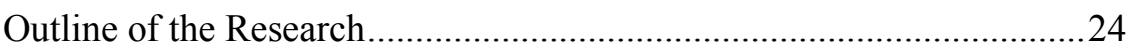

2. The Theoretical Problem: the Epistemological Stance Ascribed to

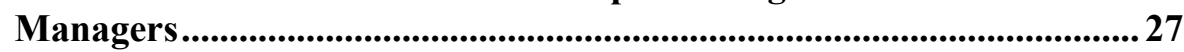

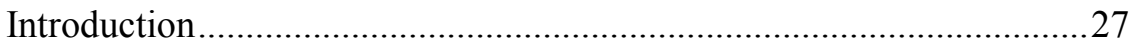

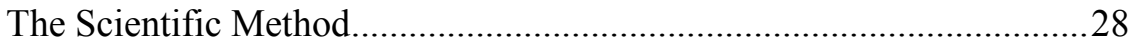

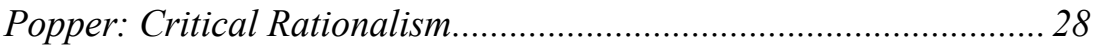

Kuhn: Normal Science and Scientific Revolution ............................... 32

Popper vs. Kuhn: critical comparison ................................................ 34

Kuhn and Popper in the Management Literature ……..............................37

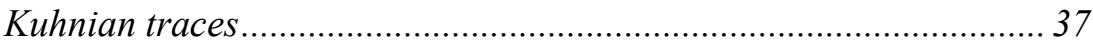

(Anti-) Popperian references ........................................................ 41

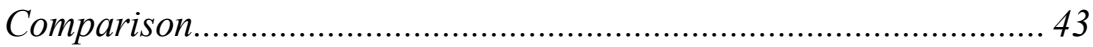

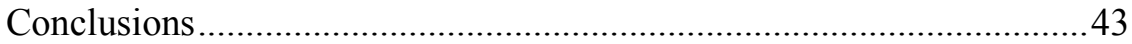


3. The Popperian Core Problem of Managerial Theories: The Detachment of the Major Premise .............................................................. 45

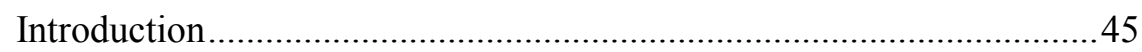

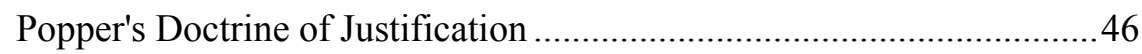

Ontology: the typology of statements............................................... 46

Theory's structure and the method of falsification........................... 47

Applicability for the social sciences ............................................... 51

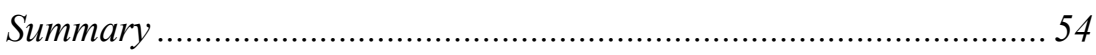

Management, Theories and Justification.............................................54

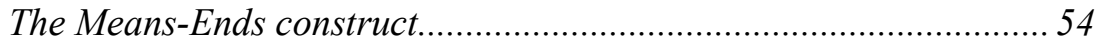

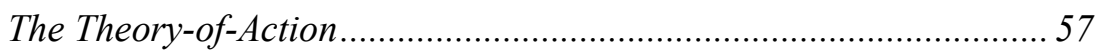

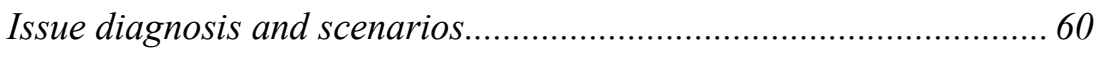

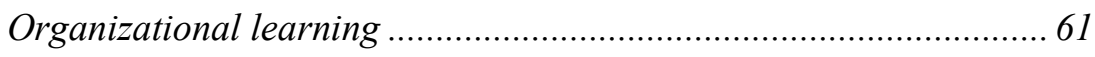

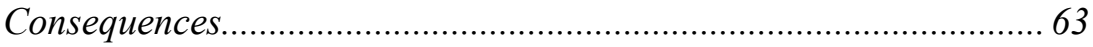

The Control System as the Justification Mechanism ..............................63

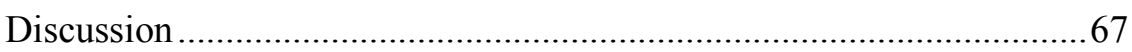

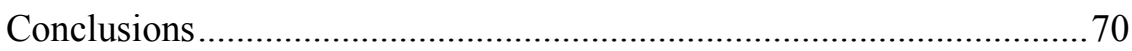

4. A Critical Review of Methods for Managerial Theory Justification 71

Introduction........................................................................... 71

Preliminary evaluation of alleged justification methods.......................72

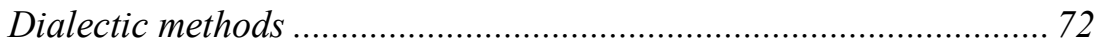

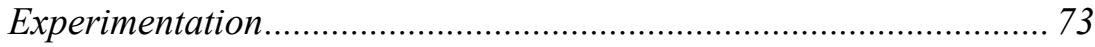

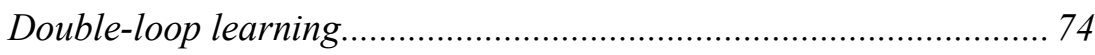

Evaluation of the Remaining Methods................................................. 74

The Critical Method ....................................................................... 74

Cognitive Mapping ....................................................................... 78

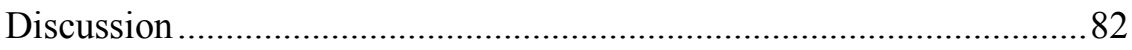

The Critical Method ................................................................... 82

The Cognitive Map....................................................................... 83

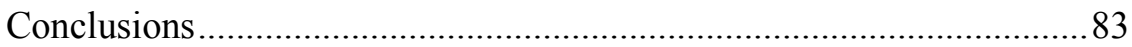

Annex to Chapter 4: The Formalism of the Cognitive Map ...................84

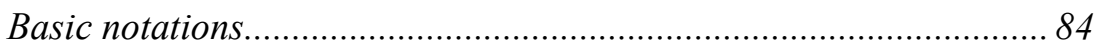

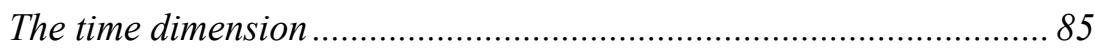

Limitations of representation ....................................................... 85

5. The Research's Method and Design.................................................8 87

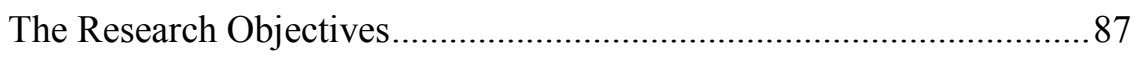

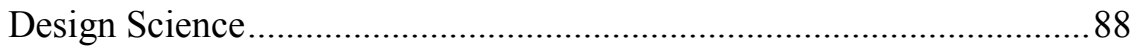




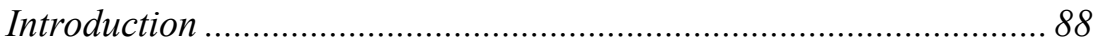

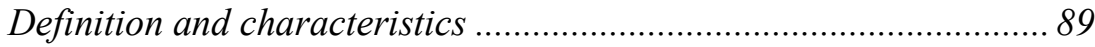

The design-science framework..................................................... 90

The framework's instantiation in the research............................... 91

Guidelines and implementation ................................................... 92

The Research Method ...................................................................... 93

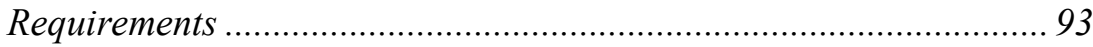

The Action Research method ............................................................ 94

Action Research and Critical Rationalism .................................... 96

Action Research and Design Science............................................ 97

Limitations of Action Research and countermeasures....................... 98

Examples of AR ........................................................................ 100

Research Design by Phases........................................................... 100

Overview .......................................................................... 100

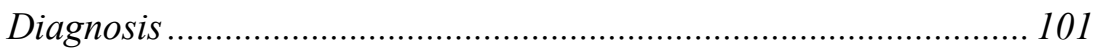

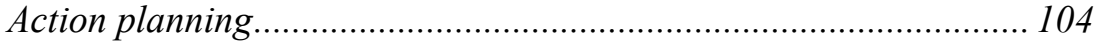

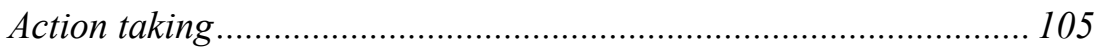

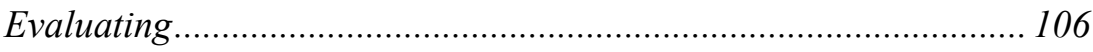

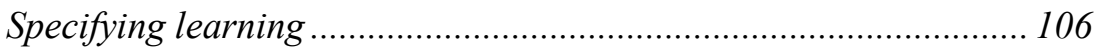

Verification of the Research Design ................................................ 107

6. Action Research, Cycle I: Introduction and Problem Diagnosis .... 109

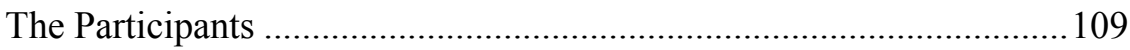

Data Collection ................................................................................ 111

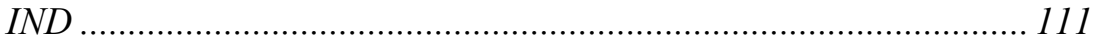

$E D U$

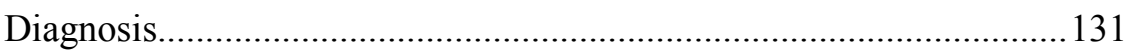

IND …......................................................................... 131

EDU

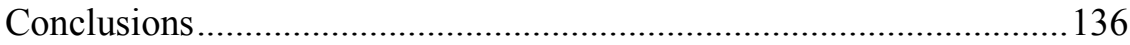

7. Action Planning: Design of the Intervention.................................... 138

The Preferable Route ....................................................................... 138

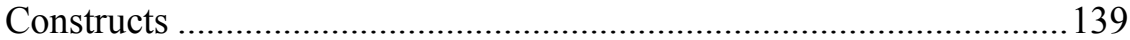

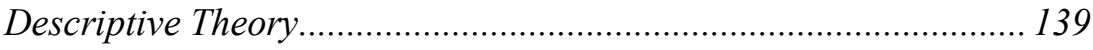

Initial condition..................................................................... 140

Scenarios.......................................................................... 141

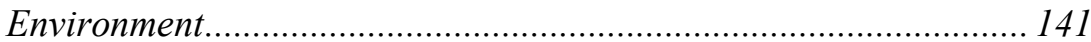

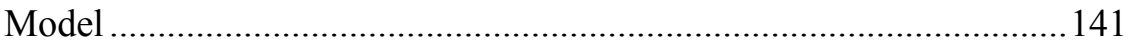




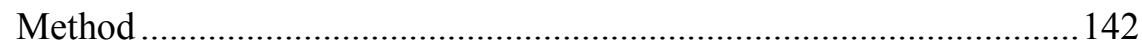

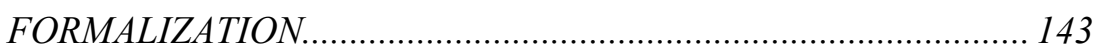

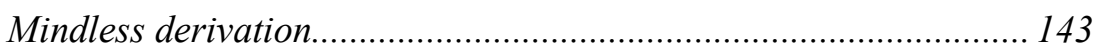

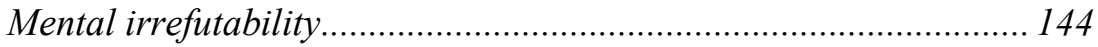

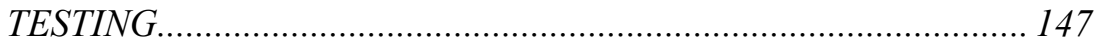

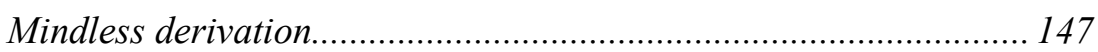

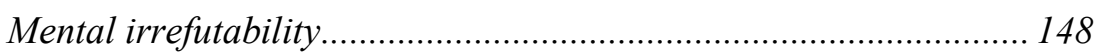

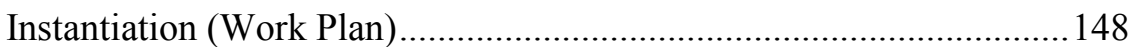

8. Finalizing Cycle I: Action Taking, Evaluating and Specifying

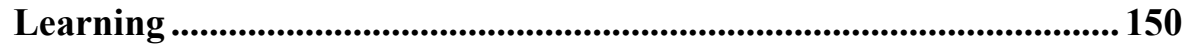

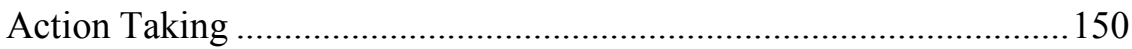

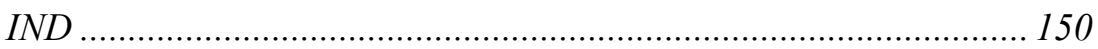

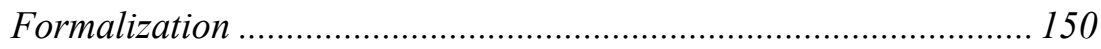

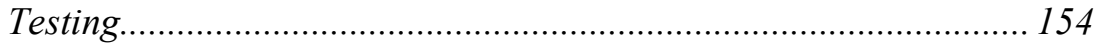

$E D U$

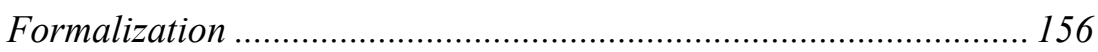

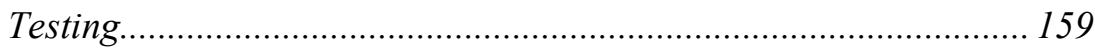

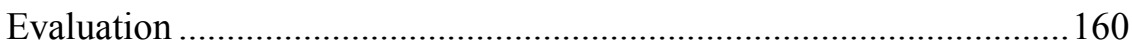

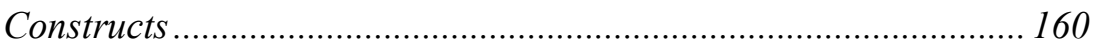

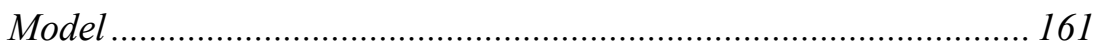

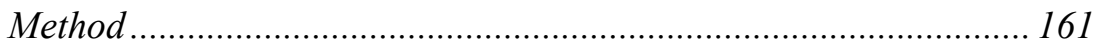

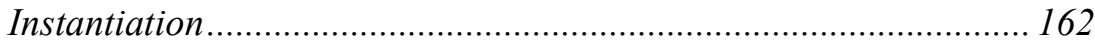

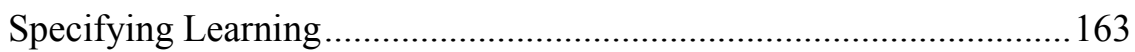

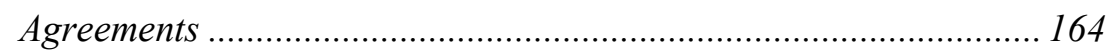

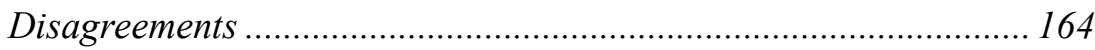

9. Action Research, Cycle II .................................................................. 166

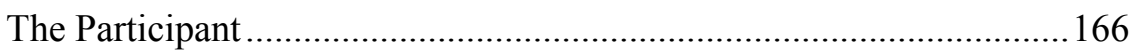

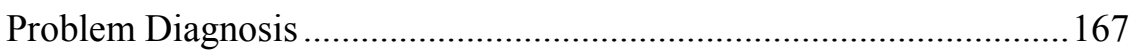

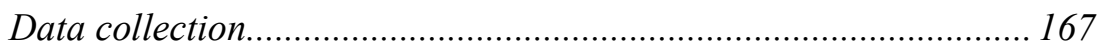

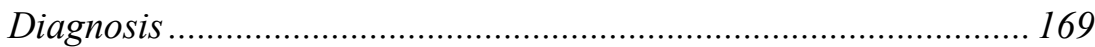

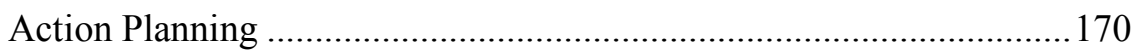

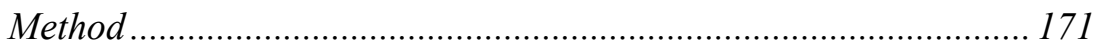

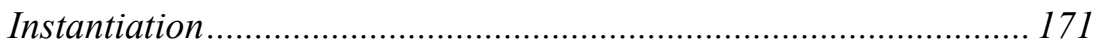

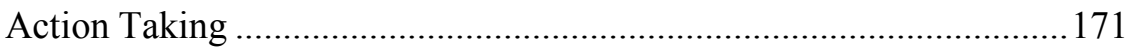

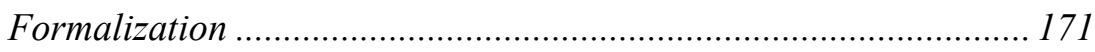

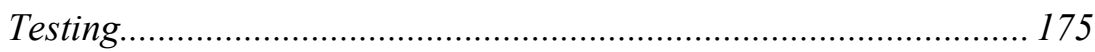

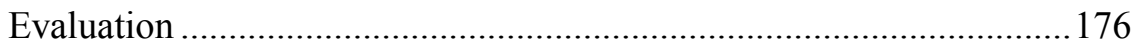

viii 
Constructs ......................................................................... 176

Model ............................................................................... 176

Method .................................................................................. 176

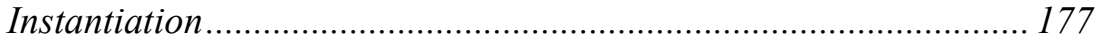

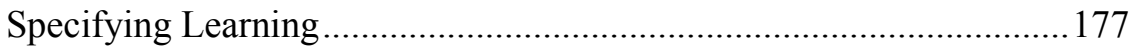

10. Discussion and Conclusions ............................................................... 179

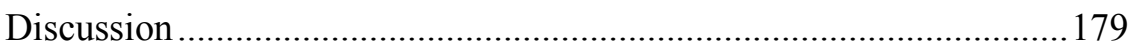

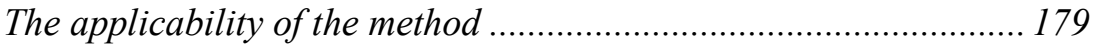

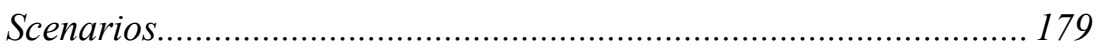

The cognitive mapping................................................................ 180

Evaluation of the research ......................................................... 180

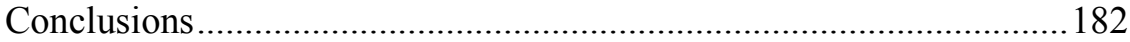

The research objectives ........................................................... 182

Need for further research .......................................................... 183

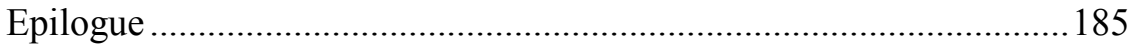

Annex to Chapter 10: Evaluation of the Action Research .................... 186

References ................................................................................. 190

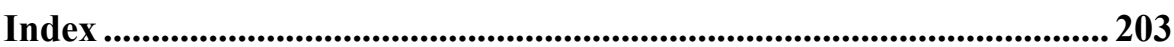




\section{Synopsis}

This study applies Critical Rationalism (CR), a stance associated with the philosophy of science, to solve a practical problem: management unawareness. Managers (as any other human being) hold a theory through which they explain the world and rationalize their decisions. Like any other theory, the one held by managers may be false. The problem of unawareness is a state in which the theory holder does not imagine the very possibility that the theory may be indeed false. Since managers' theories underlie the recognition of potential problems that managers have to address (as well as the subsequent solving process), the state of unawareness prevents problem recognition, and consequently problem solving. This study confronts the problem of unawareness and overcomes it.

There are a lot of references in the management literature to this problem (though variously labeled), usually from the cognitive perspective. The contribution of this study is in the epistemological viewpoint it posits and specifically with the innovative application of the CR method in the strategic management domain. The study undermines the common convention that $\mathrm{CR}$ is inapplicable for management.

When the management literature does take the epistemological perspective for explaining the unawareness problem, it often relies on the theory suggested by the historian of science Thomas Kuhn. According to this theory the scientist (or, in the literature, the manager) is captive of the prevailing paradigm and unable to avoid this trap. Kuhn posits the alienation and the disconnectedness among paradigms as the bedrock of unawareness. The isolated paradigm lasts until it cannot contain its contradictions any longer and then it collapses.

The philosopher of science Karl Popper disagrees with the inevitableness of the paradigmatic captivity; he argues that this stance, known as conventionalism, is a choice. Popper suggests a view and a method named critical rationalism that counteracts the conventionalist proclivity. This view applies deductive logic (since, he argues, inductive argumentation is inconclusive), and the CR method consists of a structured procedure through which the scientist exposes the theory to intended falsification. The scientist derives deductive inferences from the theory in point and repeats the derivation down to an empirically verifiable inference. The lowest derivative is then tested, and if the test fails the root statements are refuted; stated differently, a false hypothesis does not falsify itself but the one above it. This hierarchical structure of statements is called a theoretical system. The deduction forms a syllogistic structure in which the tested theory stands for the major premise, and the singular, verifiable occurrence constitutes the minor premise. In short, the Popperian doctrine confronts the problem of unawareness up front. 
The management literature holds that the $\mathrm{CR}$ doctrine is inadequate for managerial purposes, and the reason is twofold: first, the environment presents unique situations that cannot be universally theorized; second, the testing organization (whose managers hold the theory) is an obtrusive observer and the observation affects the experimented environment. These obstacles lead the literature, despite the distinct acknowledgement of the unawareness problem, to compromise with partial solutions that the managerial conditions tolerate. In line with the CR tradition it is this convention, hereinafter entitled the inadequacy argument, which is retested and falsified in this study.

Yet in a critical rationalist eye, several influencing accounts of management learning seem to reflect Popperian concepts, although in implicit and fragmented manner: they describe a hierarchy of derivations in which the upper-level assumptions are tested through the actions taken in the levels below. However, the process is incomplete because the top-level theory is implicit, ambiguous and normative, therefore not testable. The projection of these accounts on the Popperian conceptualization provides the competing theory that underlies the research.

The Theory of Falsification Obstructers that is developed and tested in this study (figure S.1) challenges the inadequacy argument and claims that the CR tradition is obstructed rather than inapplicable. The theory demonstrates that managers have a theoretical system which is quite equivalent to the Popperian model, but its harmony is harmed by several obstructers. In this theoretical system there are two alleged courses of falsification: one through the means-ends construct and the other through the scenarios. The assertion is that the inadequacy argument applies for only the former, whilst the obstructers along the latter course are surmountable. Hence managers can utilize the $\mathrm{CR}$ and challenge their unawareness once they tackle the obstructers. 


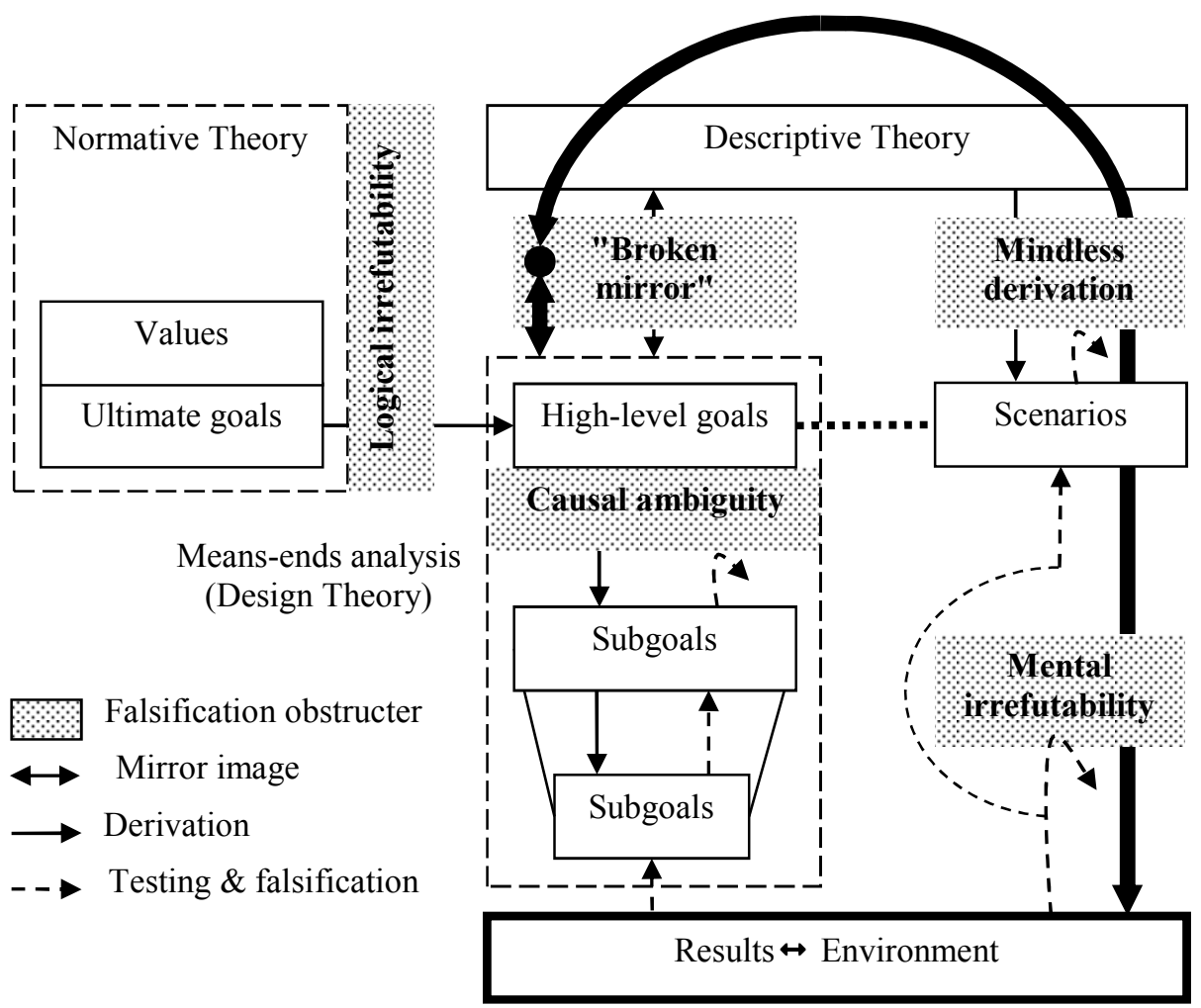

Figure S.1. The managerial "Theoretical System" and the falsification route (marked by the thick arrow)

In this system the Descriptive Theory is the one to be tested and falsified; it is mirrored by the Design Theory which is tested against the Results - the very route that the inadequacy argument negates due to the Causal ambiguity. On the other hand, the Scenarios compared to the Environment could have been the source of falsification had they been derived explicitly from the Descriptive Theory and evaluated impartially. Unfortunately the Mindless derivation and the Mental irrefutability obstructs both conditions, respectively.

The research's aim is to corroborate the Theory of Falsification Obstructers (and by that to falsify the inadequacy argument). The research method is Action Research, which was conducted along two cycles and posed the following hypotheses:

H1a. The organization's environment can be theorized in a falsifiable fashion.

$H 1 b$. The right route [Scenarios] is capable of obtaining unequivocal falsification. 
H2. The techniques employed throughout the method overcome the "mindless derivation", the "mental irrefutability" and the "Broken mirror" [added toward the $2^{\text {nd }}$ cycle] falsification obstructers.

In the first cycle, following a diagnosis based on the Theoretical System framework, the CR managerial method was designed and implemented; it was assured that the method complied with the characteristics of unawareness and provided a proper countermeasure. The results sustained the falsifying capability of the Scenarios, but failed upon the disconnection between the Descriptive and the Design theories, which was then entitled the "Broken mirror". The second cycle addressed this deficiency through a partial redesign of the method and resulted in satisfying results; the redesign concerned a mediated interface between the theories, signified by the black dot in the model. As the final conclusion of the entire research all the three hypotheses were confirmed, and the unawareness problem was effectively confronted. 


\section{The Practical Problem and the State of Unawareness}

\section{Introduction}

In a paper titled "Scenario Planning: A Tool for Strategic Thinking", which practicalizes an extensive research effort, Schoemaker (1995) concludes: "When contemplating the future, it is useful to consider three classes of knowledge: (1) Things we know we know; (2) Things we know we don't know; (3) Things we don't know we don't know ${ }^{1} .$. the greatest havoc is caused by the third" (p. 38). He counts what constitute the third class of knowledge: bounded "conceptual maps" that lead to "collective ignorance" of "factors that shape the future" (pp. 38-39).

Hedberg \& Jonsson's (1977) name this "conceptual map" a theory: "Strategies are operationalizations of theories of the world, and they serve the double purpose of (1) forming defense networks against information overloads, and (2) being ordering systems that map information into 'definitions of the situation' [categories]" (p. 90).

Whilst for Schoemaker (1993, 1995) and Hedberg \& Jonsson's (1977) the theory is an input to the strategy, Mintzberg (1987/a) suggests a part-towhole relationship. He counts five coexisting meanings of the word "strategy": plan, ploy, position, pattern and perspective. The last one reads:

Here, strategy is a perspective, its content consisting [...] of an ingrained way of perceiving the world. [...] A variety of concepts from other fields also capture this notion: psychologists refer to an individual's mental frame, cognitive structure, and a variety of other expressions for "relatively fixed patterns for experiencing [the] world"; anthropologists refer to the "culture" of a society and sociologists to its "ideology"; [...] while management theorists have used terms such as the "theory of the business" and its "driving force"; behavioral scientists who have read Kuhn on the philosophy of science refer to the "paradigm" of a community of scholars; and Germans perhaps capture it best with their word "Weltanschauung", literally "worldview", mean-

${ }^{1}$ This distinction echoes ancient wisdom: "The greatest wisdom is knowing that one does not know... Socrates claims that he is wiser than everybody else because he knows that he does not know everything" (Plato on Socrates in Apolo$g y)$. 
ing collective intuition about how the world works (Mintzberg, 1987/a, p. 16; italics in origin).

In this study we define "Theory" as: the representation of the environment, both external and internal, that the organization conceives; the Theory encompasses the external forces assumed to affect the organization, their interrelationships, and the mutual effects among them and the organization (the capital T in "Theory" stands for distinguishing the Theory of the organization from academic theories, including ours, about the organization). In other words, the Theory divides the world into two sets: one of all the relevant factors, the other (by default) of all the (irrelevant) rest.

The very notion of "theory" implies that the Theory may be false. Hedberg (1981) notes: "Individuals in organizations sometimes form their beliefs on misinterpretations of cause-effect relationships [...] This gives room for theories of action - myths - with low or no validity to the concerned organization" (p. 11). Weick (1969) emphasizes that the environment is conceived rather than "given":

Whenever we tackle a phenomenon so apparently large and complex as a human organization, we inevitably run into boundary problems. If we try to talk about an organization's adaptation to its environment, the following questions arise: What is "included" within the organization, and available for purposes of adapting? What is "outside," or "excluded" from the organization, that must be adapted to? $[\ldots]$ the environment is put there by the actors within the organization and by no one else. This reasserts the argument that the environment is a phenomenon tied to processes of attention, and that unless something is attended to it doesn't exist (Weick, 1969, pp. 27-28).

What does "false Theory" mean? Schoemaker (1992), surely unintentionally, provides a vivid example. He describes a process of five-year strategic visioning (1992-1997) held by Apple Computer, aimed at identifying major trends that the firm's strategy should address. The falsehood is in what the visioning omits: the total ignorance of the Internet among the major trends anticipated (the WWW had been invented three years earlier, in 1989). In hindsight the omission seems preposterous, not a big deal after the fact, but our aim is not to mock. Our aim is twofold: to argue that the typical failure consists of unattended forces, and that even astute visionaries are not immune against failures like that.

When the falsehood of the Theory is caused by those "things we don't know we don't know", we term the state unawareness. Unawareness applies when the Theory holder does not imagine the very possibility that the Theory is 
false, namely the relevant-irrelevant division is wrong. We argue that the state of unawareness is insensitive to measures aimed at neighboring states, e.g. the "we know we don't know" that stands for uncertainty. This study brings the unawareness problem to the forefront and quests a dedicated remedy.

What is the significance of the problem, or: can the "greatest havoc" caused by false Theories be estimated? The empirical evidence is ambiguous, since studies of the reasons for strategic failure (e.g. Gaskill, Van Auken \& Manning, 1993) do not recognize the problem (which is a problem in itself); this leaves us with approximations. A recent Forbes's survey ${ }^{2}$ (June 2009) counts five major reasons for strategic failures (in total, about one-third of strategies fail, according to the survey). The reasons are distributed as follows (figure 1.1):

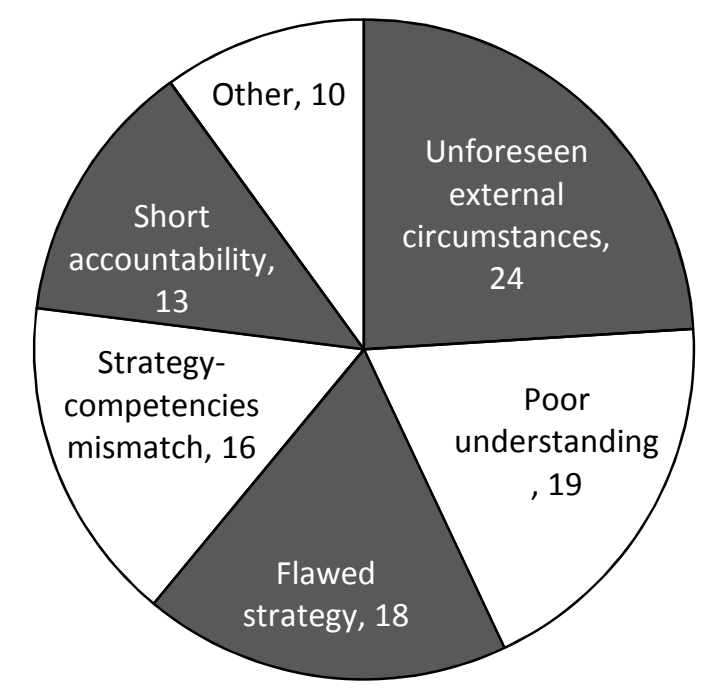

Figure 1.1. Causes of strategic failures (source: Forbes Insights, June 2009)

- Poor understanding of strategic success key factors among the strategy makers $(19 \%)$.

- Unforeseen external circumstances (24\%).

${ }^{2}$ http://www.forbes.com/forbesinsights/FDStrategy/index.html 
- The strategy itself is flawed (18\%).

- A strategy inadequate for the core competencies of the organization $(16 \%)$.

- Short accountability or team responsibility (13\%).

We may reasonably suspect that the Theory's falsehood stands behind the first four categories, to that extent or another. We can also count on Carroll \& Mui (2008), who claim that "In most instances, the avoidable fiascoes resulted from flawed strategies - not inept execution, which is where most business literature plants the blame" (p. 82). These clues, sustained by the "greatest havoc" caveat, suggest that the problem is essential.

The remainder of the chapter specifies what unawareness is, displays its characteristics and discusses the appropriate view for investigation. We precede the discussion with three case studies that make the problem vivid.

\section{Cases of Unawareness}

\section{Case no. 1: Intel and the Pentium}

Intel faced a credibility disaster in 1994. Grove (1999), then Intel's CEO, tells the story in retrospect.

One morning in November 1994 Grove was alarmed by his PR person that a CNN team was about to arrive at Intel's headquarter in order to question the floating point failure in the new Pentium processor. Grove immediately grasped the explosive potential of the coming scandal, yet although he knew what had happened he could not understand the reason for that.

1994 was the year that Intel, then the largest micro-processors manufacturer worldwide, began the mass production of the novel Pentium processor. It was the peak of a huge effort to which Intel totally committed itself, one that involved hundreds of Intel's direct customers - the computers manufacturers. A few weeks prior to this November morning some experts, all closely familiar with computing, were engaged in a hot open discussion on the Internet concerning the floating point unit (FPU) bug. Intel was aware of the bug but regarded it tolerable; after all, it caused a tiny dividing error in 1 out of 9,000,000,000 times - meaning that a regular end user might face it once in 27,000 years. The company decided to continue with business as usual and simultaneously to fix the bug, as it had done upon similar cases before.

Meanwhile the Internet discussion was echoed in the professional press, described precisely and discreetly; Intel had all the reasons to assume that the storm was over, and why not? It was a glitch with many precedents across the industry. But then CNN intervened, and their report was hostile. 
Shortly after, all the respected dailies reproduced the issue with screaming headlines ("The Pentium problem: to buy or not to buy?") that blew the public interest. The Internet witnessed plentiful responses in the US and oversees. Worried users called Intel and claimed replacement. After IBM had announced the stopping of Intel-based PCs deliveries the fuss soared: users called impatiently, Intel employees were under attack and suffered from cynical jokes. Overnight Intel was forced to improvise customer service procedures and to satisfy millions of complaints. The crisis cost Intel 475 million dollars.

Only in hindsight Grove managed to understand the occurrence. Intel's selfimage has for long been a supplier of suppliers, viz computer manufacturers. As such the company was used to solving problems between engineers, via evidence-based analysis. In this context, its decision how to handle the bug upon discovery was plausible. But the context has changed; ironically, the change had been initiated by no one else but Intel, yet the company failed to discern.

Several years earlier Intel had conducted a huge advertising campaign (the biggest in the industry by then) under the logo "Intel Inside", which was intended to identify the PC hardware by its processor. The company, thus far distant from the end user, saw it a success when PC owners identified their PC as "386" (the processor) rather than IBM or Packard Bell. But the other side of the coin was that Intel has unawares become an appliance company that at least from the end user's point of view served him directly. This aspect was ignored when Intel reacted to the Pentium bug.

Grove (p. 20) rationalizes the incident by arguing that every business acts upon a system of rules and assumptions, which despite their centrality remain latent and implicit. The system may change radically from time to time, but unfortunately the changes "sneak in" without a notice rather than announce their arrival. The rule in point here is the identity of the customer. Grove suggests a generalization, which he terms "the 10X [times ten] force", meaning that a force in the surrounding is intensified by a size of order. He, of course, points to the end-user customer; but one may dispute the mathematics: the end-user has never been considered a customer before, so zero times ten still remains zero. A completely new force requires a different detector.

\section{Case no. 2: The American car industry and the Japanese competition}

Little, if any, business history has gained so much research interest as the decline of the American car industry, and the space here is too limited to tell it in details. The following lines bring an extremely condensed synopsis drawn upon Sobel (1984) and Yates (1983).

The facts: within three decades $\left(50^{\prime}-70^{\prime}\right)$, mainly during the second half of that period (1965-1980), the American car industry lost almost 30\% of the 
fully-dominated domestic market to the import (as of 2005 the import share is over $40 \%$, mostly Japanese). Further, the industry has declined from hundreds of manufacturers prior to WWII down to the "Big Three" ${ }^{3}$. The competition was not about prices. The reasons for the deterioration, that for the authors and the reader seem quite obvious in retrospect, were ignored by the industry all along the period.

The authors count the following changes in the industry:

The emergence of alternatives: for half a century (GM was established in 1897, Ford in 1903) the American car makers' mind was molded as a sole source for the domestic market; European cars existed, but in a distant margin. Hence the huge momentum of the Japanese industrial recovery after the war (with the US support) and their car makers' penetration into the continent received little attention, and the customer loyalty was taken for granted.

Other-than-style preferences: the industry mindset centered on style and size as the only parameters the buyer looks at. Alfred Sloan, GM's chairman, promoted the equivalence between career and car to make the latter a status symbol. Flamboyant design was fashionable, epitomized by the term "the Detroit baroque age". But it was a mask: to keep efficiency, different cars shared a finite set of components and varied mainly by dress, to the adverse of the internal harmony. The Japanese (as well as the German) cars emphasized other aspects: quality, safety, economy and post-sale service all concepts that were strange to Detroit's jargon. In 1964 Ralph Nadler evoked the quality movement that - with much echo - denounced Detroit's lousy standards and set a new public agenda. However, it did not change the industry's mindset.

New needs: the urban and demographic arenas in the US have changed dramatically after WWII, as soldiers returned home craving to restart their life. Plenty of young families, striving for housing but short of wherewithal, were pushed off the crowded cities to the emerging suburbs. A wave of babies (now known as the baby boomers) forced mothers to stay at home and to take care of housekeeping, which rendered many short rides. Consequently a second family car was needed, and a small one, so the economic constraints would be met. The American industry neither supplied small cars nor respected the need for them. Just to the contrary, the style-and-size paradigm continued to conquer: "It is utterly ridiculous to use a four thousand pound car for the wife to go down to the grocery store and get a loaf of bread", George Romney, president of American Motors, stated in 1958 (Sobel, 1984, p. 51).

\footnotetext{
${ }^{3}$ The Big Three are GM, Ford and Chrysler, of which the latter is now only partly American-owned. Also, in the last years Toyota outnumbers Ford in sales.
} 
Not a monolithic customer: the east coast has been from the beginning the industry's source of inspiration. Cars were designed to meet the taste prevailed in New England (or at least thought to be), and in many cases did not leave Detroit until mass production. Dictated by geography, Japanese cars entered the continent via west coast to find a different flavor: vanguard, more anarchistic, less formalistic, and open-minded. That not all the Americans share identical preferences was not a possibility in Detroit at all.

But not only geography mattered: the national mood has changed as well. A basic assumption underlying the "no alternatives" notion was that the afterwar local patriotism has shielded the industry against foreign "invasion", let alone by a post-enemy. Meanwhile this spirit has been severely undermined by the Vietnam War as local patriotism gave way to anti-Americanism. This trend, stronger on the west coast, projected on car preferences (the typical Hippy's car was the Volkswagen Wagon [figure 1.2], nicknamed "Hippies' Van").

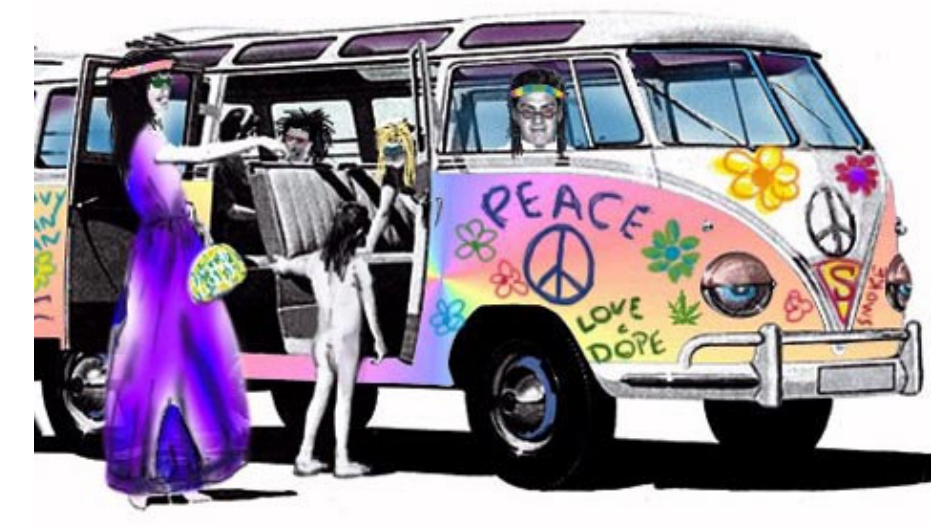

Figure 1.2. An illustration of the VW "Hippy Van" (source: Paul Leighton's blog ${ }^{4}$ )

The possibility that such huge changes over such a long time could be ignored by so many people was unconceivable for the authors, as it is still today. The explanation theorized by Yates (1983) is the astonishing mindset's homogeneity (the "Detroit mind") among executives in the automakers' headquarters, resulted from their identical demographic traits: same background, same education, same career, same style of living - in short, a duplicating socialization.

\footnotetext{
${ }^{4}$ http://www.paulsjusticepage.com/elite-deviance/vw.htm, retrieved 27.6.2007
} 


\section{Case no. 3: Theory change in two railroad companies}

Barr, Stimpert \& Huff (1992) present the effects of changes in cognitive maps on the strategic success of organizations. The method they employed, based on Axelrod (1976), was to extract and map the constructs (concepts) that compose the managers' Theory and the relations among them; the sources were written documents (the method is elaborated in chapter 4). In other words, the researchers reconstructed the Theories that had governed the organizations.

The study compared two similar railroad companies along a 25 -year period (1949-1973): C\&NW and Rock Island. Both companies were US Midwestern, shared a common geography, were about the same size and had a very similar traffic base; both were exclusively focused on railroad transportation at the beginning of the era. During those years the railroad industry in general went through a post-war significant decline, with 69 out of 135 major companies dissolve and the railroad market share falling from 58 to 38 percent. Despite the similar baseline, the two studied companies ended the period differently: C\&NW thrived whilst Rock Island declared bankruptcy and ceased to exist in the mid-'70s. The researchers asked whether the Theory can explain these deviating outcomes.

The graphical notation of the cognitive map includes constructs, causeeffect relations and the latter's proportion. The first is represented by a rectangle, the second by an arrow, and the last by "+" for direct ratio and "-" for inverse one (further explanations come in chapter 4). Figure 1.3 presents a sample from one cognitive map of Rock Island.

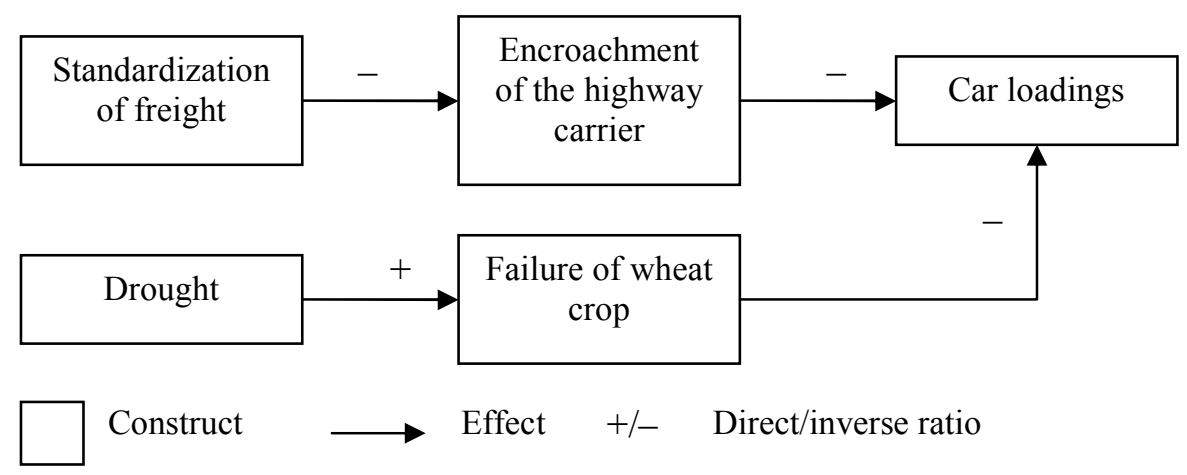

Figure 1.3. Sample of Rock Island Railroad's cognitive map (edited from Barr et al, 1992, p. 26)

The cognitive maps for each company were reconstructed year-by-year and were compared within and between the companies. Five patterns of change were distinguished: (1) adding a new concept or deleting an old one; (2) 
generalization (abstraction), namely subordinating a specific concept to a higher one; (3) new linkages among concepts; (4) change in causal signs, and (5) changes in the examples used by the executives to express the meaning they ascribe to the construct (by that a change in the meaning is implied).

Based on the generalization of the constructs made by the authors, they can be categorized into three groups: internal means, including management, cost, mergers and acquisitions and equipment; external factors, including weather, government, economy and competition; and ends, including productivity and sales.

The authors found that earlier cognitive maps showed great similarity between the companies: $50-60 \%$ of the constructs concerned weather conditions in both. However, during the late '50s the maps began to diverge. The prominent difference was that $\mathrm{C} \& \mathrm{NW}$ had better connected the means to the ends through the external factors, whilst Rock Island had held an isolated picture of the environment and failed to link it with the other two categories:

We did not find [...] that delays in the succession of mental models [cognitive maps] result from a failure to detect substantial changes in the environment. The maps for both firms indicate that changes in the environment were quickly noticed. The Rock Island managers see disturbing trends as early as $1950[\ldots]$, but fail to associate these trends with a larger shift in the environment. Its managers easily reconcile this new competition with their existing mental model that blames decline in freight traffic primarily on external forces over which the managers have little control. [...] The C\&NW managers, on the other hand, saw decline in traffic as important concepts signaling permanent changes in the environment that would require internal changes. [...] These results suggest that organizational renewal requires that managers not only notice changes, but that noticing must lead to new understandings and the adoption of appropriate responses (Barr et al, 1992, pp. 27-28).

The research ascribes the differences between the companies to differences in the learning process, specifically interpretation; cognitive biases have a significant impact on that. The conclusions stand in some contrast to those reached for the car industry: "It appears that the attitudes and beliefs that these individuals [the executives] brought to their new posts were a far greater influence on their strategic decision making than their demographic characteristics" (Barr et al, 1992, p. 33). In other words, the Theory outweighed the social convention. 


\section{Cross-case analysis}

The three cases share a common pattern: a problem that the organization does not recognize; the problem escalates until the organization faces a crisis; the crisis revises the Theory and then the problem is clarified (sometimes too late). The problem is covert in the first place because the organization is unaware of its causing forces and ignores the changes therein. We notice various objects of unawareness ${ }^{5}$ and various forms of the awareness' arousal:

- Intel was unaware of the effect, namely the direct relation that had been established between the end user and the company; in Grove's phrase, of the "times ten" multiplication of the factor. The awareness was raised by the collapse of the common wisdom, as the outcomes differed despite the same means.

- The US car industry was totally unaware of concepts like quality or service, or to the variance across demography. The awareness has been raised by the falling market share, but only after its culmination upon the 1974's oil crisis.

- $\quad$ The laggard railroad was aware of the forces but "fail[ed] to associate these trends with a larger shift in the environment", i.e. to comprehend the effect. The awareness was raised through the competitive comparison.

Table 1.1. The various objects of unawareness and arousal forms across the cases

\begin{tabular}{lll}
\hline \multicolumn{1}{c}{ Case } & Unawareness of & \multicolumn{1}{c}{ Awareness triggered by } \\
\hline Intel & Effect & Collapse of common wisdom \\
Car industry & Force & Unattained goals \\
Railroad & Effect & Disturbing comparison \\
\hline
\end{tabular}

The same three triggers are mentioned by Pounds (1969), who researched the issue of problem recognition ${ }^{6}$. The troubling point is that the recognition is too late and follows the crisis. Neither case indicates a deliberate effort to raise the awareness prior to the crisis (Grove, in first person, is clear about

\footnotetext{
${ }^{5}$ The object of unawareness is what one is unaware of.

${ }^{6}$ Pounds (1969) found that these triggers apply when the problem is recognized by the problem-owner. However, they count for less than a half of the cases; the majority of the problems faced by managers are imposed by a third-party.
} 
that); our objective is to swap the order. With this we proceed to the formal conceptualization.

\section{The Scope and Structure of Unawareness}

Unawareness is a mental state that prevents the problem recognition, and consequently the problem solving. The literature identifies several problems along the problem-solving/decision-making process, but the definitions are inconsistent and sometime overlap. For the sake of clear distinction we brief about the various decision-making problems and after that align the problems with the decision-making process. The aim is to establish common language for the following discussion.

\section{Uncertainty}

The Oxford dictionary provides two definitions for "uncertain": (1) not known, reliable, or definite; (2) not completely confident or sure. The former refers to the unknown object, the latter to the unknowing subject. The two schools of uncertainty -economic and cognitive - correspond with this distinction: the former maintains uncertainty as objective and the latter as subjective (Downey \& Ireland, 1979).

The economic school: availability of information is the prime attribute by which uncertainty is categorized in this school. Ellsberg (1961) counts three types of uncertainty: (a) risk - existence of a single probability distribution among future events; (b) ambiguity ${ }^{7}$ - when the decision-maker lacks enough information to single out one probability distribution among several alternatives, thus holds many; and (c) complete ignorance - when one has no information to base any probability whatsoever. This typology is not exhaustive, since all the types assume information to be unknown; yet information can also be unknowable.

Dequech (2000) fills the gap by suggesting a fourth state of fundamental uncertainty, where the required information is not specifiable upon decision-making. It happens when the decisions address such a distant future that no questions can yet be asked. Courtney, Kirkland \& Viguerie (1997) name this level "true ambiguity": "It might not even be possible to identify, much less predict, all the relevant variables that will define the future" ( $p$. 71).

The cognitive school: in this school, rather than being a state "out there", uncertainty is a perception (Downey \& Ireland, 1979; Milliken, 1987). Milliken (1987) takes a farther step away from the economic school and instead of the probability scale suggests a typology based on the subject matter,

\footnotetext{
${ }^{7}$ The terminology in the literature is sometimes inconsistent, as terms are interchanged.
} 
namely what is uncertain, instead of the uncertainty level. The typology is threefold: (1) state uncertainty, which concerns the environment; (2) effect uncertainty, regarding the consequences on the organization; and (3) response uncertainty, namely the outcomes of the organization's acts.

Comparison: both schools assume the existence of awareness, indicated by the phrase "we know we don't know". Further, the specific level of uncertainty is regarded identifiable, which enables to match the appropriate countermeasure (Courtney et al, 1997; Milliken, 1987). The state of uncertainty in itself raises awareness (Lyles, 1987; Lyles \& Thomas, 1988).

The essential difference between the schools is that the cognitive one can ascribe different decisions to different perceptions (Boyd, 1996; Duncan, 1972; Foss \& Mahnke, 1998; Gaglio \& Katz, 2001; Gordon \& Naravanan, 1984; Milliken, 1987; Shane \& Venkataraman, 2000; Tymon, Stout \& Shaw, 1998), whilst according to the economic school all the players in an industry face the same uncertainty so there is no information asymmetry (Foss \& Mahnke, 1998).

The ubiquity of the uncertainty concept: the uncertainty concept rationalizes several major themes of organizations. For Weick (1979) it is the raison d'etre of organization: "The activities of organizing are directed toward the establishment of a workable level of certainty" (p. 6). Mintzberg (1987/b) suggests that rather than strategizing under uncertainty, "organizations have strategies to reduce uncertainty, to block out the unexpected" (p. 29). They both represent the cognitive school. From an economic perspective, Samuelson (1994) argues that "The basic rationale of control and control systems thus seems to be the uncertainty of the situation in the future" (p. 11).

\section{Ambiguity}

Ambiguity is defined as "the quality of being [...] open to more than one interpretation" (Oxford dictionary). Unlike uncertainty, where information is unavailable, ambiguity prevails when there is information but dually interpretable (Zack, 2001). In Weick's (1979) theory of organizing and of organizational learning (Weick, 1996), the ambiguity is the key explanatory variable toward the formation of processes: the higher the ambiguity, the more cycles are required before a process is institutionalized; once it was, the process assures uniformity despite the ambiguity (respectively). In his account about sensemaking in organization, Weick $(1995 / \mathrm{b})$ posits the ambiguity as the prime enemy of sensemaking. In this sense, extreme ambiguity may result in total senselessness and consequently an organizational dissolution (Pauchant, Mitroff \& Ventolo, 1992; Weick, 1993).

Ambiguity is more than awareness-dependent: it actively raises awareness (Weick, 1995/b). And like with uncertainty, the premise of awareness is 
what enables the prescription of countermeasures (e.g. Snowden \& Boone, 2007).

\section{Conscious ignorance}

Conscious ignorance is a deliberate decision not to take something into account. Necessarily, then, this "something" must have been part of the Theory beforehand.

A good example is Apgar's (2006) distinction between learnable and random risks. He defines learnable risks as "the ones we could make less uncertain if we had the time and resources to learn more about them" (p. 25), whilst random risks are "those that no analysis of causes or drivers can make less uncertain" (pp. 25-26). Since the investigation of random risks gains no competitive advantage, the economically-correct behavior would be to save the resources for the learnable risks. Hence the most crucial decision is to classify the risks. In this regard Apgar writes:

Random risks, such as risks driven by energy prices, are hard to manage because they're, well, random. But learnable risks pose the problem of not only managing variability from the risk but also learning as much and as quickly about that variability as anyone else. If you thought randomness was bad, try ignorance (Apgar, 2006, p. 54; italics added).

Note that conscious ignorance implies that the decision-maker is aware of the relevance of the ignored, yet ignores it deliberately.

\section{Bounded awareness}

Bounded awareness, mindlessness and the "back-of-mind" mode are all phenomena that result in limited choices during decision-making.

Bazerman (2006) explains what "bounded awareness" is:

Bounded awareness exists when individuals do not attend to predictable, accessible, perceivable, and important information, while attending to other equally accessible and perceivable information. [...] Within specific domains, we can identify information that is systematically outside the awareness of most decision makers. Because of this bounded awareness, useful information remains out of focus for the decision maker. The misalignment between the information needed for a good decision and the information included in awareness results in a focusing failure. [...] The phenomenon of bounded awareness is captured by the fa- 
miliar exclamation, "How could I have missed that?" (Bazerman, 2006, pp. 170-171).

The keywords are "within specific domains": Bazerman refers to a given (i.e. recognized) problem in a well delineated environment of which all the information is available; yet the solution requires a breakthrough beyond the conservative thinking.

The similar concept of "mindlessness" is presented by Langer \& Moldoveanu (2000):

Mindlessness can show up as the direct cause of human error in complex situations, of prejudice and stereotyping, and of the sensation of alternating between anxiety and boredom that characterizes many lives. [...] Without noticing differences brought on by the passage of time within ourselves and the outside world, each day looks like every other. [...] we may discover that most stereotypes that we have formed are not rooted in fact, but in choice (Langer \& Moldoveanu, 2000, p. 6).

The "back-of-mind" thinking mode (in opposite to the "front-of-mind") indicates inattention to the alternative solutions:

...when tasks become familiar, they can often be relegated to back-of-mind (or, as some psychologists have called it, automatic) attention, freeing up more focus for challenging tasks. Processing information in the back of the mind, or automatically, seems to free up front-of-mind attention. This suggests that organizational phenomena that currently require too much attention could be made routine through practice (Davenport \& Beck, 2001, p. 24).

Other synonymous terms are "habits" (Louis \& Sutton, 1991) or "automatic retrieval" (Walsh \& Ungson, 1991). In a paraphrase, if uncertainty is "known to be unknown", then bounded awareness is "unknown to be known".

\section{Unawareness}

As noted earlier, unawareness applies when the Theory holder does not imagine the very possibility that the Theory is false, namely the relevantirrelevant division is wrong. Lyrically speaking, the Theory holder lives in a fools' paradise. 
Bohn (1994), in the context of knowledge in technological processes, uses the term Complete ignorance do describe a state where "You do not know that a phenomenon exists or if you are aware of its existence, you have no inkling that it may be relevant to your process" (p. 63). In other words, the ignorance is unconscious: the Theory holder does not imagine the very possibility that the Theory is false because the relevant-irrelevant division is wrong. This is what "things we don't know we don't know" means.

The definition by Bohn (1994) and the case studies (table 1.1) draw two degrees of unawareness:

1. One in which the concept does not exist at all; this is the concept unawareness.

2. The other is of the effect a concept (already recognized) has on the organization; this is the effect unawareness ${ }^{8}$.

This division reflects the two-step theory of categorization (Bruner, Goodnow \& Austin, 1956): "Concept formation is essentially the first step en route to attainment. [...] Attainment refers to the process of finding predictive defining attributes that distinguish exemplars from nonexemplars of the class one seeks to discriminate" (Bruner et al, 1956, p. 22; italics in origin). So: the formation ceases the concept unawareness, and the attainment conditions (but does not guarantees) the effect awareness.

\section{Alignment with the decision-making process}

Simon (1986, 1997; Simon and Associates, 1986) draws a five-step process of decision-making that starts with problem recognition (figure 1.4). The problems described above affect another step each. The alignment illustrates the unawareness' "gate keeping" function that conditions the ensuing steps and problems. Specifically the uncertainty problem is inversely affected by the extent of awareness (Milliken, 1987; O'Keefe, 1985): without awareness one cannot perceive uncertainty.

\footnotetext{
${ }^{8}$ Do not confuse it with Milliken's (1987) "effect uncertainty", which assumes awareness by definition.
} 


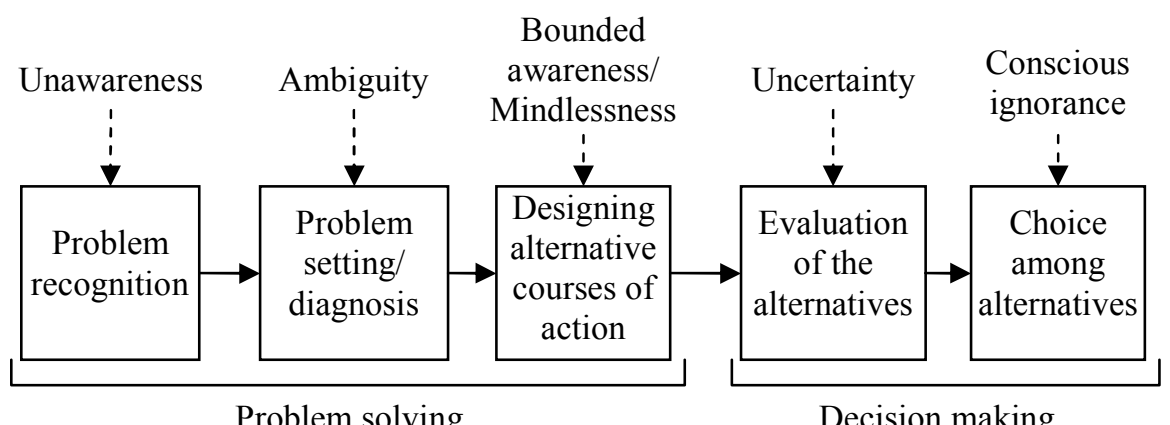

Figure 1.4. Alignment of the problems along the decisionmaking process (on Simon's model basis)

Grove (1999) demonstrates this conditional sequence - how the unawareness turns to initial awareness, accompanied by ambiguity: "Yet there is no flashing sign that heralds these rule changes [unawareness]. They creep up [...] without warning [initial awareness]. You know only that something has changed, something big, something significant, even if it's not entirely clear what that something is [ambiguity]" (p. 20).

Our knowledge of the decision making process diminishes the closer we get to its inception (Berthon, Pitt and Katsikeas, 1999; Dutton, Fahey \& Narayanan, 1983; Mintzberg, 1977; Pounds, 1969), being the least about the problem recognition. This adds an incentive to investigate the problem.

\section{Characteristics of Unawareness}

\section{Logic and accessibility}

To ask of what one is unaware is illogical. Russell (1903/1992) argues that "' $A$ is not' must always be either false or meaningless. For if $A$ were nothing, it could not be said not to be; ' $A$ is not' implies that there is a term $A$ whose being is denied, and hence that $A$ is" (p. 449). One's statement that one is unaware of $\mathrm{A}$ is as the same false or meaningless. The only logical conclusion is eliminative: if $\mathrm{A}$ is included in one's Theory, then one is not unaware of A; but if $\mathrm{A}$ is not included, it still can be the result of conscious ignorance. Hence the content of unawareness is inaccessible.

The formal representation of the above reads: let the "Theory" be the set of objects included in one's Theory; let the "not-Theory" be the rest of the objects in the universe; let the "unawareness" set be the objects that one unconsciously ignores. In the following Venn diagram (figure 1.5) the lined area designates nullity and the X stands for "there exists": 


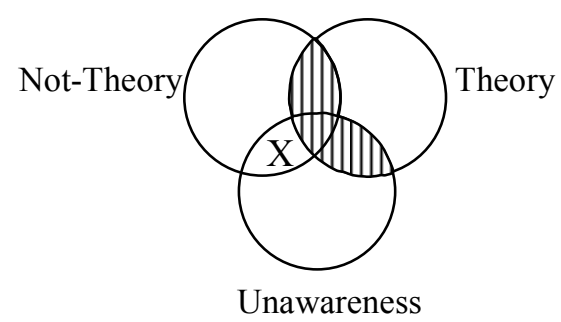

Figure 1.5. The logic of unawareness

A "there exists" statement cannot be falsified (Popper, 1961); therefore the statement "there is no unawareness" cannot be confirmed. The latter statement is inductive, so the conclusion is that unawareness cannot be eliminated by induction.

\section{Tacitness and teachability}

The sets "Theory" and "not-Theory" constitute the whole, the entire "Universe"; in Euler's style of drawing the "Theory" and the "Universe" can also be represented as concentric circles, the former inside the latter. Our question is: how is the border in between determined? Here the logical constraints meet the issue of tacitness. Polanyi (1974) parallels what we name "Theory" and "not-Theory" to object and background, respectively:

Similarly, a process unambiguously determined by an ordering principle, such as the motion of the planets round the sun, can be said to constitute a closed system of events only to the extent to which its relations to other objects and events are found to be purely random. Any entity - whether an object or determinate process - will be the more clearly set off against its background, the more amply its internal particulars show steadiness and regularity - combined with an amply confirmed absence of any co-variance between these particulars and those of the background (Polanyi, 1974, p. 38).

Here and as mentioned earlier (cf. the conscious ignorance), the randomness is the key determinant of one's attention. The crucial insight that Polanyi adds about that is the tacitness of the distinction:

...how can we tell that $[. .$.$] certain events are occurring at$ random? [...] my belief [is] that random systems exist and can be recognized as such, though it is logically impossible to give any precise definition of randomness (Polanyi, 1974, p. 38). 
The consequence resembles the notion of inaccessibility that we have just discussed above:

...in affirming these fundamental laws of nature, we accredit our capacity for knowing randomness from order in nature and that this distinction cannot be based on considerations of numerical probabilities, since the calculus of probabilities presupposes, on the contrary, our capacity to understand and recognize randomness in nature (Polanyi, 1974, p. 40).

So the tacitness aspect echoes the logical idea: that the content of unawareness is inaccessible. The tacitness bears additional consequence: the experience of awareness is ineffable, thus cannot be instructed.

The cognitive perspective is the third to reach the same conclusion: the aforementioned theory of categorization (Bruner et al, 1956) clearly distinguishes between the amorphous step of concept formation and the structured, analyzable step of concept attainment; only the latter is a target for investigation.

To sum: the characteristics of unawareness prohibit three measures: to access the content of unawareness, to confirm that "there is no unawareness", and to grasp the tacit experience. What remains? We can (1) access the content of awareness; (2) falsify the statement, and (3) explicate both.

\section{Perspectives for Inquiry}

The unawareness issue can be studied from several perspectives. For instance, each of the cases in this chapter represents another choice:

- Grove (1999) employs the economic perspective as he explains the failure through the changes in the market forces.

- Yates's (1983) point of view is sociological as he centers on the homogeneous mindset of the decision-makers caused by their uniform socialization.

- $\quad$ Barr et al (1992) suggest the cognitive lens to address the learning process. They are exceptional in explicating the research perspective and in telling its advantage: "These possibilities for further generalization make us especially enthusiastic about the cognitive theories we have used in this study of organization renewal" (p. 34).

Gardner (2006), in an inquiry of mind changing, names in addition the historical-cultural alternative. He uses and advocates the cognitive perspective (and by the way challenges Yates): "We can conceptualize what people are thinking, how they are thinking, and how, when necessary, that thinking 
can be changed $[\ldots]$ Conscious awareness of cognitivism is a boon when it comes to changing minds. [...] Neither biology nor culture can explain the events of 1960 to 2003 in the automobile industry; cognitivism at least has a shot" (pp. 42-43, 47; italics in origin).

Kiesler \& Sproull (1982) exhibit a similar rationale: "This paper outlines research on social cognition and suggests how it can be used to understand and predict managerial problem sensing. [...] Most analyses to date, however, have failed to consider explicitly how patterns of individual thinking and memory influence organizational variables and processes in adaptive behavior" (p. 548).

The economic perspective is discounted by Bowman (1995): "However, we have found that this approach, though helpful in broadening thinking about competition, can often reside firmly in the zone of comfortable [not challenging] debate" (p. 10).

The above examples (and more in the next chapter) are indicative of the popularity of the cognitive perspective, alongside of less prevalent ones. The common denominator of all these perspectives is their focus on the knower. To borrow a classification used in information science (Dervin \& Nilan, 1986), they are knower-centric rather than knowledge-centric.

In line with this analogy we expect a knowledge-centric approach to maintain "some element of absolute correspondence to reality" (Dervin \& Nilan, 1986, p. 13), namely truth - an aspect that the knower-centric approach belittles. This shift of emphasis accords with the centrality of truth in "epistemological knowledge", which is what the "Theory" contains:

\begin{abstract}
By epistemological knowledge, I am signalling a move away from the everyday knowing that things are the case towards deeper understandings of why things are as they are. It is to know why, to be knowledgeable about, to know the truth of, to be certain of, or to understand. [...] I have called it epistemological knowledge to indicate that it is the most self-conscious about its validity and, more than the other forms of knowledge, is centrally characterized by its concern for truth. [...] This form of knowledge goes beneath the surface of what appears to be the case, the domain of the empirical, to be able to account for the empirical in terms of underlying reasons or causes (Mingers, 2008, p. 73 ; italics in origin).
\end{abstract}

The emphasis put on validity and truth suggests an investigation from the epistemological perspective. Epistemology means "the theory of knowledge, especially with regard to its methods, validity, and scope" (Ox- 
ford dictionary). The epistemological perspective centers on the truth of the Theory.

The epistemological perspective with regard to organizations does exist, though marginally. Besides, the current emphasis is on knowledge as a social substance, whilst the question of truth is reduced to a shadow (examples are Cook \& Brown, 1999; Durand, Mounoud \& Ramanantsoa, 1996; Nonaka, 1994; Rowland, 2004; Von Krogh, Roos \& Slocum, 1994). Therefore this aspect of epistemology has to be extracted from vicarious references in the organizational learning literature.

\section{Summary}

This chapter introduced the research domain and the key definitions. Prime among the definitions is the Theory, which demarcates and explains the relevant part of the world (as the organization assumes). The Theory rationalizes the means employed by the organization towards its ends. The Theory's validity is a key condition for valid strategy.

Secondly we scrutinized the unawareness problem, namely "Things we don't know we don't know", that risks the Theory's validity. In this regard we addressed three issues:

- The scope and structure of unawareness: the unawareness problem functions as the "gatekeeper" of the decision-making process and conditions its initiation.

- The characteristics of unawareness: the characteristics of unawareness prohibit three measures: to access the content of unawareness, to confirm that "there is no unawareness", and to grasp the tacit experience. Yet we can (1) access the content of awareness; (2) falsify the statement, and (3) explicate both.

- The perspective from which the issue can be studied: organizational knowledge-centric approaches that address the truth question are rare. An epistemological, truth-focused investigation has to extract the theoretical background from vicarious references.

\section{Outline of the Research}

Once we defined the unawareness threat to the organizational strategy, our aim is to explain its causes in order to address and overcome them. The research takes the critical rationalist stance adapted for the social sciences, which means to prove one theory more authentic then another (details in chapter 3). The critical rationalism doctrine, founded by the philosopher Karl Popper, plays a dual role in the research: for one as the research method; for two as the hypothesized remedy for unawareness. 
Chapters 2-3 establish the theoretical foundations. Chapter 2 presents the debate between Popper and the rival account proposed by Kuhn. The bottom line concerning our interest is that Kuhn excuses unawareness whilst Popper sees it as a bad and avoidable choice. The management literature is rife with Kuhnian references whilst the Popperian alternative is regarded inapplicable for management. This stance, which we name the inadequacy argument, is our target for alteration.

In chapter 3 we construct the competing theory. First we detail the Popperian method as the yardstick. Then we review the management learning literature upon which we suggest that the Popperian method is not inapplicable but obstructed. The competing theory is named the falsification obstructers theory.

In chapter 4 we investigate methods intended to justify the validation of organizational Theories. Based on the falsification obstructers theory we identify the deficiencies in these methods, and recognize the adaptations needed in the Popperian method in order to test the theory.

Chapter 5 details the research design. The research objective is to corroborate the competing falsification obstructers theory and by that to supplant the inadequacy argument in order to counteract the unawareness problem. Toward that end a falsification method has to be designed, so the research engages design science; the concept is introduced. We show that the action research method is appropriate for both design and critical rationalist investigation and design the research in accordance with the guidelines applicable for both.

Chapters 6-9 contain the research. The problem diagnosis of cycle 1 is elaborated in chapter 6; chapter 7 covers the action planning, namely the method design; and chapter 8 describes the remaining phases of cycle 1 : action taking, evaluation and learning. A new hypothesis that follows cycle 1 is tested upon the second cycle and reported in chapter 9. The research is concluded in chapter 10 . 


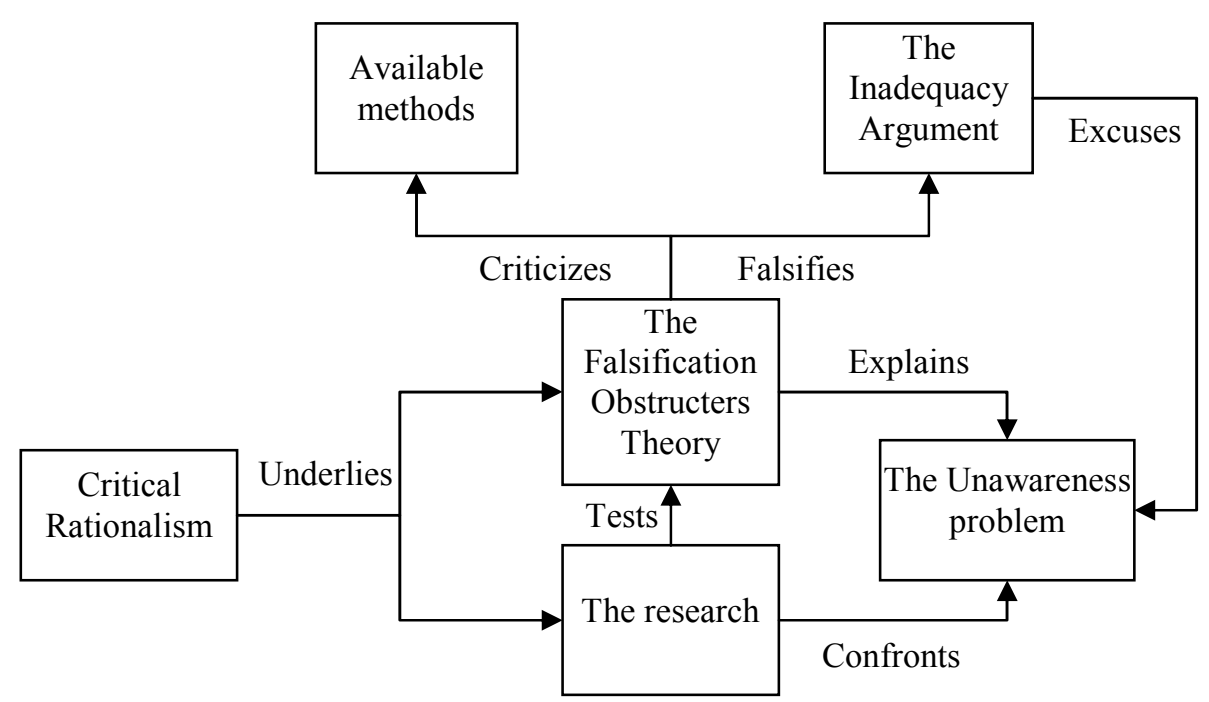

Figure 1.6. The relations among the study's components

Figure 1.6 illustrates the relations among the components in this study, and will repeat ("Figure $0 "$ ") in the beginning of selected chapters as an orientation aid (by blackening the focal component ${ }^{9}$ ). The Critical Rationalism stance (left) underlies both the management theory we propose and the research we conduct: the former yields the Falsification Obstructers Theory which is tested through the latter. The study's ultimate target is the Unawareness problem (the focus of this chapter) that the theory explains and the research confronts, with the experimented critical-rationalist remedy. In line with the Critical Rationalism approach, the corroboration of the Falsification Obstructers Theory falsifies the contradicting Inadequacy Argument (that excuses the unawareness problem). Finally, the theory guides the critical evaluation of Available counter-unawareness methods. ${ }^{9}$ When two components are blackened it means that the chapter establishes the
connection between them. 


\section{The Theoretical Problem: the Epistemological Stance Ascribed to \\ Managers}

\section{Introduction}

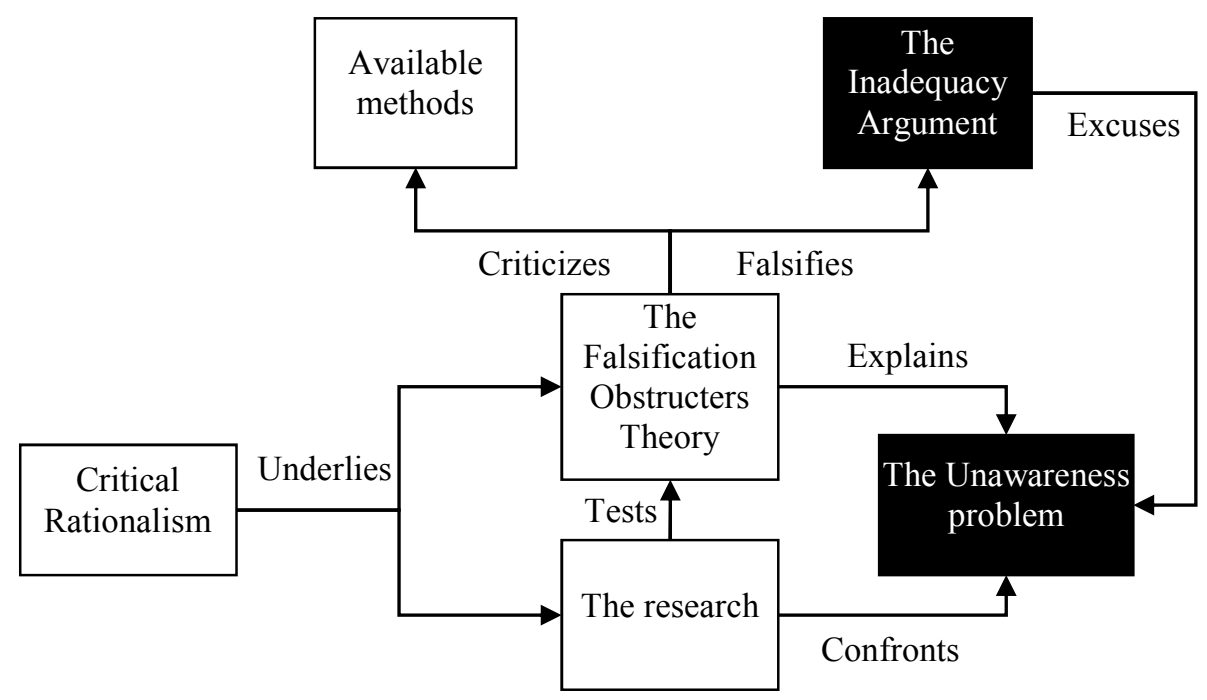

Figure 2.0. The focus of the chapter (blackened)

This chapter provides the epistemological ground, as extracted from the literature, and builds the case for our criticism. The general question is how the issues of Theory, truth and validation are theorized in the management literature. Specifically we are asking:

1. Which epistemological stance is ascribed to managers in the literature?

2. According to this stance, is the problem of unawareness corrigible?

Epistemology is a philosophical concept that has been developed in three imbalanced waves: a flimsy exploration of the concept by Plato $\left(4^{\text {th }}\right.$ century $\mathrm{BC}$ ), early developments since the $17^{\text {th }}$ century (by e.g. Hume) and during the Enlightenment, and profound essentials that have been established only in the turn of the $20^{\text {th }}$ century (Goldman, 2006). Along this timeline the social sciences have traditionally lagged behind the natural sciences; within this, the epistemology of managers is a recent development. The prevailing 
theories of managerial epistemology build upon the scientific foundations of the early $20^{\text {th }}$ century.

The issues of theory, truth and validation are at the heart of the philosophy of science. Naturally this discipline is wide and rich with doctrines and views. Without discounting others' contribution (e.g. Lakatos or Feyerabend) we limit ourselves to two prominent approaches: those of Popper and Kuhn. The reasons for that are twofold: first, Kuhn, more than other philosophers of science, is a popular reference in the management literature, to the extent that the typical manager is portrayed as Kuhnian. Second, Kuhn $(1970 / b)$ polarizes his stance specifically with that of Popper, although the latter would probably not subscribe on it (Fuller, 2004).

The chapter opens with the philosophical debate and presents Popper's doctrine, followed by Kuhn's antithesis; then they are compared. Next we check how these two competing attitudes are reflected in the management literature. Finally we return to the questions above and draw conclusions.

\section{The Scientific Method}

\section{Popper: Critical Rationalism}

Karl Popper (1902-1994), the founder of Critical Rationalism, contemplated his ideas first in the 1930's. Lincoln \& Guba (2000) associate him with postpositivism $^{10}$. Freudenthal (1977), Thornton (2006) and others hold that Popper should be read in the context of the zeitgeist, namely the "logical positivism" led by the Vienna Circle. Very briefly, the Vienna Circle (and the analytic philosophy in general) denied ideas of metaphysics that populated the philosophical thinking beforehand. They distinguished between meaningful and meaningless statements, assuming a statement as meaningful only if empirically verifiable - what became the "principle of verifiability" (Freudenthal, 1977). Popper (1963/2002) elaborates on his rivals' idea that he opposes:

...the propositions which belong to science are those deducible from true observation statements; they are those propositions which can be verified by true observation statements... verifiability, meaningfulness, and scientific character all coincide (Popper, 1963/2002, p. 52; Italics in origin).

${ }^{10}$ Positivism "generally assume that reality is objectively given and can be described by measurable properties which are independent of the observer (researcher) and his or her instruments" (Myers, 1997). 
Popper defies the epistemology of verification and contrarily suggests a methodology for falsification (Popper sees epistemology and methodology as interchangeable: "in accordance with my proposal made above, epistemology, or the logic of scientific discovery, should be identified with the theory of scientific method" [1961:49]). Verification is unachievable, Popper argues, since it is endlessly circular. The key principle he establishes is that a theory holds unless proved otherwise; hence the core of science is about refuting theories rather than affirming them. An irrefutable theory is not scientific by definition.

Along with his criticism of the logical positivism, Popper was as much a criticizer of conventionalism ${ }^{11}$, around which he and Kuhn would debate; we will return to this point shortly.

The method will be detailed later; for this chapter's purpose enough is to screen the following four pillars on which Popper grounds his method; they all, as we shall see, bear managerial consequence. The pillars are: the primacy of deductive logic, the elimination of psychologism, the quest for active criticism and the problem-solving orientation.

The primacy of deductive logic: "The problem of induction" is for Popper (1961, p. 27) the point of departure. Popper continues the line drawn by the $18^{\text {th }}$ century philosopher David Hume, who negated the validity of inductive proof. Hume (1748/2008) asserted that an inductive argument must be circular, namely rest upon another induction ad infinitum. Popper (1963/2002, pp. 55-56) accepts Hume's conclusion (despite his slight reluctance of his "psychological" argumentation); therefore his entire doctrine rests upon the unequivocal deductive logic: "Here too the procedure of testing turns out to be deductive... certain singular statements - which we may call 'predictions' - are deduced from the theory... if the conclusions [i.e. 'predictions'] have been falsified, then their falsification also falsifies the theory from which they were logically deduced" (Popper, 1961, p. 33; Italics in origin). And in order to remove any doubt, he continues:

Nothing resembling inductive logic appears in the procedure here outlined. I never assume that we can argue from the truth of singular statements to the truth of theories. I never assume that by force of 'verified' conclusions, theories can be established as 'true', or even as merely 'probable’ (Popper, 1961, p. 33).

${ }^{11}$ Conventionalism: an attitude that contrasts positivism by viewing fundamental principles as explicitly or implicitly grounded on agreements in society, rather than on external reality 
The elimination of psychologism: The progress of scientific knowledge follows two phases: discovery and justification. In the former a theory emerges, in the latter its truth is warranted (Freudenthal, 1977). Popper strictly sides with the analytic philosophy as he states his exclusive interest in justification: "I shall distinguish sharply between the process of conceiving a new idea, and the methods and results of examining it logically" (Popper, 1961, p. 31). Popper neither ignores nor discounts the power of induction, enlightenment or even mere chance that stands behind the discovery phase; nor does he disregard biases or preconceptions. He just enfolds all of them under the umbrella of "psychologism", and since these forces resist formalization they are excluded from the methodology. The theory's conception in Popper's (1961) view is definitely tacit: "...there is no such thing as a logical method of having new ideas, or a logical reconstruction of this process. My view may be expressed by saying that every discovery contains 'an irrational element', or 'a creative intuition'..." (p. 32).

Among the psychological limitations Popper (1961) stresses the unavoidable subjectivity of the scientist. An attempt to neutralize this tendency would be pointless, Popper argues, but anyway unnecessary; it is offset by the method. That is, the individual scientist is subjective but the community-shared methodology, named inter-subjectivity, assures the objectivity; "the objectivity of scientific statements lies in the fact that they can be intersubjectively tested", Popper asserts (p. 44; italics in origin), and in a footnote he adds:

I have since generalized this formulation; for intersubjective testing is merely a very important aspect of the more general idea of inter-subjective criticism, or in other words, of the idea of mutual rational control by critical discussion (Popper, 1961, footnote $* 1$ on p. 44; italics in origin).

That is to say, the deductive testability renders objectivity. This is an additional merit of "The primacy of deductive logic" principle, as only deductive logic can claim objectivity.

The quest for active criticism: the elimination of psychologism does not imply that Popper expects the scientist to be unbiased or purely rational upon discovery. Just the opposite is true: it is exactly because psychological "contamination" is inevitable that the quest for active and intentional criticism is so material. Popper (1961) expects the scientist to actively test, criticize and revise her theory if necessary: "we shall take the greatest interest in the falsifying experiment" (p. 80). Psychologism, to a great extent, is associated with conventionalism, and a conventionalist may resist the refutation of a theory by an arsenal of counterarguments. But Popper does not allow the scientist to excuse himself on that ground; he urges him to make a 
conscious decision and to take responsibility: "The only way to avoid conventionalism is by taking a decision" (Popper, 1961, p. 82; italics in origin). Actively controlling the process, according to Popper (1970), is an ideological imperative ${ }^{12}$.

However it should be noticed that the required criticism is constructive, and by no means for the sake of provocation per se: "The aim is to find theories which, in the light of critical discussion, get nearer to the truth" (Popper, 1970, p. 57).

The problem-solving orientation: "...it [science] begins when a myth [or theory] is challenged and breaks down - that is, when some of our expectations are disappointed... science begins with problems, practical problems or theoretical problems" (Popper, 1994, p. 95; italics in origin). Popper defines the scientist as primarily a problem solver, and harshly repels - even ridicules - the popular notion that science starts from observations (ibid). Concerning the "solving" side he writes: "there is only one way to learn to understand a serious problem... And this is to try to solve it, and to fail" (p. 99). This "only way" to solve a problem is to hypothesize a solution (i.e. a new theory), to test it critically and to learn from the discovered mistakes, "Or to put these four steps into four words: problems-theories-criticismnew problems" (Popper, 1994, p. 159); in other words, the criticism is aimed at problem recognition. Figure 2.1 presents the cycle.

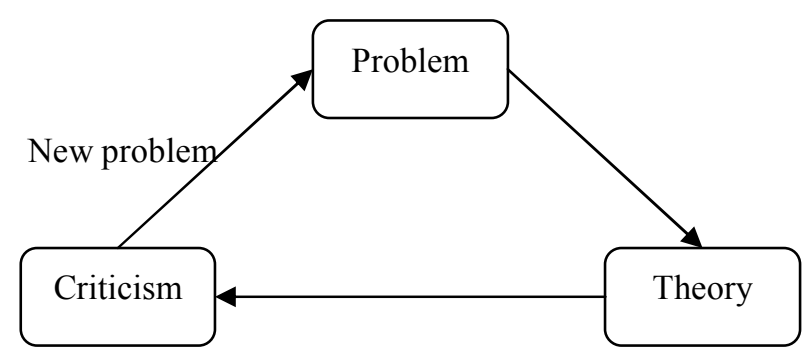

Figure 2.1. Popper's cyclical scientific process

Three of Popper's (1994) accentuations are noteworthy: (1) the identification of a problem with a missed expectation; (2) the sameness of practical and theoretical problems, and (3) the intentional trial-and-error style of

${ }^{12}$ The ideological spirit is exemplified by statements such as: "[rational criticism] ...is a way of thinking, and even a way of living" (Popper, 1994, p. xii). Also: "...an ideology which has learned from the critical approach of the sciences is likely to be more rational than one which clashed with science" (op.cit, note 43 on p. 30). 
learning. Further, the problem-solving orientation converges with the constructive attitude mentioned above.

Freudenthal (1977) reads this problem-triggered process as another distinction of Popper from the analytical philosophy in general and the Vienna Circle in particular. Whilst the latter two are concerned only with the formalism of the statements, Popper pays not the less attention to the process. Popper's approach, according to Freudenthal (1977), is balanced between historical ${ }^{13}$ and analytical.

These four grounding pillars stand in a sharp contrast with the merits that Kuhn ascribes to science, to which we now turn.

\section{Kuhn: Normal Science and Scientific Revolution}

Kuhn (1922-1996) published his seminal book "The Structure of Scientific Revolutions" in 1962 and an enlarged second edition in 1970 (Kuhn, 1970/a). It is first and foremost a historical review from which Kuhn constructs a descriptive theory. Johnson \& Duberley (2000) mark Kuhn's thesis as the finest example of conventionalism (which, as mentioned above, Popper vehemently criticizes).

Kuhn equates the establishment of a scientific domain with the emergence of a shared paradigm. A paradigm means, roughly though, a frame of common language, mutual understanding of what is important to investigate, and a general agreement about the basic premises that govern this specific domain. Kuhn defines a paradigm quite broadly: it is this shared understanding that eliminates overt disagreements among scientists concerning essential issues or fundamental postulates.

Another key concept is normal science: Kuhn distinguishes, concerning a scientific domain, between pre- and post-paradigmatic eras; during the former the domain constitutes pre-science that becomes normal science once a paradigm prevails. A scientific revolution means a paradigm shift within normal science.

Scientific progress in normal science (i.e. within a paradigm) consists of both empirical and theoretical efforts. The empirical course includes gathering of facts whose relevance is determined by the paradigm, comparison between those facts and the predictions that are derived from paradigmbased theories, and improvements of the paradigm through identification of constants, articulation of quantitative laws and expansion of the paradigm's applicability. The theoretical avenue takes the form of generating predictions, designing experiments and rearticulating theories.

${ }^{13}$ The historical stream in the philosophy of science, including Kuhn, holds that discovery and justification are inseparable and assigns little weight to the logical aspect. 
In the context of this scientific activity Kuhn presents the third keyword, namely puzzles: the "normal" scientist, Kuhn argues, is busy with solving puzzles. The use of the phrase "puzzle" in its most ordinary meaning (jigsaw-puzzle) is intentional, and means to reflect the following merits of the game: the solution is expected and does not surprise; the quality of the puzzle is not indicated by the significance of the solution; instead, the solution is evaluated by terms of elegance, and a solution makes sense only within the clear boundaries imposed by the game's rules. The sheer implication, according to Kuhn, is that bizarre problems - those that the paradigm fails to contain - are discarded and tagged as distraction, exception or metaphysical.

One may wonder what attracts a scientist to solve puzzles that seem quite conservative, far away from the heroic image of scientific exploration. Indeed, Kuhn shatters the glory of the rational, skeptic, even iconoclast scientist; instead he portrays an orthodox line follower. Kuhn exchanges socialpsychology for rationalism: the scientist, he argues, is a community member who is subject to personal drives and motives as any other human being.

The scientific community, defined by a shared paradigm, is where the scientist is socialized; where s/he internalizes the purview of admissible puzzles and the rules of solving them. The community is where s/he is evaluated and promoted. The community controls the legitimatizing power.

Psychologically, Kuhn depicts the scientist as ego-driven: the scientist is eager to demonstrate that $\mathrm{s} / \mathrm{he}$ can solve puzzles that nobody has managed to solve before, or to do it better. If so, the scientist - rather than the scientific matter - is subject to test; personal ambition is the name of the game. Scientists are subject to cognitive biases and are captivated within the paradigm, thus their criticism is neutralized. They notice only those concepts that fall within their existing categories; the observed depends on the observer, and this means subjectivity.

In a 1991's interview, which is a key for understanding the Kuhnian mindset, Kuhn nullifies the meaning of "error"; across paradigms, he clarifies, one is not "wrong" but "thinks differently":

...Kuhn opened Aristotle's Physics and was astonished at how "wrong" it was. How could someone so brilliant on other topics be so misguided in physics? Kuhn was pondering this mystery, [...] when suddenly Aristotle "made sense." Kuhn realized that Aristotle's views of such basic concepts as motion and matter were totally unlike Newton's. Aristotle used the word "motion," for example, to refer not just to change in position but to change in general the reddening of the sun as well as its descent toward the 
horizon. Understood on its own terms, Aristotle's physics "wasn't just bad Newton," Kuhn says; it was just different ${ }^{14}$

So how do paradigmatic revolutions happen? As more and more puzzles remain unsolvable under the current paradigm, sooner or later an alternative paradigm emerges, and after accumulating a critical mass it replaces the old one. Kuhn emphasizes the haphazard, unintended nature of paradigmbreaking discoveries; he clearly paints it as a social process, beyond any individual effort (often the pioneering discoveries are recognized and specified in retrospect, an indication of their occasionality). He roughly counts three stages along a new paradigm's emergence: first, initial attention to exceptions; second, gradual development of perceptibility, and third a gradual consensus over the new categories (concepts). This progress resembles what Hume (1748/2008) calls "custom" and is distinctly inductive, although Kuhn (1970/b) dislikes the inductive attribution.

In sum, Kuhn constructs a descriptive socio-psychological theory on historical basis. Based on the theory Kuhn concludes that the traditional positivist epistemology has collapsed, and specifically challenges the Popperian doctrine (which he regards as an emblem of positivism). His criticism holds that a paradigm (namely a theory in Popper's terms) is irrefutable from within and that communication across competing paradigms is impossible.

\section{Popper vs. Kuhn: critical comparison}

Whilst the anti-Popperian criticism in (Kuhn, 1970/a) is in the margins, it is the leading theme in (Kuhn, 1970/b). Much of Kuhn's arguments and Popper's response thereof (Popper, 1970) are beyond our scope; only those that pertain to the organizational angle are briefed here.

Kuhn (1970/b) reemphasizes his personal attribution within a sociopsychological frame. First he highlights how variously Popper and he define problem: Popper ascribes it to the theory, Kuhn to the scientist (in Kuhn's view the scientist is tested, not the theory ${ }^{15}$ ). Second, he justifies the usage of the term puzzle on that very ground: to keep the personal connotation that the Popperian "error" neglects ${ }^{16}$. Further, the ability to define puzzles is for Kuhn the "true" criterion for science, a substitute for the Popperi-

${ }^{14}$ Interview by John Horgan: "Profile: Reluctant Revolutionary - Thomas S. Kuhn Unleashed 'Paradigm' on the World," Scientific American, May 1991 pp. 40-49.

${ }^{15}$ In Kuhn (1970/a) the term "anomaly" maintains the qualities of the Popperian problem, namely a deviation from the expected (aka a "novelty"). As the term "anomaly" implies, it is not the normal scientific conduct.

${ }^{16}$ Kuhn argues that Popper's use of the term "error" (regarding a theory) can be appropriate only under inductive approach: an incorrect theory can only be an outcome of mistaken induction. 
an testability. Third, Kuhn insists on the dominance of socio-psychological motives upon a theoretical junction (where the Popperian "decision" is required) at the expense of logical considerations.

Kuhn draws a clear line between science and practice, based on the void of a paradigm (theory) in the latter. Thus, he asserts, practice can at best be "plausible" but not truthful: "Though they [practitioners] had rules to apply, they had no puzzles to solve and therefore no science to practice" (Kuhn, 1970/b, p. 9). In a sharp contrast, Popper (1961) sees scientific theories and practical rules as two sides of the same coin, and that symmetry allows cross-refutation (more about it in the next chapter).

In reply to Kuhn, Popper (1970) has little to add to his original exhortation; after all, in (Popper, 1961) he anticipated this exact conventionalist opposition and addressed it, plainly enough: the scientist should make a decision whether to succumb to conventionalism or to resist. Instead of contradicting Kuhn's allegations Popper neutralizes them; they are just that trap of psychologism that he wishes to avoid; note the sarcasm: "whenever the 'classical' system of the day is threatened [by falsification]... the system will appear unshaken to the conventionalist" (p. 80). Popper (1970) amplifies his "problem" concept and deprecates the minor problems with which the "Kuhnian" scientist is busy (according to Popper the Kuhnian scientist is applied scientist, whilst critical rationalism is "pure" science). Popper (1970) warrants the existence of inter-paradigm communication and warns that the seclusion within a paradigm is a defeatist choice rather than predestination:

I admit, of course, that it is much easier to discuss puzzles within an accepted common framework [...] than to discuss fundamentals - that is, the very framework of our assumptions. [...] I do admit that at any moment we are prisoners caught in the framework of our theories; our expectations; our past experiences; our languages. But we are prisoners in a Pickwickian ${ }^{17}$ sense: if we try, we can break out of our framework at any time (Popper, 1970, p. 56).

Popper might have alluded that his and Kuhn's theories are not really commensurable; after all, they are polarized upon enough dimensions (see table 2.1). Some of them are self-evident, for instance the aim: Popper presents a normative theory and designs a method (Figueiredo \& Cunha, 2007; Walls, Widmeyer \& El Sawy, 1992); Kuhn's theory, on the other hand, is descriptive. Concerning phase, Popper skips the process of the theory's conception,

${ }^{17}$ Pickwickian: of or like Mr Pickwick in Dickens's Pickwick Papers, especially in being jovial, plump, or generous. (Of words) misunderstood or misused, especially to avoid offence (Oxford Dictionary). 
i.e. discovery, which is central in Kuhn's, and concentrates on the justification phase.

With respect to our interest in unawareness, the main point is that Kuhn explains unawareness whilst Popper confronts it. Kuhn's insistence on the literal meaning of the "puzzle", let alone its centrality, associates the scientist with the bounded awareness problem, thus in the design step (figure 1.4). Popper, on the other hand, centers on the problem recognition, and his cyclical scientific process is a sheer response to the unawareness problem; further, the logical and psychological constraints (induction and tacitness, respectively) are strictly addressed. Popper urges the individual scientist to control the scientific progress and to actively recognize problems. Kuhn, in contrast, excuses the individual scientist from this burden; he sees the scientific community as the chief determinant and portrays the individual scientist as a biased, subjective and ego-driven member who is drifted upon the social current. Actually their theories do not compete but complete - being Popper's a countermeasure for the Kuhnian dysfunction. Table 2.1 summarizes the differences.

Table 2.1. Key differences between Popper's and Kuhn's theories concerning the growth of scientific knowledge

\begin{tabular}{|c|c|c|c|}
\hline No. & Dimension & Popper & Kuhn \\
\hline 1 & Type of the theory & $\begin{array}{l}\text { Normative and } \\
\text { design }\end{array}$ & Descriptive \\
\hline 2 & $\begin{array}{l}\text { Control and } \\
\text { responsibility }\end{array}$ & $\begin{array}{l}\text { Activeness of the } \\
\text { individual scientist }\end{array}$ & $\begin{array}{l}\text { By "invisible hand", } \\
\text { dispersed along the } \\
\text { amorphous scientific } \\
\text { community }\end{array}$ \\
\hline 3 & $\begin{array}{l}\text { Phase in scientific } \\
\text { progress }\end{array}$ & Justification & $\begin{array}{l}\text { Discovery and } \\
\text { justification, } \\
\text { inseparable }\end{array}$ \\
\hline 4 & Reasoning & $\begin{array}{l}\text { Deductive logic; } \\
\text { induction or } \\
\text { psychologism - out }\end{array}$ & $\begin{array}{l}\text { Historical and socio- } \\
\text { psychological }\end{array}$ \\
\hline 5 & Stimulus for action & $\begin{array}{l}\text { Problems, i.e. } \\
\text { unexpected results }\end{array}$ & $\begin{array}{l}\text { Puzzles: doing the } \\
\text { same things better }\end{array}$ \\
\hline 6 & Applicability & Science and practice & Science exclusively \\
\hline 7 & Unawareness & Confronted & Excused \\
\hline
\end{tabular}


With this dichotomy in mind we now turn to inquire how these two philosophies are reflected in the management and the organizational learning literature.

\section{Kuhn and Popper in the Management Literature}

\section{Kuhnian traces}

Kuhn is often cited in the literature, and more often inspires the writing indirectly. Five Kuhnian themes can be extracted: strategy as paradigm, the sociology of organizational knowledge, the personal accountability, the centrality of induction, and the psychological dimension. The relevant literature is plentiful and we are limiting ourselves to just the following examples.

Strategy as paradigm: Prahalad \& Bettis (1986), who coined the influential "dominant logic" concept, suggest the following analogy:

The concept of dominant logic also derives direct support from Kuhn's (1970) work on scientific paradigms... Kuhn, a historian of science, argued that a particular science at any point in time can be characterized by a set of 'shared beliefs' or 'conventional wisdom' about the world that constitutes what he called the 'dominant paradigm'. What Kuhn calls 'normal science' is carried out efficiently under this set of shared beliefs. In a sense, Kuhn's 'paradigm' is simply a way of defining and managing the world and a basis for action in that world. Kuhn points out how difficult it is to shift dominant paradigms, and illustrates this with several examples... The analogy from science to a business firm is simple and direct. The dominant paradigm and the dominant logic are conceptually similar but employed in different fields (Prahalad \& Bettis, 1986, p. 492; italics in origin).

Huff, Huff \& Barr (2000) provide another analogy. Their thesis assumes two conflicting forces that act upon the strategy: stress (to change the strategy) against inertia (to stick with it). Satisfying strategic results counteract any tendency to question basic assumptions, and reversely - "enough" disappointing outcomes lubricate the emergence of alternative premises (resemblance of Kuhn's paradigm shift); the older the strategy, the more powerful is the inertia - "with interesting parallels to the process Kuhn (1970) describes for the adoption of a new scientific paradigm" (p. 82). The motive of satisfactory results as inhibiting criticism repeats in Simon (1945/1997) as well as Isenberg (1986/a, 1986/b). Huff et al (2000) further observe: "Just as Kuhn (1970) describes rules, instrumentation, and experimental standards as the component parts of a scientific paradigm, so, too, the details of 
administrative structure and day-to-day organizational activity constitute the reality of an accepted organization strategy" (p. 87). This notion of the institutionalization of the strategy/paradigm is also suggested by Foster \& Kaplan (2001).

Lyles \& Schwenk (1992) parallel organizational core knowledge (i.e. Theory) to Kuhn's paradigm, and Mintzberg (1987/b) compares strategic change to Kuhnian paradigm shift. Schein (1990) "paradigmatizes" the core of the organizational culture that comprises "taken-for-granted, underlying, and usually unconscious assumptions that determine perceptions, thought processes, feelings, and behavior" (p. 112).

Hedberg \& Jonsson's (1977), dubbing the Theory a "myth", express the Kuhnian idea of "scientific revolution" that emerges upon the previous myth's collapse: "The main features of our perception of the development and replacement of myths over time are the habituation and filtering effects of the established strategy that create inertia, which in turn results in crises" (p. 95). The "filtering effects" reappear in what Weick (2004) calls "evolutionary epistemology", which reigns as long as one paradigm holds: "Organizing emerges as an ongoing stream of failed experiments and relentless mortality, updating, surprise, adaptations that threaten to reduce adaptability, winnowing, and occasional convergence" (p. 659).

Hedberg \& Jonsson's (1977) echo the notion of passivity, namely how managers are driven rather than drive the situation:

If and when the old myth is undermined by anomalous information - for example, when divergences from expectations cannot be explained within the frame of reference given by the old myth - there is genuine subjective uncertainty. Decisionmakers feel uncertain because they do not know the causes behind the unexpected outcome, and they have no clue as to where to find ideas for corrective action (Hedberg \& Jonsson, 1997p. 97).

Finally, Christensen, Raynor \& Verlinden (2001), when telling a false decision made by IBM, excuse the decision-makers just as Kuhn has "exculpated" Aristotle:

"When IBM decided to outsource its operating system and processor chips in the early 1980 s, it $[\mathrm{IBM}]$ was $[\ldots]$ at the top of its game. [...] Yet disaster famously ensued, as Intel and Microsoft subsequently captured the lion's share of the computer industry's profits, and Big Blue entered a decade of decline. It's easy to look back and ask, "What were they thinking?" but, in truth, IBM's decision fit well with prevailing orthodoxies, particularly with the idea that compa- 
nies should outsource all but their core competencies [...] Indeed, at the time, many observers hailed IBM's move as a masterstroke of strategy, forward-looking and astute" (Christensen et al, 2001, p. 74; italics added).

The sociology of organizational knowledge: Kuhn regards the paradigmshared scientific community as the truth reference for the individual scientist; this is the quintessence of conventionalism. The organizational literature reflects this view in two levels: the organization and the industry; it is a recent wave in the organizational research (Lant, 2005).

In the organization level, as mentioned earlier, the knowledge's social aspect is the major concern of the epistemological accounts. The central theme is that the truth meaning is socially created by and resides in the ties among the organization's members; it exists independently and beyond the individuals; it defines the "right" context (Cook \& Brown, 1999; Durand, Mounoud \& Ramanantsoa, 1996; Sandelands \& Stablein, 1987; Schein, 1992; Von Krogh, Roos \& Slocum, 1994; Weick, 1996). The notion of the paradigm-shared community is fundamental: "Organizing is first of all grounded in agreements concerning what is real and illusory, a grounding that is called consensual validation" (Weick, 1979, p. 3; italics in origin). Weick $(1995 / b)$ adds that the shared paradigm absorbs the conflicts in organizations.

Strategic problems are recognized upon that collective mind (Lyles \& Mitroff, 1980), up to the point that makes Spender (1998) to claim that management means to manage context. A case in point: Huff et al (2000, ch. 6) describe a major regulatory change that affected the US pharmaceutical industry during the 1960s. The authors parallel the firm's management with Kuhn's scientific community and show that shared understanding among the managing directors, just like among scientists, is a precondition for strategic change, and that the paradigm shift precedes strategic change.

The community theme in the industry level is not the less dominant. Recall (chapter 1, p. 11) the syndrome entitled "the Detroit mind" (Yates, 1983:77). More recently, James (2000) analyses a 1980s' paradigm shift in the pharmaceutical industry: from the Contract/Collaboration to the Strategic Alliances paradigm. The shift was as gradual and as decentralized as Kuhn describes the scientific parallel. James names the community mechanisms through which the change was spread (e.g. media and professional networks) "social learning".

The personal accountability: Kuhn's attribution of the test to the individual scientist (rather than the theory) has a parallel in management. So pervasive is the personal attribution that Pfeffer \& Sutton (2006) count it among the most dangerous "nonsense" myths in the managerial thinking. They accuse: 
So much is written about leaders because we believe that our fate, and the fate of our organizations, is in their hands and ought to be. We talk and act as if leaders are allpowerful deities and devils who wield complete command over even the largest organizations and that the organizations are better off for this fact. [...] It is not just that people believe leaders have almost total control of their organizations. Many people believe that leaders should have complete control (Pfeffer \& Sutton, 2006, pp. 187-188; italics in origin).

The conviction spreads below the top echelon; Merchant (1982) applies it to mid-level and line managers as well:

[The results] control comes in only one basic form, results accountability, which involves holding employees responsible for certain results. Use of results accountability control systems requires: (1) defining the dimensions along which results are desired, such as efficiency, quality, and service; (2) measuring performance on these dimensions; and (3) providing rewards (punishments) to encourage (discourage) behavior that will lead (not lead) to those results. [...] Results-accountability systems [...] attempt to motivate people to behave appropriately (Merchant, 1982, pp. 45-46; italics added).

Like in normal science, the standards are paradigmatic and the individual is accountable to follow the track.

The centrality of induction: according to Weick (1995/b), "The idea of a paradigm captures two qualities of sensemaking in organizations: its association with conflict [see above] and its inductive origin" (p. 118, italics added). Indeed, the inductive nature of both the emergence of a new paradigm and the progress within an established one is conspicuous in Kuhn's (1970/a) account. Similarly, the inductive quality of organizational learning is prominent.

Weick (1995/b) further connects the sensemaking concept with induction: "given the proclivity of people to engage in induction, despite its 'scandalous' reputation [...] as a thinking operation, and given the relative ease with which meaning can be established (all it takes is two connected elements), it is not surprising that a repertoire of [experience-based] stories is important for sensemaking" (p. 129).

Organizations learn, infer and recognize problems inductively. The Humean concept of "custom" (Hume, 1748/2008), i.e. learning by repetition, is echoed in the following excerpt: 
The term 'experience' refers to an organization's contact with the environment which forms the basis for knowledge structures. [...] As it [the organization] becomes more expert, the knowledge structure builds on the base established by the past experiences (Lyles \& Schwenk, 1992, p. 164).

Levinthal \& March (1993) connect awareness and problem recognition with induction; they show how inductive accumulation of precedents blunts the sense of criticism and increases the illusion of certainty:

Learning generates successes rather than failures. In every domain of learning, the likelihood of success tends to increase with competence (even allowing for aspiration level adjustments). As learners settle into those domains in which they have competence and accumulate experience in them, they experience fewer and fewer failures. Insofar as they generalize that experience to other domains, they are likely to exaggerate considerably the likelihood of success (Levinthal \& March, 1993, p. 104).

The managerial thinking is regularly described as intuitive (e.g. (Agor, 1986; Isenberg, 1986/a; Shapiro \& Spence, 1997; Simon, 1945/1997; Simon, 1987), and intuition is the embodiment of induction (Erat \& Von Krogh, 2000; Goldberg, 1989; Morris, 1967).

The psychological dimension: this Kuhnian aspect is loudly reverberated in the management literature. In chapter 1 (p. 22) we mentioned the dominance of the cognitive perspective in explaining strategic conceptions (or misconceptions). Two themes are prominent in this dimension: one is the filtering function of the paradigm and the consequent inter-paradigm disconnection (Bettis \& Prahalad, 1995; Hedberg \& Jonsson, 1977; Mintzberg, 1987/b). The other theme concerns the fixation phenomenon: the vicious cycle through which the paradigm is ossified on the one hand, and the alienation of self-criticism on the other (Heuer, 1999; Schwenk, 1984/a).

In short, the Kuhnian scientists and the manager are portrayed as equally equipped with a mental structure that shields the prevailing paradigm.

\section{(Anti-) Popperian references}

The relative shortness of this section is indicative: the organizational applicability of Popper's doctrine is by and large discredited ${ }^{18}$. The opposition

18 Two exceptions are Faludi (1983), who advocates the Popperian tradition for urban planning, but not in the context of falsification; and Ben-Israel (1989), which is elaborated in chapter 4 . 
is the logical result of negating two fundamental premises that underlie the doctrine: universality and objectivity.

The organizational literature identifies Popper as a positivist, so his doctrine reflects two qualities of positivism: first, "One of the principal difficulties with the positivist vantage point is that we are forced to treat processes as special cases of models built from static entities" (Spender, 1998, p. 234). Second, the positivist view assumes independent observation, which is "observation detached from the values and idiosyncrasies of the observer. This does not mean observation without the presence of an observer: it simply means observation that is judged by scientists to be independent of the peculiarities of any particular individual" (Midgley, 2008, p. 56; italics in origin). Therefore, the observer "is expected to preserve his distance from experimental phenomena, keeping his biases and interests from affecting the object of study" (Schon, 1983, p. 144).

Both premises are negated. The organization and the theorized environment cannot be separated; and the environment is in a continuous flux - either as a response to the organization's "observation" or independently. Therefore the observation is actually an intervention, which "could create a change, thereby making it possible to say that the observation is a result of the intervention rather than the intrinsic characteristics of the phenomenon being observed" (Midgley, 2008, p. 56). The intervention in the already-dynamic environment makes each situation idiosyncratic rather than derivable from a universal theory, so nothing like the latter can be falsified (Majone, 1980; Schon, 1983). Therefore "...we do not have adequate theory to apply to problems in any policy area [...] it [the theory] is typically insufficiently precise for application to a policy process" (Lindblom, 1959, p. 87). Tsoukas (1996) reaches a similar conclusion: "...the circumstances of a particular firm are bound to be, at least to some extent, unique. [...] It turns out, therefore, that the propositional type of knowledge per se cannot accommodate knowledge of local conditions of time and space" (p. 12).

The common bottom line is that critical rationalism is inadequate for the organizational circumstances. Both reasons are interwoven: (1) the "Theory" of the environment is too singular to be falsified and (2) the organization is too much involved to theorize impartially. This double-edge rejection is labeled the inadequacy argument, and the two pillars on which it stands are the environment and the organization.

One aspect that the organizational literature sees eye to eye with Popper (although without an explicit reference) is the problem notion. Like in Popper, the managerial problem is defined as a deviation from the expected (e.g. Berthon, Pitt \& Katsikeas, 1999; Cowan, 1986; Dervin, 1999; Dervin, 2003; Kiesler \& Sproull, 1982; Kilmann \& Mitroff, 1979; Simon, 1945/1997; Wilson, 1999). Smith's (1988) emphasis on the difficulty and importance that makes a problem "real" is an exact duplication of Popper's (1994) assertion. 
Whilst the Kuhnian "puzzle" connotes a closed system and predefined rules, the managerial problem solving is in a sharp contrast:

[...] professional practice is [allegedly] a process of problem solving. [...] But with this emphasis on problem solving, we ignore problem setting, the process by which we define the decision to be made, the ends to be achieved, the means which may be chosen. [...] When we set the problem, we select what we will treat as the "things" of the situation, we set the boundaries of our attention to it, and we impose upon it a coherence which allows us to say what is wrong and in what directions the situation needs to be changed. Problem setting is a process in which, interactively, we name the things to which we will attend and frame the context in which we will attend to them (Schon, 1983, pp. 39-40; italics in origin).

Zaleznik (1977/2004) implies that operational management may exhibit some puzzle-like orientation, but makes no room for such a parallel in the strategic apex: "Leaders work in the opposite direction. Where managers act to limit choices, leaders develop fresh approaches to long-standing problems and open issues to new options" (p. 77).

But as we said, the resemblance is our brainchild; the literature does not associate the problem notion with Popper.

\section{Comparison}

The Popperian and the Kuhnian traces are hardly comparable but upon the following two criteria:

- Acceptance: Popper's doctrine is regarded inadequate for organizations, whilst Kuhn's theory is readily borrowed.

- Compatibility: the Kuhnian puzzle is incompatible with the theoretical understanding of managerial activity, whilst the Popperian and the managerial problems are quite the same. The literature ignores both the contradiction and the similarity.

\section{Conclusions}

The chapter was aimed at answering two questions:

1. Which epistemological stance is ascribed to organizations in the organizational learning literature?

2. According to this stance, is the problem of unawareness corrigible? 
Concerning the first question, the organizational literature portrays a conventionalist organization, reflected by the intensive use of the Kuhnian conceptualization. Besides the explicit references, the building blocks that assemble the Kuhnian argument are largely echoed in the literature. In contrast, the Popperian critical rationalism is sweepingly regarded inadequate for organizations. The arguments are the non-replicable environment (that prevents theorization) on the one hand and the obtrusiveness of the organization's observations on the other.

With respect to the second question, Popper and Kuhn present two dichotomous views about knowledge acquisition. Prime among the disagreements is the control over the process: Popper holds the scientist responsible for challenging his theory, whilst Kuhn portrays a passive, biased scientist who is captured in a paradigm; the paradigm shift is uncontrolled and occasional. The state of unawareness is integral to the Kuhnian fashion, as the consequence of: (1) the absence of inter-paradigm communication; (2) the closeness of the paradigm against conflicting cues, and (3) the inattention to problems recognition. Taken together, the scientist is hopelessly confined (prisoned, in Popper's words) within the prevailing paradigm.

As dominated by the Kuhnian viewpoint, the organizational unawareness seems to be a pathology. The Popperian thesis that conventionalism is a matter of decision that can be counteracted is regarded inadequate for the organizational circumstances. This leaves the unawareness problem unsolved ${ }^{19}$.

Our criticism targets both ideas. Indeed, the similarity of some Kuhnian aspects is tempting, but the distance between the "puzzle" and the managerial problem is unbridgeable. After all it is Kuhn himself who posts the puzzle criterion as a necessary condition and on that basis excludes the practice from his scope. On the other hand, the problem-solving similarity and the science-practice symmetry drive us to reconsider the inadequacy argument.

To sum, the research objectives are (in a means-ends order):

1. To explicate the Popperian face of organizations in order to posit a competing theory to the inadequacy argument.

2. To corroborate the competing theory and by that to supplant the inadequacy argument.

3. To counteract the unawareness problem.

The next chapter addresses the first objective.

19 Non-Popperian stances are not necessarily Kuhnian, but are not counterunawareness either. Further stances are reviewed and criticized in chapter 4. 


\section{The Popperian Core Problem of Managerial Theories: The Detachment of the Major Premise}

\section{Introduction}

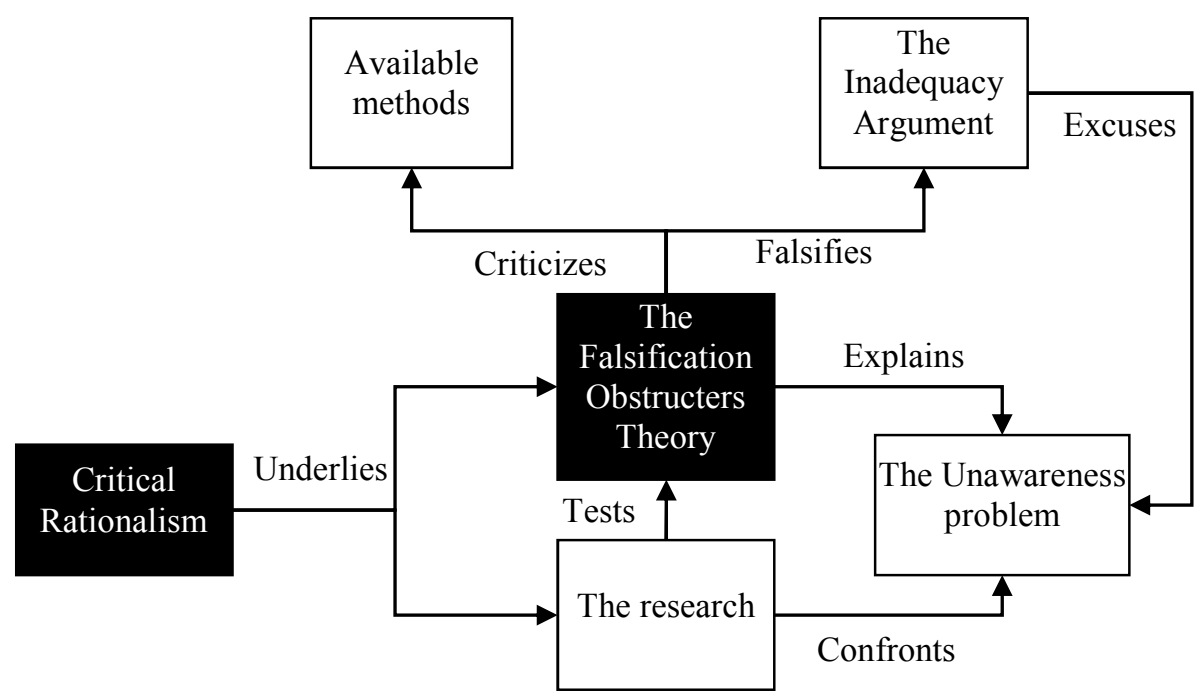

Figure 3.0. The focus of the chapter (blackened)

In this chapter we suggest a theory that competes against the inadequacy argument. We argue that critical rationalism is not inapplicable but obstructed, and specify the obstructers. Further, we assert that critical rationalism is actually applied in organizations, implicitly though, whenever the obstructers are ineffective.

We first provide a detailed review of Popper's method with the double purpose of (1) establishing the conceptual framework, and (2) posting a yardstick. Next we review several cornerstones of the management epistemology tradition, from a different angle each. We analogize the managerial control system to scientific justification, and present it in light of the management epistemology theories. Then we integrate the organizational theories and project them on the Popperian framework; the outcome is the competing theory we suggest. 


\section{Popper's Doctrine of Justification}

Popper (1961) sees his doctrine as a meta-theory: "the logic of scientific knowledge can therefore be described as a theory of theories" (p. 59). The theory rests upon ontology and epistemology; the former, namely the theory's ingredients, consists of a set of well-defined concepts; the latter constitutes the methodology of falsification. They are introduced below in that order.

\section{Ontology: the typology of statements}

Against the restricted definition of a statement advocated by Logical Positivism, Popper (1961) suggests an augmented typology along a scale of universality $^{20}$. He distinguishes between universal and singular statements, wherein a universal statement claims truth for the entire population to which it refers; it is "a hypothesis of the character of natural law" (p. 60), which means "of all points in space and time [...] it is true that..." (p. 63). In contrast, a singular statement claims truth for a specific portion of the population and/or under specific circumstances: "[it] applies to a specific event in question" (p. 60). An event in this sense is a general set of circumstances bounded by time and space, whereas an occurrence is individual, namely time-and-space specific; in other words, an event universalizes all the equivalent occurrences. It follows from the above that only an occurrence is observable and empirically testable, thus forms a basic statement: "a statement of a singular fact" (p. 43).

Popper (1961:60) provides the following example:

(1) Universal statement: "Whenever a thread is loaded with a weight exceeding that which characterizes the tensile strength of the thread, then it will break".

(2) $\quad \mathbf{1}^{\text {st }}$ Singular statements: "The weight characteristic for this thread is $1 \mathrm{lb"}$.

(3) $\quad 2^{\text {nd }}$ Singular statement (also basic statement or occurrence): "The weight put on the thread was $2 \mathrm{lb}$ ".

In this example lines (2) and (3) constitute initial conditions: an event that is applied upon a universal statement. The syllogistic structure explicates the deductive facet of the last singular statement, which is -

\footnotetext{
20 "My use of the concept of a strictly universal statement (or "all- statement") stands opposed to the view that every synthetic universal statement must in principle be translatable into a conjunction of a finite number of singular statements. Those who adhere to this view [the Logical Positivists] insist that what I call "strictly universal statements" can never be verified, and they therefore reject them, referring either to their criterion of meaning, which demands verifiability, or to some similar consideration" (Popper, 1961, p. 63).
} 
(4) Singular prediction: "This thread will break".

Popper (1961) further distinguishes between a strict universal statement, which is a "real" universal statement, i.e. "claims to be true for any place and any time" (p. 62); a numerical universal statement, namely a statement that "refers only to a finite class of specific elements within a finite individual (or particular) spatio-temporal region" (ibid), therefore replaceable by a finite set of singular statements (a strict universal statement is irreplaceable); and a strictly (purely) existential statement, which is a statement of the form "there is", meaning that there is at least one occurrence of the object in point. The distinction concerns the object to which the statement applies, where a strict statement refers to a universal concept (or name), i.e. a class; an instance within a class is an individual concept (or name). However, there is a hierarchy of classes so that a subclass can be at the same time individual for its parent class and universal for its child subclasses or instances.

\section{Theory's structure and the method of falsification}

A scientific theory, according to Popper (1961:59), is aimed at rationalizing, explaining and mastering the world. The aim of prediction is intentionally excluded since for Popper the prediction is not an end in itself but only a device for falsification ${ }^{21}$.

A genuine scientific theory expresses a natural law and constitutes both a synthetic $^{22}$ and a strict universal statement (e.g. $\mathrm{E}=\mathrm{MC}^{2}$ ). Popper emphasizes that a universal name is necessary but not sufficient in order to form a strict universal statement; a universal name can still represent a singular instance. Also, Popper (1961:66) contravenes universality that emerges upon generalization or abstraction. This is to say, a strict universal statement is qualitatively different from the sum of the singular statements it encompasses; any other distinction rests upon induction (and thus is problematic). Consider the following example:

${ }^{21}$ Popper (1961:60) comments that the prediction is actually a "retrodiction" (SIC), since it reflects the past. His stance is the antithesis of what he calls instrumentalism, which holds a theory as just an instrument for prediction.

${ }^{22}$ Popper (1961) adopts the Kantian definition where an analytic statement is tautological, one which "its antecedent entails its consequent" (p. 76, note 1); a statement that is true by definition (i.e. defines a class, for instance: "a bachelor is not married"). A synthetic statement is a statement that adds knowledge beyond a definition, e.g. an attribute; hence it is refutable (the analytic/synthetic distinction is not identical with the a priori/a posteriori distinction, although the connection exists: the former distinction is logical whilst the latter is epistemological [Baehr, 2006]). 
Compare, for example, the following two statements: (a) Of all harmonic oscillators it is true that their energy never falls below a certain amount; and (b) Of all human beings now living on the earth it is true that their height never exceeds a certain amount. [...] Statement (a) claims to be true for any place and any time. Statement (b) refers only to a finite class of specific elements within a finite individual (or particular) spatio-temporal region. Statements of this latter kind can, in principle, be replaced by a conjunction of singular statements; for given sufficient time, one can enumerate all the elements of the (finite) class concerned. This is why we speak in such cases of "numerical universality". By contrast, statement (a), about the oscillators, cannot be replaced by a conjunction of a finite number of singular statements about a definite spatio-temporal region. [...] It is clear that on any such view of natural laws which obliterates the distinction between singular and universal statements, the problem of induction would seem to be solved; for obviously, inferences from singular statements to merely numerically universal ones may be perfectly admissible. But it is equally clear that the methodological problem of induction is not affected by this solution (Popper, 1961, pp. 62-63; italics in origin).

Now, a strict universal statement is unverifiable, as verification - in the inductive sense - requires infinite observations. Based on the same logical thread, an existential statement is irrefutable (because infinite observations are required to negate it) but is easily verifiable on a single positive instance basis. Taken together, a natural law is actually prohibitive - it excludes a certain sort of existential statements; the law "all A's are B's" proscribes any of "there is an A that is not-B". This distinction allows the interplay which is the kernel of falsification:

In this formulation we see that natural laws might be compared to "proscriptions" or "prohibitions". They do not assert that something exists or is the case; they deny it. They insist on the non-existence of certain things or states of affairs, proscribing or prohibiting, as it were, these things or states of affairs: they rule them out. And it is precisely because they do this that they are falsifiable. If we accept as true one singular statement which, as it were, infringes the prohibition by asserting the existence of a thing (or the occurrence of an event) ruled out by the law, then the law is refuted [...] Strictly existential statements, by contrast, cannot be falsified. No singular statement (that is to say, no 


\begin{abstract}
"basic statement", no statement of an observed event) can contradict the existential statement, "There are white ravens". Only a universal statement could do this. On the basis of the criterion of demarcation here adopted I shall therefore have to treat strictly existential statements as nonempirical or "metaphysical" (Popper, 1961:69; italics in origin).
\end{abstract}

Hence falsification requires both kinds of statements, and the way it works is as follows: "whenever it is found that something exists here or there, a strictly existential statement may thereby be verified, or a universal one falsified" (Popper, 1961:70). Note that the falsifying statement can be produced by either assigning initial conditions or via prohibition.

These two kinds of statements are the building blocks of a theoretical system, a construct that exhibits two additional key concepts: levels and derivation. A theoretical system consists of a hierarchy of statements that are derived from one another in a diminishing universality. At the top there are the hypothesized axioms (the term does not imply mandatory truth, just that it allows all the lower statements to be logically deducible), and at the bottom - singular predictions (in the form of strict existential statement). Each level is falsifiable by the level underneath, which means that a singular statement can still be regarded a hypothesis (or an "axiom") for a subsystem as long as it stands a further derivation. The implication of a "successful" falsification in a low level is not necessarily decisive, as it may apply to just a part of the system. Figure 3.1 schematizes the idea.

Each system or subsystem, in order to be tested, has to be axiomatized. Axiomatization is reached upon satisfying all the four following requirements: (a) there are no contradictions within or between the axioms; (b) each axiom is independent, namely is not derived from another axiom; (c) the axioms are exhaustive, i.e. allow the derivation of the entire set of lower statements, and (d) they are mutually exclusive, which means that none of them is redundant. 


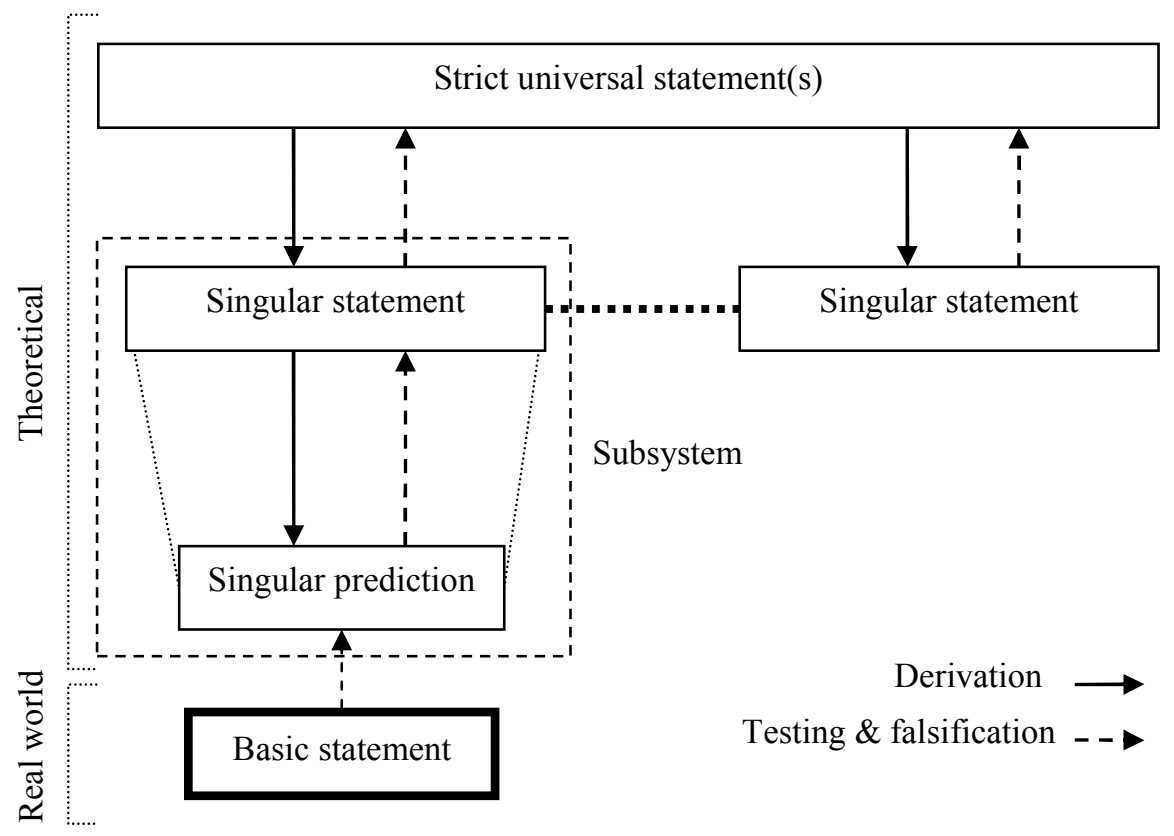

Figure 3.1. Schematization of Popper's "Theoretical System" concept

The substance of deduction materializes in one of the two strategies aforementioned: either initial conditions or prohibition. The former is manifested as every two sequential levels of statements form a syllogism in which the upper is the major premise, the lower is the minor premise, and the deduced inference is the singular prediction; the comparison of the prediction to the actual results constitutes the theory testing. In other words, the minor premise represents an event, or initial conditions, that cause the effect (Popper [1961:60] prefers not to use the cause-and-effect terms, because causality is a metaphysical principle; he mentions that in physics the term "cause" is replaced by action). The thread-and-tensile example brought above exhibits the idea; in Popper's words:

[...] On the one hand there is the hypothesis: "Whenever a thread is loaded with a weight exceeding that which characterizes the tensile strength of the thread, then it will break"; a statement which has the character of a universal law of nature. On the other hand we have singular statements (in this case two) which apply only to the specific event in question: "The weight characteristic for this thread is $1 \mathrm{lb}$. ", and "The weight put on this thread was $2 l b s^{\prime \prime}[\ldots]$ We have thus two different kinds of statement, both of which are necessary ingredients of a complete causal explanation. They are (1) universal statements, i.e. hypotheses of the 
character of natural laws, and (2) singular statements, which apply to the specific event in question and which I shall call "initial conditions". It is from universal statements in conjunction with initial conditions that we deduce the singular statement, "This thread will break". We call this statement a specific or singular prediction (Popper, 1961, p. 60 ; italics in origin).

The notion of prohibition is illustrated by Popper $(1961, \S 23)$ this way:

We can say of a theory, provided it is falsifiable, that it rules out, or prohibits, not merely one occurrence, but always at least one event. Thus the class of the prohibited basic statements, i.e. of the potential falsifiers of the theory, will always contain, if it is not empty, an unlimited number of basic statements; for a theory does not refer to individuals as such $[\ldots]$ Let us now imagine that the class of all possible basic statements is represented by a circular area. The area of the circle can be regarded as representing something like the totality of all possible worlds of experience, or of all possible empirical worlds. Let us imagine, further, that each event is represented by one of the radii (or more precisely, by a very narrow area - or a very narrow sector -along one of the radii) [...] Then we can illustrate the postulate of falsifiability by the requirement that for every empirical theory there must be at least one radius (or very narrow sector) in our diagram which the theory forbids (Popper, 1961, p. 90; italics in origin).

\section{Applicability for the social sciences}

Whilst his original interest concerned the natural sciences, Popper (1994) is eager to prove the applicability of his method for the social sciences. Yet the difference between the sciences requires some modifications, of which the most substantial is compensating for the lack of universal laws in social sciences.

Popper (1994) distinguishes in the natural sciences between two kinds of explanation or prediction problems: (1) a singular occurrence (e.g. "when will the next lunar eclipse occur?"), and (2) a typical event (e.g. "why do lunar eclipses occur?"). For solving the former, enough is to project certain initial conditions on universal laws (e.g. Newton's laws of motion); the latter, however, is much easier explained by constructing a model. The model may be "rough", or maintain a low fidelity, as long as it serves the purpose of explanation; it is sufficient as well to limit the model to those entities involved in the problem. 
What makes the model valid? Suppose, Popper (1994) suggests, that in order to address the second question ("why do lunar eclipses occur?") we construct a mechanical model of the sun, the earth and the moon that is propelled by a human hand. Accompanying the model is the question: what does propel the bodies in the real world? Or, How can we know that the modeled reality works without the hand? Here we reengage the universal law of motion. Popper concludes:

While explanations or predictions of the first kind - that is, explanations or predictions of singular events - operate with universal laws and initial conditions, explanations and predictions of the second kind - that is, those which explain and predict typical events - operate with models, which represent something like typical initial conditions. But the latter also need universal laws if we wish to make the model move, or work, or, as we may say, if we wish to 'animate' the model - that is, if we wish to represent the way in which the various elements of the model may act upon each other (Popper, 1994, p. 164; italics in origin).

The notion of animation is further clarified in the following:

Models represent typical initial conditions rather than universal laws. And they therefore need to be supplemented by "animating" universal laws of interaction - by theories which are not models in the sense here indicated (Popper, 1994, p. 165).

In other words, the model enters between the two syllogistic premises - neither a universal law like the major nor a specific condition like the minor. It simultaneously encapsulates the universal law and explains a typical event.

So far with the natural sciences; what about the social sciences? Here models are even more essential, since the social sciences lack universal laws in the first place:

They [social sciences] operate almost always by the method of constructing typical situations or conditions - that is, by the method of constructing models. (This is connected with the fact that in the social sciences there is [...] less "explanation in detail" and more "explanation in principle" than in the physical sciences.) But the role or function of models in the theoretical social sciences can perhaps be better understood if we look at them from another point of view. The fundamental problem of both the theoretical and the historical social sciences is to explain and understand events in 
terms of human actions and social situations. The key term here is "social situation". The description of a concrete historical social situation is what corresponds in the social sciences to a statement of initial conditions in the natural sciences. And the "models" of the theoretical social sciences are essentially descriptions or reconstructions of typical social situations. In my view, the idea of a social situation is the fundamental category of the methodology of the social sciences. I should even be inclined to say that almost every problem of explanation in the social sciences requires an analysis of a social situation (Popper, 1994, p. 166; italics in origin).

But the missing universal law deprives the major premise of the syllogism and thus is problematic, since a deduction based on a single premise is invalid; the stratagem that Popper employs is a fictive ("empty") universal law, which artificially provides the missing major premise. This law enables "animation", namely explains the interactive effects among the model's variables (Popper suggests the premise of rationality). Why is it fictive? Because the premise is not tested, or better say not testable; yet, if we compare two models that comply with the same law we can conclude which of them is more authentic, regardless the law's validity. To use a statistics analogy, the universal law functions as a dummy variable that is removed after the calculation. This strategy is called "the rationality principle" (Popper, 1994, p. 177).

Popper stresses that the model represents a social situation, and loyal to his non-psychologism credo (see chapter 2, p. 30) he insists on screening out any psychological elements from the model. In his words:

In fact, I propose to use the name "social institution" for all those things which set limits or create obstacles to our movements and actions almost as if they were physical bodies or obstacles. Social institutions are experienced by us as almost literally forming part of the furniture of our habitat. But if we wish to explain Richard's [the exemplifying character] movements, then we have to do more than locate the various physical and social obstacles in physical and social space. Indeed, in order that a thing may become an obstacle to Richard's movements, we must first attribute to Richard certain aims [...] Next, we must attribute to him certain elements of knowledge or information - that knowledge, for example, of social institutions [...] (Thus language is a social institution, and so are markets, prices, contracts, and courts of justice). Now some social scientists would say that we are operating with psychological as- 
sumptions when we attribute to Richard such things as this information or these aims. But I do not think that is so [...] However this may be, I propose to treat both Richard's aims and Richard's knowledge not as psychological facts, to be ascertained by psychological methods, but as elements of the objective social situation [...] Thus the situational analysis will comprise some physical things and some of their properties and states, some social institutions and some of their properties, some aims, and some elements of knowledge. Given this analysis of the social situation, we may be able to explain, or to predict, Richard's movements (Popper, 1994, pp. 167-168; italics in origin).

\section{Summary}

The Popperian doctrine is summarized in two principles that will substantiate the organizational adaptation:

- The hierarchical structure made of downward derivation and upward falsification. The derivation employs two alternative mechanisms: initial conditions or prohibition.

- The applicability of the Popperian methodology for the social sciences through the fictive substitution of the universal law. The elimination of psychologism applies despite the social substance.

\section{Management, Theories and Justification}

The organizational theories that are introduced below were selected based on three criteria: diversity, prominence and relevance. As for diversity, each emphasizes a different aspect; for prominence, they either announce or bolster various currents within the mainstream; and their relevance stems from the implied association (in our opinion) with critical rationalism, as the following integration demonstrates.

\section{The Means-Ends construct}

March \& Simon's (1958/1993) means-ends conceptualization stems from a vehement disagreement with the mechanistic-instrumental view of organizations. Their perspective is cognitive, underlain by the postulate of bounded rationality (in a nutshell: organizations and their environments are too complex to allow for complete informed and rational choice). In this context the means-ends construct explains how organizations interpret their environment, attain goals and solve problems. The problem-solving viewpoint and the problem's definition as an unmet expectation are a close resemblance of Popper's tradition. 
Organizations are goals-oriented systems, whether those goals are self-set or imposed. The goal reflects an aspiration level that can either challenge the status-quo (e.g. "to increase the market share") or preserve it (e.g. "to prevent shortages in supply"). The gap between the aspired and the current level constitutes the problem to be solved.

The end goal is attained by means. Due to the complexity of all the entities involved - organizations, environments, ends and means - the means are executed by various organizational functions, for which they constitute a subgoal. Thus we get a hierarchy of goals and subgoals, or a means-ends chain. The decomposition of goals into subgoals is defined as means-ends analysis, from which an action program emerges. Note the deductive pattern - subgoals are derived from goals.

The alignment of means to ends reflects the assumptions that (1) those means would yield the desired ends, and (2) that they are feasible; however, the rigor of the first assumption varies upon two distinctions. The first distinction concerns the extent of operationality: "when a means of testing actions is perceived to relate a particular goal or criterion with possible courses of action, the criterion will be called operational; otherwise the criterion will be called nonoperational" (March \& Simon, 1958/1993, p. 177; emphasis added). Elsewhere (Simon, 1945/1997) an equivalent distinction is made between ethical and factual decisions (non-operational and operational, respectively). Secondarily, March \& Simon (1958/1993) distinguish between ends that are operational ex-ante or ex-post: in the former case the effect has already been tested and verified; in the latter case the effect is still hypothesized (because it has never been experienced before), yet - since operational - is testable. The first process, characteristic of repetitive problems, is defined as problem solving; the last, typical of new problems, is defined learning, and is embodied in Milliken's (1987) "response uncertainty" (chapter 1, p. 16).

The nonoperational criteria plague the top of that hierarchy, where the sequence of deductive derivation is fractured:

The goals at the higher levels of this hierarchy are not, however, operational; i.e., there do not exist agreed-upon criteria for determining the extent to which particular activities or programs of activity contribute to these goals (March \& Simon, 1958/1993, p. 216).

The problems addressed by those high-level, strategic goals are known as "wicked problems"; the traits that make them nonoperational are augmented by Rittel \& Webber (1973):

- The problem is open-ended, without a natural frame; further, the frame is determined by the solution one opts to employ. Symptoms 
and root problems are undistinguishable, so that any solution may evoke additional problems. Therefore methods of linear programming (like the aforementioned means-ends analysis) are inappropriate. One can never know the final effect of an implemented solution, nor be sure that all the alternatives have been considered.

- Solutions or remedies for the problem can be judged only by values (hence "ethical decisions"); there is no "correct" answer.

Taken together, the consequence is that "in dealing with wicked problems there are several more ways of refuting a hypothesis than there are permissible in the sciences. [...] That is to say, the choice of explanation is arbitrary in the logical sense" (Rittel \& Webber, 1973, p. 166). In other words, the Theory that underlies the action is not refutable - consistent with the conventionalist pathology that Popper (1961) precludes.

Hence the logical sequence is interrupted, all the more so toward the toplevel goals; this syndrome is named elsewhere "[intrafirm] causal ambiguity" (King, 2007), which Lippman \& Rumelt (1982) define as "the ambiguity surrounding the linkage between action and performance" (p. 421). The discrepancy is exacerbated as it falls between the cracks; if one expects that such ambiguous means-ends relations will encourage a careful follow-up, March \& Simon (1958/1993) observe the opposite.

We appeal again to the principle of bounded rationality - to the limits of human cognitive powers - to assert that in the discovery and elaboration of new programs, the decisionmaking process will proceed in stages, and at no time it will be concerned with the "whole" problem in all its complexity, but always with parts of the problem (March \& Simon, 1958/1993, p. 211).

It may seem that the rigid, top-down and unidirectional process presented here is what prevents a holistic view; but the same image of scattered and partial decisions repeats in accounts that depict a looser structure as well (e.g. Langley et al, 1995; Mintzberg, Raisinghani \& Theoret, 1976; Mintzberg \& Waters, 1990).

To conclude: the means-ends construct is a process of deductive derivation, where the hypothesized appropriateness of the means for the ends is tested upon action. Two deficiencies are manifested in the process: first, the consequence of deductive derivation is fragmented at the top level; second, the emanating ambiguity is not checked systematically.

The means-ends construct implies three Popperian elements (especially in the learning mode): the identification of cause with action, the idea of testing, and the process of sequential deductive derivation (through the vehicle of prohibition). 


\section{The Theory-of-Action}

The theory-of-action (Argyris, 1976/a, 1976/b) drives and rationalizes the human behavior; of the alternative types of theories it is a theory of control - equivalent to Popper's (1961) purpose of mastering the world. Whilst Argyris originally concerns the individual level, Weick (1995/b) counts the theory-of-action among the vehicles that prompt sense-making in organizations; and as we have seen earlier, Hedberg (1981) ascribes it to the organizational level as well: "...organizations form theories of action with questionable validity" (p. 11).

The theory consists of three constructs: if-then statements, assumptions, and values (Argyris, 1976/a). They maintain:

- If-then statements: the basic form of a theory reads "in situation $\mathrm{S}$, if you want to achieve consequence C, do A" (Argyris, 1976/a, p. $5)$.

- Assumptions: a fuller schema of a theory-of-action is "in situation $\mathrm{S}$, if you want to achieve consequence $\mathrm{C}$, under assumptions $\mathrm{a}_{1} \ldots \mathrm{a}_{\mathrm{n}}$, do A" (ibid). Assumptions are the circumstances (or the initial conditions) under which the theory applies.

- Values: norms or ultimate goals that govern the individual's behavior and from which the desired achievements are derived.

Hereinafter we elaborate on three aspects of the theory-of-action: the state of unawareness, the hierarchical structure and the extent of testability.

The state of unawareness: Argyris (1976/a) divides the theory-of-action into theory-in-use and espoused theory; the former governs the actual behavior, is visible for any outside observer, but is not necessarily overt for the actor. The latter is explicit for the holder, whom it serves in rationalizing his or her actions. A gap between the two indicates that part of the theory-in-use is tacit, namely reflects unawareness; this part, which its proportion varies, hinders the theory's testability. A striking example of that unawareness is the following explanation of an experiment in which the subjects failed to revise their theory:

...they were unaware that they could not do so; every bit of their behavior helped to reinforce their unawareness - they became unaware that they were unaware (Argyris, 1976/a, p. 25).

The hierarchical structure: Argyris (1976/a) notes that "as with any complex body of knowledge, a person's theory-in-use may be organized in a variety of ways. Some theories-in-use have a hierarchical structure..." (p. 7). The hierarchy refers to either the if-then statements or the assumptions. Regarding the first, the hierarchy reflects Popper's notion of event: an up- 
scaling generalization of occurrences to which the theory applies. Concerning assumptions, the stratification spans over two dimensions - depth and width. The depth indicates the universality of an assumption that stipulates the theory, up to what Popper calls "universal statement". The width suggests that a particular assumption is shared across several theories and sustains their respective actions.

The extent of testability: allegedly a theory-of-action may be confirmed like any other applied theory - based on the specification of the situation, the action and the expected result. Yet, beyond the immediate obstacle of tacitness (see above), the testing of a theory-of-action faces two unique difficulties (Argyris, 1976/a). Both are the consequence of the normativeness embedded in the theory:

1. Whilst it is quite easy to test if-then statements via deductive logic, the governing values (e.g. "stay healthy" - p. 16) do not maintain this quality; they are taken for granted. The only check they allow is of inter-consistency (and by that they resemble the axioms as defined by Popper). We name this effect logical irrefutability.

2. The theory becomes a self-fulfilling prophecy; since the actor is not a distant observer but actively applies the theory for the sake of control, he or she drives the theory to be true: "The so-called testing brings the behavioral world more nearly into line with the theory. [...] We call such a theory self-sealing" (Argyris, 1976/a, p. 16; italics in origin). We name this effect mental irrefutability.

The second point reflects the "organizational pillar" of the inadequacy argument, and is expanded by additional theories that shed light on associated aspects:

- Schon (1983) describes the behavior behind the self-sealing tendency. The actor does test his hypotheses (even if not consciously), but his prime interest is not in understanding the reality but in shaping it. Being results oriented, he ceases the testing once the result satisfies; whatever made it so does not matter anymore. Further, of the three involved variables (external situation, action and result), the manipulation is paradoxically acted on the first: the actor adjusts the situation to make it compatible with his repertoire of actions (and not vice versa, as might be expected). In other words, the problem succeeds the hypotheses - and in a flexible manner; the more complex is the situation (the more "wicked" the problem), the more open-ended is the problem definition. We will refer later to this syndrome as the "flexible environment".

One way to avoid the theory-situation tension is to ignore contradicting data (the materialization of Conscious ignorance): "Many practitioners have adopted this response to the dilemma of rigor or relevance, cutting the practice situation to fit professional 
knowledge. [...] They may become selectively inattentive to data that fall outside their categories. [...] They may use 'junk categories $^{123}$ to explain away discrepant data" (Schon, 1983, p. 44).

- Weick's (1969) "enactment" concept represents the self-fulfilling prophecy, where the preconception an organization has about the environment determines the environment's reaction to the organization: "...the human creates the environment to which the system then adapts. The human actor does not react to an environment, he enacts it" (Weick, 1969, p. 64; italics in origin). The self-fulfilling implication of enactment is explicit:

Perceptual activity seems to move in the direction of self-fulfilling rather than self-defeating prophecies, and it is this bias that is behind much of our feeling that enacted environments are commonplace rather than rare. [...] A standard operating procedure is a frame of reference that constrains exploration and often unfolds like a self-fulfilling prophecy (Weick, 1979, p. 156).

- Once the goals and the actions are determined, the organization is susceptible to the availability bias: the disproportional weight ascribed to available data, regardless its proportion in the real world (Nisbett \& Ross, 1980). The data availability is affected by the organizational structure, the departmentalization, that obviously reflects the means-ends structure (March \& Simon, 1958/1993), and by the over-attention paid to current customers (Christensen, 1997/b).

- $\quad$ Dutton \& Duncan (1987) add the "responsibility effect" - the impact of the perceived responsibility on biased justification: "A strategic issue may also be judged in terms of how responsible management believes it is for the issue's occurrence. [...] attributions of internal responsibility for an issue - particularly if it involves a problem - enhance pressures to justify the appropriateness of past decisions" (p. 284; emphasis added). Staw (1981) reaches the same conclusion and adds that this bias enhances the problem of mindlessness ("locked in to a course of action" - p. 578).

To conclude, the theory-of-action maintains two principles: for one, it is first and foremost a theory, and as such should be tested (and indeed it is);

${ }^{23}$ Recall Kuhn (chapter 2, p. 27): bizarre problems - those that the paradigm fails to contain - are discarded and tagged as distraction or exception. 
for two, the testing is restricted towards its apex by both the higher values' axiomatic nature and the bias associated with the normativeness.

\section{Issue diagnosis and scenarios}

Dutton, Fahey \& Narayanan (1983) analyze the process of strategic issue diagnosis (SID). Among other factors they refer to what they call Retroductivity:

The process [of issue comprehension] is characterized by both deductive and inductive modes of thinking. [...] A deductive mode of thinking begins with a set of explicit assumptions from which conclusions flow as logical extensions. For example, if one assumes that competitors are committed to continuance of their current strategies and that other environmental changes are unlikely, a logical deduction may be that the firm's current performance may be maintained by a continuation of its strategy. What frequently goes unnoticed is that the choice of assumptions in deduction is always to some extent arbitrary and that [...] individuals rarely know for certain that their assumptions accord with reality and this relationship cannot be tested within a deductive frame of thinking alone (Dutton et al, 1983, pp. 312-313; italic added).

The deduction process employs the initial conditions course: "the deductive element in SID translates an individuals' initial assumptions into specific judgements or predictions about an issue" (Dutton et al, 1983, p. 313; italics added). Alas, the initial conditions are assigned to an incomplete Theory: "The conflicting, ambiguous and incomplete nature of a strategic issue forces individuals to draw conclusions and inferences from disparate and diffuse data. Furthermore, the assumptions which individuals rely upon are themselves built inductively through past experience and learning [...] deriving cause-effect relationships [Theory] from conceptual categories is rarely, if ever, completely justified by the available evidence" (ibid).

Why is the Theory incomplete, and why is the data ambiguous? March, Sproull \& Tamuz (1996) elaborate on the process in which organizations learn "from samples of one or fewer". This is done through what the authors call hypothetical histories:

Organizations use small samples of specific historical events to construct theories about events, and then simulate hypothetical histories that can be treated as having interpretive significance comparable to, or even greater than, the history actually experienced. In this process, the analysis of unique historical outcomes emphasizes identifying the un- 
derlying distribution from which that realization was drawn rather than explaining the particular draw [...] A pervasive contemporary version of hypothetical histories is found in the use of spread sheets to explore the implications of alternative assumptions or shifts in variables in a system of equations that portrays organizational relations. More generally, many modern techniques of planning in organizations involve the simulation of hypothetical future scenarios, which in the present terms are indistinguishable from hypothetical histories... The logic is simple: small pieces of experience are used to construct a theory of history from which a variety of unrealized, but possible, additional scenarios are generated. In this way, ideas about historical processes drawn from detailed case studies are used to develop distributions of possible futures (March et al, 1996, p. 7).

In short, the above learning process consists of three steps:

1. Generalizing a Theory from a limited set or a single occurrence by abstracting the variable from the specific value; this step presents an inductive mode of inferring.

2. Substitute various values (i.e. initial conditions) for each variable.

3. Deducing scenarios from each different set of values.

The process described above is of deductive derivation that follows the track of Theory-initial conditions-predictions (scenarios). Two points are noteworthy: first, as Dutton et al emphasize, there is unawareness of the hypothetical basis of the Theory. Second, the predictions are not for the sake of testing but for predicting per se (what Popper calls instrumentalism).

Besides initial conditions, the strategy of prohibition is implied by Schoemaker (1995), who warns: "do the scenarios combine outcomes of uncertainties that indeed go together? As noted above, full employment and zero inflation do not go together, so eliminate that possible pairing or scenario" (p. 29).

\section{Organizational learning}

Hedberg (1981) portrays two modes of organizational learning: one occurs when the learning cycle is complete, the other when it is not. A "learning cycle" is a continuous feedback loop between the environment (the stimulus) and the organization (that responds by action) through which the organization constructs its Theory-of-action (see above). The complete cycle is an endless phase of discovery during which the organization absorbs signals from the changing environment and instantly adjusts its Theory; hence the Theory is allegedly correct at any time. 
However, this is an unachieved ideal; Hedberg dubs the Theory-of-action a "myth" to indicate its "low or no validity to the concerned organization. [...] Myths are created on spotty evidences" (p. 11). Hence the incomplete cycle is much more realistic and frequent, due to the inevitable impediments that characterize organizational learning: role-restricted vision, politics, ambiguous stimuli from the environment and cognitive biases.

Therefore, more often than not, the myth is false; but the falsification is forced upon the organization rather than exercised voluntarily. Here emerges a pattern of quasi-justification in which the strategy tests the Theory:

A ruling myth is a theory that generates strategies and actions. Strategies are hypotheses, and actions test these hypotheses, verifying or falsifying the theory (Hedberg, 1981, p. 12).

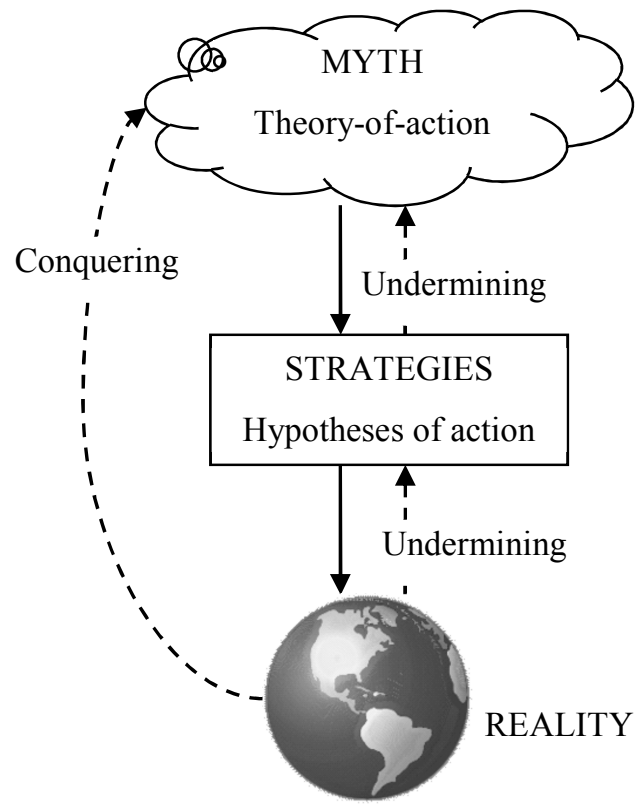

Figure 3.2. The interplay between myth, strategies and reality (source: Hedberg, 1981, p. 12)

In other words, the strategy is substituted for the prediction. However, the unintended and uncontrolled justification is invalid, since "direct empirical falsification does not work when learning cycles are incomplete" (Hedberg, 1981, p. 12). The argument is that, unlike in science, the organizational environment is in constant flux; therefore organizational "experiments" are not 
replicable. This explanation echoes the "environment pillar" of the inadequacy argument as well as the causal ambiguity.

To conclude: this explanation pictures the quasi-falsification as the almostexclusive source of justification (unless the learning is complete). Alas, the process is immanently inefficient.

\section{Consequences}

Many Popperian themes appear across the theories: hierarchical structure, derivation, prediction, testing, falsification, initial conditions and prohibition; but rather than a coherent system they form two disconnected fragments:

- The testing system, including the means-ends construct, the theoryof-action (save the values) and the incomplete learning, is associated with hierarchical structure, derivation, testing, falsification and prohibition; alas, the falsification is disabled by either the environment or the organization - the two pillars of the inadequacy argument.

- $\quad$ The predicting system derives predictions (scenarios) upon initial conditions, but is not associated with testing or falsification.

\section{The Control System as the Justification Mechanism}

Control to planning in organizations is like justification to discovery in science: "After strategies are set and plans are made, management's primary task is to take steps to ensure that these plans are carried out, or, if conditions warrant, that the plans are modified. This is the critical control function of management" (Merchant, 1982, p. 43). As the justification mechanism the control system is indicative of the organization's epistemology.

The classic form of control is known as feedback (aka results or diagnostic). Simons (1995) introduces the concept as follows:

These feedback systems, which are the backbone of traditional management control, are designed to ensure predictable goal achievement. [...] Diagnostic control systems are the formal information systems that managers use to monitor organizational outcomes and correct deviations from preset standards of performance. Three features distinguish diagnostic control systems: (1) the ability to measure the outputs of a process, (2) the existence of predetermined standards against which actual results can be compared, and (3) the ability to correct deviations from standards (Simons, 1995, p. 59). 
Using the means-ends conceptualization, this control is over the ends, or goals. Ultimate ends, rather than measured directly, can be indicated by the results of subgoals:

Diagnostic control systems attempt to measure output variables that represent important performance dimensions of a given strategy. [...] critical performance variables are those factors that must be achieved or implemented successfully for the intended strategy of the business to succeed. One way to uncover these variables is to imagine that a strategy failed and then ask what factors would be identified as causes for this failure (Simons, 1995, p. 63; italics added).

These quotations and the relating figure (3.3) portray a hierarchical structure of goals and subgoals, derived downwards and validated upwards.

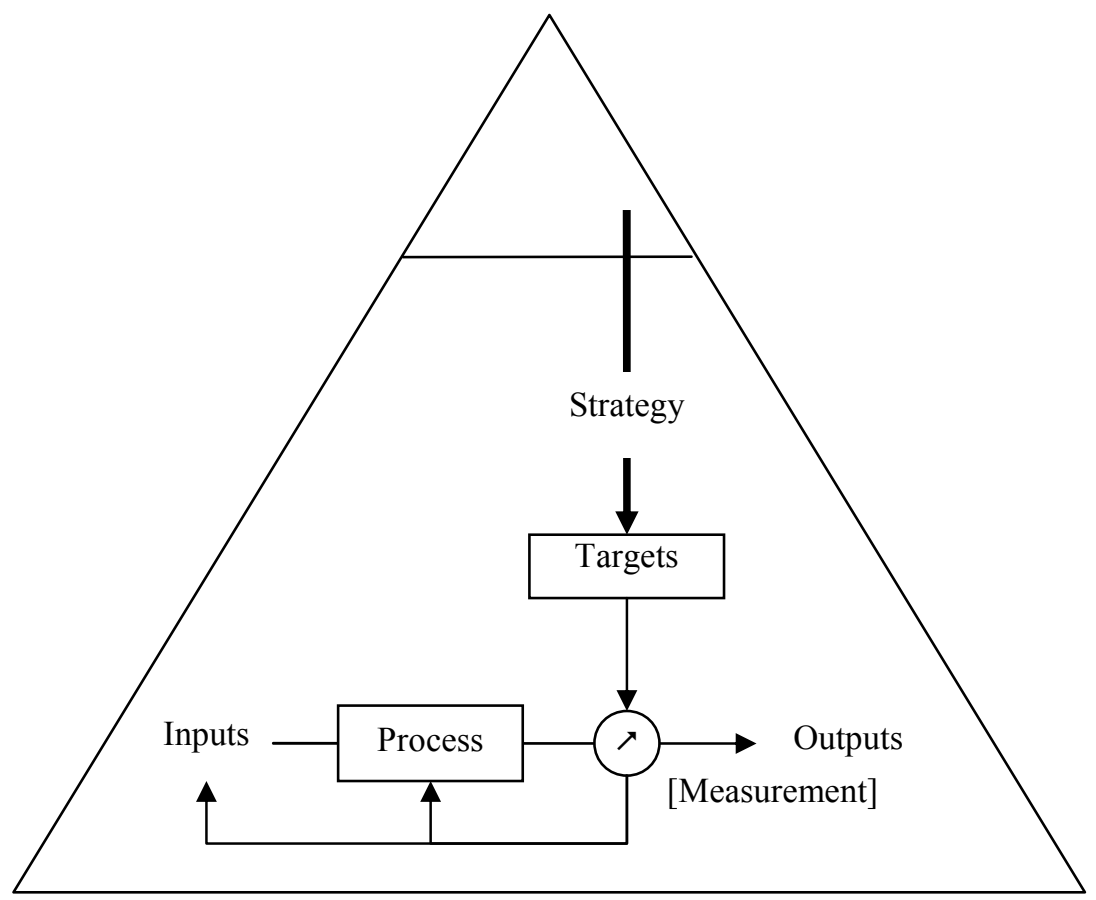

Figure 3.3. Feedback control system (source: Simons, 1995, p. 63). The connecting arrows signify the transformation process; the small circled arrow signifies the act of measurement. 
A special emphasis is put on the unequivocalness and the objectivity of the expected results, both enabled by the careful derivation throughout the hierarchy:

For control over results, the most serious constraint is the ability to measure the desired results effectively. [...] Ideally, measurements should: (1) assess the correct performance areas - the ones for which results are truly desired;

(2) be precise - not determined by only crude estimations;

(3) be timely and (4) be objective - not subject to manipulation (Merchant, 1982, p. 46; italics in origin).

Whilst good enough for the operational level, the results control is strategically insufficient since the strategy depends on factors beyond the organization's means. Those exogenous factors do not meet the above criteria and thus cause the "causal ambiguity"; the strategic level requires a different method.

Durden (2001) reviews and integrates three strategic control methods ${ }^{24}$. The resulting framework is two-tiered as well, below or above the operationality line, respectively. These are the layers (figure 3.4):

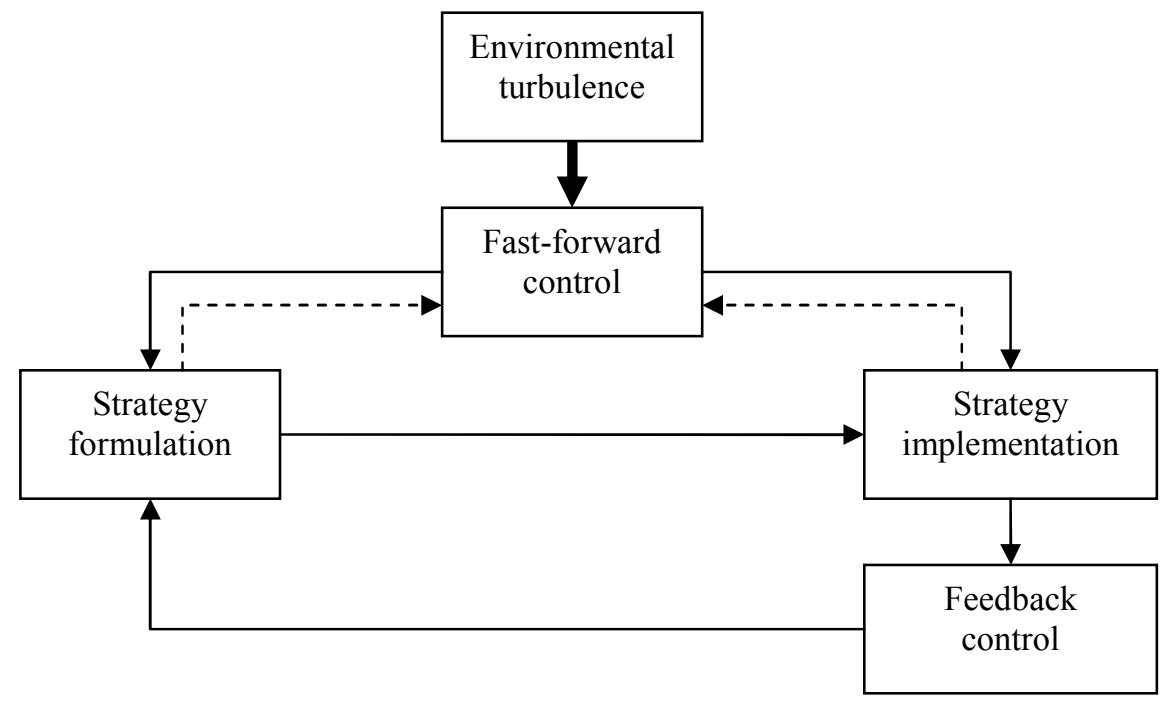

Figure 3.4. Strategic control framework (source: Durden, 2001, p. 15). The solid arrows designate the information flow, whilst the dashed arrows signify direction biases

${ }^{24}$ The methods are: Ittner \& Larcker, 1997; Schreyogg \& Steinmann, 1987; Simons, 1995. 
- Feedback (or results) control is directed inward and "is focused on control issues relating to the implementation and accomplishment of established strategies" (p. 14; italics in origin). In other words, it corresponds with the incomplete learning (or more generally with the testing system, whilst the predicting system is encapsulated in the "strategy formulation").

The feedback control has two limitations: first, beyond the operationality line "interpretation of the feedback control information is likely to be difficult or even meaningless" (Durden, 2001, p. 16). Second, the results may be realized too late. Therefore the next control is needed.

- Fast-forward (or feed-forward) control is directed outward and is expected to sense earlier. It is focused on "events that may threaten the continuing viability of established strategies" (ibid; italics in origin), because "organisations increasingly operate in environments that are rapidly changing and capricious and which are likely to necessitate a greater focus on the appropriateness of strategic direction and goals" (p. 15). Stated differently, this control contends for complete learning.

This sort of control is also known as "environmental scanning", which Choo (1999) defines "the acquisition and use of information about events, trends and relationships in an organization's external environment, the knowledge of which would assist management in planning the organization's future course of action. [...] Environmental scanning casts an even wider net and analyzes information about every sector of the external environment that can help management to plan for the organization's future. Scanning covers not only competitors, suppliers and customers, but also includes technology, economic conditions, political and regulatory environment, and social and demographic trends" (p. 21).

The feedback control is circular, same as Popper's scientific process (figure 2.1, p. 31), and this represents the notion of falsification. The fast-forward control is linear, with the "environment" as the origin but not a destination. This is the allegedly-redundant falsification element in the complete learning mode.

The dashed arrows signal that the strategy biases the fast-forward control (e.g. through the "flexible environment"). Rather than a weakness it is desired: Durden (2001) condemns the objectivity of the results control as a source of problems, and Goold \& Quinn (1990) advocate even a greater reliance on subjective judgment instead of results control.

In sum, the control system demonstrates another fragmentation: the subsystems are disintegrated. Besides, the system exhibits a paradox: the 
"complete" learning compensates for the incomplete mode, rather than vice versa.

\section{Discussion}

There are three types of theory: descriptive, normative and design. The descriptive theory explains "why it is", the normative theory claims in favor of "how it should be", and the design theory bridges the gap by answering "how to attain the desired (normative) goal" (Walls, Widmeyer \& El Sawy, 1992, p. 41; also Gregor, 2006). By these definitions, the myth, the meansends construct and the theory-of-action (save the values) are design theories; the values are the normative theory; and the implicit theory from which the scenarios are derived is descriptive. According to the theory-of-action, the normative part subordinates the design theory.

Both descriptive and design theories are causal. This understanding stands on Aristotle, who (in Physics II 3) divided causality into four types: material, formal, efficient and final. The efficient cause stands for description: "the primary source of the change or rest" and the final cause for design: "the end, that for the sake of which a thing is done" (Falcon, 2008). Schon (1983) holds both theories as epistemologically equal and falsifiable.

Popper's doctrine is equally applicable for descriptive and design theories (which he terms "technological form"). Popper regards the design theory as the mirror image of the descriptive theory: "The negative formulation of empirical laws is described as their technological form" (Faludi, 1983, p. 273). Popper's vocabulary resembles the means-ends concept:

...every natural law can be expressed by asserting that such and such a thing cannot happen; [...] This way of formulating natural laws is one which makes their technological significance obvious and it may therefore be called the "technological form" of a natural law. [Concerning social interventions] ...we see at once that it may well be expressed by sentences of the form: "You cannot achieve such and such results", or perhaps, "You cannot achieve such and such ends without such and such concomitant effects" (Popper, 1961/a, p. 61).

Especially when Popper concerns the testing procedure of a theory, the equivalence between the descriptive and the design theories is conspicuous:

The purpose of this last kind of test is to find out how far the new consequences of the theory $[\ldots]$ stand up to the demands of practice, whether raised by purely scientific 
experiments, or by practical technological applications (Popper, 1961, p. 33;).

However, Popper's doctrine is not applicable for normative theories. As Argyris (1976/a) notes, a normative theory respects deductive logic only within its boundaries; that is, the values should be consistent with one another. But the normative theory is not falsifiable by derivatives. The Popperian exclusion is understandable, since normative theories are foreign to the natural sciences (imagine how weird it could be if a physicist suggested changing the light speed...). For that reason Popper (1994) is so anxious to eradicate any normativeness from the social situation model as a testing precondition: "I propose to treat both Richard's aims and Richard's knowledge not as psychological facts, to be ascertained by psychological methods, but as elements of the objective social situation" (p. 167; italics in origin).

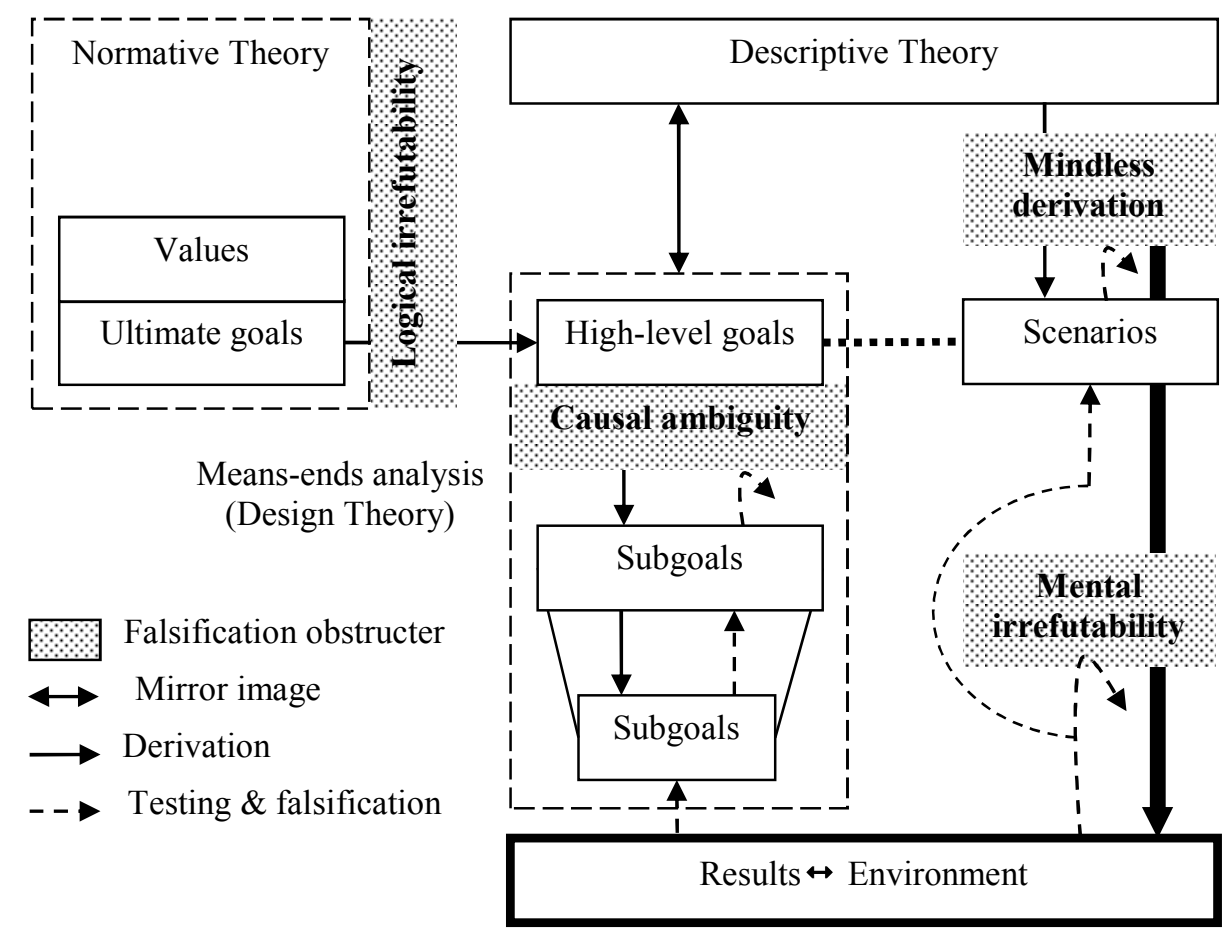

Figure 3.5. The organization's "Theoretical System"

In organizations, all the three kinds of theory exist: there is a descriptive Theory, represented by the source for scenarios derivation; there is a design Theory, represented by the myth, the means-ends construct and the theoryof-action (save the values); and there is a normative Theory within the theo- 
ry-of-action. All the three constitute the organization's theoretical system (figure 3.5), an adaptation of the Popperian origin (the equivalent concepts from figure 3.1 are mentioned in parentheses).

We describe the system from top to bottom (derivation) and next from the bottom up (falsification). On the upper-hand side there are the two governing Theories: normative and descriptive. The normative Theory (left) contains values and ultimate goals, according to the theory-of-action. The ultimate goals drive the high-level goals.

At the same level there is the descriptive Theory (consisting of numerical universal statements), with which two subsystems are associated. On the right-hand side, via syllogistic derivation, the assignment of initial conditions to the Theory results with scenarios (singular predictions). To the left, the design Theory mirrors (implicitly) the descriptive Theory, by prohibition. The design Theory constitutes the means-ends analysis, in which the high-level goals are the means aimed at attaining the ultimate goals and so on downward (singular statements). The dotted line between the scenarios and the design Theory signifies that from the repertoire of means, a certain set is selected to accord with the actual scenario.

At the bottom, the results and the environment (basic statements, the "real world") are interwoven, to signify the blurred border that the enactment renders.

Now the falsification: ideally, there would have been two routes of falsification: from the results to the mirrored design/descriptive Theory (hereinafter: left) and from the environment, through the scenarios, to the descriptive Theory (right). By definition, no route returns to the normative Theory because of the logical irrefutability. However, the ideal is hampered by further Falsification obstructer.

The left route is obstructed by the causal ambiguity, which splits the design Theory at the operationality line. The right route is obstructed twice. The mental irrefutability affects this part of the environment that is subject to enactment (whilst the farther environment bypasses the obstructer). The rationale for placing this obstructer on the right route is the "flexible environment" (unlike the "hard data" that the results control provides).

Higher on this route, the mindless derivation under which the scenarios were deduced is now operating in the reverse direction: it conceals the Theory from which the route originated.

The accumulated result is that both potential routes of falsification are obstructed; sooner or later they hit a ceiling and draw back. Borrowing Popper's syllogistic articulation, we define the core problem as the detachment of the major premise: because of the mindless derivation or the causal ambiguity, the upward falsification falls into a "black hole"; elsewhere Popper (1961/a:124) establishes his criticism against the "poverty of historicism" on 
this very detachment: that the historical trend (the "initial condition") is accounted without a universal law as a reference. Johnson-Laird (1983) specifies the problem in a cognitive manner: although human beings normally think through syllogisms, they are often unaware of that and especially of the major premise. "The ability to reason [...] lies at the heart of human mentality. [...] Typically, it proceeds from several premises to a single conclusion, though sometimes it may be an immediate step from a single premise to a conclusion. [...] in the case of some practical inferences the premises may consist of a perceived or imagined state of affairs" (pp. 23-24).

\section{Conclusions}

The purpose of this chapter was to hypothesize a theory that, if corroborated, falsifies the inadequacy argument. The alleged inadequacy stands on two pillars: the environment and the organization; the competing theory (hereinafter: the falsification obstructers theory) addresses both:

- Environment: the inadequacy argument holds that each strategic situation is singular, whilst the Popperian method is capable of falsifying universal theories. Our counter argument is twofold: for one, the Popperian doctrine can do even without universal laws (recall the social modeling). For two, the organization's theoretical system maintains distinct Popperian structure that, theoretically (and subject to test), should have fitted falsification unless been obstructed.

- Organization: the inadequacy argument focuses on the left route, where the organization is indeed an obtrusive observer; the theories we count on support the argument. Our counter theory hypothesizes that the right route is not sensitive to this contamination, and its ineffectiveness is curable once the obstructers are cleared.

Before we test our theory we would like to gain lessons from previous efforts in the same direction. In the next chapter we evaluate methods aimed at the Theory's justification in light of the falsification obstructers theory. 


\section{A Critical Review of Methods for Managerial Theory Justification}

\section{Introduction}

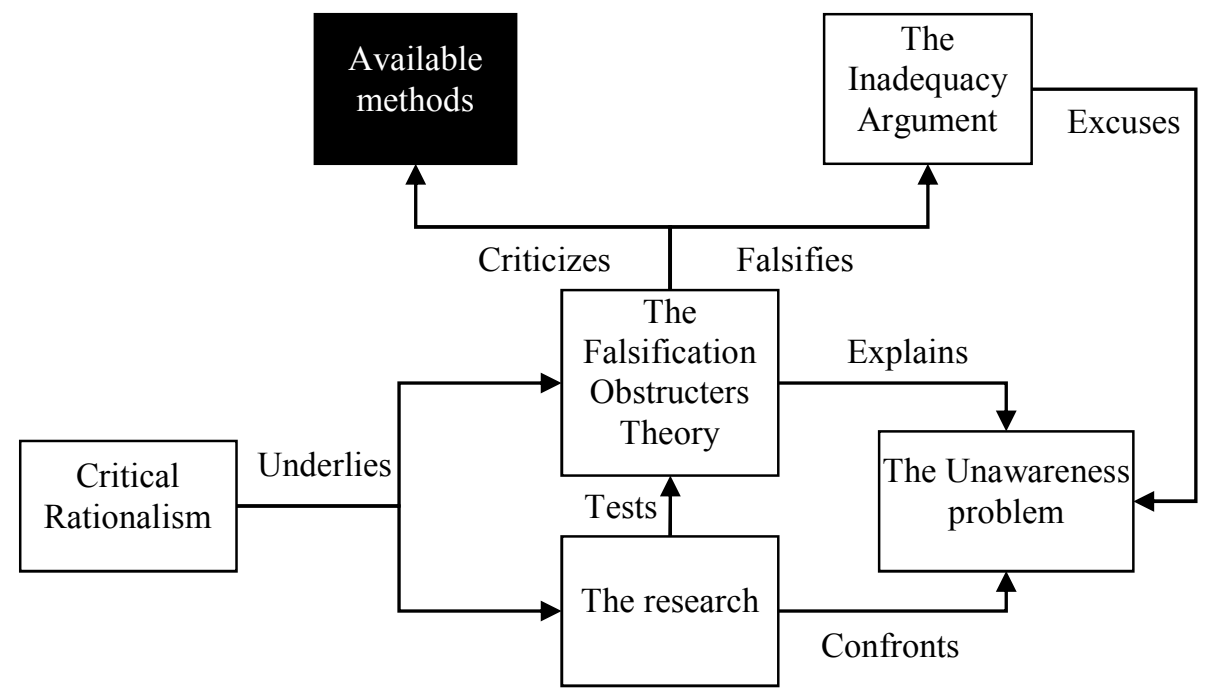

Figure 4.0. The focus of the chapter (blackened)

The purpose of this chapter is to exploit the accumulated experience in the field. The havoc caused by false Theories has been paid significant attention in the management literature, followed by intensive efforts aimed at providing remedies. The chapter reviews and criticizes selected methods that target the Theory's justification in organizations, preferably Poppercompatible. Once the falsification obstructers were specified they provide the benchmark for evaluation.

The evaluation was conducted in three steps:

1. Screening out methods that do not deal with justification (but with discovery or ideation).

2. Preliminary evaluation of alleged justification methods against Popperian criteria and according selection.

3. Thorough evaluation of the selected methods in light of the falsification obstructers.

The chapter is structured respectively: we begin with the preliminary evaluation (step 2) of the methods that passed the justification threshold but 
failed upon the Popperian criteria, then proceed with the thorough examination of the remaining.

\section{Preliminary evaluation of alleged justification methods}

Table 2.1 (p. 36) lists the key qualities of Popper's tradition which we use as criteria for the sake of evaluation. However, not all the qualities make a distinction at this stage: as managerial methods all exhibit the merits of design, activeness and applicability; following step 1, all deal with justification. Hence we maintain three criteria against which we evaluate the remaining methods (table 4.1); that is, the methods have to stand the following criteria:

Table 4.1. Criteria for justification methods' evaluation.

\begin{tabular}{lll}
\hline No. & Criterion & \multicolumn{1}{c}{ Description } \\
\hline 1. & Reasoning & $\begin{array}{l}\text { The methods have to employ deductive logic aimed } \\
\text { at falsification, and to be insensitive to psychologism. }\end{array}$ \\
2. & $\begin{array}{l}\text { Stimulus for } \\
\text { action }\end{array}$ & $\begin{array}{l}\text { The methods should specify certain conditions upon } \\
\text { which unequivocal and recognizable problems that } \\
\text { indicate falsification can materialize. }\end{array}$ \\
3. & Unawareness & $\begin{array}{l}\text { The methods should be insensitive to the existing } \\
\text { awareness; just to the opposite, they have to address } \\
\text { the zone of unawareness. }\end{array}$ \\
\hline
\end{tabular}

In order to refrain from repetition we review three seminal methods that represent distinct streams of justification; each of the three has inspired several variations to which the root evaluation applies. The evaluation is presented in three subsections: brief description, justification instruments and unmet criteria.

\section{Dialectic methods}

According to Starbuck \& Milliken (1988) managers may hold contradicting theories simultaneously and by that obtain competing explanations; the dialectic notion takes advantage of this situation toward the validation of the firm's basic assumption (Theory). The dialectic tradition thrived during the 1980 's and was nurtured by students of C. West Churchman, who promoted methods like the devil advocate, dialectic inquiry or SAST ("strategic assumptions and testing"). The rationale was to improve existing theories through synthesis, the aim was verification, and the main critical vehicle was confrontation among competing theories (Cosier, 1981). The purpose of testing, explicit in these methods, is executed through dialectic debates 
among competing views that yield a co-accepted synthesis (e.g. Mason \& Mitroff, 1979).

Justification instruments: the legitimacy awarded to the plurality of Theories; the deliberate attempt to challenge the Theories in order to synthesize the best.

Unmet criteria: the validation process is argumentative; the method ideologically adheres with the positivist "principle of verifiability" (p. 28), as manifested by a prominent advocate: "falsification can never be more certain than confirmation ${ }^{25 "}$ (Mitroff, 1973, p. 273). The awareness is guaranteed only within the union of the competing theories.

\section{Experimentation}

Williams (2007) celebrates the permeation of Popperian ideas into the management field, and emphatically nominates Peters \& Waterman's (1982) In search of excellence as the quintessence of this trend. Alas, this influential book is distinctively counter-Popperian: in a nutshell, it proposes a "new theory" for business making that substituted experimentation for the oldfashioned planning. However, the "new theory" is explicitly inspired by Kuhn, radiates a strong empiricist flavor ("Experimentation is the fundamental tool of science" - p. 48), and relies heavily on the managers' intuition $^{26}$; in short, it is both inductive and psychologistic.

The notion of experimentations is repeated by Garvin (1993), in the context of the Learning Organization, and by Fahey \& Prusak (1998) concerning Knowledge Management. Experiments are also strongly associated with the concept of evidence-based management (Garvin, 1993; Pfeffer \& Sutton, 2006). Yet both experiments and evidence are for the sake of verification.

Justification instruments: the intended pursuit of rival Theories; the pseudo-scientific use of experiments.

Unmet criteria: the experiments serve the objective of discovery; they are not problem-triggered (actually they are intended to generate problems); the approach is inductive (Levinthal \& March, 1993) and psychologistic. Confrontation of unawareness, if occurs, is by chance.

${ }^{25}$ This argument is exactly what Popper (1961) expects to hear from a conventionalist: "I admit, a conventionalist might say, that the theoretical systems of the natural sciences are not verifiable, but I assert that they are not falsifiable either" (p. 81).

${ }^{26}$ It is not to insinuate that intuition is necessarily wrong; to the contrary, it plays a central role along the discovery phase ("every discovery contains 'an irrational element', or 'a creative intuition'..." - Popper, 1961, p. 32). Nevertheless, intuition is a poor deductive vehicle: "...it is irrelevant to the logical analysis of scientific knowledge" (op cit. p. 31). 


\section{Double-loop learning}

The double-loop learning definitely targets the Theory's alteration: "The results... [of double-loop learning] will take the form of restructuring of organizational norms, and very likely a restructuring of strategies and assumptions associated with those norms, which must then be embedded in the images and maps which encode organizational theory-in-use" (Argyris $\&$ Schon, 1978, p. 22). More to the point, the double-loop learning addresses the unawareness problems embedded in the means-ends analysis: "One of the most difficult learning problems organizations may face is to learn that they are not able to learn, and that the cause of this inability is the focus on what is taken for granted namely, routines" (Argyris, 1996, p. 82).

How is the intended result achieved? Double-loop learning "...couples articulateness and advocacy [associated with single-loop learning] with an invitation to others to confront one's views, to alter them [...] Every significant Model II action [double-loop learning] is evaluated in terms of the degree to which it helps the individuals involved generate valid and useful information (including relevant feelings)..." (Argyris, 1976, pp. 21-22; italics added).

Justification instruments: sincere scrutiny of entrenched Theories-ofaction in order to open them up and ground the emerging ones on a sounder basis. The plurality of viewpoints is legitimized.

Unmet criteria: the process is distinctively psychological, based on interhuman interactions. The unawareness that the method confronts is predefined: one's unawareness of others' perspectives (of which the facilitator is aware).

\section{Evaluation of the Remaining Methods}

Of the two following methods only the first is distinctly Popperian. The second was "proselytized" at our discretion.

\section{The Critical Method}

The Critical Method, proposed by Ben-Israel (1989), is the only method I have found that explicitly stems from the Popperian tradition. Its context is Military Intelligence and specifically the Israeli Intelligence failure back in 1973.

After a brief review of Popper's doctrine and after the author establishes a "superficial analogy" (sic) between the scientific forecast and the intelligence estimate, he presents the following principles:

How should an intelligence analyst make his estimates? Must he first thoroughly check all relevant facts and past experience, and then generalize from them universal formu- 
la (induction)? As indicated above, I intend to prove that this is a wrong approach to intelligence. An intelligence officer has to raise possible (hypothetical) estimates (theories) from his free imagination, and then test them against the known facts. Hence, an intelligence estimate is a conjecture. An estimate that is incompatible with a known fact has to be discarded. Only an estimate that is compatible with all known facts should be retained (until a refuting fact is found). The main daily activity of an intelligence researcher (once he has created possible estimates) must be endless testing and refuting of those estimates. To test and refute effectively he must actively seek relevant new facts, ask the right questions, develop new sources - just as the scientist creates "crucial experiments" for testing his theories (Ben-Israel, 1989, pp. 667-668; italics in origin).

Figure 4.1 illustrates the analogy:

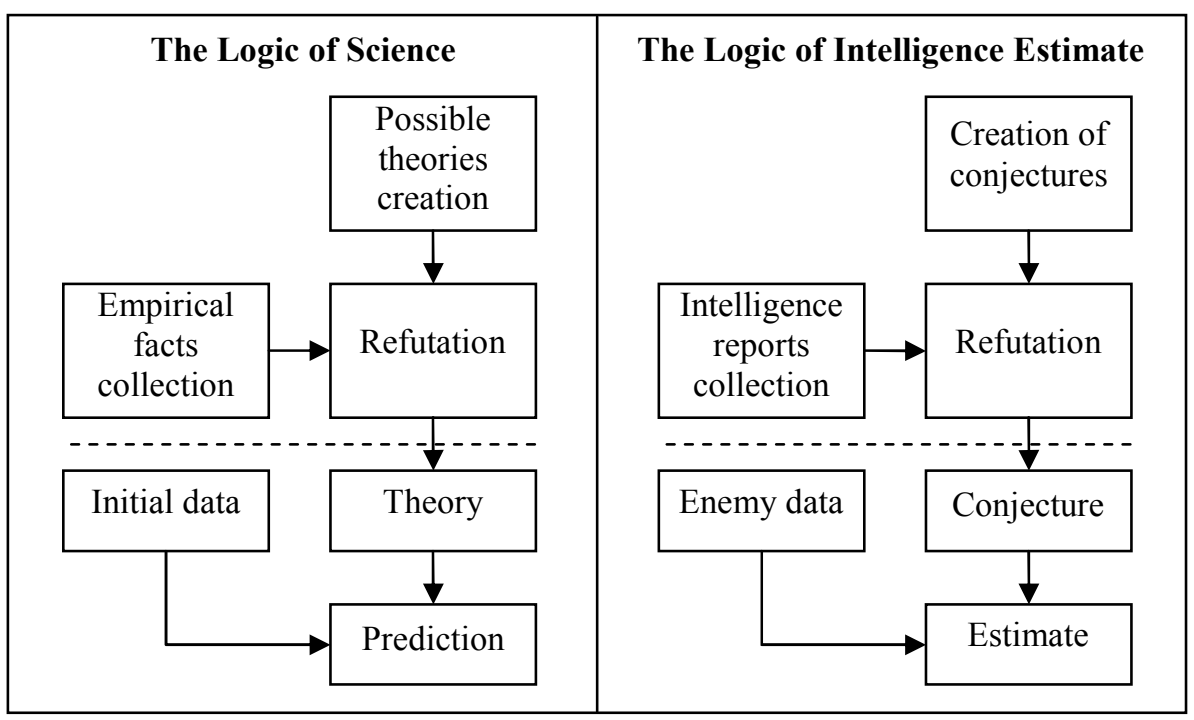

Figure 4.1. An analogy between science and intelligence (source: Ben-Israel, 1989, p. 668)

Ben-Israel suggests the following example, which reflects the actual situation faced by the Israeli Intelligence analysts in 1973:

What happens when we have two different estimates, each supported by a different number of facts? Let us assume that estimate A ('a war is going to break out soon') is sup- 
ported by some dozens of reports; and that estimate B ('it's going to be an exercise') is confirmed by some hundreds, or even thousands, of facts. (This situation more or less corresponds to that on the eve of Yom-Kippur War.) Is estimate B 'more probable'? Popper says not. Neither estimate is better-confirmed than its companion. What determines the situation is whether there are facts which falsify one of the estimates. If such a fact exists, the refuted estimate must be dropped. If no such fact exists, both estimates are equally possible. A good intelligence officer would not stop at this point. He would try to falsify both, tackling the bold theory first. If it is untrue, there is a higher probability of discovering a falsifying fact which will eliminate it (Ben-Israel, 1989 , p. 668; italics in origin).

The author is fully aware of the dissimilarities between science and intelligence, but is convinced that the gaps are to a large extent bridgeable. Among the gaps, the inability to conduct controlled experiments in the intelligence field gets a special emphasis. He argues that the inability is as the same true in astronomy; yet unquestionably astronomy is science, where the undoable experiments are compensated by observations ${ }^{27}$. Another significant difference is that Nature has no intention to deceive the researcher, whilst the enemy certainly has. More generally, unlike still entities, human beings maintain free will - an echo of Popper's reference to the social sciences. Ben-Israel (1989) uses the arbitrary postulate of rationality that Popper (1994) substitutes for the universal law in social situations; we return to this point later.

But what about the hierarchical structure of the theoretical system? Recall that Popper does not refute directly the theory in question, but does so through the refutation of a statement derived thereof. Ben-Israel (1989) is inconsistent about this point; on the one hand he acknowledges a higherlevel Theory, which he entitles "conception", but on the other hand he regards it as a means rather than an end:

In the introduction to this article I raised the question of the role and function of 'conceptual frameworks' in intelligence estimate. What can we now say about it? A conceptual framework is a system of basic assumptions, theories and beliefs, which is used as a yardstick to judge any incoming information. Our discussion above clearly shows

${ }^{27}$ Popper (chapter 3, p. 42) exemplifies how an astronomical theory can underlie a model, from which a prediction is derived to be later compared against an observation. 
that no theory should be accepted as absolutely proven, including conceptual frameworks. It can be considered 'true' only temporarily until sound and credible factual falsifying information is found. Nevertheless, no conclusion can be reached without theories, even if they are temporary. There is thus a need for conceptual frameworks because without them information would be no more than a huge set of uncorrelated facts. The main function of a conceptual framework is to arrange and interpret facts wisely. But it should never be treated as final. On the contrary, discrepancies in this conceptual framework should continually be sought, and an active attempt to refute it in every possible way should be made (Ben-Israel, 1989, pp. 710-711; italics in origin).

Add to that the previous quote - "An intelligence officer has to raise possible (hypothetical) estimates (theories) from his free imagination" (p. 667; italics added) - which clearly contradicts the idea of deduction and considers the war/no-war hypotheses as the primary competing theories under test. The "conception", so it looks like, does not function as the Theory.

It is essential, for the sake of the forthcoming discussion, to understand the subtleties behind the term conception: In the post-1973's war vernacular of the Israeli Intelligence, The Conception became synonymous to mental fixation, by all means with a negative connotation. In brief, the conception presented the following logic: the Egyptian ultimate war objective is to retake the whole Sinai desert, for which a prerequisite is aerial superiority - or at least another countermeasure against the Israeli superior air force (e.g. by antiaircraft missiles). Since this condition has not been met yet, war is unreasonable. Alas, the war did erupt; what we know nowadays is that the major premise was outdated: the objective had been reduced to a limited conquest, just enough for unfreezing the status-quo (Bar-Yosef, 2001).

Ben-Israel (1989) addresses the difficulty in assessing future intentions of rivals. He ascertains categorically that we cannot verify an intention; yet we are able to negate one: as long as the necessary consequences of an intention (i.e. alarming indicators of preparation) are missing, the intention is most probably missing as well. He concludes:

An immediate consequence can be inferred from the foregoing discussion. It concerns the structure of the periodical intelligence estimate. According to our system, its main part should consist of a list of basic assumptions and hypotheses which underlie its predictions. This list should guide the estimators and especially the gathering agencies (who should try to test these assumptions and hypotheses 
by actively gathering data which may refute them), during the whole period of estimate. Whenever one of the statements on the list no longer holds true, an entirely new estimate should be made (Ben-Israel, 1989, p. 697; italics in origin).

All has been said, Ben-Israel (1989) is still disturbed by the unreliability of the intelligence information due to the concealment and deceit of it characteristic. The consequence is a fragmented picture in which an "observation" may be as untrue as the hypothesis it allegedly refutes. Therefore, he argues, implementation of the pure Popperian doctrine may be misleading. Instead he suggests a "softer" method, in which the refutation is subject to the analyst's discretion (wishfully without slipping toward conventionalism). The amended process, which integrally includes the authentication of the data, is presented in figure 4.2.

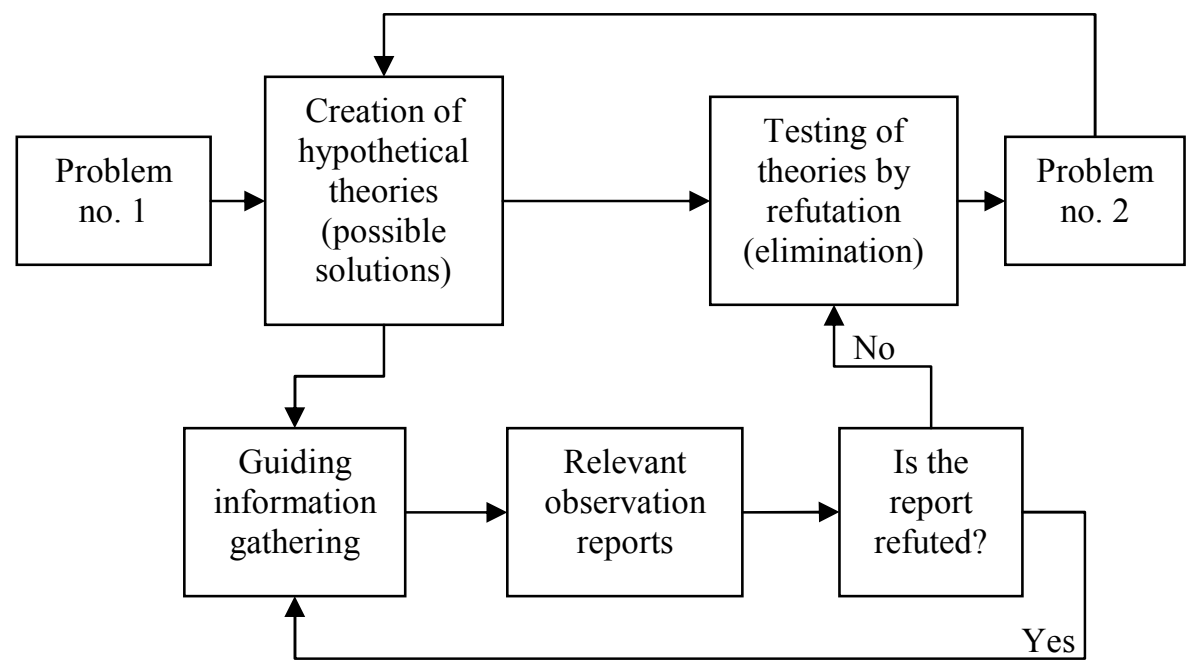

Figure 4.2. The Amended Critical Method (source: BenIsrael, 1989, p. 680)

\section{Cognitive Mapping}

The cognitive mapping was not originated as a method for justification. It was destined by Axelrod (1976) to explore the rationale of third-party's decisions in retrospect. Nevertheless, the method is useful: it is qualified to explicate and represent the Theory and to test it through derived scenarios.

The cognitive map is a product of induction that by deduction yields the predictions (scenarios): 
First, the interaction of induction and deduction highlights the role that cognitive maps play in determining [problem] diagnosis outputs. [...] Second, it is impossible to predict diagnosis outputs from cognitive maps or data alone: the persistent interplay of deduction and induction indicate that both are necessary (Dutton et al, 1983, p. 313).

So the equation is: cognitive map + data $=$ diagnosis. The challenge faced by Axelrod (1976), in the context of strategic foreign policy, was to extract the cognitive map of decision makers from the available data and diagnosis. In doing so he embraces the assumption of rationality:

The laws of interaction of the parts of cognitive maps are intended to be rational $[. .$.$] The interpretation is simply that$ a person whose concepts and beliefs are accurately represented in a particular cognitive map should rationally make predictions, decisions, and explanations that correspond to the predictions, decisions, and explanations generated from the model. [...] The basic result is that the expressed set of beliefs produces a cognitive map from which it is relatively easy to make correct deductions (Axelrod, 1976, pp. 5657).

Axelrod (1976) and his associates developed a formal representation of one's beliefs system, namely the cognitive map; the detailed formalism appears in an annex to this chapter. At this point enough is to say that the map represents two kinds of constituents: variables, i.e. driving forces, and causal relationships among them; equally important is to note that for the sake of calculability the variety of expressible relationships is limited so that complicated ones suffer from under-representation (details in the annex).

The overall structure of the map consists of three areas (figure 4.3): means ("policies" in origin) on the left-hand side, interrelated variables (concerning the environment) in the middle, and ends ("utilities") on the right. Since the map concerns strategic policies, the "ends" are by definition at the top level; so we can correlate the "interrelated variables" with the causal ambiguity (figure 3.5). 


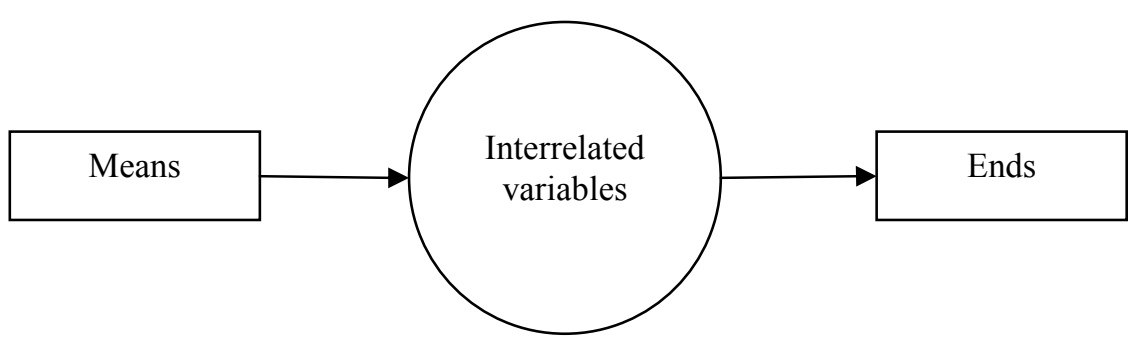

Figure 4.3. Schematic structure of the cognitive map

Beyond representation, the cognitive map is qualified to cope with four kinds of problems that Axelrod (1976) count:

Problem 1 - The Decision-Making Problem: Given a cognitive map with one or more policy variables and a utility variable, which policies should be chosen and which policies should be rejected?

Problem 2 - The Forecasting Problem: If certain given variables increase, and certain others decrease, what will happen to each of the points of the cognitive map?

Problem 3 - The Explanation Problem: Given a cognitive map, and given some observed changes in some of the points, what explanations are consistent with these observed changes? [...] This question is like the forecasting problem in reverse.

Problem 4 - The Strategic Problem: Given a cognitive map, what would be the consequence of changing the sign of a given variable? For example, which changes in the causal links would change an undesirable policy into a desirable policy? (Axelrod, 1976, pp. 64-65)

In our terms, problem 1 addresses the causal ambiguity, problem 2 is equivalent to scenarios derivation and problem 3 to the Theory's testing. Problem 4 implies enactment - a reshape of the environment.

To what extent is the represented Theory true? Axelrod (1976) considers three dimensions of rigor: validity, sincerity and accuracy. Validity is about the representational power, namely the extent to which the map represents the mind. Sincerity relates to the subject, the decision maker, and measures the match between his real and announced beliefs (in Argyris's terms, between the theory-in-use and the espoused theory); in other words it means reliability. Accuracy is defined as follows: 
Accuracy is different from validity or sincerity in that accuracy depends not only on the speaker but also on the environment. A cognitive map is accurate if the predictions derivable from the map are correct. For example, if a map predicts that an increase in A will cause an increase in G, then the map is accurate in this prediction if $\mathrm{G}$ actually does go up when A goes up. Put another way, a map is accurate if it correctly reflects environmental contingencies (Axelrod, 1976, p. 281).

In other words, the "accuracy" is our aspired product of justification. The three dimensions vary by importance (for Axelrod): validity and sincerity way outweigh the accuracy. The first is tested empirically (using case studies); the second is guaranteed by the data collection techniques. The issue of accuracy is marginal, delegated for further research. Note that Axelrod (1976) is skeptical about the chance to resolve this issue anyway ${ }^{28}$ :

The difficulty with studying accuracy is simply that the researcher is often in no better position to evaluate the accuracy of a set of assertions than is the decision maker himself. [...] Using either method [for accuracy evaluation], the basic idea is [to] be in a position to compare the (presumably more accurate) cognitive map of the researcher with the cognitive map of the decision maker in order to see where the decision maker was wrong (Axelrod, 1976, pp. 282-283).

The low priority assigned to justification is because the tool is not destined to serve decision-makers in real-time but researchers in retrospect (the "post-mortem" analysis in case study 3 is a classical exercise). Axelrod's (1976) first priority is that "the method should be unobtrusive" (p. 6) for the sake of reliability. Two data collection methods comply with the unobtrusiveness requirement (Axelrod, 1976): documents analysis (like in the aforementioned case) or questioning a panel of uninvolved experts in retrospect. The latter method is elaborated in chapter 7 .

\footnotetext{
${ }^{28}$ Axelrod's skepticism alludes a constructivist stance: "...constructivism means that human being do not find or discover knowledge so much as we construct or make it. We invent concepts, models, and schemes to make sense of experience..." (Schwandt, 2000, p. 197). In this sense Axelrod compares constructs to one another and not a construct to the reality. It is a sort of dialectic inquiry.
} 


\section{Discussion}

\section{The Critical Method}

Although inspired by the Popperian approach, the Critical Method does not test the major premise (the Theory) but eliminates predictions. Had the method really targeted the Theory (or the "conception"), the hypotheses should have been derived from it; but Ben-Israel regards the conception as a loose framing reference and urges the analyst to freely generate hypotheses. Logically speaking, the alternative results are checked with neither a major nor a minor premise. The invited "free imagination" upon raising the hypotheses is counter to the Popperian logic:

In this way we are led to the demand that the theory should allow us to deduce, roughly speaking, more empirical singular statements than we can deduce from the initial conditions alone (Popper, 1961, p. 85; italics in origin).

The suggested hypotheses (war/no-war) are named in the intelligence jargon "enemy's alternative courses of action", equivalent to the managerial concept of scenarios. But scenarios, we figured out, are not theories in themselves; they are logical predictions deduced from the Theory. The Critical Method skips the derivation but emphasizes the refutation; in other words it targets the mental irrefutability (with a wink at conventionalism) but ignores the mindless derivation.

The scenarios, out of the context of falsification, are regularly used as a tool that addresses uncertainty (Courtney, Kirkland \& Viguerie, 1997; Wack, $1985 / \mathrm{a}, 1985 / \mathrm{b})$; they exactly correspond with the notion that uncertainty is "lack of enough information to choose from an exhaustive and well-defined set of possible states" (Zack, 2001, p. 20). In this light the Critical Method is capable for uncertainty rather than for unawareness.

This shortcoming is probably the result of the tight tailoring for a unique situation: a war decision. Two traits of this situation differ from Popper's guideline: first, it depends on the intention of a specific agent rather than natural law; this is the causality type that Aristotle calls "formal", which differs substantially from the "efficient" or "final" causality we address (see chapter 3, p. 67). Second, the information flow is largely controlled and purposefully distorted, whilst in an open "social situation" the information flow is decentralized. Hence the "Amended Critical Method" is overqualified in settings other than intended; actually this amendment applies the Hegelian inquiry (Wijnhoven \& Meertens, 2010) rather than the Popperian method, and the hypothesizing process is inductive rather than deductive as it pursues the "best-explanation inference" (Ennis, 1987). 
We did not find an empirical evidence of the method's effectiveness (there is no documented experience, at least not public).

\section{The Cognitive Map}

The Cognitive Mapping method is distinguished by its proved validity and reliability in Theory representation, the formalized notation and the sound data collection methods. The weaknesses from our point of view are the marginal attention paid to the Theory's justification, the emphasis put on unobtrusiveness, and the limited representation capabilities.

The original objective of the method is associated with the causal ambiguity, but the qualities related to problems 2-3 imply extended usefulness: counter mindless derivation.

\section{Conclusions}

In this chapter we looked for insights from past experience in dealing with justification. The Popperian criteria filtered most of the methods but two.

The Critical Method, exclusive in its Popperian pretention, presents a solution that is partial, sectoral, and inexperienced. Yet the idea of scenarios refutation hints at a counter mental irrefutability strategy (without the extra care for the data credibility).

The cognitive mapping method provides a starting point from which the mindless derivation can be confronted. The main adaptation that the method requires concerns the obtrusiveness.

Both methods apply to the right falsification route, which anyway seems to be preferable. The available experience adds to its attractiveness. 


\section{Annex to Chapter 4: The Formalism of the Cognitive Map}

(Based on Axelrod, 1976)

\section{Basic notations}

According to Axelrod (1976), the cognitive map is a mathematical representation (in graph or equation) of one's beliefs system. It contains two kinds of constituents: variables (notated by points) and relationships (notated by arrows). The variables are concepts that relate to physical or social entities in the surrounding and can be assigned varying values. The relationships presented are solely causal ${ }^{29}$, designating both the effect's direction and ratio; of ratio, the effect can be either direct (positive, signed "+") or inverse (negative, signed "-"). Consider a causing A and an affected B: in the case of direct ratio, increase in A leads to increase in B, and decrease in A leads to decrease in $B$; in the case of inverse ratio, increase in $A$ leads to decrease in B, and decrease in A leads to increase in B. Further ratios unable to be presented are detailed under "limitations".

A sequence of connected variables (i.e. a chain of points and arrows), either all the way from means to ends or a subset in between, is called a path, which can come in various forms. Figure 4.4 schematizes the four possible forms of paths, analyzed hereinafter (A and B are the cause and the effect variables, respectively).

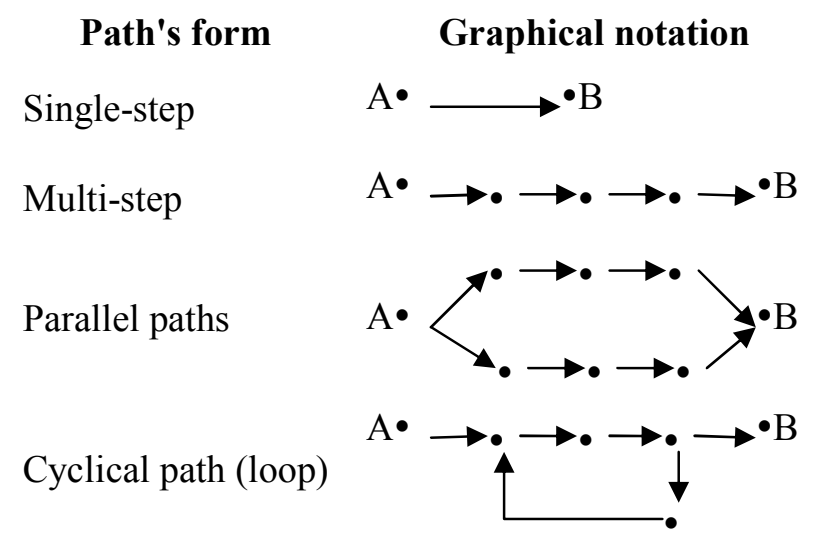

Figure 4.4. Forms of paths in a cognitive map

\footnotetext{
${ }^{29}$ Further relations, such as part-whole, are possible but interfere with the quest for simplicity. They are presented in e.g. Huff et al, 2000, chapter 6 .
} 
As each arrow can be either positive or negative, the more the steps along an A-B path the higher the complication of determining the ultimate effect. Here the mathematical merits of the map are realized via two calculation rules:

Rule 1: Along a path, the overall effect is positive (i.e. direct ratio) if the path consists of even number of negative signs, and negative (inverse ratio) if it has an odd number of negative signs.

Rule 2: In case of parallel paths, if all the paths are positive then the total effect is positive; if all the paths are negative, then the total effect is negative; if some paths are positive and others are negative, the total effect is indeterminate.

The overall effect throughout a loop is according to the $1^{\text {st }}$ rule, but it demonstrates another quality: if the overall effect is positive, then the loop is deviation-amplifying; it means that a one-time increase in A, for instance, will be amplified in every loop ad infinitum. In contrast, if the overall effect is negative then the loop is deviation-counteracting, meaning that a onetime increase in A will be followed by increase and decrease alternately.

\section{The time dimension}

The time dimension (namely how long it takes an effect to apply) is not an issue in the cognitive mapping. This dimension exists, though primitively, in the system dynamics tradition, originally in industrial context (Sterman, 2000) and later in regard to organizational learning (Senge, 1995). The notation is simply a label that announces "delay", which reads: "A delay is a process whose output lags behind its input in some fashion" (Sterman, 2000 , p. 411). The notation is shown in figure 4.7 and means that $B$ is affected by A in some unspecified delay.

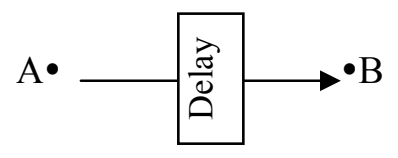

Figure 4.7. The notation of "Delay"

\section{Limitations of representation}

Save the positive or negative notations, other possible relationships among driving forces cannot be represented. Axelrod (1976) counts the inexpressible relationships:

1. Conditional or interactive causation. Sometimes the causal impact of two or more different variables interact in determining the result of the effect variable. For ex- 
ample, "if A is high, B promotes $\mathrm{C}$, but if $\mathrm{A}$ is low, $\mathrm{B}$ retards C." $[\ldots]$

2. Nonreversible causation. Nonreversible causation occurs when "an increase in A causes an increase in B, but a decrease in A does not cause a decrease in B." [...]

3. Nonmonotonic causation. The basic type of causal relationship assumes that a change in the cause variable in a given direction causes a change in the effect variable in a determinable direction. For a positive relationship, the change in the effect variable will be in the same direction as the change in the cause variable, while for a negative relationship, the change in the effect variable will be in the opposite direction from the change in the cause variable. In a nonmonotonic relationship, this does not hold. Instead, for some values of the cause variable an increase will yield an increase in the effect variable, while for other values of the cause variable an increase will yield a decrease in the effect variable. [...]

These are limitations in the type of causal relationships that may be coded. But a much more troublesome limitation is that even for simple causal relationships there is no way at present to measure the relationship's magnitude (Axelrod, 1976, pp. 260-262).

Another limitation that Axelrod does not mention is the time notation. The solution suggested by the system dynamics is binary (delay/no delay) and quite poor. The only information it provides is relative, i.e. that some effect is longer than others. 


\section{The Research's Method and Design}

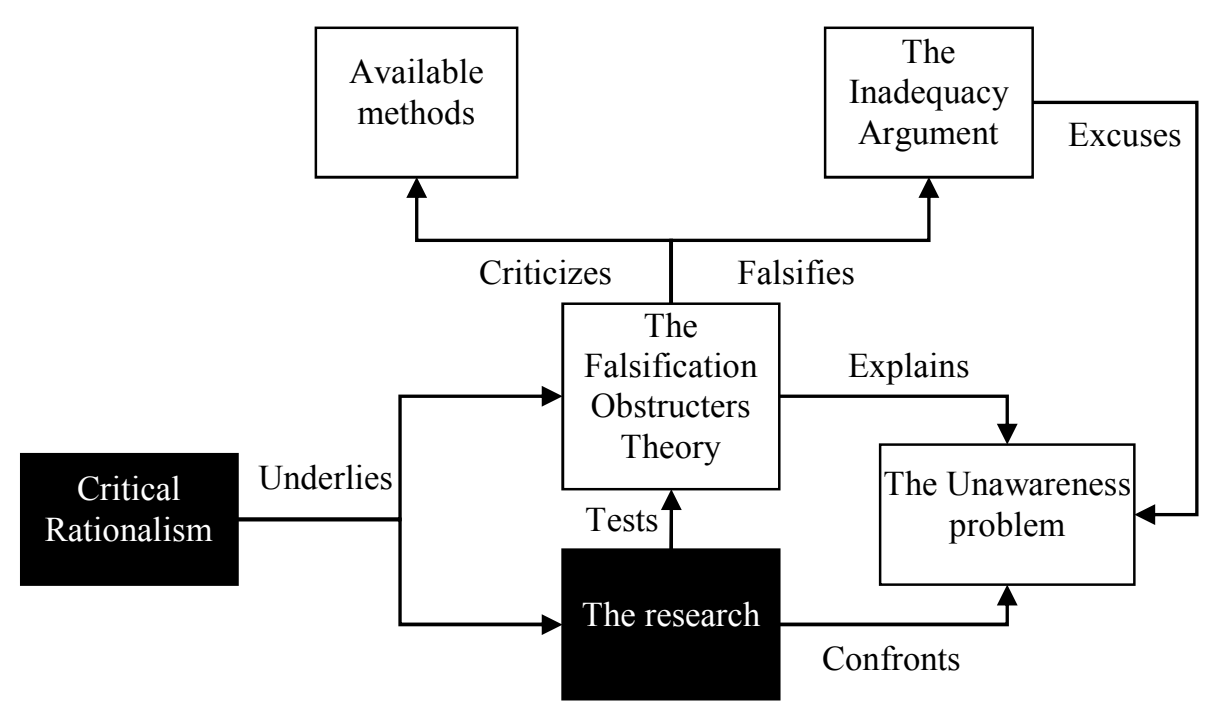

Figure 5.0. The focus of the chapter (blackened)

In this chapter we will:

- Formalize the research's objectives;

- Specify the requirements from the research method;

- Describe and justify the preferable research method, and -

- Design and validate the research method.

\section{The Research Objectives}

Once we posited the falsification obstructers theory (at the end of chapter 3), the remaining objectives are as follows:

- $\quad$ To corroborate the competing theory and by that to supplant the inadequacy argument (chapter 2 ).

- To counteract the unawareness problem.

The social science's version of critical rationalism (chapter 3, p. 51) does not pretend to falsify a universal law, because there are not such in social science. Instead, we compare two competing models; both comply with the same unproved principle. The model with the superior explanation power 
falsifies the other and supersedes it, but does not falsify the umbrella principle:

I regard the principle of adequacy of action (that is, the rationality principle) as an integral part of every, or nearly every, testable social theory. Now if a theory is tested, and found faulty, then we have always to decide which of its various constituent parts we shall make accountable for its failure. My thesis is that it is sound methodological policy to decide not to make the rationality principle, but the rest of the theory - that is, the model - accountable (Popper, 1994, p. 177; italics in origin).

The research was triggered by the problem of unawareness, which we hypothesize is solvable by the Popperian doctrine. This doctrine is deemed inapplicable by the inadequacy argument. The objective of the research is to confirm the superior explanation power of the falsification obstructers theory over the inadequacy argument. We will assume confirmation if the removal of the falsification obstructers will enable the Theory's falsification via the Popperian doctrine. Toward this end we have to design a method that removes the falsification obstructers, apply it in real organizational setting and evaluate the impact. These requirements associate the research with design science.

\section{Design Science}

\section{Introduction}

The double aim of developing an instrument that simultaneously tests a theory and solves a problem merges two scientific activities - explanation and design - into one discipline known as design science. March \& Smith (1995) introduce the unification that way:

...artificial phenomena can be both created and studied [...] Rather than being in conflict, however, both activities can be encompassed under a broad notion of science that includes two distinct species, termed natural and design science (March \& Smith, 1995, p. 253).

Where the explanation-design interplay is carried out as follows:

...design science creates artifacts, giving rise to phenomena that can be the targets of natural [explanatory] science research (March \& Smith, 1995, p. 254). 


\section{The Research's Method and Design}

The idea is practically expanded by Walls, Widmeyer \& El Sawy (1992), who state:

...a design theory must be subject to empirical refutation. An assertion that possession of a particular set of attributes will enable an artifact to meet its goals can be verified by building and testing the artifact. A hypothesis that a certain method will result in an artifact which meets its goals can be verified by using that method to build the artifact and testing the artifact to see whether it satisfies its goals (Walls et al, 1992, p. 41).

Likewise, the practice of designing a method for the sake of scientific explanation is sustained by March \& Smith's (1995) assertion that "Design science creates the methodological tools that natural scientists use" (p. 258), which by the way portrays Popper as a design scientist. Indeed, Van Aken (2005) equates the outcome of design science with the "technological rule" of Popper: "a technological rule is 'a chunk of general knowledge linking an intervention or artefact with an expected outcome or performance in a certain field of application'. [...] a technological rule is a mid-range theory, whose validity is limited to a certain application domain" (p. 23). The last sentence implies the non-universality of the rule.

Design science is advocated for both management (Van Aken, 2005) and IT domains (Hevner et al, 2004). Whilst the former is contextually closer to our interest, the latter is practically more developed and quite the same applicable; therefore we draw upon the IT version.

\section{Definition and characteristics}

The key character of a design theory is the extra step beyond explanation or prediction that a descriptive theory provides:

The purpose of a design theory is to support the achievement of goals. [...] For example, while organization theory is a social science theory concerned with explanation and prediction, management theory is related to design theory because it is concerned with how managers can achieve their goals (Walls et al, 1992, p. 40).

A special case of prediction exists where the theory provides a description of the method or structure or both for the construction of an artifact (akin to a recipe). The provision of the recipe implies that the recipe, if acted upon, will cause an artifact of a certain type to come into being (Gregor, 2006, p. 619). 
Walls et al (1992) regard the genre as "procedural rationality". A design theory comprises both the properties an artifact should have in order to attain a certain goal and the methods required for the artifact's construction. The symbiosis between descriptive and design science is bidirectional: "Design theories involve both the application of scientific [descriptive] theory and the use of the scientific method to test design theories" (Walls et al, 1992, p. 41), and by that they corroborate the descriptive theory.

\section{The design-science framework}

Walls et al (1992) provide a research framework ("design theory") that manifests the double meaning of "design": for one as a product, for two as a process. The framework is exhibited in figure 5.1.

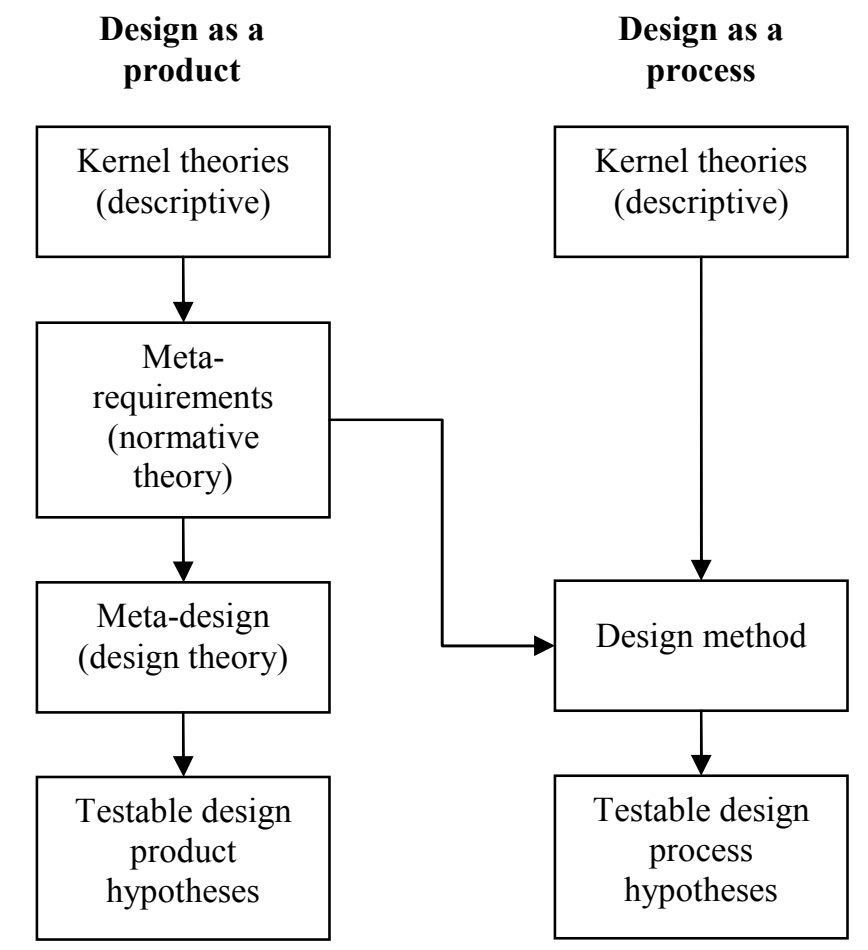

Figure 5.1. Components of Design Theory (source: Walls et al, 1992)

The product's components are defined as follows:

The first component of a design theory dealing with the product of design is a set of meta-requirements which describe the class of goals to which the theory applies. We use the term "meta-requirements" rather than simply re- 
quirements because a design theory does not address a single problem but a class of problems. The second component is a meta-design describing a class of artifacts hypothesized to meet the meta-requirements. We use "metadesign" because a design theory does not address the design of a specific artifact (e.g., a payroll system for XYZ corporation) but a class of artifacts (e.g., all transaction processing systems). The third component is a set of kernel theories from natural or social sciences which govern design requirements. The final component is a set of testable design process hypotheses which can be used to verify whether the meta-design satisfies the meta-requirements (Walls et al, 1992, pp. 42-43; italics in origin).

And the process' components read:

The second aspect of a design theory deals with the design process. The first component of this aspect is a design method which describes procedure(s) for artifact construction. The second is a set of kernel theories from the natural or social sciences governing the design process itself. These kernel theories may he different from those associated with the design product. The final component is a set of testable design process hypotheses which can be used to verify whether or not the design method results in an artifact which is consistent with the meta-design (Walls et al, 1992, p. 43; italics in origin).

\section{The framework's instantiation in the research}

The product is the Popperian method adapted for organizations, and the adaptation constitutes the process. The design components are detailed in table 5.1. Note that the hypotheses (highlighted by italics) encounter both pillars included in the inadequacy argument, i.e. the environment and the organization ( $\mathrm{H} 1$ and $\mathrm{H} 2$, respectively).

Table 5.1. The Design Theory components as instantiated in the research

\begin{tabular}{cll}
\hline Component & \multicolumn{1}{c}{ Design as a product } & \multicolumn{1}{c}{ Design as a Process } \\
\hline Kernel theories & $\begin{array}{l}\text { Popper's Critical } \\
\text { Rationalism doctrine. }\end{array}$ & $\begin{array}{l}\text { The organization theories } \\
\text { (means-ends, theory-of- } \\
\text { action, SID, organizational } \\
\text { learning) that underlie the }\end{array}$ \\
\hline
\end{tabular}




\begin{tabular}{|c|c|c|}
\hline Component & Design as a product & Design as a Process \\
\hline & & $\begin{array}{l}\text { falsification obstructers } \\
\text { theory. }\end{array}$ \\
\hline $\begin{array}{l}\text { Meta- } \\
\text { requirements }\end{array}$ & $\begin{array}{l}\text { Exclusive justification, } \\
\text { deduction-based } \\
\text { falsification, insensitivity } \\
\text { to psychologism, } \\
\text { unequivocal and testable } \\
\text { criteria for problem } \\
\text { recognition (compatible } \\
\text { with table } 4.1 \text { ). }\end{array}$ & Not applicable. \\
\hline $\begin{array}{l}\text { Meta-design/ } \\
\text { Design method }\end{array}$ & $\begin{array}{l}\text { Syllogistic structure in } \\
\text { which the descriptive } \\
\text { Theory stands for the } \\
\text { major premise and the } \\
\text { right route (scenarios) } \\
\text { provides the minor } \\
\text { premise, the prediction and } \\
\text { the conclusion. }\end{array}$ & $\begin{array}{l}\text { Crafting an assortment of } \\
\text { techniques that confront } \\
\text { the obstructers along the } \\
\text { selected route. }\end{array}$ \\
\hline \multirow[t]{2}{*}{$\begin{array}{l}\text { Testable } \\
\text { design/process } \\
\text { hypotheses }\end{array}$} & $\begin{array}{l}\text { H1a. The organization's } \\
\text { environment can be } \\
\text { theorized in a } \\
\text { falsifiable fashion. }\end{array}$ & \multirow{2}{*}{$\begin{array}{l}\text { H2. The techniques } \\
\text { employed throughout } \\
\text { the method overcome } \\
\text { the "mindless } \\
\text { derivation" and the } \\
\text { "mental irrefutability" } \\
\text { falsification } \\
\text { obstructers. }\end{array}$} \\
\hline & $\begin{array}{l}\text { H1b. The right route is } \\
\text { capable of obtaining } \\
\text { unequivocal } \\
\text { falsification. }\end{array}$ & \\
\hline
\end{tabular}

\section{Guidelines and implementation}

Hevner et al (2004) count seven guidelines for design science research, which are listed below. Later we will verify that the research design takes all of them into account.

${ }^{30}$ The "can be" phrasing is intentional, since this is the verifiable form (see p. 48 for further details). Recall that the Inadequacy argument is the one to be falsified. 
Table 5.2. Design-Science Research Guidelines (source: Hevner et al, 2004, p. 83)

\section{Guideline}

\section{Description}

1 Design as an Design-science research must produce a viable

Artifact artifact in the form of a construct, a model, a method, or an instantiation.

2 Problem Relevance

The objective of design-science research is to develop technology-based solutions to important and relevant business problems.

3 Design

Evaluation

4 Research Contributions

The utility, quality, and efficacy of a design artifact must be rigorously demonstrated via well-executed evaluation methods.

Effective design-science research must provide clear and verifiable contributions in the areas of the design artifact, design foundations, and/or design methodologies.

5 Research Rigor Design-science research relies upon the application of rigorous methods in both the construction and evaluation of the design artifact.

6 Design as a The search for an effective artifact requires utilizing Search Process available means to reach desired ends while satisfying laws in the problem environment.

7 Communication Design-science research must be presented of Research effectively both to technology-oriented as well as management-oriented audiences.

\section{The Research Method}

\section{Requirements}

The integrated design-explanation objectives and the research domain pose the following requirements that the research method has to satisfy:

1. The design should be authentic across two dimensions: the unawareness problem and the usage setting (it should appease two entrenched convictions: Kuhnianism and the inadequacy argument).

2. The hypotheses testing entail an experiment in which the independent variables (the obstructers) are manipulated; so the method should be experimental.

3. The variables are complicated and multifaceted. 
4. The quantity does not matter: theoretically we need a single verification of "there is" kind for the sake of falsification (though practically we prefer more).

In light of these requirements a qualitative research method is preferable, in particular the Action Research (AR) method. The AR is definitely an experimental method (Hatchuel, 2005) which is explicitly recommended for methodological innovation purposes (Baskerville \& Wood-Harper, 1996). The AR eliminates the weakness of laboratory experiments that are limited to simple, isolable variables (Mitroff \& Mason, 1981), therefore is proper for investigating complex social systems (Argyris, Putnam \& Smith, 1985); Baskerville \& Wood-Harper (1996) note: "The aim is the understanding of the complex human process ${ }^{31}$ rather than a universal prescriptive truth" ( $\mathrm{p}$. 239). The AR matches the insensitivity to quantity (Cunha \& Figueiredo, 2002). Further reasons are presented right after the method is introduced.

\section{The Action Research method}

AR is a genre rather than a monolithic method (Baskerville \& WoodHarper, 1998), which is eligible for various research views: positivist, interpretive or critical (Davison, Martinsons \& Kock, 2004; Hirscheim, Klein \& Lyytinen, 1996; Johnson \& Duberley, 2000; Kemmis \& McTaggart, 2000; Lincoln, 1995). In an attempt to incorporate all these views under a common denominator, Hult \& Lennung (1980) suggest the following general definition:

Action research simultaneously assists in practical problem-solving and expands scientific knowledge, as well as enhances the competencies of the respective actors, being performed collaboratively in an immediate situation using data feedback in a cyclical process aiming at an increased understanding of a given social situation, primarily applicable for the understanding of change processes in social systems and undertaken within a mutually acceptable ethical framework (Hult \& Lennung, 1980, p. 247).

Historically, the method emerged in the 1940's within the social sciences (sociology and psychology). It emphasized the active participation and involvement of the researched objects, in particular those who have been previously excluded (Baskerville \& Wood-Harper, 1998; Kemmis \& McTaggart, 2000); therefore the method is associated with emancipation (Wadsworth, 1998). Later it became popular in the field of education and

\footnotetext{
${ }^{31}$ The aimed "understanding" is in line with Popper's request of the social sciences "to explain and understand events in terms of human actions and social situations" (Popper, 1994, p. 166; see chapter 3, p. 52).
} 
nowadays also in information systems development (e.g. Lindgren, Henfridsson \& Schultze, 2004) and management (e.g. French, 2009/a). Over the time the method has diversified along several streams, including "the action research stream that focuses on changing practice, the action science stream for conflict resolution, the participatory action research stream for participant collaboration, or the action learning stream through experiential learning" (Lau, 1999, p. 162); our research affiliates to the first, i.e. "plain" action research. Like the design science case, this stream has matured in the IT domain whilst the management field employs the participatory action research (Johnson \& Duberley, 2000); hence we follow the IT version.

Basically the AR consists of two phases: diagnosis and change (Baskerville \& Wood-Harper, 1998). The Canonical Action Research (CAR) model (Susman \& Evered, 1978), which is shared across many AR variations, is expanded up to five phases (figure 5.2). The leading idea is the iterative cycle around a client-system infrastructure, defined as "the social system in which the members face problems to be solved by action research" (Susman \& Evered, 1978, p. 588).

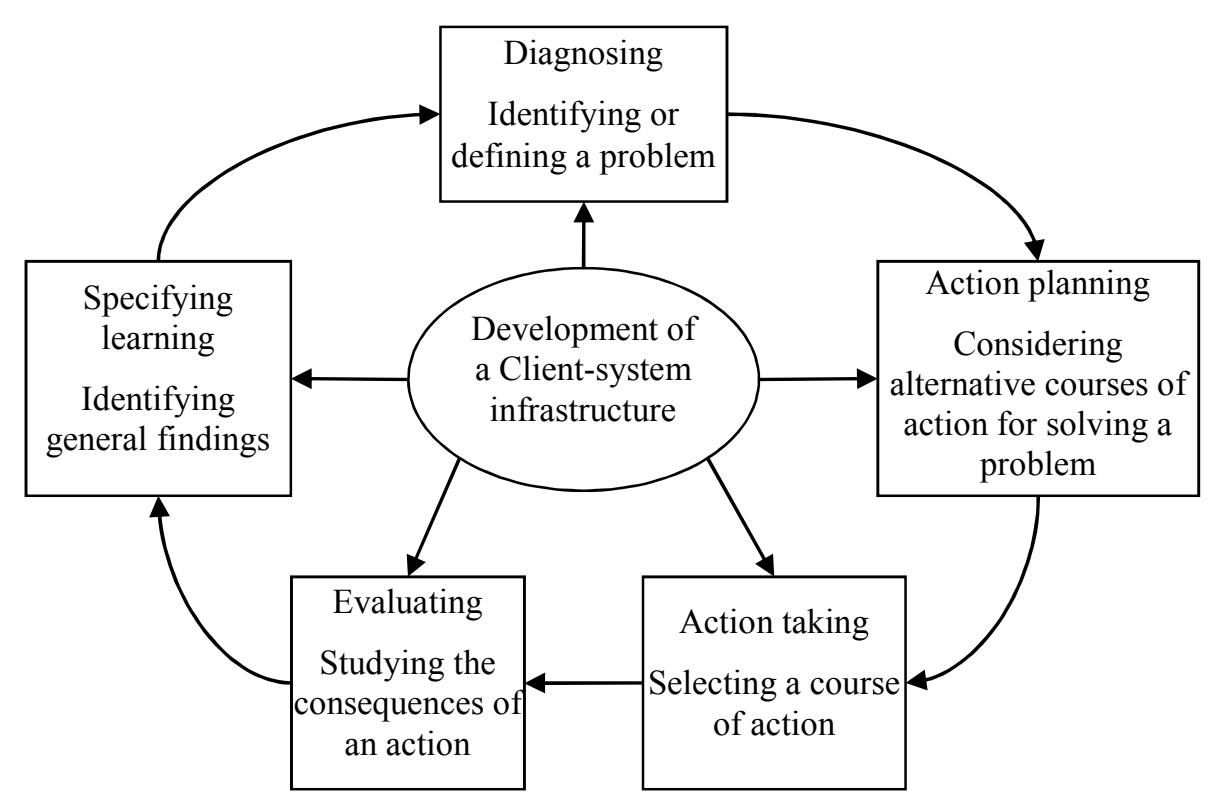

Figure 5.2. The cyclical process of canonical action research (source: Susman \& Evered, 1978, p. 588)

Davison et al (2004) provide five principles that underpin the basic model:

1. Researcher-client agreement (RCA): the CAR has to be achieved before or during the research, and has to recognize the potential for change and to set success factors and termination terms. 
2. Cyclical process model (CPM): a single cycle is rarely sufficient for AR. Although the client may be satisfied with the solution, the researcher should strive understand the problem - and that may last longer. The evaluation in the end of every cycle should confirm that the change has stemmed from the intended reasons.

3. The principle of theory: the AR must rest upon a theory; otherwise it is not a research. The theory may precede the research or emerge along its course.

4. Change through action: change is the essence of AR, and nochange indicates either a false problem or the consideration of the wrong causes.

5. Learning through reflection: this principle is intended to guard the interests of the scientific community and to assure that all the relevant insights come to light under careful distinction between facts and judgments.

Two merits make the AR specifically appropriate for our purpose: its compatibility with critical rationalism and its suitability for design science. Both are detailed below.

\section{Action Research and Critical Rationalism}

AR and Critical Rationalism (CR) share two fundaments: cyclicality and deductive refutation. Popper repeats the idea of cyclicality quite often, as for instance in the following (see also figure 2.1):

It is my view that the methods of the natural as well as the social sciences can be best understood if we admit that science always begins and ends with problems. [...] Practical problems may give rise to theoretical problems. [...] My whole view of scientific method may be summed up by saying that it consists of these four steps:

1. We select some problem - perhaps by stumbling over it.

2. We try to solve it by proposing a theory as a tentative solution.

3. Through the critical discussion of our theories our knowledge grows by the elimination of some of our errors, and in this way we learn to understand our problems, and our theories, and the need for new solutions.

4. The critical discussion of even our best theories always reveals new problems. 


\section{The Research's Method and Design}

Or to put these four steps into four words: problems-theories-criticism - new problems (Popper, 1994, pp. 155-159; italics in origin).

The same cycle is echoed in the AR that starts with problem identification, goes through theorization and testing, and resumes with the next problem. Figueiredo \& Cunha (2007) stress the identical rationale:

The use of cycles [in AR] is strongly encouraged. In each cycle the researcher should try to falsify the emerging interpretation (Figueiredo \& Cunha, 2007, p. 89; italics in origin).

Concerning deductive refutation, the AR applies the CR approach as (rather than inductive generalization) it employs the initial conditions course of deduction: to change the hypothesized cause and to compare the actual result with the expected (Argyris et al, 1985; Baskerville \& Wood-Harper, 1996; Cunha \& Figueiredo, 2002; Davison et al, 2004). Unexpected results generate conjectures to be tested upon the succeeding cycle (Susman \& Evered, 1978).

Thus Cunha \& Figueiredo (2002) can conclude:

We propose that, when using action-research, authors should find support for the epistemological legitimacy of their research on the roots of Critical Rationalism, by Karl Popper... the eight procedures previously described [introduced later] to ensure the rigor of the research process and the validity of results in action-research do fit well the Popperian principles (Cunha \& Figueiredo, 2002, p. 25).

\section{Action Research and Design Science}

AR claims suitability for DS on two grounds: the knowledge's source and the contour of implementation. Concerning the former, in both AR and DS the knowledge is acquired from the practice (Susman \& Evered, 1978). The question "why?" is answered by "in order to..." rather than "because of..." (Figueiredo \& Cunha, 2007); stated differently, the focus is on the results instead of the causes (Argyris et al, 1985). The shared notion is constructivist in the sense that the knowledge is not "out there" but emerges through practice (Hatchuel, 2005). In the context of the previous section, this last argument is in line with Popper's dual emphasis on the process as well as on the logic of knowledge generation (Freudenthal, 1977; Williams, 2007).

The analogy with respect to implementation is as the same conspicuous, summarized in details by Järvinen (2005) in the following table. His con- 
clusion is that "action research and design science should be considered as similar research approaches" (p. 13).

Table 5.3. Similarities of the fundamental characteristics of action research and design science (edited from: Järvinen, 2005, p. 13).

\begin{tabular}{ll}
\hline \multicolumn{1}{c}{ Action research } & \multicolumn{1}{c}{ Design science } \\
\hline $\begin{array}{l}\text { Action research emphasizes the } \\
\text { utility aspect of the future system } \\
\text { from the people's point of view. }\end{array}$ & $\begin{array}{l}\text { Design science's products are } \\
\text { assessed against criteria of value or } \\
\text { utility. }\end{array}$ \\
$\begin{array}{l}\text { Action research produces } \\
\text { knowledge to guide practice in } \\
\text { modification. }\end{array}$ & $\begin{array}{l}\text { Design science produces design } \\
\text { knowledge (concepts, constructs, } \\
\text { models and methods) }\end{array}$ \\
$\begin{array}{l}\text { Action research means both action } \\
\text { taking and evaluating. }\end{array}$ & $\begin{array}{l}\text { Building and evaluation are the two } \\
\text { main activities of design science. }\end{array}$ \\
$\begin{array}{l}\text { Action research is carried out in } \\
\text { collaboration between action }\end{array}$ & $\begin{array}{l}\text { Design science research is initiated } \\
\text { by the researcher(s) interested in } \\
\text { researcher and the client system. } \\
\text { developing technological rules for a } \\
\text { problem setting. }\end{array}$ \\
$\begin{array}{l}\text { certain type of issue. Each } \\
\text { individual case is primarily oriented } \\
\text { at solving the local problem in close } \\
\text { collaboration with the local people. }\end{array}$ \\
$\begin{array}{l}\text { Action research modifies a given } \\
\text { reality or develops a new system. }\end{array}$ & $\begin{array}{l}\text { Design science solves construction } \\
\text { problems (producing new } \\
\text { innovations) and improvement } \\
\text { problems (improving the } \\
\text { performance of existing entities). }\end{array}$ \\
$\begin{array}{l}\text { Knowledge is generated, used and } \\
\text { tested and modified in the course of } \\
\text { the action research project. }\end{array}$ & \begin{tabular}{l} 
action. \\
\hline$*$ In
\end{tabular} \\
\hline
\end{tabular}

* In line with the concept of "meta-design" by Walls et al (1992), aforementioned.

\section{Limitations of Action Research and countermeasures}

Whilst AR has a clear advantage for practical relevance, its scientific rigor and generalizability are questionable. Potential risks are that the circumstances in which the research is done are idiosyncratic and that the researcher is too much involved, therefore prone to follow his or her values (Davison et al, 2004; Rapoport, 1970).

However, the AR is not a monolithic method; Baskerville \& Wood-Harper (1996) distinguish between participatory and design research and claim 98 
much more rigor for the latter. Admittedly, they say, designerly AR is susceptible to biases - but not more than other methods. The key for assuring rigor is to maintain a theory in the first place and to conduct the research as a testing vehicle (Baskerville \& Wood-Harper, 1998; Davison et al, 2004). As a by-product, the theoretical basis strengthens both relevance and generality if corroborated (Figueiredo \& Cunha, 2007).

But this key requirement is not enough from a critical-rationalist eye; nor are Davison's et al (2004) five principles mentioned earlier. Therefore Cunha \& Figueiredo (2002) augment the list up to eight tactics, aimed "to ensure rigor in the action-research process, that is, to guarantee the quality of the evidence and, thus, of the assertions that are made based on it" (Cunha \& Figueiredo, 2002, p. 23). The design purpose, they add, is not the less contributed. The tactics are:

1. A theoretical framework must be set at the beginning of the process. It is in light of this framework that new knowledge arising from the research will be identified.

2. The use of cycles is strongly encouraged. In each cycle the researcher should try to falsify the emerging interpretation. Using several short cycles may lead to more opportunities for that. Cycles can be used within cycles, with larger ones spanning whole phases of the research program.

3. Research methodology, as well as the research questions, should be critically analyzed and refined in each cycle.

4. Data collection and interpretation should be a part of each cycle. This lets both be challenged in later cycles.

5. In each cycle, the researcher should focus only on agreements and disagreements, ignoring the idiosyncratic data. Apparent agreements should be tested and apparent disagreements explained.

6. Divergent data should be deliberately sought. This increases the chances that any piece of data or interpretation be challenged. The existing literature can also play an important role in this effort.

7. Multiple sources of information should be sought (or different perspectives concerning the same source) in order to create a dialectical process.

8. Results from change induced into the research situation should be used as an additional source of information for challenging emerging theories (since the planned ac- 
tions have been grounded on previous data and interpretations) (Figueiredo \& Cunha, 2007, p. 89).

The research will strictly follow these guides. When applicable we will use the exact terminology in order to stress the fidelity.

\section{Examples of $A R$}

Two exemplifying AR's are presented. The first demonstrates the double purpose of explanation and design, the second deals with the establishment of a method.

Lindgren, Henfridsson \& Schultze (2004) conducted a canonical AR in order to develop a competence management system. The project was initiated by the researchers with the aim of transforming the traditional job-based human resource management (HRM) into competence-based, in order to regain fit with the dynamic competitive requirements. As a canonical AR the most emphasized point is that of iteration, with two cycles implemented. The first cycle drew upon theoretical model and provided the hypothesized problem definition; during the second a solution was conceived and tested. The main contribution of this research is in conceptualizing the problem space and in discovering behavioral patterns; the emerging IS materializes the concepts into a comprehensive methodology. The authors stress the AR qualification for both hypotheses testing and design.

Kullven \& Mattsson (1994) used AR to construct control model for the service sector; the outcome of their research is an ontology-based methodology for this domain. The authors find as especially valuable the deep involvement of mid and upper level echelons. The AR produced the conceptual foundation for the method in point.

\section{Research Design by Phases}

\section{Overview}

The span of the research has to balance the tension between two considerations. On the one hand, the AR method is time-consuming and costly, all the more so when strategic consequences are expected. On the other hand, a narrow study faces the risk of over-singularity. In order to compromise both conflicting constraints the AR is planned to encompass three organizations in two cycles: two organizations in the first cycle, one organization in the second cycle (more cycles will be considered if required).

The first priority in selecting the participants is diversity (i.e. various characteristics); however, Lindgren et al (2004) stress the criticality of personal ties as a constraint upon selection. The plurality and the diversity (each or- 
ganization represents another industry) allow cross-case generalization, whereas the cyclicality promotes corroboration.

Due to the intensive involvement required from the participants, the participation has to be conscious and committed; the researcher-client agreement will institutionalize and reflect the mutual commitment. We will deliver as much information as possible to the participants, prior to and during the research, and make sure that the objectives as well as the arrangements are clear and accepted. Cooperation and sincerity are essential, and both depend on trust.

The research design is detailed by the AR phases.

\section{Diagnosis}

The aims are threefold:

1. To validate the "Theoretical system" model (figure 3.5, p. 68) and the theoretical problem (i.e. the detachment of the major premise).

2. To characterize the Descriptive Theory in that system (the testing target).

3. To obtain the participants' acknowledgment of the problem definition.

The model will be valid if we find evidence for the existence of the constructs and their interrelations; to that end we will use the model as a framework for the data arrangement (detailed below). The problem's validation will be inferred from the content. Hereinafter the sub-steps within the diagnosis phase are elaborated.

Data collection: data will be collected through one-on-one, in-depth and semi-structured interviews with a small but representative sample of decision-makers. Respondents will be asked, sometimes vicariously, what (Theories) guide their decisions, and how they warrant the truth of those Theories. The interviews have to be interactive because the practitioners are assumed to be unfamiliar with the concept.

Data processing: toward the model validation, and for the cross-case comparability, the data collected through the interviews (dissected to utterances) will be presented in a table that corresponds one-to-one with the organization's "Theoretical System" (figure 3.5, p. 68). The table's skeleton is presented below, where the white cells represent the Theory's segments, the gray cells signify the falsification obstructers, and the black cells manifest the method of deduction. Below the cells are explained. 
Table 5.4. The skeleton of the data table

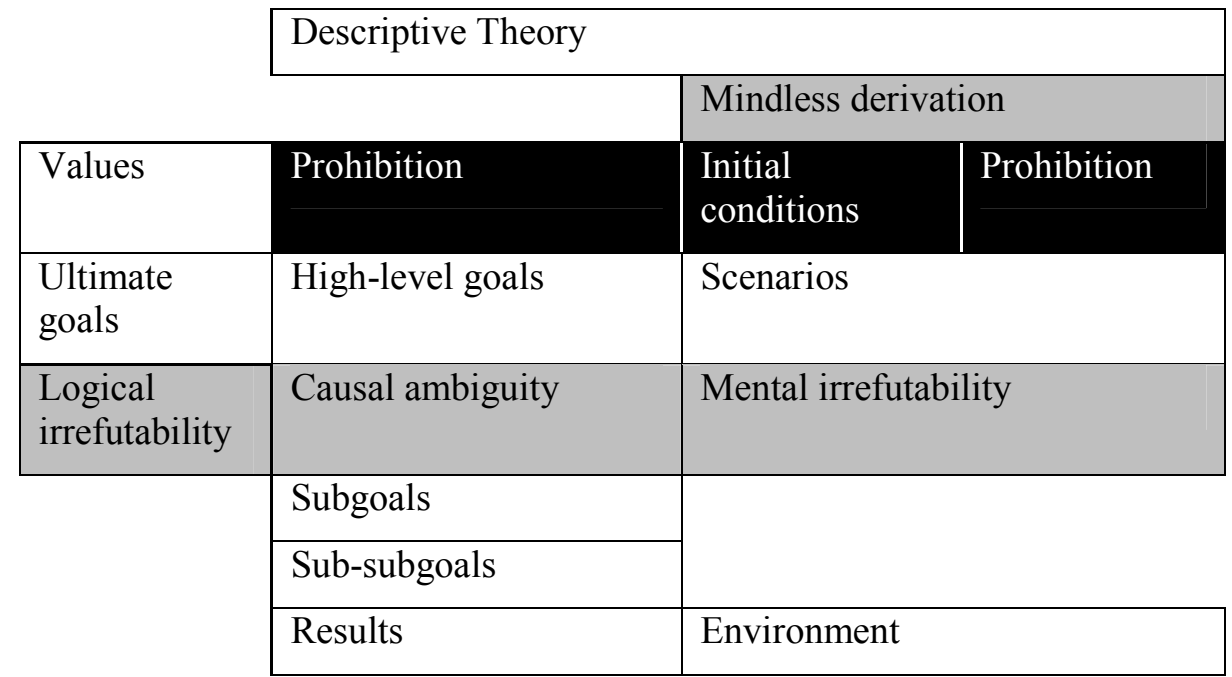

The Descriptive Theory contains utterances that explain the "world" as-is, where to explain means either causality ("because of $X$, then $Y^{\prime \prime}$ ) or structure ("X consists of $\left.\mathrm{x}_{1}, \mathrm{x}_{2} \ldots \mathrm{x}_{\mathrm{n}} "\right)$.

The Values and the Ultimate goals make the normative theory. Values are those statements that tell right from wrong or declare an always-true convention. The Ultimate goals are the grand mission or the raison d'être of the organization (distinctly non-operational).

The High-level goals, Subgoals and Sub-subgoals express the Means-ends analysis (the Design Theory). The hierarchical break-down is inferred from the content: by default, a goal is considered high-level unless it serves a higher (operational) goal. The Prohibition cell above the goals concerns statements that constrain or restrict the goals/subgoals.

The Scenarios include sentences that portray a future situation. It is important to distinguish between Scenarios and Initial conditions: the latter specifies (no matter how - it may be a guess, prediction or whatever) a possible future state of a single variable or force; the former (Scenarios) is deduced from one or more of those states and depicts the resulting situation. The prohibition here excludes future situations that are considered unreasonable.

The Results and the Environment contain references to the past or present state of the organization and its surrounding, respectively.

Finally, the falsification obstructers: as Mindless derivation will be considered those expressions that "delink" the Descriptive Theory from the Scenarios or the other way around. The Causal ambiguity concern unexplainable results or vague means-ends relations; and the Mental irrefuta- 
bility contains expressions of biases or inhibitions along the Environment's assessment. The Logical irrefutability will reflect the unidirectional influence from the normative theory toward the design theory. To be sure, positive expression (i.e. that negates the obstructers) will be cited as well.

Horizontal arrows in the table will be used to denote an explicit link to the neighboring cell; for instance, $\leftarrow$ [scenario] means that the interviewee has distinctly connected the denoted utterance, classified under Scenarios, to the subject of the cell on the left - in this case, High-level goals. Likewise, the notation [high-level goal] $\leftarrow$ signifies a goal to which a Scenario is related.

Data analysis: the aim of the analysis is twofold; for one, to deconstruct the Descriptive Theory toward the design of the testing method; that is, the method will have to be able to represent and to address the discovered facets of the Theory. For two, the aim is to validate the falsification obstructers and to specify their magnitude and attributes, again as the input to the method design. In this sense, low level of obstruction is evidenced by the coherence of the theoretical system, whilst high level is indicated by either poor coherence or explicit expressions of obstructers.

The analysis is mainly textual except for the Mindless derivation, in which we will use an illustrative aid, titled "consistency measure", along the scenarios-based falsification route. The assumption that underlies this measure is that the researcher -

...might search for frequent use of related concepts as indicators of the strategic emphasis of a particular decision maker or group, for example, and then look for the association of these words with other concepts to infer mental connection between important strategic themes. Further judgments might be made about the complexity of these relationships or differences in the use of concepts (Huff, 2000, p. 164; emphasis added).

The sought consistency is between the descriptive theory, the initial conditions, the scenarios and the environment, i.e. the use of the same or akin concepts along this route. Visually the "consistency measure" is a table in which the rows are the concept (the union across the four segments), the columns are the segments, and a "+" indicates the inclusion of the concept in the segment.

No further calculations are implemented, since the presentation "...require[s] relatively little researcher interpretation and judgment. The data are allowed to speak directly..." (Huff, 2000, p. 167). 
Table 5.5. The form of the "consistency measure"

\begin{tabular}{|c|c|c|c|c|}
\hline Concepts & $\begin{array}{c}\text { Descriptive } \\
\text { Theory }\end{array}$ & $\begin{array}{c}\text { Initial } \\
\text { conditions }\end{array}$ & Scenarios & Environment \\
\hline [Concept] & + & + & + & + \\
\hline
\end{tabular}

Analysis confirmation: The synthesized diagnosis will be presented for approval in a plenary meeting in each organization, attended by the respondents and other stakeholders if applicable. The validation and the acknowledgment are the criteria for the phase's success.

\section{Action planning}

This phase materializes the method's design and builds on the framework provided by March \& Smith (1995). Like Walls et al (1992), March \& Smith divide the design into product and process. The combination forms the matrix presented in table 5.6.

The phase actualizes the first three components of the Build activity. Following are the products to be built here (the other activities are elaborated upon the respective phases):

- Constructs: "Constructs or concepts form the vocabulary of a domain. They constitute a conceptualization used to describe problems within the domain and to specify their solutions. They form the specialized language and shared knowledge of a discipline or sub-discipline. [...] Conceptualizations are extremely important in both natural and design science. They define the terms used when describing and thinking about tasks" (March \& Smith, 1995, p. 256).

Table 5.6. A Design Science research framework (edited from: March \& Smith, 1995, p. 255)

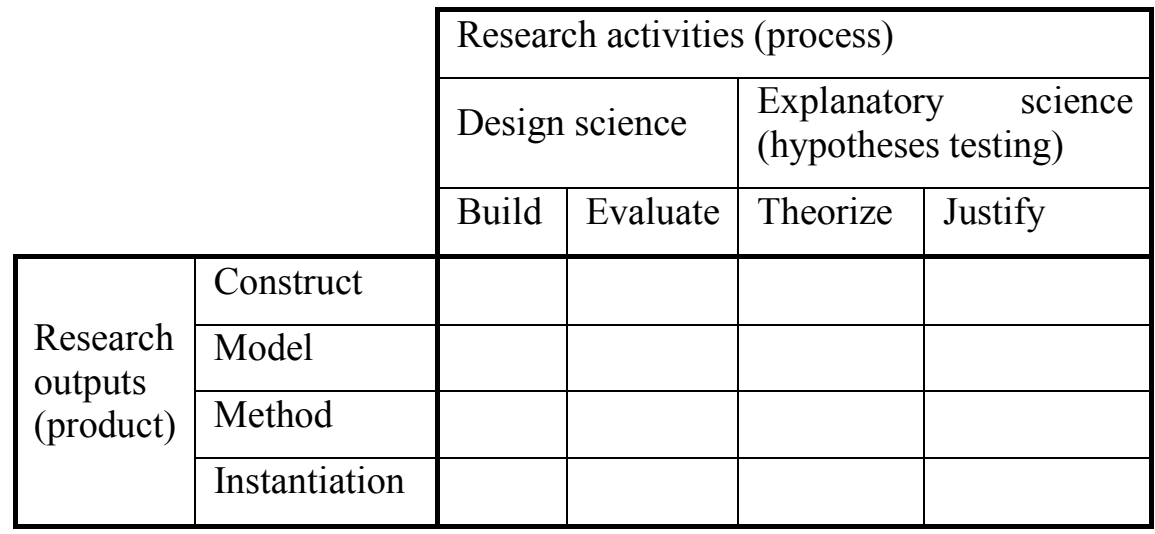


- Model: "A model is a set of propositions or statements expressing relationships among constructs. In design activities, models represent situations as problem and solution statements. A model can be viewed simply as a description, that is, as a representation of how things are. [...] In our framework... the concern of models is utility, not truth ${ }^{32 "}$ (ibid, p. 256). Concerning the model's type and accuracy, "Simulation and mathematical models, for example, can be of immense practical value, although lacking in many details" (ibid, p. 257).

- Method: "A method is a set of steps (an algorithm or guideline) used to perform a task. Methods are based on a set of underlying constructs (language) and a representation (model) of the solution space. [...] Methods can be tied to particular models in that the steps take parts of the model as input. Further, methods are often used to translate from one model or representation to another in the course of solving a problem. [...] The desire to utilize a certain type of method can influence the constructs and models developed for a task" (ibid, p. 257).

It should be clear that these output (the three above plus Instantiation) constitute the ultimate results of the research, namely the countermeasure against unawareness. The criterion for that phase is feasibility: "Build refers to the construction of the artifact, demonstrating that such an artifact can be constructed" (March \& Smith, 1995, p. 258).

\section{Action taking}

In this phase the method is instantiated, in line with the fourth Build activity:

- Instantiation: "An instantiation is the realization of an artifact in its environment. [...] Instantiations operationalize constructs, models, and methods. [...] Instantiations demonstrate the feasibility and effectiveness of the models and methods they contain (ibid, p. 258).

This phase is expected to be the longest of the research, since strategic changes in the environment that may refute the Theory usually take time. Due to our deliberate dependency on real situations, we have no control on the duration.

\footnotetext{
${ }^{32}$ In contrast, March \& Smith (1995) argue that "the concern of [scientific] theories is truth" (p. 256).
} 


\section{Evaluating}

"Evaluate refers to the development of criteria and the assessment of artifact performance against those criteria" (March \& Smith, 1995, p. 258). The following table presents the applicable evaluation criteria that the authors suggest (IT-specific criteria are omitted).

Table 5.7. Criteria for evaluation (based on: March \& Smith, 1995, p. 261)

\begin{tabular}{|c|c|}
\hline $\begin{array}{l}\text { Design } \\
\text { product }\end{array}$ & Evaluation criteria \\
\hline Construct & $\begin{array}{l}\text { Completeness, simplicity, understandability, and ease of } \\
\text { use. }\end{array}$ \\
\hline Model & $\begin{array}{l}\text { Validity, as the result of internal consistency and fidelity } \\
\text { with real world phenomena. }\end{array}$ \\
\hline Method & $\begin{array}{l}\text { Operationality (the ability of humans to effectively use the } \\
\text { method), efficiency, generality, and ease of use. }\end{array}$ \\
\hline Instantiation & $\begin{array}{l}\text { Efficiency and effectiveness of the artifact and its impacts } \\
\text { on the environment and its users. }\end{array}$ \\
\hline
\end{tabular}

The phase will engage the leading figures from the studied organizations through in-depth interviews, in which they will be asked to reflect on the findings. We will compare their evaluations against the empirical data and the researcher's observations.

\section{Specifying learning}

In this phase we materialize the hypotheses testing. The "Theorize" and "Justify" activities that constitute this phase read:

Discover, or more appropriately for IT research, theorize, refers to the construction of theories that explain how or why something happens. In the case of IT research this is primarily an explanation of how or why an artifact works within its environment. Justify refers to theory proving. It requires the gathering of scientific evidence that supports or refutes the theory (March \& Smith, 1995, p. 258).

The "theorize-justify" sequence embodies the critical-rationalist cycle of problems-theories-criticism-new problems: we initiate the AR in order to justify a theory, and re-theorize upon "new problems" encountered in the 
first cycle; the emergent theory will be justified in the second cycle, and so on.

\section{Verification of the Research Design}

In this section we verify that the research design, by applying the principles listed by Davison et al (2004) and Cunha \& Figueiredo (2002), respects the guidelines set by Hevner et al (2004; table 5.2).

Table 5.8. Verification of the Research Design (reference: table 5.2)

\begin{tabular}{|c|c|c|}
\hline & Guideline & Verification \\
\hline 1 & $\begin{array}{l}\text { Design as an } \\
\text { Artifact }\end{array}$ & $\begin{array}{l}\text { The design applies all the four components that form } \\
\text { a viable artifact: constructs, model, method and } \\
\text { instantiation. Both phases of action planning and } \\
\text { action taking address this guideline. }\end{array}$ \\
\hline \multirow[t]{2}{*}{2} & $\begin{array}{l}\text { Problem } \\
\text { Relevance }\end{array}$ & $\begin{array}{l}\text { The case for the practical problem was established } \\
\text { prior to the research, in chapter } 1 \text {. The significance of } \\
\text { the problem was further demonstrated by the curing } \\
\text { efforts reviewed in chapter } 4 \text {. }\end{array}$ \\
\hline & & $\begin{array}{l}\text { Along the research the relevance is confirmed upon } \\
\text { the researcher-client agreement in which the } \\
\text { participants commit themselves to the problem. Then } \\
\text { the problem diagnosis phase validates the relevance } \\
\text { and tunes the problem to the specific participants. }\end{array}$ \\
\hline 3 & $\begin{array}{l}\text { Design } \\
\text { Evaluation }\end{array}$ & $\begin{array}{l}\text { The evaluation is a distinguished phase strictly } \\
\text { aligned with the artifact. The evaluation rests upon } \\
\text { Cunha \& Figueiredo's (2002) principles concerning } \\
\text { careful data collection, focus on agreements and } \\
\text { disagreements, diversity and multiplicity of data. }\end{array}$ \\
\hline 4 & $\begin{array}{l}\text { Research } \\
\text { Contributions }\end{array}$ & $\begin{array}{l}\text { The research contributes to both scientific and } \\
\text { practitioners' communities. The former is benefited } \\
\text { by literally the "growth of knowledge", as a superior } \\
\text { theory supersedes an inferior one, and by the } \\
\text { experience added to the AR utilization. The latter is } \\
\text { exposed to an underused epistemological stance that } \\
\text { has been discredited (for that context), enhances the } \\
\text { problem recognition's ability and is equipped with a } \\
\text { practical method. }\end{array}$ \\
\hline 5 & Research Rigor & $\begin{array}{l}\text { The rigor obtains the logical validity conveyed by } \\
\text { critical rationalism. Rigor is also gained through the } \\
\text { theoretical foundation, the established methodology, }\end{array}$ \\
\hline
\end{tabular}




\begin{tabular}{ll}
\hline \multicolumn{1}{c}{ Guideline } & \multicolumn{1}{c}{ Verification } \\
\hline & $\begin{array}{l}\text { the change-through-action principle that verifies the } \\
\text { independent variables and the careful distinction } \\
\text { between facts and judgments. } \\
\text { The search process is expressed by the cyclicality and } \\
\text { the enduring attempt to revise and falsify the } \\
\text { hypotheses, which is the essence of the "specifying } \\
\text { learning" phase. }\end{array}$ \\
$\begin{array}{ll}\text { Search Process } \\
\text { of Research }\end{array}$ & $\begin{array}{l}\text { The research is documented in details and published. } \\
\text { of }\end{array}$ \\
\hline
\end{tabular}




\section{Action Research, Cycle I: Introduction and Problem Diagnosis}

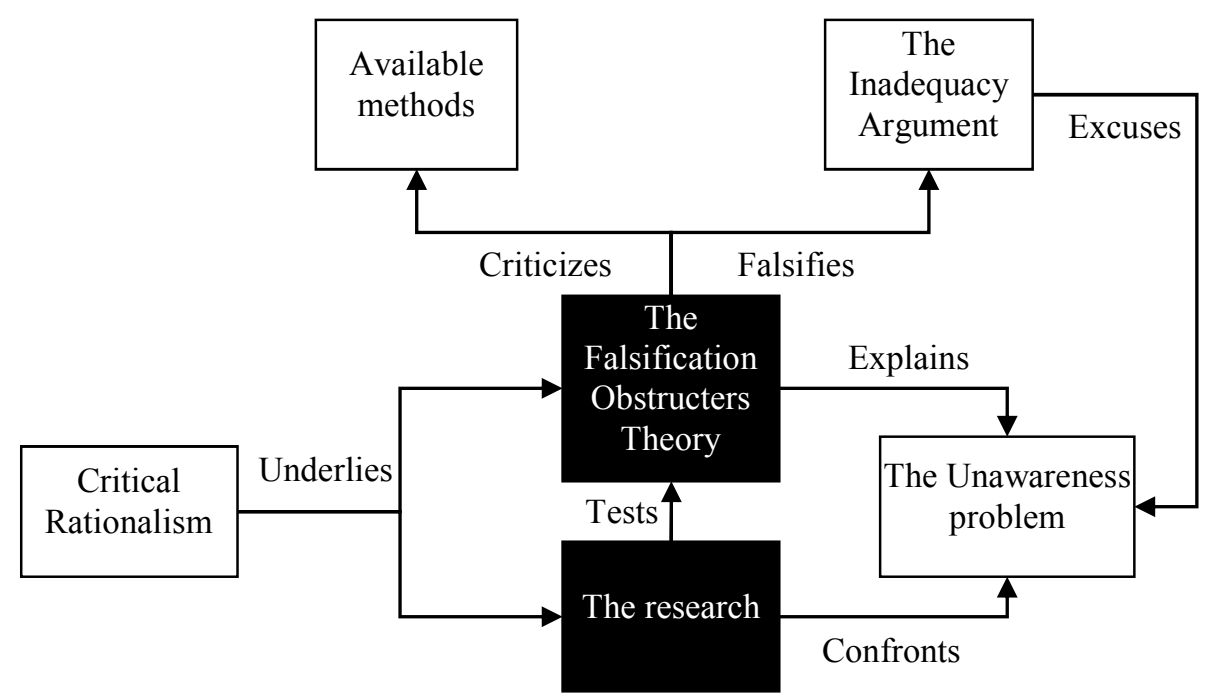

Figure 6.0. The focus of the chapter (blackened)

\section{The Participants}

The $1^{\text {st }}$ cycle involved two participants, varied by their motivation to engage and by their characteristics. Hereinafter they are identified as IND and EDU. The research was conducted at both simultaneously while each is unbeknown to the other, being the researcher the sole linking connector. The period in point is 2002-2006, and the following details are updated as of the research's outset.

IND is an Israeli medium high-tech manufacturer of video streaming equipment. The company is vertically integrated along its product line, from R\&D through production to worldwide marketing and sales. Horizontally, however, the company largely depends on the environment since its products should be integrated in complex systems beyond the company's control. The company consisted of headquarter (HQ) and two SBUs: one engaged in TV broadcasting over telephone wires and the other in video encoding (all the three units participated). Short before the research the dotcom bubble had exploded, driving the environment into extreme turbulence during the research.

IND joined a research project funded by the European Commission, aimed at studying and developing knowledge management practices in small and medium enterprises. The research was part of this project, so the official 
project contract covered the researcher-client agreement. It so happened that the research started a few months after the company had crafted its strategy, and this accidental proximity made the investigation relevant and vivid.

EDU is an Israeli academic college of engineering. It is a public NGO, budgeted by the national Council for Higher Education (CHE). EDU maintains five programs toward an engineering degree, each in a department: mechanical engineering, electronics, bio-technology, software and industrial engineering.

A brief background: up to the 1990s the higher education system in Israel consisted of seven research universities, all in big cities. Since demand for academic education has outnumbered the supply, the universities could be selective; consequently academic degree remained exclusive, associated with high socio-economic status. The government encountered massive pressure to enhance social mobility through education, meaning more universities; alas, universities are costly. The CHE adopted another idea: to establish colleges, dedicated solely for teaching first degrees (i.e. no research); it was assumed a much cheaper alternative. In order to attain another social objective, to boost the periphery, most colleges ought to be located in small and distant towns. EDU, among other, was the outcome of this policy: an academic school of engineering in northern Israel. At the same time several private colleges were also licensed, all in central areas (and with much higher tuition). Consequently, the education supply has increased significantly in a very short time. The instant increase introduced all the academic institutions in Israel (including universities) to an unfamiliar playground: market competition.

For long, public academic institutions around the world have not been associated with competitive thinking; it was strange to the "ivory tower" image. However, major social changes did affect the academia (Brown \& Duguid, 2000), and business practices - competitive strategy included - made their way into the board room (e.g. Morrison \& Mecca, 1989). Nevertheless the strategic thinking idea remained unfamiliar with EDU, and when the newlyarrived president acknowledged the need for formal strategy he asked for advice. I proposed to integrate the research within the strategic process, and the president - acquainted with academic research, to be sure - accepted. That was the platform on which the researcher-client agreement was established.

Strategy is regarded confidential; the participants were explicitly aware of the publicity this research would receive, and agreed. Anyway, the lasting of the research made the content outdated and competitively valueless. For the sake of privacy neither the organizations nor the involved individuals are named. Table 6.1 summarizes the identifying details of both participants. 
Table 6.1. "ID card" of the $1^{\text {st }}$ cycle's participants

\begin{tabular}{lll}
\hline Alias & IND & EDU \\
Identity & High-tech manufacturer & Academic college \\
Industry & Video streaming & Higher education \\
$\begin{array}{l}\text { Ownership } \\
\begin{array}{l}\text { Size (number of } \\
\text { employees) }\end{array}\end{array}$ & $\begin{array}{l}\text { Public enterprise } \\
\text { Budgeted NGO }\end{array}$ & 250 \\
$\begin{array}{l}\text { Structure } \\
\begin{array}{l}\text { Range of } \\
\text { activities }\end{array}\end{array}$ & $\begin{array}{l}\text { Vertically integrated: from } \\
\text { R\&D to selling }\end{array}$ & $\begin{array}{l}\text { President, five faculties, } \\
\text { administration } \\
\text { fre-academic studies, } 1^{\text {st }} \\
\text { engineering }\end{array}$ \\
\hline
\end{tabular}

\section{Data Collection}

The data, as planned for this phase, was collected through semi-structured, face-to-face and one-on-one interviews. Each interview lasted between 1-2 hours. The interviews were conducted in Hebrew, taped or transcribed in real-time. Upon translation I tried to keep as much fidelity as possible while at the same time to convey the meaning across the languages. Editing was slightly exercised when required to enhance readability, but in essence the data is conveyed almost literally.

In IND four senior executives were interviewed: the president, the marketing director (also in charge of strategic planning), the chief operation officer and the R\&D director. In EDU I conducted seven interviews with: the vice president for academic affairs, three faculty deans, one senior lecturer and two administrators. The identity of each individual interviewee is concealed.

\section{IND}

IND's interviewees had much experience in strategic thinking, a process they had undergone many times (recently as well). Consequently they could mention many insights and examples they had obtained in previous instances. Their expressions are presented in table $6.2^{33}$.

\footnotetext{
${ }^{33}$ The numbers in square parentheses are indexes to the raw data.
} 
Table 6.2. IND's expressions

\begin{tabular}{|l|l|}
\hline & $\begin{array}{l}\text { Descriptive Theory } \\
\text { What are the interdependencies among the forces that are } \\
\text { relevant for me [13]. } \\
\text { We assume that the same attribute [that the market is price- } \\
\text { sensitive] will hold in the future. I don't have any way to } \\
\text { check it but retroactively [154]. } \\
\text { Driving forces: customers, market players, regulation, } \\
\text { technological advances [15-20]. The market size and the } \\
\text { amount of competitors [701]. } \\
\text { The product's decline is influenced by both customers and } \\
\text { new technology... [32]. } \\
\text { The market is price-sensitive [154]. } \\
\text { The world is divided into MPEG and non-MPEG. The } \\
\text { value chain contains platforms, components, applications } \\
\text { and solutions [171]. } \\
\text { The technology has the most significant influence on the } \\
\text { company [277]. } \\
\text { The forces that influence the technology's trends are the } \\
\text { standardization bodies, the big industrial companies } \\
\text { (sometimes against the standardization bodies). There are } \\
\text { also market trends, which are hard to detect; there is a } \\
\text { social dimension there [291]. } \\
\text { Besides the technology, the trend will be influenced by the } \\
\text { demand, e.g. the big broadcasters [330]. } \\
\text { The [customers'] market consists of the Telco's and the } \\
\text { cables companies and is split between them [503]. } \\
\text { We have a hidden assumption that the technology } \\
\text { progresses gradually, that a new technology will not pop } \\
\text { up out of a sudden [512]. } \\
\text { There are macro-economic influences, standardization, and } \\
\text { transfer of large bodies to new technologies [543]. } \\
\text { Video is a psychological need, easily given up [579]. }\end{array}$ \\
\hline & \multicolumn{1}{|c|}{$\begin{array}{l}\text { Mindless derivation } \\
\text { the strategic thinking. Some } \\
\text { scenarios came up here and there } \\
\text { sporadically [210]. }\end{array}$} \\
\hline
\end{tabular}


Table 6.2. IND's expressions

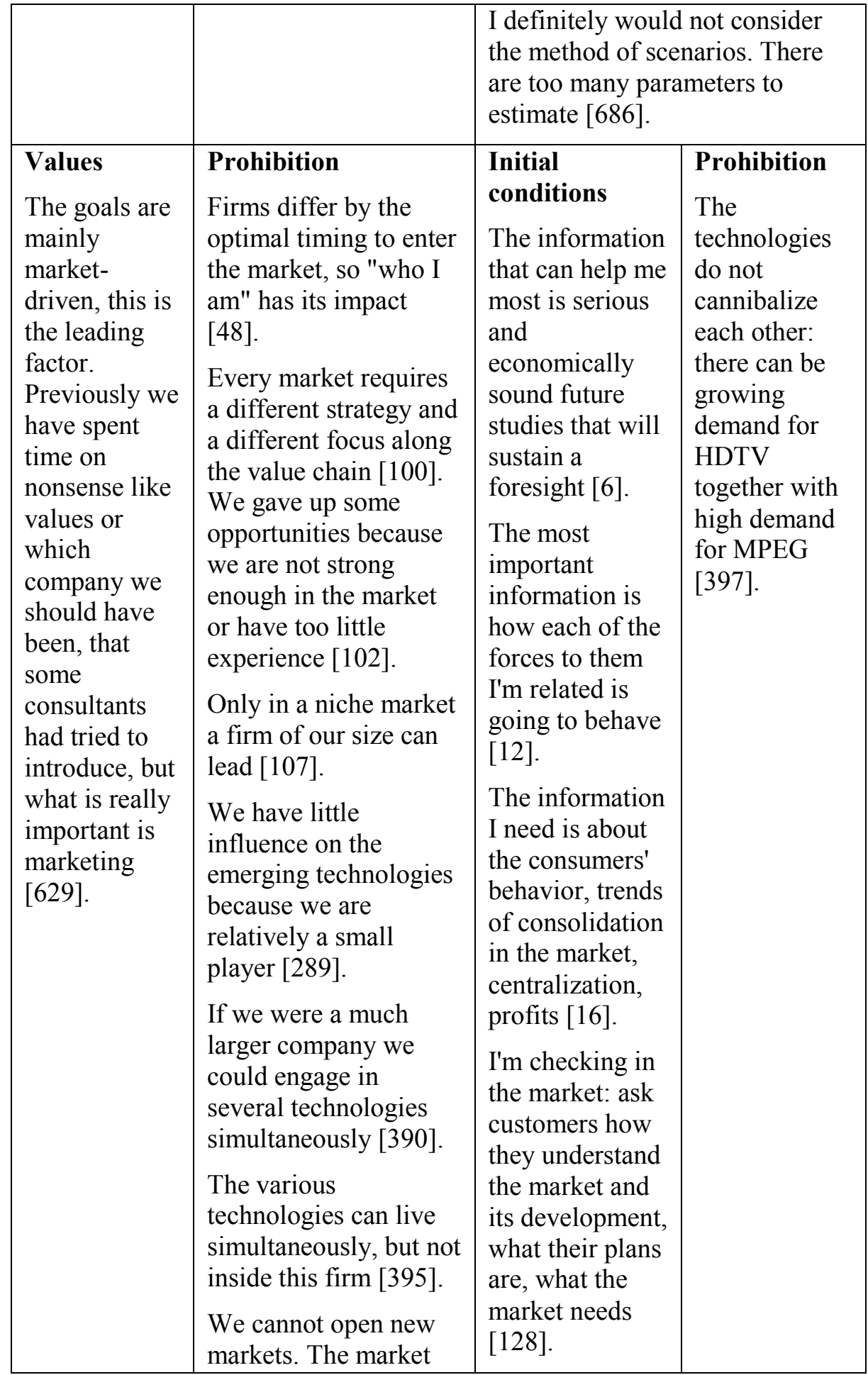


Table 6.2. IND's expressions

\begin{tabular}{|l|l|l|}
\hline $\begin{array}{l}\text { must be prepared with } \\
\text { infrastructure before it } \\
\text { can utilize our } \\
\text { products [543]. }\end{array}$ & $\begin{array}{l}\text { We maintain } \\
\text { much activity in } \\
\text { order to search } \\
\text { for the } \\
\text { emerging } \\
\text { technologies } \\
{[287] .} \\
\text { The product } \\
\text { managers are } \\
\text { expected to } \\
\text { provide the } \\
\text { answer about } \\
\text { what the market } \\
\text { demands [416]. } \\
\text { The most } \\
\text { important } \\
\text { information is } \\
\text { what the big } \\
\text { players in the } \\
\text { market will do } \\
\text { [540]. } \\
\text { The main } \\
\text { problem is that } \\
\text { we are not good } \\
\text { enough at } \\
\text { anticipating the } \\
\text { future of the } \\
\text { market [636]. } \\
\text { Most of the } \\
\text { initial } \\
\text { assumptions are } \\
\text { proved wrong. } \\
\text { The challenge is } \\
\text { to make the } \\
\text { right estimate } \\
\text { and to verify the } \\
\text { estimation over } \\
\text { time [687]. } \\
\text { When will } \\
\text { regulations be } \\
\text { issued? When } \\
\text { will the market }\end{array}$ \\
\hline
\end{tabular}


Table 6.2. IND's expressions

\begin{tabular}{|c|c|c|}
\hline & & $\begin{array}{l}\text { be obliged to } \\
\text { adopt the } \\
\text { standard? [330] } \\
\text { In order to } \\
\text { decide whether } \\
\text { or not to enter } \\
\text { the HDTV } \\
\text { market we need } \\
\text { solid } \\
\text { information } \\
\text { about the } \\
\text { market trends: } \\
\text { the regulation, } \\
\text { schedule of the } \\
\text { infrastructure, } \\
\text { places and } \\
\text { amounts. From } \\
\text { the regulation } \\
\text { one can derive } \\
\text { the market } \\
\text { trends [404]. }\end{array}$ \\
\hline $\begin{array}{l}\text { Ultimate } \\
\text { goals } \\
\text { To lead the } \\
\text { market, to } \\
\text { grow [95]. } \\
\text { To earn } \\
\text { money [700]. }\end{array}$ & $\begin{array}{l}\text { High-level goals } \\
\text { Focus on customers in } \\
\text { the local community } \\
\text { level, rather than the } \\
\text { nation-wide Telco's } \\
{[555] . \leftarrow} \\
\text { Adoption of MPEG } \\
\text { [560]. } \leftarrow \\
\text { To produce the most } \\
\text { profitable product } \\
{[701] .}\end{array}$ & $\begin{array}{l}\text { Scenarios } \\
\text { The required information is } \\
\text { which markets are going to grow } \\
\text { in my business environment [11]. } \\
\leftarrow \text { Because we have to decide } \\
\text { which strategic courses to take. } \\
\text { Should we focus on this or that } \\
\text { market? [24]. } \\
\leftarrow \text { What are the competitors } \\
\text { doing and which share of the } \\
\text { market each is taking? This will } \\
\text { determine my choice [26]. } \\
\text { Today I count mainly on market } \\
\text { research available on the shelf } \\
\text { [38]. } \\
\leftarrow \text { Based on this rough } \\
\text { "guesstimation" I'm going to } \\
\text { make my decision [54]. } \\
\leftarrow \text { In order to choose among the }\end{array}$ \\
\hline
\end{tabular}


Table 6.2. IND's expressions

\begin{tabular}{|l|l|}
\hline & alternative courses of action I \\
have to compare the market \\
opportunities. A market \\
opportunity is the prospect of \\
size and growth [84]. \\
The most important information \\
that I need is which technology \\
will be the most significant in a \\
year from now [265]. \\
$\leftarrow$ I mean the specific \\
technology that can differentiate \\
us against the competitors [268]. \\
First of all I have to know which \\
technology will be demanded by \\
the market, then whether we can \\
and wish to develop that \\
technology [274]. \\
$\leftarrow$ We need feedback from the \\
market about the products that \\
will be requested [407]. \\
$\leftarrow$ First we look at the market \\
and try to understand its trends, \\
and then we look inside and \\
check what we can offer [436]. \\
When the product reaches its \\
lifecycle's end consolidation will \\
follow, firms will go bankrupt \\
[29]. \\
$\leftarrow$ Based on this forecast I have \\
to decide whether to invest more \\
in this product line or to exploit \\
it till its end. The growth \\
determines the decision when to \\
enter the market [45]. \\
We estimate that in 2003 the \\
same quantity level will hold, \\
may be even slightly increases, \\
but because the prices drop down \\
the revenues will remain the \\
same [58].
\end{tabular}


Table 6.2. IND's expressions

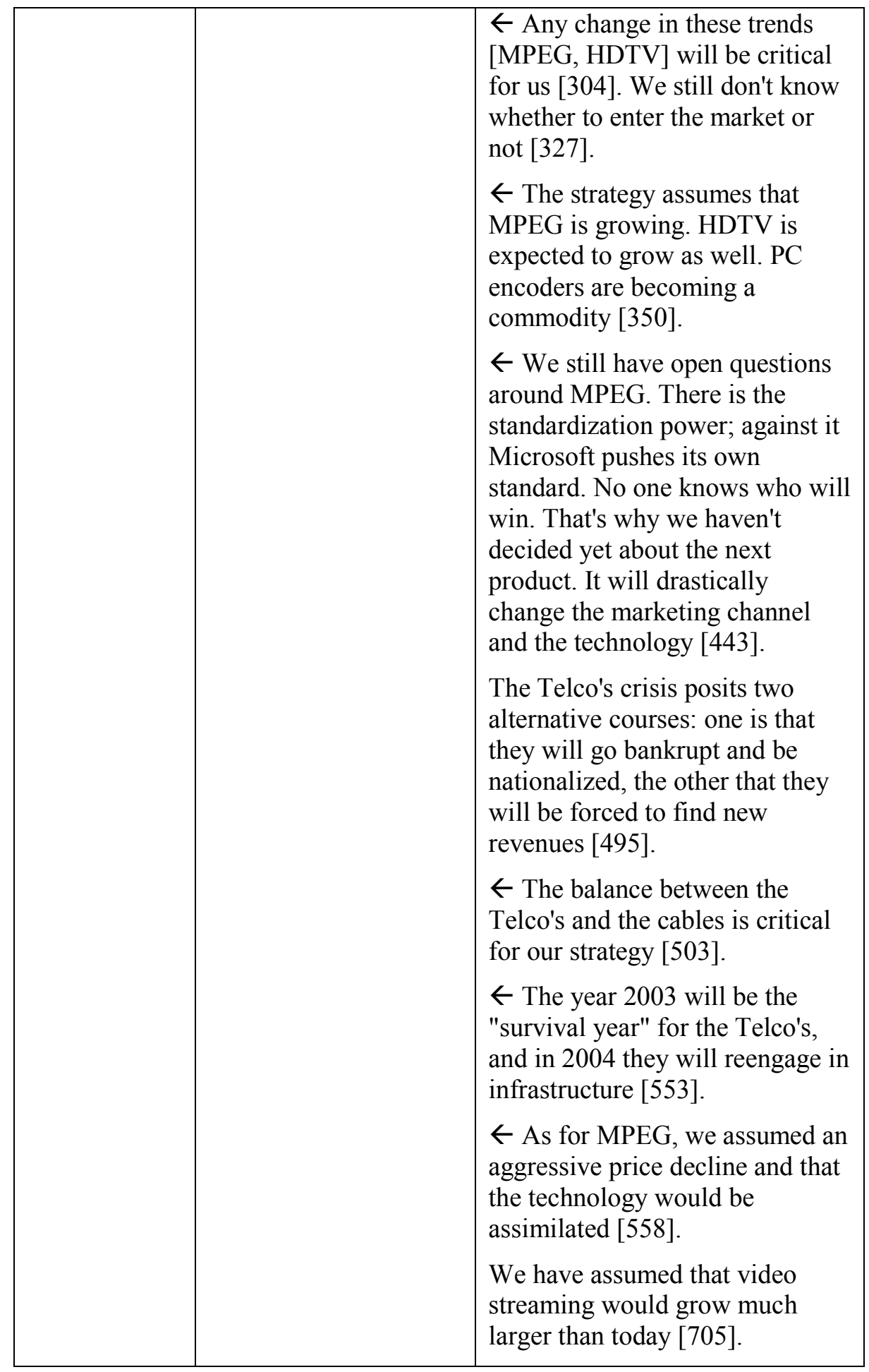


Table 6.2. IND's expressions

\begin{tabular}{|c|c|c|}
\hline $\begin{array}{l}\text { Logical } \\
\text { irrefutability }\end{array}$ & $\begin{array}{l}\text { Causal ambiguity } \\
\text { We ask our customers: } \\
\text { will we sell more if we } \\
\text { do such-and-such } \\
\text { [140]? We don't } \\
\text { always ask the same } \\
\text { questions; after each } \\
\text { session we rethink and } \\
\text { ask other questions } \\
\text { [142]. } \\
\text { At some point you see } \\
\text { that you can't get more } \\
\text { information, still must } \\
\text { make a decision [383]. } \\
\text { We have to proceed } \\
\text { and see what will } \\
\text { happen to the product } \\
\text { [389]. } \\
\text { We have made quite a } \\
\text { progress in information } \\
\text { processing. Many } \\
\text { inputs arrive from } \\
\text { customers. But the } \\
\text { distance between } \\
\text { understanding the } \\
\text { market and } \\
\text { transforming this } \\
\text { understanding to a } \\
\text { product is still long } \\
\text { [649]. } \\
\text { The problems I've } \\
\text { identified were: (1) the } \\
\text { firm is not focused, } \\
\text { and (2) we lead none } \\
\text { of the markets wherein } \\
\text { we're engaged. Then I } \\
\text { tried to discover the } \\
\text { actual strategy that the } \\
\text { firm has been } \\
\text { implementing and } \\
\text { looked for correlations } \\
\text { [167]. }\end{array}$ & 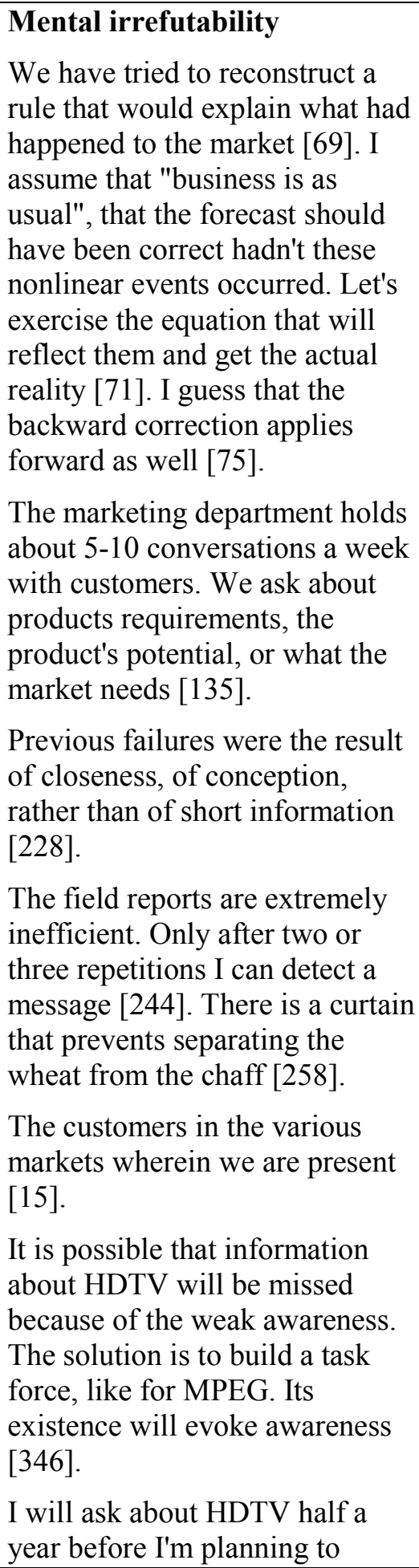 \\
\hline
\end{tabular}


Table 6.2. IND's expressions

\begin{tabular}{|l|l|l|}
\hline & $\begin{array}{l}\text { We are not alone in the } \\
\text { market, so if our } \\
\text { product is declined the } \\
\text { reason may be that a } \\
\text { competitor offered a } \\
\text { better or a cheaper } \\
\text { product [360]. }\end{array}$ & develop the product [420]. \\
\hline $\begin{array}{l}\text { Subgoals } \\
\text { If I add some features } \\
\text { to my product I'll gain } \\
\text { a 40\% market share } \\
\text { [152]. }\end{array}$ & \\
$\begin{array}{l}\text { Previously we have } \\
\text { failed because we } \\
\text { hadn't focused on a } \\
\text { niche [714]. } \\
\text { We depend on big } \\
\text { customers much less } \\
\text { than before. We have } \\
\text { spread the risk, } \\
\text { although it decreased } \\
\text { our sales [659]. }\end{array}$ & \\
\hline $\begin{array}{l}\text { Sub-subgoals } \\
\text { Results }\end{array}$ & \\
\hline I've started the \\
strategic thinking from \\
the firm's problem: \\
why it isn't succeeding \\
[165]. \\
The best indicator, \\
although too late, is \\
how the product is \\
accepted in the market \\
[356]. \\
$\begin{array}{l}\text { Besides the calendar, } \\
\text { strategic rethinking is } \\
\text { triggered by extreme } \\
\text { changes: loses, } \\
\text { "bleeding" [623]. }\end{array}$ & $\begin{array}{l}\text { I wish I had a system that could } \\
\text { track my [initial] assumptions } \\
\text { and make me recheck them } \\
\text { [237]. } \\
\text { We try to understand the market } \\
\text { before we enter it based on } \\
\text { interviews with customers... All } \\
\text { the time recheck our initial } \\
\text { assumptions [364]. } \\
\text { We direct the field reports, we } \\
\text { the sales persons. The template } \\
\text { points to permanent issues rather } \\
\text { than changing questions. I often } \\
\text { respond following such a report: }\end{array}$ \\
\hline
\end{tabular}


Table 6.2. IND's expressions

\begin{tabular}{|c|c|}
\hline $\begin{array}{l}\text { In the strategic } \\
\text { discussions we look } \\
\text { backward and checked } \\
\text { whether we have } \\
\text { attained our goals } \\
\text { [628]. } \\
\text { Sales data are an } \\
\text { excellent indication, } \\
\text { retrospective } \\
\text { notwithstanding [668]. } \\
\text { It certainly can } \\
\text { indicate future trends } \\
\text { [678]. } \\
\text { Our sales are declining } \\
\text { [42]. }\end{array}$ & $\begin{array}{l}\text { is any specific trend } \\
\text { recognizable? [591]. We also } \\
\text { lean on suppliers and OEM } \\
\text { channels. The technological } \\
\text { information streams from the } \\
\text { R\&D and the marketing staff } \\
\text { alike [597]. } \\
\text { Today our estimations are much } \\
\text { more conservative and cautious. } \\
\text { We don't throw numbers but } \\
\text { validate them with the customers } \\
\text { [615]. } \\
\text { In the strategic discussions we } \\
\text { look forward to see whether what } \\
\text { we have planned does } \\
\text { materialize [629]. } \\
\text { The terror attack in the US, the } \\
\text { stock crisis, and other factors } \\
\text { caused the market's decline [51]. } \\
\text { I'm identifying two areas in } \\
\text { which I see intensive activity: } \\
\text { one is MPEG and the other is } \\
\text { HDTV [297]. } \\
\text { Concerning MPEG, we have an } \\
\text { interface with the standardization } \\
\text { bodies; we are also informed via } \\
\text { exhibitions. In exhibitions we } \\
\text { investigate specific topics: what } \\
\text { the companies offer, what the } \\
\text { customers want [310]. } \\
\text { We have created deep awareness } \\
\text { of MPEG in the company: } \\
\text { anyone who sees something is } \\
\text { expected to tell [314]. } \\
\text { We've started asking our } \\
\text { suppliers who has appropriate } \\
\text { technology for the HDTV } \\
\text { standard [325]. } \\
\text { Signals that the market follows } \\
\text { the course we've predicted: }\end{array}$ \\
\hline
\end{tabular}


Table 6.2. IND's expressions

\begin{tabular}{|l|l|}
\hline & MPEG infrastructure, supporting \\
& technologies, citations in \\
& technological periodicals, video \\
& services [573]. \\
\hline
\end{tabular}

\section{$E D U$}

EDU's interviewees were unfamiliar with the strategy's notion, therefore had no former experience on which they could rely; an indicative example is the statement made by a faculty dean: "I have never asked myself how the college's environment would look like in the next five years". EDU's expressions are presented in table 6.3.

Table 6.3. EDU's expressions

\begin{tabular}{|l|l|}
\hline $\begin{array}{l}\text { Descriptive Theory } \\
\text { "College" is different from "university" [2]. } \\
\text { Educational telecommunication enhances learning abilities } \\
\text { [6]. } \\
\text { The academic competitive arena is divided to three } \\
\text { leagues: universities, national colleges, and regional } \\
\text { colleges [6]. } \\
\text { The competition is driven by prestige and the market's } \\
\text { evaluation [7]. } \\
\text { There is a feedback loop between the students and the } \\
\text { faculty. More high-level students add prestige; the } \\
\text { allocated budget increases, resulting in more attractiveness } \\
\text { for new faculty members. Consequently the students are } \\
\text { more satisfied [7]. } \\
\text { More students bring more resources and more staff } \\
\text { positions [23]. } \\
\text { The Israeli student expects to get more than just } \\
\text { professional knowledge [8]. } \\
\text { Part of the added value for the student is the institution's } \\
\text { name on the diploma [11]. } \\
\text { Students prefer close teachers-students relations [10]. } \\
\text { The borders today are less clear than a century ago: the } \\
\text { professional spectrum is continuous rather than discrete; }\end{array}$ \\
\hline
\end{tabular}


Table 6.3. EDU's expressions

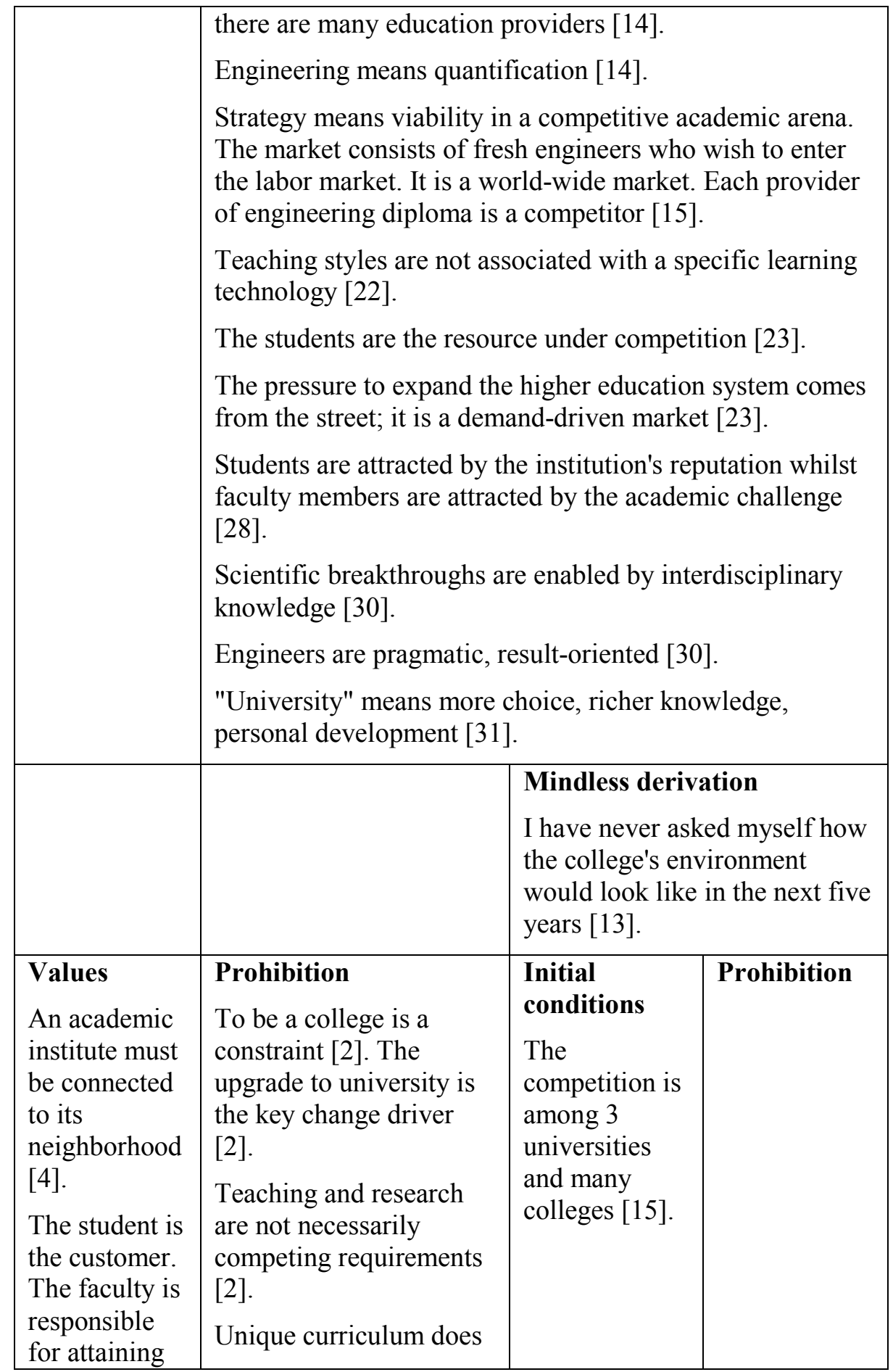


Table 6.3. EDU's expressions

\begin{tabular}{|l|l|l|}
\hline the student's & not make a difference; it & \\
goals [5]. & is easily duplicated [3]. & \\
Commitment & The Council for Higher & \\
for & Education (CHE) is a & \\
continuous & restricting force [4]. & \\
renewal [8]. & Local training facility & \\
Our mission & will always be needed; & \\
is to provide & full distant learning is & \\
low-cost & impossible [4]. & \\
engineering & The university is & \\
education. & evaluated on research & \\
That's what & basis. Our quality & \\
we have been & criterion is the teaching & \\
established & level. We have to & \\
for [11]. & compete on service [7]. & \\
There should & It is difficult to be good \\
be tight & across many disciplines. \\
connection & Focus is mandatory [10]. \\
with the & Improved teaching is not & \\
community. & impossible within the & \\
The town & \\
should feel & traditional methods [19]. \\
contributed & Without unique offerings & \\
[12]. & the survival is in danger & \\
As a public & [24]. Advances in \\
institution & teaching methods alone & \\
which is & are not enough for & \\
budgeted by & attracting more students & \\
the state we & [24]. \\
have to pay & The focus on research at \\
back [13]. & the universities comes at & \\
We must & the expense of teaching & \\
involve the & quality. The less & \\
CHE. How & qualified students that & \\
come we & enter the colleges need & \\
suddenly & stronger support [26]. & \\
have our own & Research orientation is \\
desires?! [13]. & intrinsic, not an institu- \\
Our customer & tional imperative, and I & \\
\end{tabular}


Table 6.3. EDU's expressions

\begin{tabular}{|c|c|c|}
\hline $\begin{array}{l}\text { is the } \\
\text { industry, not } \\
\text { the student } \\
\text { [15]. }\end{array}$ & $\begin{array}{l}\text { doubt whether engineers } \\
\text { have such an inclination } \\
\text { [29]. }\end{array}$ & \\
\hline $\begin{array}{l}\text { The student is } \\
\text { not expected } \\
\text { to be an } \\
\text { autonomous } \\
\text { learner [27]. }\end{array}$ & & \\
\hline $\begin{array}{l}\text { Studies } \\
\text { should be } \\
\text { interesting. } \\
\text { Academic } \\
\text { learning } \\
\text { means open } \\
\text { mind [29]. }\end{array}$ & & \\
\hline $\begin{array}{l}\text { We don't have } \\
\text { to listen to } \\
\text { each student } \\
\text { [30]. }\end{array}$ & & \\
\hline $\begin{array}{l}\text { It is } \\
\text { academically } \\
\text { improper to } \\
\text { target the } \\
\text { industry [31]. }\end{array}$ & & \\
\hline $\begin{array}{l}\text { The college } \\
\text { has to enrich } \\
\text { the } \\
\text { community } \\
\text { [31]. }\end{array}$ & & \\
\hline \multirow{4}{*}{$\begin{array}{l}\text { Ultimate } \\
\text { goals } \\
\text { Our mission } \\
\text { is to teach; } \\
\text { research is a } \\
\text { means to keep } \\
\text { the faculty } \\
\text { updated [1]. }\end{array}$} & High-level goals & Scenarios \\
\hline & $\begin{array}{l}\text { Relevance of the } \\
\text { curriculum for the } \\
\text { market [1]. }\end{array}$ & \multirow{3}{*}{$\begin{array}{l}\text { The traditional frame of } \\
\text { course-teacher-students will } \\
\text { hold [3]. } \\
\text { Distant learning will not } \\
\text { replace the traditional method } \\
\text { in the next } 5 \text { years [10]. } \\
\text { Mechanical engineering is a }\end{array}$} \\
\hline & $\begin{array}{l}\rightarrow \text { We'll be the first } \\
\text { choice if we offer high } \\
\text { value: a combination of }\end{array}$ & \\
\hline & academic level, learning & \\
\hline
\end{tabular}


Table 6.3. EDU's expressions

\begin{tabular}{|c|c|c|}
\hline $\begin{array}{l}\text { To be } \\
\text { attractive for } \\
\text { students [3]. } \\
\text { To be a } \\
\text { regional } \\
\text { intellectual } \\
\text { center [4]. } \rightarrow \\
\text { To be in the } \\
\text { national } \\
\text { league [6]. } \\
\text { To equip the } \\
\text { students with } \\
\text { updated } \\
\text { knowledge as } \\
\text { much as skills } \\
\text { for analysis, } \\
\text { criticism and } \\
\text { assessment } \\
\text { [6]. } \\
\text { To be the first } \\
\text { choice for any } \\
\text { student in the } \\
\text { country in our } \\
\text { field [10]. } \rightarrow \\
\text { To attract } \\
\text { students from } \\
\text { all over the } \\
\text { country [11]. } \\
\text { To be an } \\
\text { independent } \\
\text { institution } \\
{[11] \text {. }} \\
\text { To be the } \\
\text { engineering } \\
\text { knowledge } \\
\text { center for the } \\
\text { north of the } \\
\text { country [12]. }\end{array}$ & $\begin{array}{l}\text { environment, and } \\
\text { convenience [10]. } \\
\text { To grow to } 5000 \\
\text { students [25]. }\end{array}$ & $\begin{array}{l}\text { classic discipline; no } \\
\text { revolutions are expected } \\
\text { beyond one or two new sub- } \\
\text { fields of expertise [11]. } \\
\text { Nothing will replace the basic } \\
\text { teaching instruments: } \\
\text { blackboard, chalk and } \\
\text { laboratory [17]. } \\
\text { The future teaching will } \\
\text { integrate technological } \\
\text { instruments with enhanced } \\
\text { personal relations: less frontal } \\
\text { classes, more projects and } \\
\text { personal facilitation. Still the } \\
\text { disciplinary expertise [rather } \\
\text { than the teaching skills] of the } \\
\text { teacher will remain the key } \\
\text { consideration [26]. } \\
\text { The information in the future } \\
\text { will be rich with connections, } \\
\text { metadata and multimedia [21]. } \\
\text { If the planned cluster of } \\
\text { northern colleges materializes, } \\
\text { it will fix our identity as an } \\
\text { engineering college [4]. }\end{array}$ \\
\hline
\end{tabular}


Table 6.3. EDU's expressions

\begin{tabular}{|c|c|c|}
\hline $\begin{array}{l}\text { We have to } \\
\text { decide in } \\
\text { which league } \\
\text { we play: the } \\
\text { colleges or } \\
\text { the } \\
\text { universities } \\
\text { [14]. } \\
\text { To produce } \\
\text { graduates } \\
\text { whose } \\
\text { contribution } \\
\text { is } \\
\text { recognizable } \\
\text { by the } \\
\text { industry [17]. }\end{array}$ & & \\
\hline $\begin{array}{l}\text { Logical } \\
\text { irrefutability } \\
\text { I have chosen } \\
\text { the university } \\
\text { where I } \\
\text { learned } \\
\text { because a } \\
\text { renowned } \\
\text { professor } \\
\text { whom I'd } \\
\text { heard about } \\
\text { from my } \\
\text { school } \\
\text { teacher. } \\
\text { That's how } \\
\text { my daughters } \\
\text { made their } \\
\text { choice years } \\
\text { later [28]. }\end{array}$ & $\begin{array}{l}\text { Causal ambiguity } \\
\text { I don't know what makes } \\
\text { the student mentally } \\
\text { mature [16]. }\end{array}$ & Mental irrefutability \\
\hline & $\begin{array}{l}\text { Subgoals } \\
\text { Learning skills are the } \\
\text { key for future success } \\
{[1] .}\end{array}$ & \\
\hline
\end{tabular}


Table 6.3. EDU's expressions

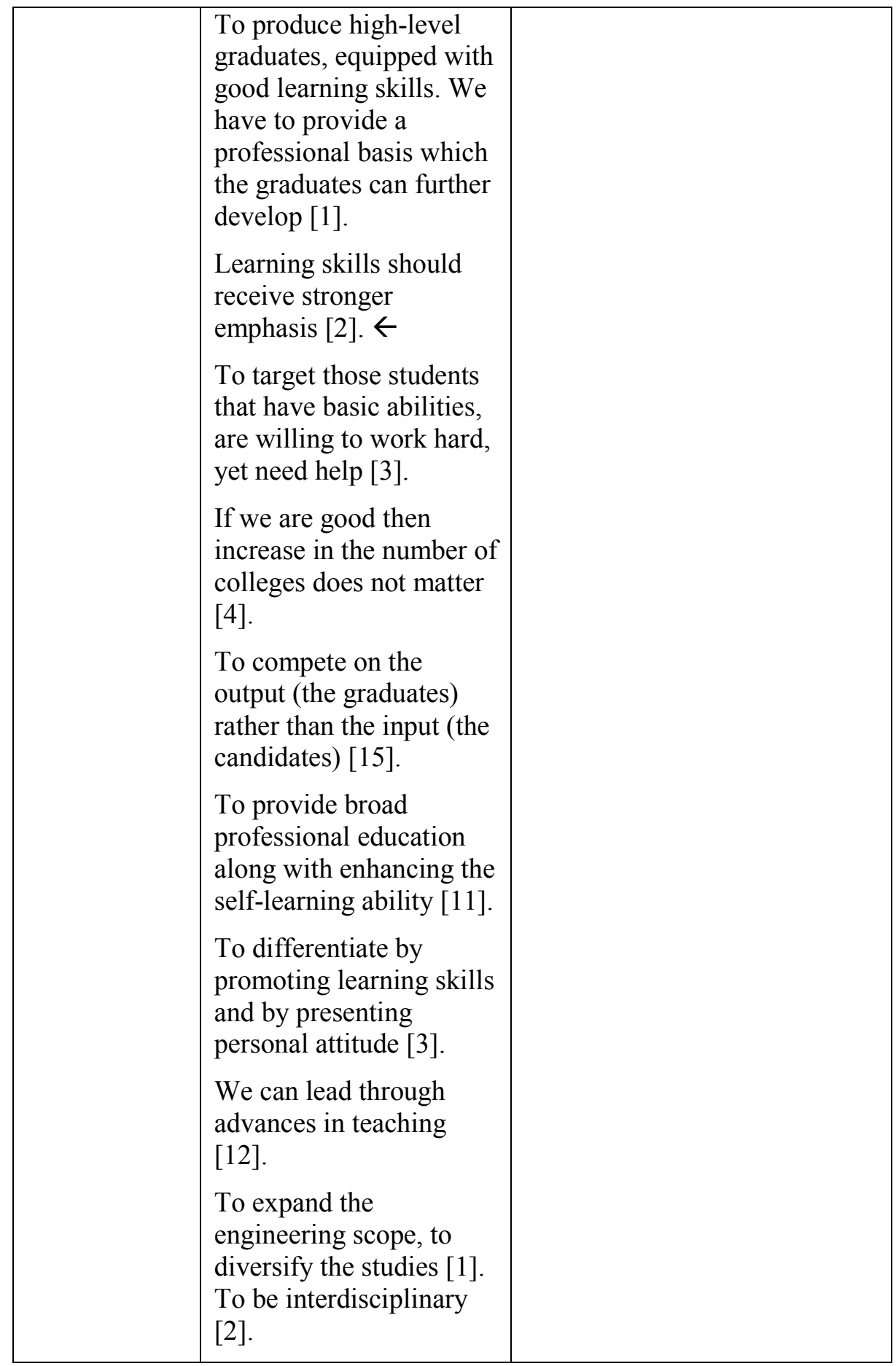


Table 6.3. EDU's expressions

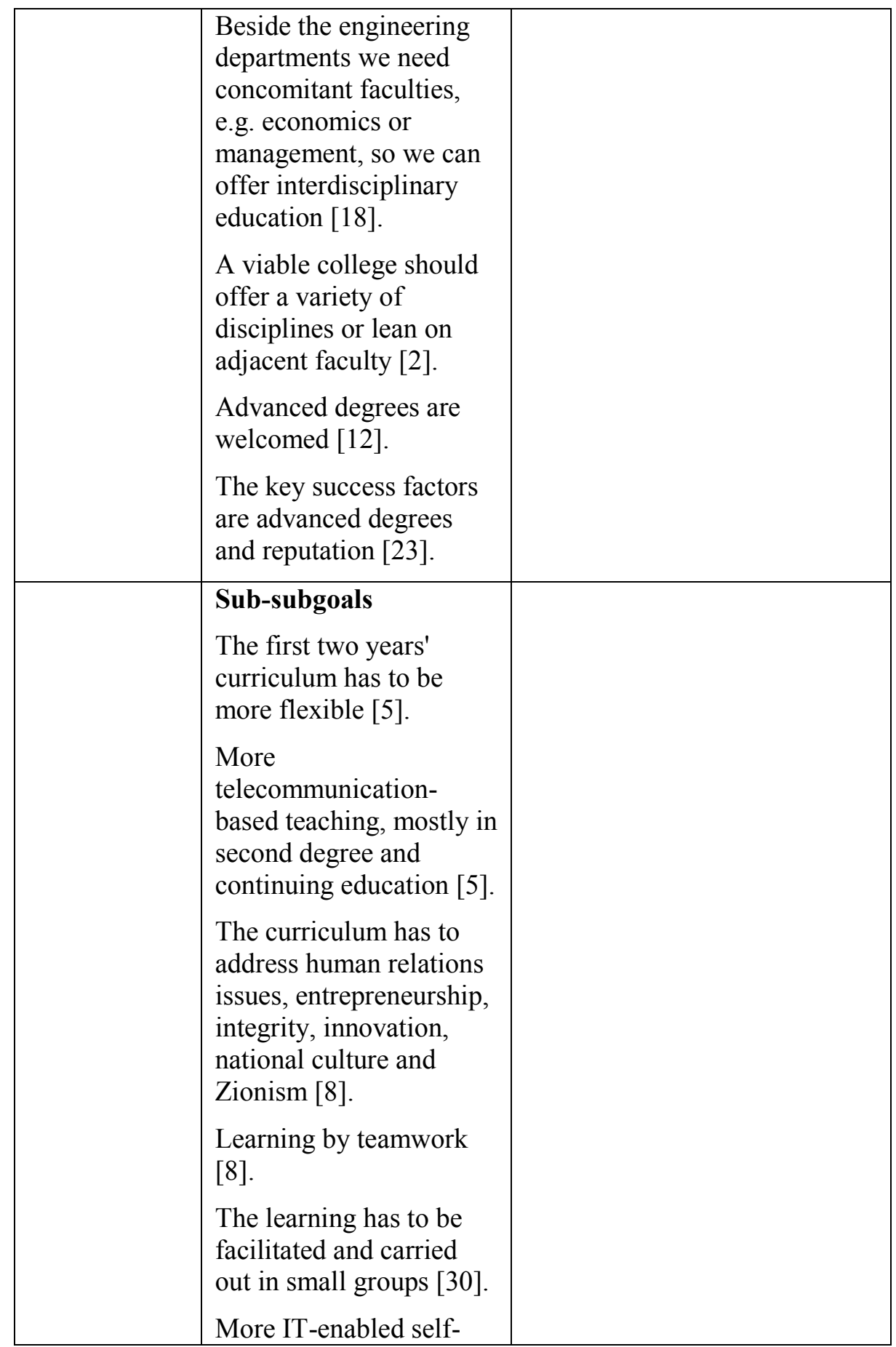


Table 6.3. EDU's expressions

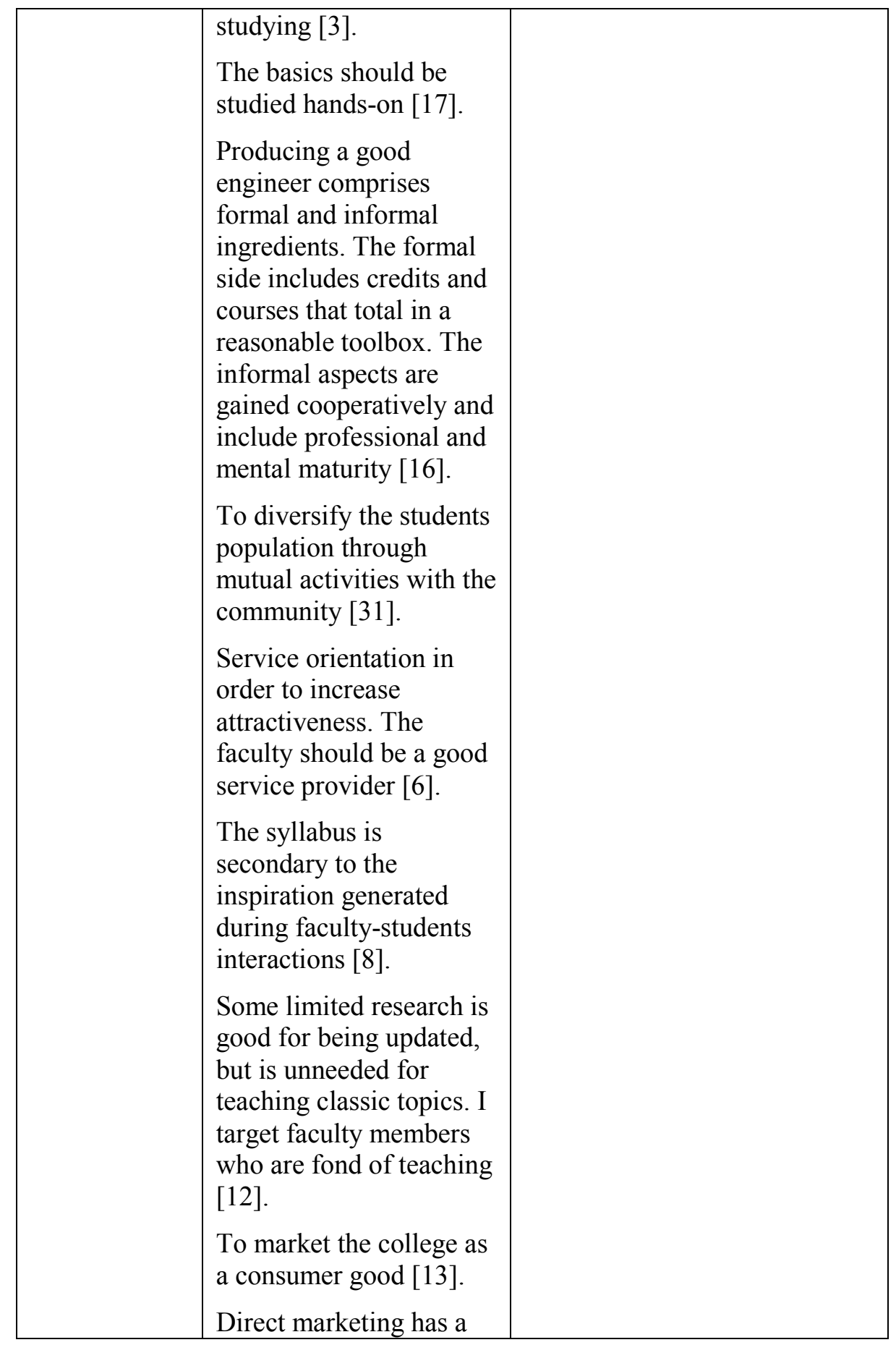


Table 6.3. EDU's expressions

\begin{tabular}{|c|c|}
\hline $\begin{array}{l}\text { limited effect; word-of- } \\
\text { mouth is better [25]. } \\
\text { To introduce ourselves } \\
\text { to the industry [17]. } \\
\text { Lowering the academic } \\
\text { level is a means to solve } \\
\text { other problems [14]. } \\
\text { One option, less } \\
\text { prioritized, is to refresh } \\
\text { the faculty [1]. } \\
\text { A different training is } \\
\text { required for the faculty } \\
\text { [3]. } \\
\text { To employ teachers with } \\
\text { industrial background. } \\
\text { To insist on students' } \\
\text { internship [16]. } \\
\text { Industrial R\&D is a fair } \\
\text { substitute for academic } \\
\text { research [17]. } \\
\text { To promote inter- } \\
\text { institutional cooperation } \\
\text { on libraries and data } \\
\text { bases [20]. } \\
\text { The library has to host } \\
\text { supporting learning sites } \\
\text { [22]. }\end{array}$ & \\
\hline $\begin{array}{l}\text { Results } \\
\text { The college is not } \\
\text { recognized, people don't } \\
\text { know us. That's the } \\
\text { problem [17]. } \\
\text { The participation rate in } \\
\text { teachers' training } \\
\text { programs is very low } \\
\text { [30]. }\end{array}$ & $\begin{array}{l}\text { Environment } \\
\text { The teaching method has } \\
\text { changed [1]. } \\
\text { There are more potential } \\
\text { students than the universities } \\
\text { can afford [2]. } \\
\text { The world is changing faster } \\
\text { than ever [2]. } \\
\text { The pursuit of knowledge is a }\end{array}$ \\
\hline
\end{tabular}


Table 6.3. EDU's expressions

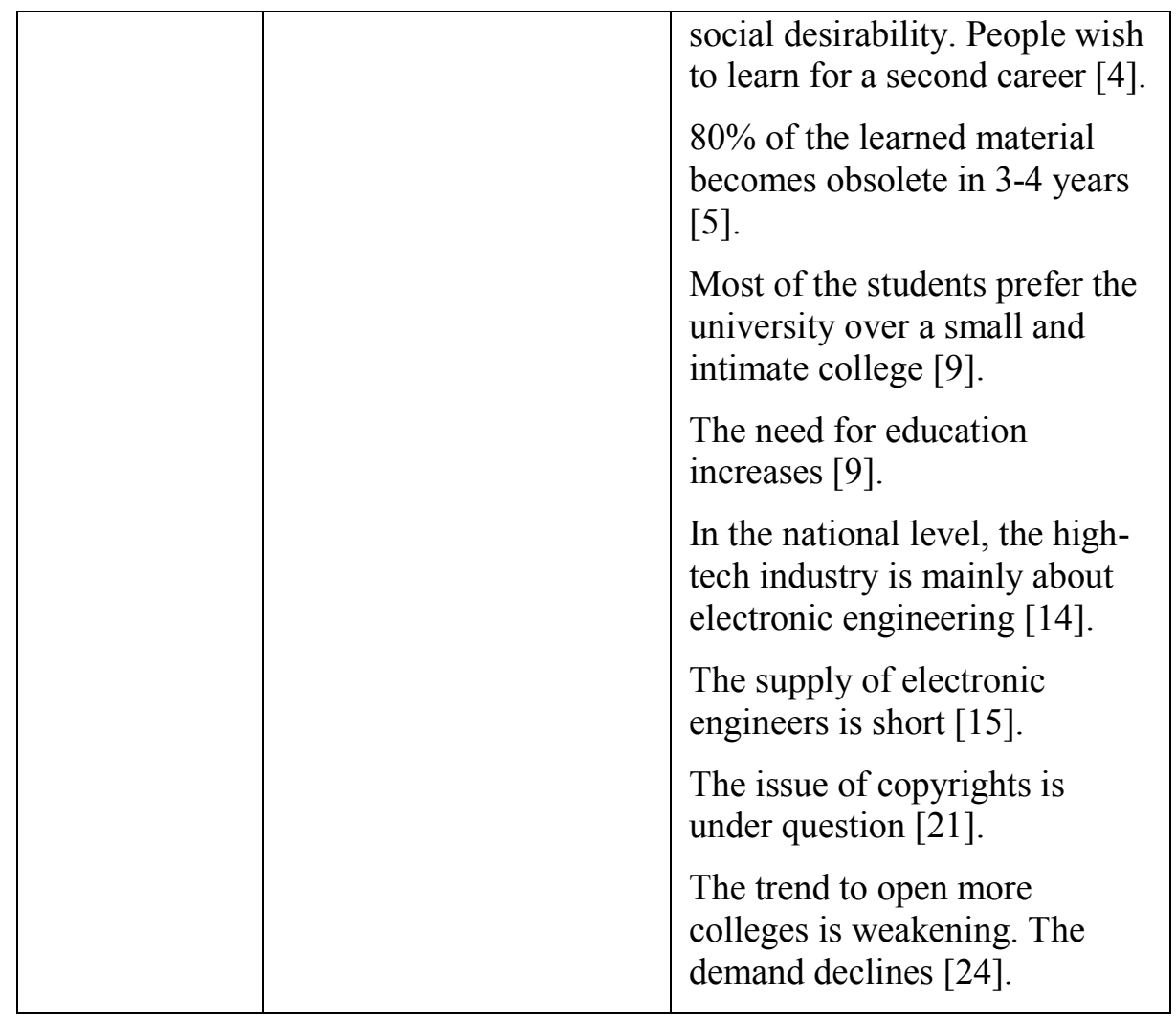

\section{Diagnosis}

\section{IND}

The Theory: the descriptive Theory comprises three types of statements. The first discloses the conceptual structure; for instance, the subcategories in the customers' market: "The market consists of the Telco's and the cables companies". The second reflects the concept attainment, i.e. attribution: "Video is a psychological need". The third relates the concepts by causality: "The product's decline is influenced by both customers and new technology".

Problems: table 6.2 indicates three problems: mindless derivation, mental irrefutability and causal ambiguity. The forth problem suggested in the model, i.e. logical irrefutability, is insignificant due to the marginality of the normative Theory. The marginality is implied by the sparsity in the respective cells and clearly exclaimed in the statement: "The goals are mainly 
market-driven, this is the leading factor", followed by defining values as nonsense and a waste of time.

Accordingly, the most extensive influence is of the scenarios on the highlevel goals. Process examples are: "What are the competitors doing and which share of the market each is taking? This will determine my choice"; or: "First we look at the market and try to understand its trends, and then we look inside and check what we can offer". A content example: "Any change in these trends [MPEG, HDTV] will be critical for us. We still don't know whether to enter the market or not".

Below we discuss the three discernible problems.

Mindless derivation: The prime indication of mindlessness is the unawareness of the very existence of scenarios. Although scenarios are exercised in practice, the "espoused theory" is in denial: "We didn't use scenarios during the strategic thinking", and "I definitely would not consider the method of scenarios".

Another sign of mindlessness is fragmented scenarios. Table 6.4 exhibits IND's "consistency measure": the extent to which the concepts reappear along the right falsification route. On face value the scenarios' derivation is consistent with the Theory; but the picture is misleading. Almost each driving force generates a stand-alone scenario, isolated from the others. Consider for example the following two dimensions:

- The "standards" dimension, by which two scenarios emerge: the triumph of either MPEG or Microsoft.

- $\quad$ The "customers" dimension, with two scenarios: "The Telco's crisis posits two alternative courses: one is that they will go bankrupt and be nationalized, the other that they will be forced to find new revenues"; therefore -

"The balance between the Telco's and the cables is critical for our strategy".

However, no scenario integrates these dimensions (or any of the others) coherently, although they all shape a unified reality. 
Table 6.4. IND's "consistency measure"

\begin{tabular}{|c|c|c|c|c|}
\hline Concepts & : & 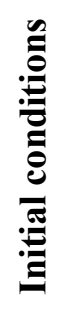 & 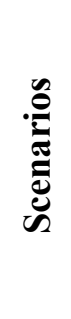 & 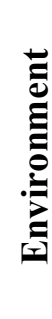 \\
\hline Market players/Competitors & + & + & + & + \\
\hline Market/Trends/Market size & + & + & + & + \\
\hline Product price & + & & + & \\
\hline Customers & + & + & + & + \\
\hline Demand & + & + & + & + \\
\hline Technology & + & + & + & + \\
\hline Products & + & + & + & + \\
\hline Technological standards & + & + & + & + \\
\hline Regulation & + & + & & \\
\hline Infrastructure/Value chain & + & + & & + \\
\hline Society \& Economy & + & & & \\
\hline
\end{tabular}

Mental irrefutability: four facets are detected. One is the commitment to previous predictions, exemplified by the following episode: the firm counted on a five-year forecast, which after three years was proved incorrect. Rather than rechecking the underlying Theory -

We have tried to reconstruct a rule that would explain what had happened to the market. I assume that "business is as usual", that the forecast should have been correct hadn't these nonlinear events occurred. Let's exercise the equation that will reflect them and get the actual reality. I guess that the backward correction applies forward as well.

The "nonlinear events" applies the "junk category" and the reconstruction echoes the "flexible environment" syndrome (see Schon in chapter 3, p. 58).

The second facet is the availability bias, indicated by three instances. First, the relevance is taken for granted; when asked about his first-priority knowledge gap, the interviewee answered: "What are the interdependencies 
among the forces that are relevant for me". Second, each issue is watched by a dedicated taskforce. Consider the following conversation:

Question: could it be that a salesperson who occasionally heard something about the [HDTV] topic was unaware of your interest in that topic?

Answer: yes. It is possible that information about HDTV will be missed because of the weak awareness. The solution is to build a task force, like for MPEG. Its existence will evoke awareness.

Third, the environmental feedback relies heavily on current customers, whose perspective is aligned with that of IND in the first place (see Christensen, in chapter 3, p. 59).

The third facet represents the self-sealing phenomenon: the environmental scanning is subordinated to the production capacity. During the aforementioned conversation the interviewee declared: "I will ask about HDTV half a year before I'm planning to develop the product". A colleague commented: "this schedule is right for you, but the market may dictate a different schedule", to that the interviewee answered: "may be, but I won't decide earlier anyway".

The forth facet is low esteem of the testing capability; when asked about an attribute contained in the Theory (that the market is price-sensitive), the interviewee answered: "We assume that the same attribute will hold in the future. I don't have any way to check it but retroactively".

Causal ambiguity: clearly the results - especially the market's response to the company's products - are the most essential (even if late) measure: "The best indicator, although too late, is how the product is accepted in the market". However, the meaning of the results is ambiguous (like the control framework suggests): "We are not alone in the market, so if our product is declined the reason may be that a competitor offered a better or a cheaper product". The ambiguity prevails in the other way around as well: "the distance between understanding the market and transforming this understanding to a product is still long". Likewise the strategy officer testified that only after he knew the results he would try to understand what in the strategy had caused them.

Another indicator for causal ambiguity concerns the information collection from the customers. The interviewees pictured a confused dialogue in which both sides guess what the market's signals mean.

Diagnosis confirmation: the diagnosis was confirmed by a panel assembled of the interviewees (except one) and additional staff officers. 
$E D U$

The Theory: the descriptive Theory comprises the same three types of statements as in IND. The first discloses the conceptual structure; for instance, "The academic competitive arena is divided to three leagues: universities, national colleges, and regional colleges". The second reflects the concept attainment, i.e. attribution: "Engineering means quantification". The third relates the concepts by causality: "More students bring more resources".

Problems: the prominent problems in EDU are the logical irrefutability (which literally "goes without saying") and the mindless derivation. The former reflects the remarkable influence that the normative Theory has on the means-ends construct; we do not address this problem. The mindless derivation is apparent upon the "consistency measure" (table 6.5): the vast majority of the Theory's concepts are omitted from the initial conditions or the scenarios. Both Theory and scenarios exist, but disconnected.

The mental irrefutability obstructer is neutralized since no attempts at refutation were exercised. The causal ambiguity obstructer was not detected; to the contrary, the interviewees were confident about how to attain their goals. Two factors propel this confidence: first, the sound normative Theory stands as a guideline; second, the reliance on self-experience. For example, one interviewee justified her design Theory on her and her children's experience basis.

Table 6.5. EDU's "consistency measure"

\begin{tabular}{|c|c|c|c|c|}
\hline Concepts & 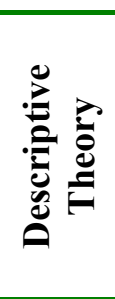 & 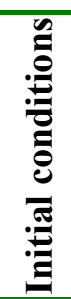 & 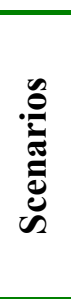 & : \\
\hline Competition/Universities/Colleges & + & + & + & + \\
\hline Academic leagues & + & & & \\
\hline [Other] education providers & + & & & \\
\hline $\begin{array}{l}\text { Attractiveness/ Prestige/ Reputation/ } \\
\text { Diploma/Market's evaluation/Added } \\
\text { value }\end{array}$ & + & & & \\
\hline Budget/Resources/Staff positions & + & & & \\
\hline Engineering/Engineers/Graduates & + & & + & + \\
\hline Professional knowledge & + & & + & + \\
\hline
\end{tabular}




\begin{tabular}{|c|c|c|c|c|}
\hline Concepts & 胥 & 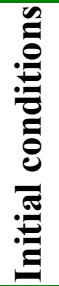 & 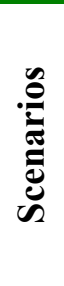 & 昰 \\
\hline Change rate & & & & + \\
\hline Learning abilities & + & & & \\
\hline $\begin{array}{l}\text { Demand for education/Labor market/ } \\
\text { Society ("the street") }\end{array}$ & + & & & + \\
\hline $\begin{array}{l}\text { Students/ Students' level/ Students' } \\
\text { expectations \& preferences }\end{array}$ & + & & & + \\
\hline Faculty members/Academic challenge & + & & & \\
\hline Scientific breakthroughs & + & & & \\
\hline $\begin{array}{l}\text { Teaching styles/Teachers-students } \\
\text { relations/ Educational } \\
\text { telecommunication }\end{array}$ & + & & + & + \\
\hline Information & & & + & + \\
\hline
\end{tabular}

Diagnosis confirmation: the diagnosis was confirmed by the expanded strategy forum that included the senior and the mid management; all the interviewees attended.

\section{Conclusions}

We posed three objectives for the diagnosis phase:

4. To validate the "Theoretical system" model (figure 3.5, p. 68) and the theoretical problem (i.e. the detachment of the major premise).

5. To characterize the Descriptive Theory in that system (the testing target).

6. To obtain the participants' acknowledgment of the problem definition.

The model and the problem were validated. The mindless derivation obstructer was detected in both organizations; the other three obstructers were found in one organization each. Neither participant attempted to falsify its descriptive Theory.

In both organizations we found the Descriptive Theory to consist of three types of statements: conceptual structure, attribution and causality. 
Both organizations acknowledged the diagnosis. We now have the required input for the action planning, namely the attributes of the Theory to be tested and the obstructers toward that end. 


\section{Action Planning: Design of the Intervention}

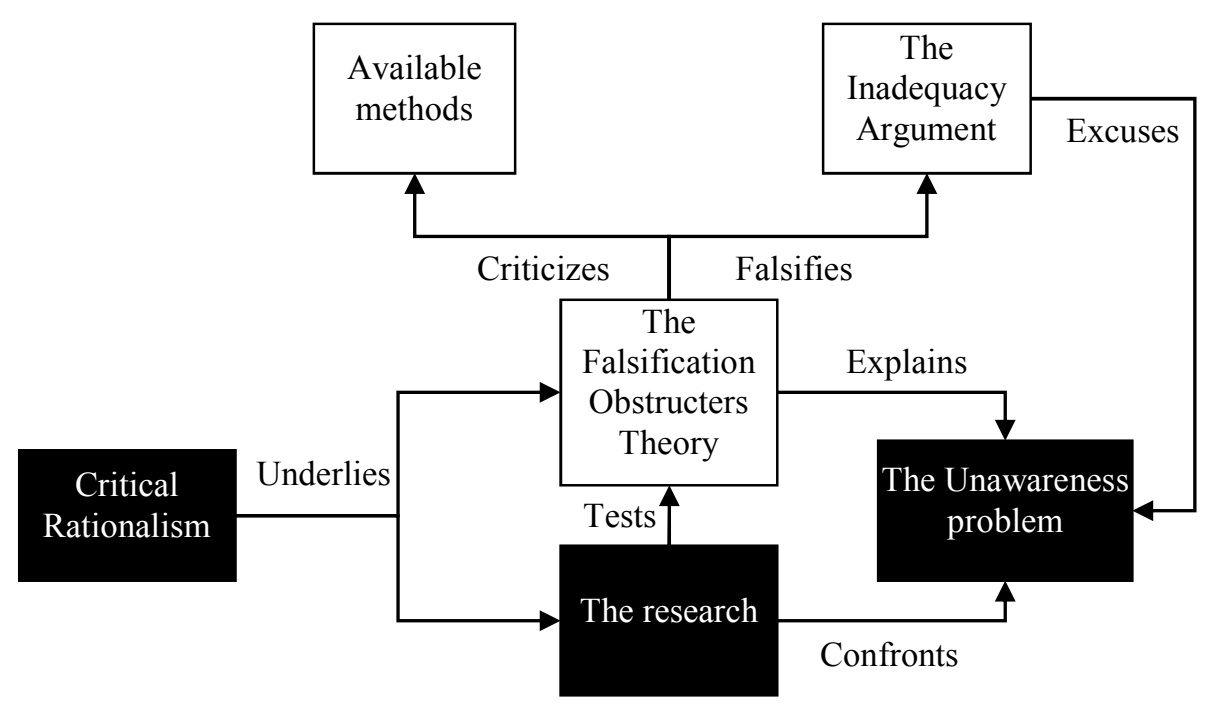

Figure 7.0. The focus of the chapter (blackened)

\section{The Preferable Route}

Earlier we implied that the right route (scenarios) is preferable ${ }^{34}$; the diagnosis reaffirms this preference. The reasons in favor of the right route are as follows:

1. The left route (results control) is in the eye of the storm, according to the inadequacy argument, the organizational theories reviewed in chapter 3 and the control framework. The diagnosis supports the argument: from the normative load, through the causal ambiguity, to the outdatedness of the results: "The best indicator, although too late, is how the product is accepted in the market"; "Sales data are an excellent indication, retrospective notwithstanding" (from IND). The right route, in contrast, is quite a virgin soil.

2. The causal ambiguity is to a significant extent produced by exogenous forces, whilst the mindless derivation and the mental irrefutability are endogenous, therefore more controllable.

3. The available methods provide a lead at this direction.

\footnotetext{
${ }^{34}$ Out of two alternatives, since the normative route is not an option. 
Therefore the intervention engages the scenarios route. In this phase we design the first three components of the "product": constructs, model and method. In the sense of operationalization the design can be called "Popperationalization" of the method.

\section{Constructs}

The scenarios' derivation flow constitutes a syllogism, so the first three of the following constructs present a syllogistic structure: the descriptive Theory as the major premise, the initial conditions as the minor premise and the scenarios as the conclusion. The last construct ("Environment") stands for the basic statement that is compared against the conclusion.

\section{Descriptive Theory}

The descriptive Theory designates the relevant forces, identifies their attributes and explains the interrelationships. Accordingly, the Theory comprises three types of statements:

- Structure: statements that specify the concepts and the subconcepts included in the Theory; in other words, the Theory's structure. Examples: "The world is divided into MPEG and non-MPEG" (IND); "'College' is different from 'university"' (EDU). Such a statement is the product of concept formation (chapter 1, p. 19).

Do not confuse this type with initial conditions (see below). For instance, the statement "The competition is among 3 universities and many colleges" (EDU) specifies a unique initial condition.

- Attribution: statements that ascribe attributes to concepts; for instance: "the technology progresses gradually", "The market is pricesensitive" (IND); "Engineers are pragmatic, result-oriented" (EDU). The attributes are the product of concept attainment (chapter 1, p. 19).

Shared attributes enable comparison among concepts. For example, the attribute "video-on-demand (VOD) compatibility" enables the statement "the cables support VOD better than the satellite".

- Causality: statements that define cause-and-effect relations between concepts. Examples: (1) "The product's decline is influenced by the customers" (IND); or: (2) "More students bring more resources" (EDU).

But note the difference: statement (1) is incomplete, because it does not specify which attribute of the customers affects the product's decline and how; consequently no prediction is possible. Statement (2), in contrast, specifies a direct ratio between the attributes of "amount". 
Hence a complete causality statement should consist of level variables, which are "a property of a thing that may be presented in degree" (Dubin, 1969, p. 35), and have to specify direction and ratio.

Representation and prohibition: the Theory is basically represented by the cognitive map format, which is limited to simple causality relations. One limited expression (chapter 4, the annex) is "conditional causation", where one variable condition the causality between two other variables ${ }^{35}$. Due to the Popperian hierarchical structure we need to represent another conditioning: prohibition, in which the causality is derived from a prohibitive attribute. Consider the following example: the attribute is "engineers are pragmatic" and the causality states that "since engineers are pragmatic, the higher the institute's reputation among employers the higher its attractiveness". The hierarchy is represented in the following format:

Institute's reputation among employers

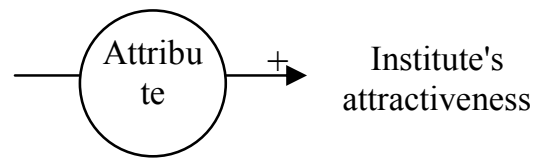

Figure 7.1. Representation of prohibition in the cognitive map

Other issues of representation:

- In causal relations the cause is the independent variable and the affected one is the dependent. Along a multi-step or a cyclical path a variable can be dependent and independent simultaneously. Variables that are exclusively independent (present only outflows) are titled "primary forces".

- The structural statements are not represented directly, but expressed through the other statements or stored textually.

\section{Initial condition}

These are specific qualitative values that are assigned to each of the primary forces in the cognitive map. By "qualitative" we mean high-low, increasedecrease or another contrasting pair (relative to the present state). The initial conditions do not reflect anticipation but possibility, so each primary force is assigned twice, one value at a time.

\footnotetext{
${ }^{35}$ The example was: "if A is high, B promotes $\mathrm{C}$, but if A is low, B retards C".
} 


\section{Scenarios}

The scenarios are the testing hypotheses. A scenario is the integrated conclusion, across all the variables, which is deduced from the cognitive map under a set of initial conditions (one initial condition per primary force). The deduction conforms to the cognitive map's rules (chapter 4, p. 85), i.e. an arithmetic exercise along each path. A prohibitive attribute is regarded effective until further notice, i.e. the ratio remains constant.

It stems from the above that with $n$ primary forces in the map there are as many scenarios as two to the power of $n$. For example, from figure 7.1 we can extract two scenarios: one in which the reputation and the attractiveness increase, another in which the reputation and the attractiveness decrease.

\section{Environment}

The "environment" stands for the actual values of all the variables included in the map, primary and non-primary alike, as observed in the real world.

\section{Model}

The model is adapted from figure 3.5 and connects the constructs in a syllogistic structure:

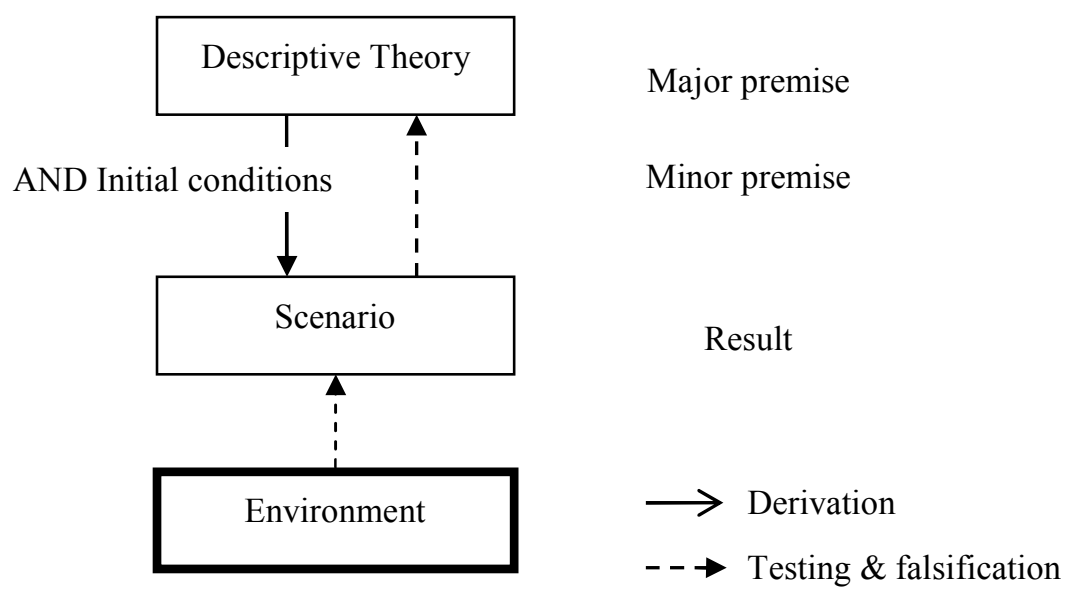

Figure 7.2. The design model 
The logical notation of the model ${ }^{36}$ is as follows: let $T$ be the descriptive Theory, let $C$ be a set of initial conditions $\left(c_{1}, c_{2} \ldots c_{n}\right)$, let $S$ be the scenario and let $E$ be the environment. Then:

$$
\left(\left(\left(T \mid\left(C=C_{e}\right)\right) \rightarrow S\right) *(S \neq E)\right) \rightarrow \bar{T}
$$

This reads: if the Theory, under initial conditions equal to the actual conditions in the environment, yields the scenario $S$, and if the scenario $S$ is not materialized in (is unequal to) the environment, then the Theory is false (not-T).

\section{Method}

In addition to the logical requirements, the design has to cope with the "Falsification obstructer" along the route, namely mindless derivation and mental irrefutability. It is the duty of the method to confront them.

The method presents a two-phase procedure ${ }^{37}$ : formalization and testing; the former establishes the platform for the latter. Table 7.1 spreads the techniques that assemble the method by phase and by the addressed obstructer; hereinafter the techniques are detailed.

Table 7.1. The method: techniques by phase and obstruction

\begin{tabular}{l|ll}
\hline \multicolumn{1}{c|}{\begin{tabular}{c}
\multicolumn{1}{c}{ Phase } \\
Obstruction
\end{tabular}} & \multicolumn{1}{c}{ Formalization } & \multicolumn{1}{c}{ Testing } \\
\hline $\begin{array}{l}\text { Mindless } \\
\text { derivation }\end{array}$ & $\begin{array}{l}\text { Elicitation, explication } \\
\text { and systematization of } \\
\text { the Theory. }\end{array}$ & $\begin{array}{l}\text { Genuine and risky } \\
\text { testing of the Theory. } \\
\text { Exhaustive and } \\
\text { comprehensive derivation } \\
\text { of the deducible } \\
\text { scenarios. }\end{array}$ \\
\hline
\end{tabular}

${ }^{36}$ This is an adaptation of Popper's formula: $((t \rightarrow p) * \bar{p}) \rightarrow \bar{t}$; in words: "if $p$ is derivable from $t$, and if $p$ is false, then $t$ also is false" (Popper, 1961, p. 76). Whilst this formula applies the course of prohibition, the one developed here applies the course of initial conditions (see p.50).

${ }^{37}$ It is a practical contraction of Popper's (1961, pp. 32-33) four phases: consistency, logicality, significance and confirmation. 


\begin{tabular}{l|ll}
\hline \multicolumn{1}{c|}{$\begin{array}{c}\text { Phase } \\
\text { Obstruction }\end{array}$} & \multicolumn{1}{c}{ Formalization } & \multicolumn{1}{c}{ Testing } \\
\hline & $\begin{array}{l}\text { Exclusive focus on the } \\
\text { Mental } \\
\text { irrefutability } \\
\text { (detached from the } \\
\text { normative and the design } \\
\text { Theories). }\end{array}$ & $\begin{array}{l}\text { Predefined hypotheses. } \\
\text { Observations of basic } \\
\text { statements. }\end{array}$ \\
\hline
\end{tabular}

\section{FORMALIZATION}

\section{Mindless derivation}

Elicitation, explication and systematization of the Theory: the elicitation of the Theory builds on two techniques in combination. One is the panel questioning method employed by Roberts $(1976)^{38}$, aimed at constructing a cognitive map. The panel undergoes three rounds:

1. In the first round an assortment of variables is freely suggested, individually by each of the participants.

2. In the second round the variables are rated, integrated and clustered, as the outcome of collective consideration (which, Roberts testifies, is extremely uneasy).

3. In the third round the variables are interrelated and the relations are notated with positive or negative signs.

The panel method is amended according to the different purpose: instead of distant observers who are questioned after the fact we interview the decision-makers themselves in real-time.

The other technique is the laddering interview, which "refers to an in-depth, one-on-one interviewing technique used to develop an understanding of how consumers translate the attributes of products into meaningful associations with respect to self, following Means-End theory" (Reynolds \& Gutman, 1988, p. 12). We borrow the essential idea (to expose the attributes behind the causation) with one technical adaptation: a panel instead of personal interviews.

Beyond this, the explication is attained through the visualized of the verbal expressions in the cognitive map. The systematization concerns the distinction between the three types of statements, followed by: (1) aligning the

${ }^{38}$ This is one of the two unobtrusive techniques that Axelrod (1976) mentions. The panel consists of uninvolved experts and is conducted after the fact. 
attributes with the respective causalities, and (2) assuring the variableness of the causal relationships.

Exhaustive and comprehensive derivation of the deducible scenarios: the scenarios reflect neither discretion nor anticipation; they are strictly derived from the map and encompass all the possibilities that the Theory allows. The exhaustiveness is achieved as each primary force is assigned with both poles of its spectrum, one at a time, where each assignment generates another scenario. The comprehensiveness is attained as each scenario integrates all the paths across the map.

The comprehensiveness enhances the scenario's falsifiability, in line with the Popperian principle of logical probability (Popper, 1961). The principle reads that the more conditions a theory has to meet, the less it is probable; the less it is probable, the more it is falsifiable - hence a better theory.

\section{Mental irrefutability}

Exclusive focus on the area of interest: the key countermeasure against the mental irrefutability is the distance from its sources: the normative and the design Theories. For the formalization of this technique we borrow a military concept.

The Western military doctrine ${ }^{39}$ divides the battlefield into two areas (figure 7.3):

1. "An area of influence is a geographical area wherein a commander is directly capable of influencing operations by maneuver and fire support systems normally under the commander's command or control. The area of influence normally surrounds and includes the area of operations."

2. "An area of interest is that area of concern to the commander, including the area of influence, areas adjacent thereto, and extending into enemy territory to the objectives of current or planned operations. This area also includes areas occupied by enemy forces who could jeopardize the accomplishment of the mission."

${ }^{39}$ The following excerpts are from "Operations", FM (Field Manual) 3-0, US Department of the Army, p. 5-5 (http://www.army.mil/fm3-0/fm3-0.pdf ), visited April 10, 2010. 


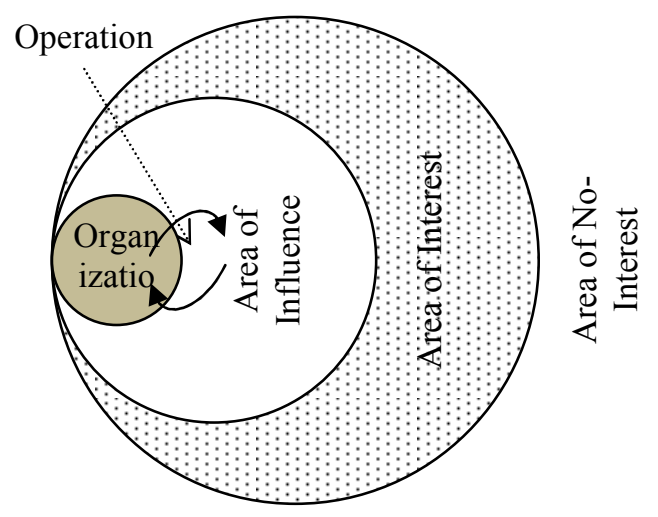

Figure 7.3. The organization and the areas of influence, interest and no-interest

Save the "geographical", "fire" and "enemy", these concepts hold for civil organizations analogically. Our focus is on the dotted area, i.e. the area of interest excluding the area of influence (hereinafter: area of net interest). The sources of mental irrefutability are much less effective in the area of net interest: the no-control eliminates the "self-sealing" and the responsibility effects; the distance neutralizes the enactment; and the noninvolvement blunts the availability bias. To borrow from Axelrod, the unobtrusiveness enhances the reliability.

The open-ended area beyond the area-of-interest is by default of no-interest (irrelevance); according to figure 1.5, this is the zone of "there is unawareness". We have to confirm this statement in order to falsify the statement "there is no unawareness", which is equivalent to: "the outer envelope of the area-of-interest is true".

The rule for the inner envelope (i.e. the distant border of the area-ofinfluence) is "one up": the first variable that affects the industry, where the industry is one level above the subject organization. Preferably this variable (hereinafter: First cross-industry force) is beyond the industry's accumulated influence, i.e. insensitive to competitive maneuvers (for the sake of net interest).

Subject to these guidelines, the map is schematized in figure 7.4; note that the primary forces are distinguished by bold letters. 


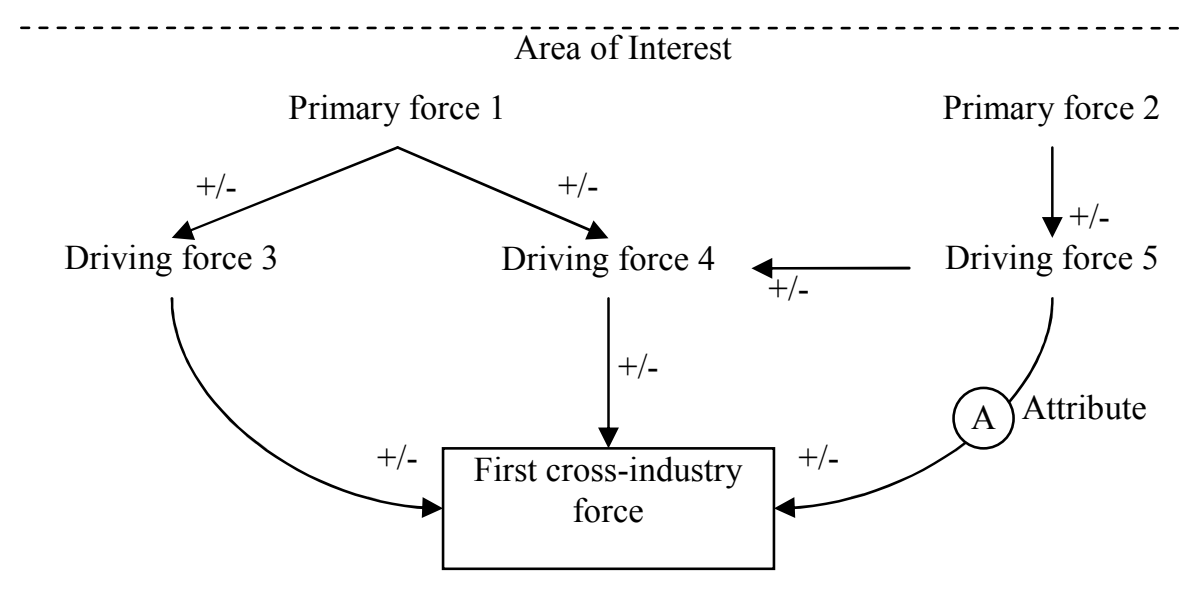

Area of Influence

Figure 7.4. Schematic view of the Theory (the boundaries of the areas are for illustration)

In light of the above, what should be the order of elicitation? There are two opposite alternatives: from ends to means, like in the means-ends analysis (chapter 3); or from means to ends, like in the cognitive mapping (chapter 4). The desired exclusion of the "area of influence" makes the first alternative favorable, assuming the "First cross-industry force" the higher end. Once determined, we proceed outward by asking what affects the "First cross-industry force", and so on. The stopping point cannot be instructed, since it is tacit (chapter 1, p. 21).

By applying the "Exhaustive and comprehensive derivation of the deducible scenarios" technique on the map, the following schema ${ }^{40}$ emerges (figure 7.5):

${ }^{40}$ The graphical presentation is borrowed from Barabba (1998). 


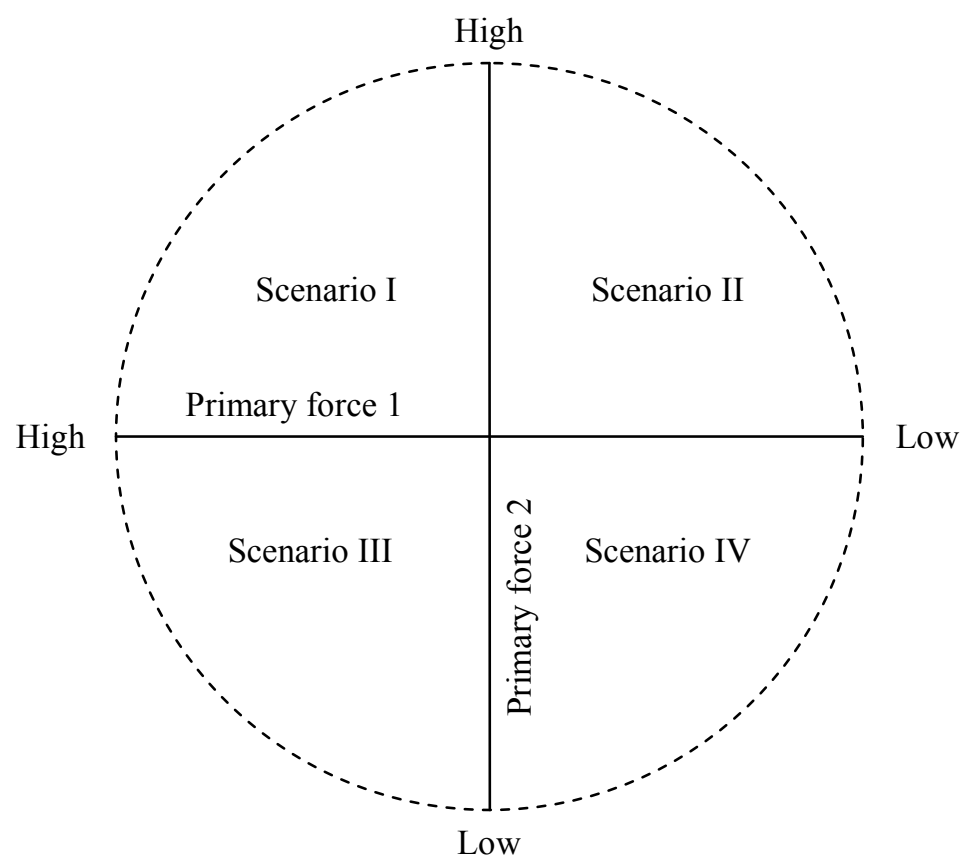

Figure 7.5. The circle of scenarios derivable from the Theory

The dotted circle symbolizes Popper's image of the theory as the span of events that the theory allows (chapter 3, p. 51).

\section{TESTING}

\section{Mindless derivation}

Genuine and risky testing of the Theory: this is the kernel of method. The testing procedure is conducted every 6-12 months, assuming that detectable changes require that time to evolve. The evaluator identifies the actual state of the primary forces in the environment, and singles out the scenario that has been assigned accordingly. Then the scenario, variable by variable, is compared to the real environment. A mismatch of one or more variable falsifies the Theory (or part of it).

For example (consider figure 7.4): we look at the environment and conclude that, since the last test (or the Theory's formalization), primary forces 1 and 2 have increased; therefore, if the Theory is true, scenario 1 (figure 7.5) should match the environment. We compare the real values of driving forces 3-5 and the "First cross-industry force" to those predicted by the scenario; a mismatch of any of them falsifies the Theory. 


\section{Mental irrefutability}

Predefined hypotheses: the reason for predefining all the scenarios in advance rather than deriving the respective scenario in real-time (i.e. upon the test) is to prevent the "flexible environment" syndrome. We suspect that a derivation after the fact enables a flexible adaptation of the scenario to the reality or a retrospective justification thereof (as noticed in IND). The predefined scenarios force the decision makers to confront their original hypotheses and (with the next technique) amplify the inter-subjective objectivity of the method.

Observations of basic statements: Popper (chapter 3, p. 46) expects the observations to convey basic statements, i.e. "a statement of a singular fact". Unfortunately most of the Theory's substance consists of social artifacts (e.g. "prestige") or abstract concepts (e.g. "competition"). If, as Popper argues, the observation at the nature is theory-laden, all the more so when the observed is an abstract concept (Hines, 1988). The interpretation of such observations is a conventionalist trap, Popper (1961) warns, since as conventionalists -

...we may adopt a sceptical attitude as to the reliability of the experimenter whose observations, which threaten our system, we may exclude from science on the ground that they are insufficiently supported, unscientific, or not objective, or even on the ground that the experimenter was a liar (Popper, 1961, p. 81).

As a countermeasure we require that the scenarios will be dissected down to the level of expected occurrences, i.e. basic statements. For example: "more than three competitors" and not "tough competition". The benefit is threefold: first, to focus the observations on empirical facts in the environment; second, to prompt undisputable comparisons between the scenario and the reality; third, to share common language across multiple sources (e.g. the media), and by that to obtain diversity.

In chapter 1 (p. 22) we deduced the constraints imposed by the logic of unawareness: it is impossible to access the content of unawareness, to confirm that "there is no unawareness", and to grasp the tacit experience. However we can (1) access the content of awareness; (2) falsify the statement, and (3) explicate both. The method complies with all the three as it explicates the Theory and explicitly puts it under test.

\section{Instantiation (Work Plan)}

The method will be implemented in both participants with the researcher's facilitation. Once the Theory, the map and the scenarios are constructed, we 
will run the testing 2-3 times per participant, and evaluate. Next we will specify the learning.

Following are the participant-specific arrangements upon which we have agreed:

IND: the research will be conducted in the SBU level, namely twice, simultaneously. This was the management's preference in light of the different environment assumed for each SBU. Each SBU will involve the local management team, about 3-4 persons. One executive (the CTO) will represent the HQ in both SBUs, in order to synthesize the final evaluation. Testing is due approximately every six months.

EDU: the research will involve the strategic committee, a body assembled of the management plus several senior incumbents (in total about 20 persons). The president will sponsor the research and will evaluate its outcomes. Testing is due once a year. 


\section{Finalizing Cycle I: Action Taking, Evaluating and Specifying Learning}

\section{Action Taking}

IND

As planned, this phase of the research has been delegated to the SBU level and started in both SBUs quite simultaneously; unfortunately, SBU2 had been closed short before the research was completed, but nevertheless enriched the findings. For that reason and for the sake of brevity, only the products of SBU1 are presented, whilst the methodological insights integrate both experiments (which were by and large identical).

SBU1 develops equipment for broadband video streaming over phone lines, which enables phone companies ("Telco's") to supply television services. This ability is part of the "triple play", a strategy in which telephone, internet and television are supplied by a single provider. In this playground the Telco's (as of 2003) competed against the cable companies. For IND this is a demand market, directed by a limited number of customers with a great buying power each.

\section{Formalization}

Theory construction: we started the formalization phase with the Theory's elicitation, explication and systematization. The first round yielded about 15 variables, which were consolidated upon the second round into eight (12 in SBU2). The Theory construction consumed the largest time share, about 9 hours in 3 sessions. Two steps were particularly problematic: one concerned the designation of the "First cross-industry force", which was confused with the unit's own ends. Finally the decision was "Telco's broadband television (BTV) supply"; this variable was assumed uncontrolled by the industry still with a direct effect on the competition, i.e. the area of influence.

The same difficulty was encountered by SBU2, whose products are consumed by plenty of anonymous end-users in the free market. The "First cross-industry force" they named was the size of the market, clearly beyond the control of each single competitor.

Once the "First cross-industry force" was agreed upon, the designation of the farther forces was straightforward. The second difficulty (in both units) emerged upon systematization, and was twofold: to name a variable rather than a state (e.g. "economic situation", not "recession"), and to assure the levelness of the causal relationships; close supervision of the researcher was required. 
The Theory (figure 8.1) presents four independent variables. The Rate of deregulation affects the competition within the traditional telephone market, as cable and wireless (cellular) providers are let in. The new competitive front presses the Telco's to find additional revenues and drives them towards the TV supply; from another direction the deregulation legalizes this move. An alternative for the Telco's is to merge or acquire incumbent vendors, e.g. satellite broadcasters, a move that affects the direct TV supply inversely.

The effect of Expansion of fast Internet is dual: for one, it provides the infrastructure necessary for TV supply; for two, it lessens the prospect of future revenues from further expansion. The accumulated effect is more pressure on the Telco's to supply TV.

The Popularity of personalized video services is advantageous for the Telco's, as the medium they offer is the best for bidirectional traffic. The prohibitive attribute (1) reads: "The satellite is incapable of personalized video services".

The integrated variable "Pace of technology change" positively affects the capacity of the phone lines and therefore enhances the attractiveness of this alternative. At the same time the satellite's competitive advantage, its capacity, is eroded (balanced with its disadvantage - sensitivity to weather conditions).

The former effect is relatively slow (slower than the other effects), as indicated by the "Delay" label. The reason for that is attribute (2) that reads: "The technology is standards-based (therefore comes after the standards are established)". This is an example of the map's limitations ${ }^{41}$ : the ratio is negative before the standards exist and positive afterward (Conditional or interactive causation). In addition, too rapid change turns the ratio negative because the market waits until the technology is stable (Nonmonotonic causation). We have faced several limitations of that kind.

\footnotetext{
${ }^{41}$ See the annex to chapter 4.
} 


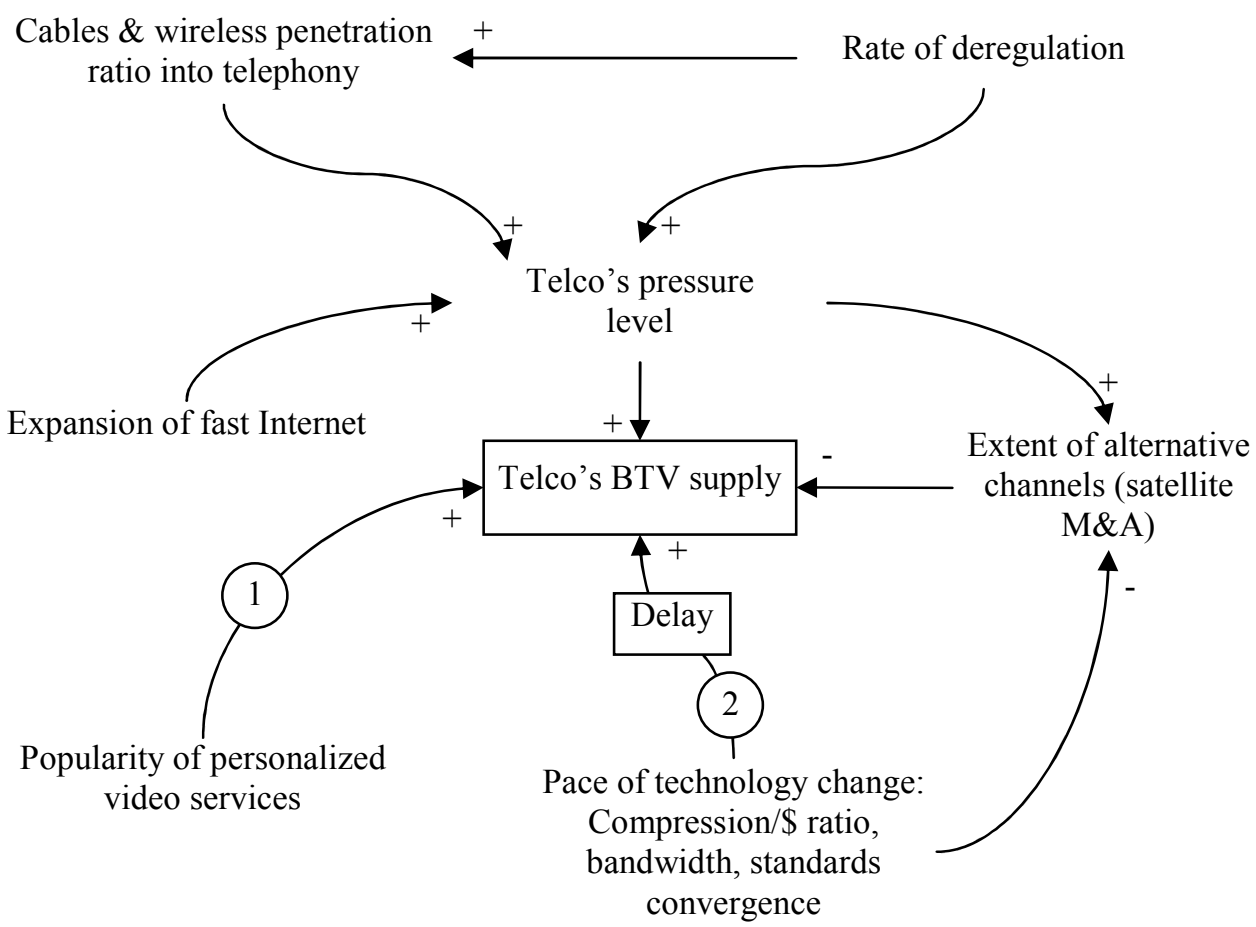

Figure 8.1. The Theory of IND's SBU1

Scenarios derivation: this phase faced a dilemma. Four primary forces (in bold letters) lead to 16 scenarios, quite a cumbersome amount. On the other hand, the method requires Exhaustive and comprehensive derivation of the deducible scenarios. The compromise was to treat two primary forces as attributes, i.e. still subject to test but regarded true until otherwise noticed (anyway it was the authentic assessment). Both forces are assumed to grow steadily:

1. The Expansion of fast Internet.

2. The Popularity of personalized video services.

Save this dilemma, the derivation was straightforward. With the remaining two primary forces, the following four scenarios are derivable (figure 8.2): 


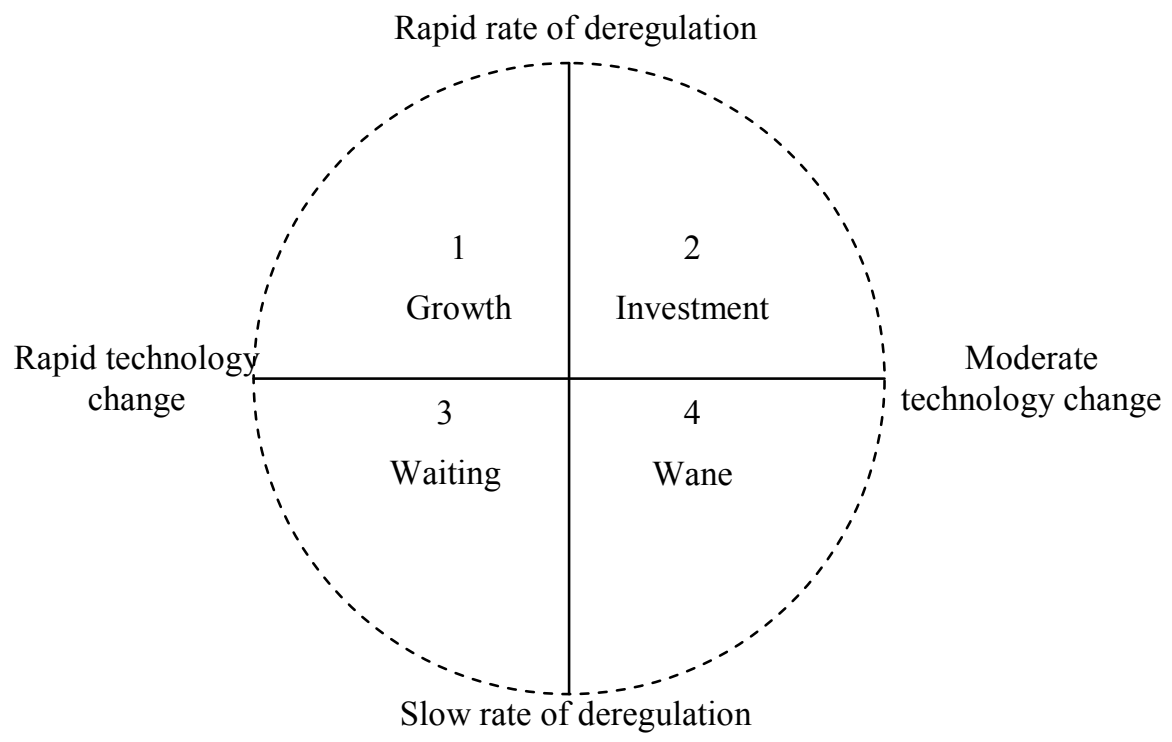

Figure 8.2. The scenarios derived in SBU1

In the following elaboration the "indicators" stand for the predicted observations, i.e. "basic statements":

1. Growth: fast growing and highly competitive BTV market. The technology development and the personalized services weaken the demand for satellite, thus the BTV supply increases. Under extreme circumstances the trend turns over due to the lack of common standards.

Indicators: over 5\%, flat-rate quarterly increase in the total sales to the Telco segment; over $20 \%$ annual increase in Telco TV subscribers worldwide; over $20 \%$ annual increase in personalized TV services revenues; continuous deregulation.

2. Investment: immense Telco's investment in technology's R\&D and in companies alike. Deployments of many small pilots. Increasing Telco's investment in satellite. Ample supply of premature products by high-tech manufacturers.

Indicators: continuous deregulation; contracts of cooperation among the Telco's and satellite companies; the Telco's acquire or invest in video-compression developers; quarter-by-quarter decrease in the industry's sales to the Telco segment; stagnation of Telco TV's subscribers; companies announce new products that actually are not marketed/offered, or they are offered with other than announced spec; increase in the Telco's investment in VoIP technology. 
3. Waiting: emergence of alternative channels; breakdown of video technology companies.

Indicators: contracts of cooperation among the Telco's and satellite companies; quarter-by-quarter decrease in the industry's sales to the Telco segment; stagnation of Telco TV's subscribers; competitors abandon the market; increase in the Telco's investment in VoIP technology.

4. Wane: the Telco's are shrinking, zero to low demand for BTV products. Perfect competition (equilibrium) among numerous Telco's, cellular and cable enterprises. Satellite companies are acquired by the Telco's. Potentially less latitude for the cables. The Telco's refrain from investing in technology.

Indicators: Increase in Telco investment in VoIP technology; quarter-by-quarter decrease in the Telco's revenues; decrease in Telco TV subscribers.

\section{Testing}

We conducted testing sessions every 6-10 months. The first two were indecisive, since the changes in the environment (primary and other forces) were too marginal to reach conclusions. The change in the work process, however, was salient: the environmental scanning was data-oriented, strictly focused on the indicators listed above; disagreements around observations were scarce.

The third session, that took place two years after the formalization, was different. The actual state of the primary forces indicated scenario 2 (Investment), but the environment partly resembled scenario 3 (Waiting) whilst the rest did not respect any scenario. Specifically, the Telco's invested very little in BTV equipment (part of the Waiting scenario) and cooperated with the cellular companies on content initiatives (not mentioned in any scenario). Apparently the Theory has been falsified.

The Theory was reviewed in attempt to specify the fallacy. One participant pointed to the missing of the emerging High-Definition (HD) technology, which he thought had caused the Telco's to wait until it would be assimilated, but there was no consensus about it. Another participant insisted that the Theory was not falsified al all, since the HD is wrapped in the "technology change" force, already in the Theory. Yet she acknowledged that the "delay" attached to the "technology change" variable was much longer than originally assumed. The debate would not be settled until the next session.

The fourth and last session was held after another eight months. The environment-scenarios contradiction continued, but much more disturbing was the results input: the company lags behind its objectives. Now the acknowledgement of a problem was unanimous. 
The analysis that followed consisted of four insights, presented in the order of emergence:

1. The results are worse than expected, but the cause for that is ambiguous: "we do not sell because the competitors have better products, or cheaper ones, or they have better markets, or they are positioned better or... I don't know".

2. The scenarios contradict the environment but do not necessarily falsify the Theory, because of (1) the unreliability of the observations and (2) the doubtful validity of the scenarios (note the conventionalist attitude ${ }^{42}$ ): "the argument that certain indicators signify a specific scenario, or that the Theory dictates only these and not other scenarios, may be incorrect". In other words, let's kill the messenger.

3. Practically the Theory is still valid: "the issue of the Telco TV is exactly as presented [in the Theory], although the Telco-mobile cooperation does not appear in any scenario... the more I examine the Theory the more it is true".

4. Still the dissonance exists: "the same dissonance that we had [when the Theory was formalized] still exists: does it [the design Theory] imply that we will sell? Not necessarily; but the analysis is true". After a while, the enlightenment: "we see that we don't sell, the question is why we fail to sell, and the answer is definitely not in the [descriptive Theory]". The falsehood is imputed to the design Theory: it skips a crucial factor - the leading system integrators, which prefer their own products rather than those provided by IND. The conclusion is that the descriptive Theory is true whilst the design Theory is false: "our analysis [of the descriptive Theory] is true but IND is not the right provider under these circumstances".

The bottom line is that a new driving force, claimed critical, emerged in the design Theory but was denied upon the descriptive Theory (that is, only the design Theory was falsified). The reaction to this discovery was: "it is a logical movement [in the market]... but I don't understand what we are trying to prove; this is the regular evolution in this industry".

The documentation evidences that the "regular evolution" has never been mentioned up to that moment.

\footnotetext{
${ }^{42}$ These arguments, according to Popper (1961), are the conventionalist's escapeway; the first, that denies the reliability of the observations, was quoted in chapter 7 (p. 116). The second reads: "...there is always the possibility of "...attaining, for any chosen axiomatic system, what is called its 'correspondence with reality"'; and this can be done in a number of ways [...]. Thus we may introduce ad hoc hypotheses. Or we may modify the so-called 'ostensive definitions"' (p. 81).
} 


\section{$E D U$}

As planned, the research involved the entire strategic committee, and was integrated in the strategic thinking process as its starter.

\section{Formalization}

Theory construction: we started the formalization phase with the Theory's elicitation, explication and systematization. The first round ${ }^{43}$ yielded 6 variables:

1. The national economic situation.

2. The demand for academic education in general, for engineering education in particular, interwoven with the prestige of the engineering profession.

3. The regulation in the academic market.

4. The labor market and the employers' expectations from the graduates.

5. The competition in the academic market.

6. Trends and developments in teaching, locally as well as globally.

This list presented a double problem: first, the variables were too vague to be workable; second, the participants felt uneasy with their low acquaintance with them (recall that they have not been experienced with strategic thinking). Therefore five teams were nominated to study topics 2-6 more deeply. The result was a breakdown of the above into the 9 variables presented in figure 8.3.

There was an instant consensus around the "First cross-industry force", which reads "Demand for engineering education in colleges"; it directly affects the first variable within the area of influence, which is "Demand for studying in EDU". It is important to note that very few engineering colleges existed at the time, quite distant from one another, so the interest-influence border was thin.

Upon systematization, the IND-like difficulty with the levelness along the causal relationships was realized and required facilitation. The plenary session lasted about 15 hours, to which the teams' working time should be added. The resulting Theory is depicted below.

\footnotetext{
${ }^{43}$ The elicitation technique was as same as in IND.
} 
Level of high-school education in science and

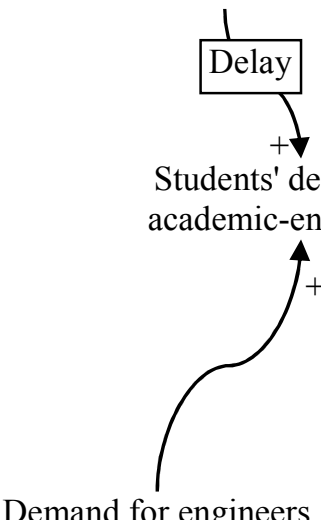

Demand for engineers

in the labor market

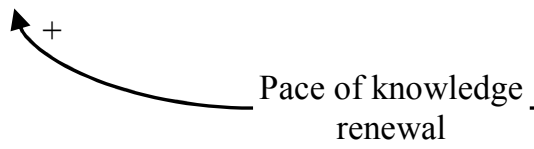

Dominance of the values approach in education

Figure 8.3. The Theory of EDU

The Economic situation has a double effect: on the total demand for engineers in the labor market and on the distribution within that demand. The total demand is a sheer consequence of the economic activity. The distribution is more complicated: the better the economic state, the larger is the $\mathrm{R} \& \mathrm{D}$ share of the activity; the worse the situation, the larger is the maintenance share. The former enhances the advantage of self-learning abilities.

The latter effect reflects attribute (1): the engineering profession is a twofold construct, consists of R\&D and maintenance; the former is distinguished by the higher emphasis put on self-learning abilities.

The Pace of knowledge renewal affects both variables as well. When the pace is slow some engineering jobs are occupied by practical engineers or by technicians; rapid pace reverses the trend. The effect on the Employers' relative emphasis on self-learning abilities reflects the aging of the acquired knowledge.

The colleges-universities allocations ratio encapsulates two assumptions: on the one hand, universities' graduates are regarded better self-learners; on the other hand, the regulator (CHE) is reluctant to expand the universities due to their higher cost. The ratio reflects the tension between the two.

The Demand for engineers in the labor market affects the Students' demand for academic-engineering education, in addition to Level of high-school education in science and math; but the latter has a significant delay. The variable Employers' relative emphasis on self-learning abilities presents a 
double negative effect: on the regulator and on the students, because the universities are regarded superior when self-learning abilities are concerned. The students' preference draws upon attribute (2) that reads "Engineers are pragmatic and result-oriented", therefore their prime concern is the prospect of employment.

Last but not least, the variable Dominance of the values approach in education stands against the dominance of the excellence approach; the latter is assumed to promote the students' preference for universities.

Scenarios derivation: two out of the four primary forces were maintained as attributes, effective at least throughout the strategy's lifespan. They read:

- The Level of high-school education in science and math is stable.

- The Dominance of the values approach in education is unreasonable.

The scenarios based on the remaining two primary forces are presented and described below.

1. Balance: technological jobs are upgraded, more emphasis on selflearning abilities, growth of the labor market and intensive R\&D investments. Increase in the total demand for engineers with the same proportion of qualities.

2. Quality rules: upgraded technological jobs, more emphasis on selflearning abilities, the labor market shrinks and the focus is on maintenance and conservation. Decrease in the total demand for engineers with larger proportion of the higher quality.

3. Double increase: technological jobs are stable, extended longevity of knowledge, growth of the labor market and intensive R\&D investments. Increase in the total demand for engineers with larger proportion of the higher quality.

4. Stagnation: technological jobs are stable, extended longevity of knowledge, the labor market shrinks and the focus is on maintenance and conservation. Decrease in the total demand for engineers with the same proportion of qualities. 


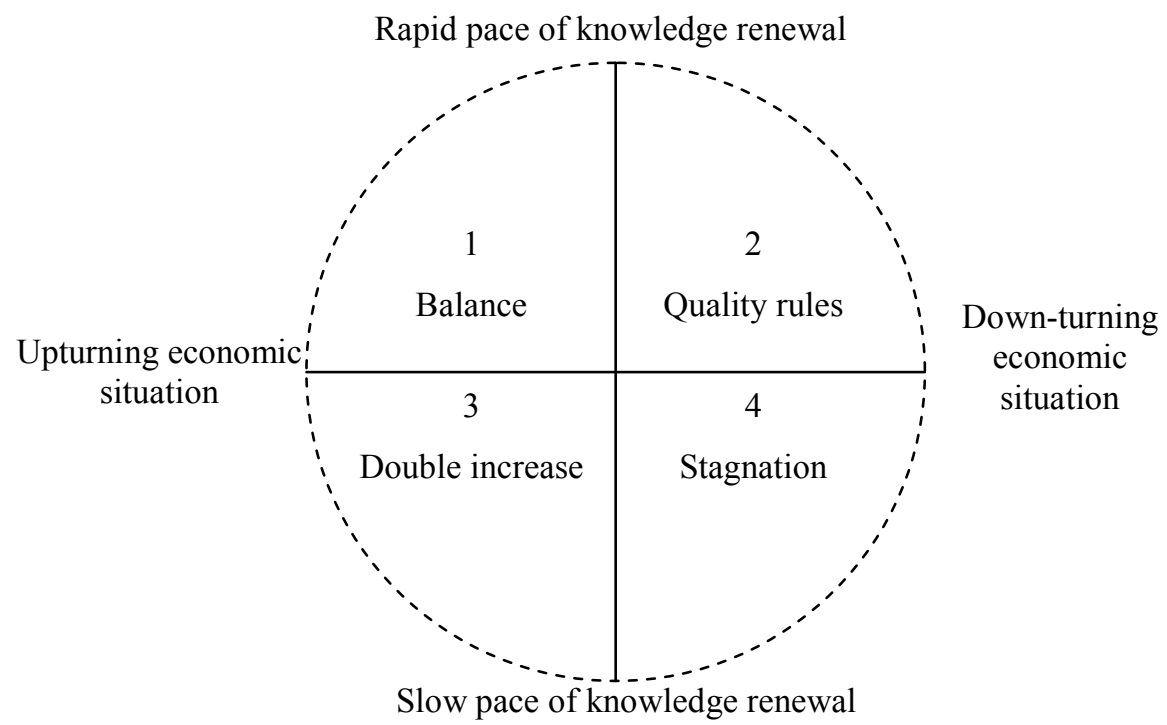

Figure 8.4. The scenarios derived in EDU

The governing mindset along the formalization process held a competitive arena consisting of two groups: the universities on one hand and a few colleges on the other. The emanating strategy reflected this perception.

\section{Testing}

We conducted testing sessions once a year. In the first session scenario 4 was materialized without contradictions; save the insight that the effect of Pace of knowledge renewal is slower than assumed, the Theory was corroborated.

In the second session (two years after formalization) the economic situation turned up, so (with the "Slow pace of knowledge renewal" still) the actual conditions singled out scenario 3; however, the scenario did not fit the environment. Despite the evidenced increase in demand, the engineering colleges (IND included) have not grown.

The reaction to this finding was spontaneous: the Theory is false; and the pointing to the false assumption was as quick:

The competition among the colleges became tougher, and the larger amount of students is distributed across more institutions.

In other words, the colleges-universities allocations ratio is no more a factor; instead the significant ration is of the colleges that provide engineering 
education to the colleges in total ${ }^{44}$. It is noteworthy that despite the intensive attention paid to the strategy throughout the period (and the explicit reliance of the strategy on the Theory), the falsity has not been noticed but upon the testing.

The falsification had an instant impacted on the strategy, which was revised in line with the updated Theory. With that the phase ended.

\section{Evaluation}

\section{Constructs}

The Theory: we regard the completeness criterion as equivalent to the $v a$ lidity of the cognitive map; in this sense the criterion is partly satisfied. IND's participants accentuated the authenticity or the knowledge representation. The understandability was acknowledged by both participants: IND highlighted the clarity of the causal relations and EDU emphasized the common language gained through the mapping. The Theory appeared simple as well: around 10 variables, easy to represent and grasp. The structureattribute-causality distinction is exhaustive and mutually-exclusive (i.e. complete) and understandably represented.

The negative aspect is that the Theory inherits the limitations embedded in the cognitive map; especially inflictive is the lacking time dimension (duration). The weak representation of duration was encountered in both implementations: in IND it concerned the "Technology change", and in EDU the "Knowledge renewal". The IND case demonstrates the damage of that limitation: it "mitigates" the falsity of the Theory and postpones the falsification. For example, the environment-scenario contradiction upon session 3 was explained that way: "There is no problem, this is the reality. The Telco BTV supply increases, slowly though, because the Technology change is lengthy".

As for the other limitations, the need for nonmonolithic expression is exemplified by IND's $1^{\text {st }}$ scenario: "Under extreme circumstances the trend turns over", a relation that the Theory cannot exhibit. In the Theory of SBU2, which is not presented, we faced the need for Conditional or interactive causation: where one variable enables another one but does not drive it.

In summary, the simplicity of the map is gained at the expense of its completeness, but the understandability is still fair; the limitations do not exceed the expectations.

\footnotetext{
${ }^{44}$ What happened was that the CHE has granted many colleges an engineering degree. Consequently the supply outnumbered the demand, although more than half the students learned in colleges.
} 
The initial conditions stand all the criteria but ease of use: as happened in IND, a long time was required before they could render a meaningful, testable change. This limitation is inherent.

The scenarios meet all the criteria, especially the ease-of-use: no further contemplation is required thanks to the structured derivation from the Theory.

The environment construct meets all the criteria.

\section{Model}

The criteria concern internal and external validity (internal consistency and fidelity with the real world, respectively). The internal consistency is a priori, follows from the logical formalism; in contrast, the fidelity with the real world requires empirical evidence. This point is controversial.

Prima facie the answer is yes: each instance of $S \neq E$ (scenario unequal to environment) indicated a falsity in the Theory. Yet the participants' perceptions are contrasted. IND's evaluation questions both the reliability of the observations and the validity of the scenarios ("the argument that certain indicators signify a specific scenario, or that the Theory dictates only these and not other scenarios, may be incorrect"). In EDU, the opposite is true: "the scenarios' examination supports the Theory's falsification - and indeed, that's what happened".

So there is an "apparent disagreement" to explain (will be done upon "Specifying learning").

\section{Method}

Clarification: in this section we evaluate the procedure; the impact on the user is examined in the next section.

The method is operational, effective and efficient, but weak upon the easeof-use criterion. The techniques vary by contribution to each criterion.

There is unanimous agreement about the effectiveness of the Elicitation and explication of the Theory, yet with a different emphasis. EDU's president highlighted the elicitation as an eye-opening vehicle:

The "Pace of knowledge renewal" is a variable that I did not notice before, as well as the "Economic situation". They definitely were not in my mind. The "Dominance of the values approach in education" issue was also unclear to me. It might have been the most significant discovery in retrospect.

IND's participants were more satisfied with the explication, since in their opinion the elicitation was trivial. They liked the analytical modeling, the 
visual representation and the amplified awareness of the relationships granted by the analysis. They had two reservations: one, that not all the attributes had been unveiled; two, that the process was too long and too fragmented.

On the other hand, the systematization was difficult and required tight facilitation. The laddering interview was efficient in extracting the attributes, but neither this nor the levelness of the causal relations could be reached without the researcher's involvement.

There was wide agreement about the effectiveness of the Observations of basic statements. Both participants noted that their scanning became much more focused and targeted. For example, in IND: "I gained much higher awareness of what to look around"; in EDU, the president stated:

The Theory's explication definitely sharpened my information needs. I notice elements previously unattended to.

The Exhaustive and comprehensive derivation of the deducible scenarios was efficient, and remarkably easy. As of the effectiveness, we may ask whether the "attributionalization" tactic applied on the steady forces violates the rule. The results show a positive balance, as the tactic does not undermine the logical line whilst is clearly more practical. In total the earned efficiency pays off.

The Exclusive focus on the "area of net interest" was effective, although counterintuitive for the participants. A special attention by a trained facilitator is required in order to keep the focus on track. The effectiveness is expressed by elimination: we did not encounter normative resistance when the Theory was falsified. The Predefined hypotheses, which the participants had to confront, contributed to that end as well.

The core technique of Genuine and risky testing of the Theory is also operational and efficient. The testing procedure succeeded to differentiate between corroboration and falsification of the Theory. However, the participants varied upon the ease-of-use of the testing and the understanding of its consequences (more about it shortly).

The similar results across as varied organizations as IND and EDU suggest that the method stands the criterion of generality.

\section{Instantiation}

We witnessed two different impacts of the method on the users:

- In IND, the design Theory is falsified whilst the parallel falsification of the descriptive Theory is denied; in other words, there is no mirroring. The strategy corresponds with the design Theory alone. 
- In EDU, the descriptive Theory is falsified; the falsification is simultaneously projected on the design Theory, and the strategy is revised accordingly.

The participants evaluated the impact in light of their attitude. In IND:

This is all about the way of thinking.... We did not feel that the analysis had added to our understanding of the reality; we understand the reality anyway and know what is going on. We intuitively understand that there are these and other driving forces, and the forces are conceptualized in our mind. We think differently from the method: we notice that we do not sell and ask ourselves what the problem was. We definitely don't look for answers form the [descriptive] Theory. We take for granted some future scenarios and after the fact try to explain what was wrong. Even if the [descriptive] Theory is true, that does not guarantee the validity of the strategy.

Since the strategy obtains its validity from the design Theory, the last sentence denies the mirroring between the descriptive and the design Theories.

In EDU:

I [the president] have no doubt that the idea of "reality control" is right. As a manager I apply the scientific logic through process flowcharts [i.e. design Theory]. The method reminds us that science also means falsification [of the descriptive Theory], and in issues as central as strategy the hypotheses' testing is literally a must. The scenarios' examination supports the Theory's falsification - and indeed, that's what happened, fortunately still in time. After all we are an academic institute, and our managerial attitude should be scientific as well.

In short he says: as a manager I lean on the design Theory; as a scientist I concern the descriptive Theory; the method connects both worlds.

\section{Specifying Learning}

In this section we theorize about the disagreements; in order to separate them we highlight the agreements first. 


\section{Agreements}

Agreements were reached about the constructs and the method. Two aspects share a wide agreement in particular:

1. The contribution of the Theory's explication.

2. The effectiveness of the honed environmental scanning that the testing orientation dictates.

\section{Disagreements}

Two disagreements were detected, relating to:

1. The model, concerning its fidelity with the real world.

2. The instantiation and the inter-Theory mirroring.

The first disagreement is attitude-driven; IND's arguments indicate the entrenchment of the conventionalist (Kuhnian) stance. For us it signifies that the method failed to bridge the attitude gap.

The second disagreement suggests that the mirroring, again in IND, is not as straightforward as assumed. Common to both disagreements is IND's resistance against EDU's acceptance of the method. The deliberate diversity of participants was aimed at such occasion, so we ask which organizational idiosyncrasy could cause the differences.

A hint in this direction is EDU's testimony: "As a manager I apply the scientific logic through process flowcharts. The method reminds us that science also means falsification [...] After all we are an academic institute, and our managerial attitude should be scientific as well". This means: the scientific orientation drives both the not-to-be-conventionalist decision and the comprehension of the mirroring.

On that basis we theorize that (unless uniquely scientific-oriented) organizations face one more falsification obstructer between the descriptive and the design Theories. Since the Theories are claimed to mirror each other, we name the added obstructer the "Broken mirror" (figure 8.5).

The consequences of this theory on the second cycle are:

1. The intervention has to incorporate "scientific indoctrination".

2. The method has to take into account the "Broken mirror" obstructer.

3. Unlike EDU's uniqueness, the participant organization should not be scientific-oriented (but not too similar to IND).

The process hypothesis is updated accordingly (the update is underlined): 
H2. The techniques employed throughout the method overcome the "mindless derivation", the "mental irrefutability" and the "Broken mirror" falsification obstructers.

Note that the agreements relate to $H 1$ (the environment, p. 92). In the second cycle (described in the next chapter) the agreements are retested and the disagreements are explained through $H 2$. Figure 8.5 below updates the theory.

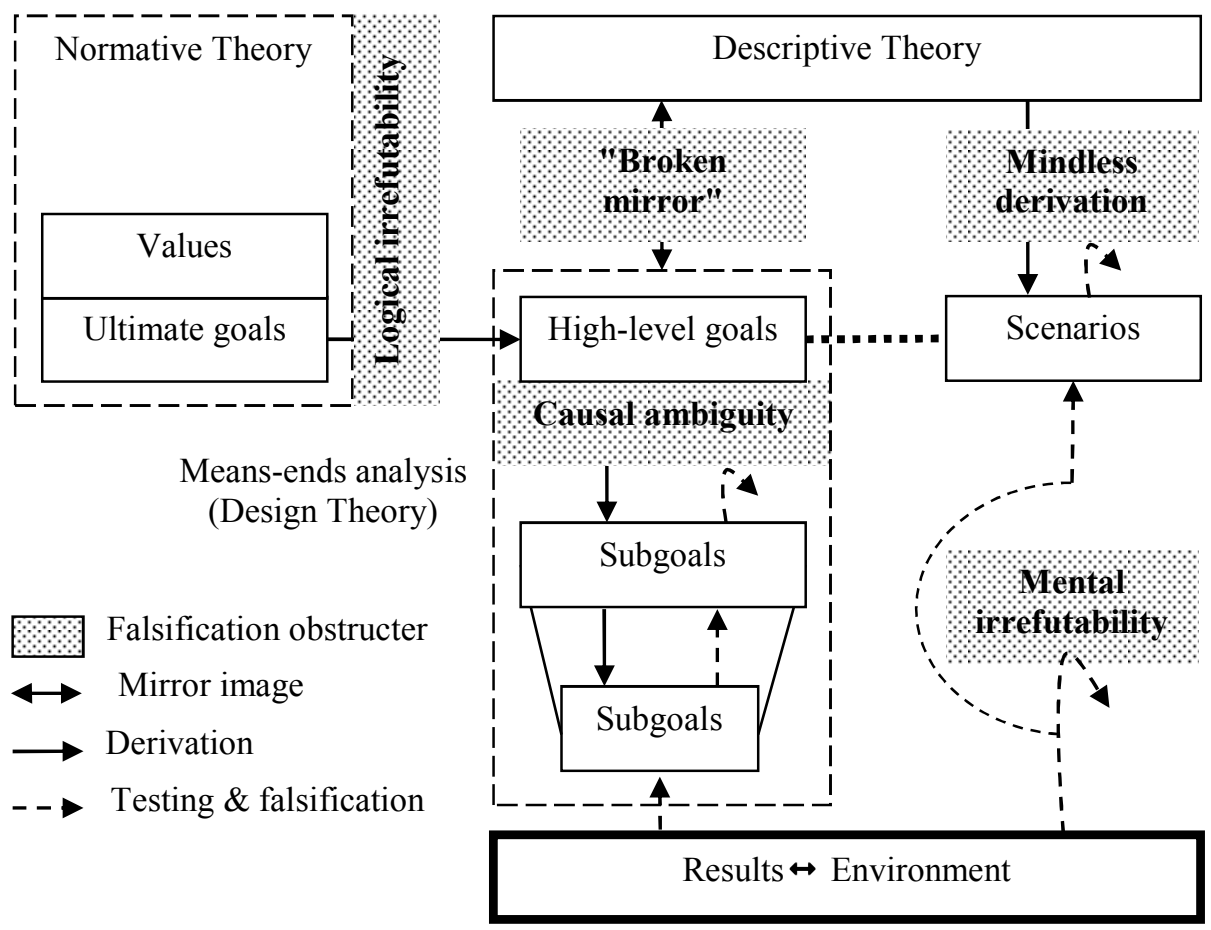

Figure 8.5. The Falsification Obstructers theory, updated 


\section{Action Research, Cycle II}

\section{The Participant}

Cycle II involved one participant: a software company nicknamed SOFT. The cycle was conducted during 2009, a year of which the first half was shadowed by the economic recession.

SOFT is a small Israeli private company, of about 20 employees, which is owned and run by its founder. The company specializes in IBM collaboration products and is an official IBM business partner. SOFT provides the full range of IT services including sales, development, implementation and maintenance. The company targets the enterprise market, usually for enduring contracts.

SOFT shares the commercial orientation of IND, but differs by size, structure and industry - hence an eligible participant. As the same important was the full-hearted willingness to participate.

SOFT's CEO (identified hereinafter as B') accepted my request to join the research for definitely the sake of curiosity. She received an explanation about the study, its theoretical ground and objectives, the action-research method, and was briefed about the $1^{\text {st }}$ cycle. B' preferred not to involve subordinates in the research, because of their workload (a side-effect of the tough economic situation). Anyway, she stressed, nothing is the company is beyond her supervision.

B' has over 15 years of experience in the market, of which the last five in SOFT and the rest as a salaried senior executive in a larger company. A prominent characteristic of this particular market (in Israel) is its stability mild competition among very few providers; $\mathrm{B}^{\prime}$ is among the most experienced veterans.

Table 9.1. "ID card" of the $2^{\text {st }}$ cycle's participant

\begin{tabular}{ll}
\hline Alias & SOFT \\
Identity & IT services company \\
Industry & $\begin{array}{l}\text { Collaboration software } \\
\text { Ownership }\end{array}$ \\
$\begin{array}{l}\text { Size (number of } \\
\text { employees) }\end{array}$ & 20 \\
$\begin{array}{l}\text { Structure } \\
\text { Range of activities }\end{array}$ & CEO, 3 senior managers, temporary project teams \\
\hline
\end{tabular}


The $2^{\text {nd }}$ cycle is planned and implemented as same as the $1^{\text {st }}$ cycle.

\section{Problem Diagnosis}

\section{Data collection}

Table 9.2 aligns the utterances with the Theoretical System's constructs, same way as in the former cycle.

Table 9.2. SOFT's expressions

\begin{tabular}{|c|c|c|c|}
\hline & \multicolumn{3}{|c|}{$\begin{array}{l}\text { Descriptive Theory } \\
\text { Constructs: "navigation" (how the customer finds a } \\
\text { provider) [19]; marketing channels [29]; clients/risk } \\
\text { distribution [41]; marketing intensity [57]. } \\
\text { The customer's economic robustness is a driving force, } \\
\text { although not the prime [227]. } \\
\text { Investment in enterprise-wide software is for the long } \\
\text { run [275]. }\end{array}$} \\
\hline & & Unconsciol & rivation \\
\hline $\begin{array}{l}\text { Values } \\
\text { Leeway for the } \\
\text { employees. Not } \\
\text { to decide alone } \\
\text { [184]. } \\
\text { The customer is } \\
\text { above all [195]. } \\
\text { To be on the } \\
\text { safe side: where } \\
\text { the need is } \\
\text { recognized and } \\
\text { addressable } \\
\text { without further } \\
\text { investment } \\
\text { [206]. } \\
\text { Preference for } \\
\text { the long-term } \\
\text { considerations } \\
\text { [248]. } \\
\text { Fairness [252]. }\end{array}$ & Prohibition & $\begin{array}{l}\text { Initial } \\
\text { conditions }\end{array}$ & Prohibition \\
\hline
\end{tabular}


Table 9.2. SOFT's expressions

\begin{tabular}{|c|c|c|}
\hline Ultimate goals & High-level goals & Scenarios \\
\hline $\begin{array}{l}\text { Entrepreneurial- } \\
\text { mode strategy } \\
{[127] .}\end{array}$ & $\begin{array}{l}\text { To maximally exploit } \\
\text { the extant channels } \\
{[11] \text {. }} \\
\text { To promote IBM's } \\
\text { strategic products } \\
{[103] \text {. }} \\
\text { To reach customers } \\
\text { through both needs } \\
\text { and solutions [110]. } \\
\text { To expand the activity } \\
\text { overseas [120]. }\end{array}$ & $\begin{array}{l}\text { As a business partner I depend } \\
\text { on IBM's forthcoming policy } \\
{[270] \text {. }}\end{array}$ \\
\hline $\begin{array}{l}\text { Logical } \\
\text { irrefutability }\end{array}$ & $\begin{array}{l}\text { Causal ambiguity } \\
\text { The business in which } \\
\text { I operate is a very } \\
\text { inexact science [420]. }\end{array}$ & $\begin{array}{l}\text { Mental irrefutability } \\
\text { Unless confronting a crisis, } \\
\text { managers don't check their } \\
\text { paradigm [419]. } \\
\text { I'm a captive of my perceptions } \\
\text { [564]. }\end{array}$ \\
\hline & $\begin{array}{l}\text { Subgoals } \\
\text { Expansion through } \\
\text { good customer } \\
\text { relations [22]. } \\
\text { To target medium- } \\
\text { large enterprises [52]. } \\
\text { Problem-driven } \\
\text { solutions: addressing } \\
\text { the needs that the } \\
\text { customer has already } \\
\text { recognizes [34; 67]. } \\
\text { To respond to the } \\
\text { customer's needs } \\
\text { rather than being } \\
\text { pushy [94]. } \\
\text { The seller has to have } \\
\text { control over the } \\
\text { development [50]. } \\
\text { When cooperating, } \\
\text { other firms mind only }\end{array}$ & \\
\hline
\end{tabular}


Table 9.2. SOFT's expressions

\begin{tabular}{|c|c|}
\hline $\begin{array}{l}\text { their interests [69]. } \\
\text { Adaptive strategy } \\
\text { [80]. } \\
\text { To establish long- } \\
\text { term, trust-based } \\
\text { relations with the } \\
\text { customer [152]. }\end{array}$ & \\
\hline $\begin{array}{l}\text { Sub-subgoals } \\
\text { Developers should be } \\
\text { trained in-house [74]. } \\
\text { To cope with our } \\
\text { weaknesses through } \\
\text { cooperation [177]. } \\
\text { To offer applications, } \\
\text { not infrastructure } \\
\text { [279]. }\end{array}$ & \\
\hline $\begin{array}{l}\text { Results } \\
\text { I justify my strategy } \\
\text { first of all by the } \\
\text { results [138]. } \\
\text { The company makes a } \\
\text { progress despite the } \\
\text { recession [140]. } \\
\text { We're excluded from } \\
\text { the Microsoft market, } \\
\text { from the small } \\
\text { enterprises segment } \\
\text { [269]. }\end{array}$ & $\begin{array}{l}\text { Environment } \\
\text { Information sources: IBM, } \\
\text { colleagues, customers, } \\
\text { employees [85]. } \\
\text { I direct my employees to open } \\
\text { their eyes and to look for } \\
\text { opportunities [91]. } \\
\text { The present tendency in the } \\
\text { market is to reduce costs [93]. } \\
\text { The competition is almost zero } \\
\text { [228]. } \\
\text { The collaboration software } \\
\text { market is split between IBM } \\
\text { and Microsoft [265]. } \\
\text { Microsoft is more sensitive to } \\
\text { the customer than IBM [295]. }\end{array}$ \\
\hline
\end{tabular}

\section{Diagnosis}

The normative and the design Theories were readily articulated; their utterances are quite often interwoven. Three underlying motifs can be extracted: 
1. The tight, long lasting relations with the customer. The family metaphor is salient, epitomized by the repeated usage of the term "Catholic marriage". The firm believes in trust-based relations, long-run considerations and personal contacts.

2. The need-driven approach: the right way is to make the customer feel that he sensed the problem and then to respond with a solution. The motto is "need from the field".

3. The conservative, safe-bets attitude, which prefers flexible cooperative contracts whenever it is possible rather than bold investments.

Whilst the third principle is a tentative reaction to the economic constellation, the first two reflect a long-standing tradition which is to stay.

Unlike the solidness of these both Theories, the other constructs are sparse. The descriptive Theory mentions only concepts or attributes whilst empty of causality. No scenarios are mentioned save one: the IBM-conducted future; and the environment is a closed vendors-distributers ${ }^{45}$-customers loop.

The expressions in table 9.2 explain why these constructs are unheeded. First, the firm restricts its attention to the IBM environment, which is considered tightly regulated (by IBM). Second, there assumed to be enough sensors within this environment, so changes are anyway detectable. Third, "the business in which I operate is a very inexact science", so intuition or feelings are as the same valuable as a systematic surveillance. Forth, the results justify the attitude.

In summary, two problems are diagnosed in SOFT:

1. The Theory is static (no causality) and strictly confined; no attention is paid to the wider environment.

2. The sole validation method is the results control.

The scenarios' falsification obstructers do not apply since there are no scenarios.

\section{Action Planning}

Based on cycle 1 we added the "Broken mirror" as a falsification obstructer. In order to re-mirror we revise the method whilst the constructs and the model remain unchanged.

${ }^{45}$ For distinction, IBM and Microsoft are labeled "vendors" and the secondarymarket companies (like SOFT) are referred to as "distributers". 


\section{Method}

The revision concerns the first formalization technique: instead of plain Elicitation, the technique consists of Structured mirroring, explication and systematization of the descriptive Theory. This is done in the following order:

1. Explication of the design Theory, with which the participant ought to be familiar.

2. Structured mirroring of the descriptive Theory through laddering, i.e. asking what rationalizes the design Theory.

3. Completion of the explication and systematization steps.

The remaining techniques still apply, except that the area-of-interest principle becomes more delicate; this is because the mirroring necessarily concerns the area-of-influence, so the systematization has to clear out the superfluous range.

\section{Instantiation}

The method will be implemented in SOFT with the researcher's facilitation. Once the Theory and the scenarios are constructed, we will run the testing every 6 months until we can substantiate an evaluation. Next we will specify the learning.

The CEO is the single participant, as agreed upon the researcher-client agreement.

\section{Action Taking}

\section{Formalization}

Once the design Theory was explicated (table 9.2 and beyond), we applied the structured mirroring technique. We departed from two major themes in the design Theory:

1. The tight, long lasting relations with the customer.

2. The confined market (SOFT's inability to penetrate the smallbusiness segment was regarded the main constraint on the strategy).

The following excerpt demonstrates the technique:

R' (Researcher): let's switch our perspective [to the descriptive Theory]. What are the factors that influence the company? What is out there that drives your strategy?

B': the customer's economic situation; it is not the most influential, but it is a factor. The issue of competitors is mar- 
ginal. We are considered the best in the market, because we are professional and honest. I know how my competitors act, and my approach is different. I prefer moderate but enduring profits over short-run high profits. We and the customer cooperate.

R': you said that the market is sensitive to economic fluctuations, so we assume that the product is not a commodity. You also claim that trust and honesty play a crucial role. What else?

B': I'm subject to IBM's policy. IBM competes with Microsoft, so I compete with Microsoft's distributers. The IBM's approach determines who will be my client. IBM is not so friendly for small enterprises and consequently I'm not there.

R': are the customers loyal to the product? Do they switch from one product to another?

$B^{\prime}$ : no, it is a long-standing choice. It is uneasy to replace the technology. We talk about cross-organization solutions and the initial investment is high. There is no reason to change. Therefore we concentrate on applications that exploit the infrastructure.

Besides, there are little experts like us in the market, and that's another reason for the customer's hesitation. The product we offer is undoubtedly superior, but a small business appreciates other factors. They are less interested in security or reliability and are more troubled by price and service.

R': so you are influenced by segment distribution. If there are more or less small (or big) businesses your situation will be different.

B': that's right. I'm trying to penetrate the small business segment but they look for different features.

The discussion continued back and forth between the design and the descriptive Theories. The next excerpt, chronologically a bit later, is a distinct reflection of the "Broken mirror" syndrome and of the re-mirroring. It concerns the positive relation from "Sensitivity to user's habits" to "Split market" in the descriptive Theory (figure 9.1).

The first paragraph demonstrates the "Broken mirror"; B' recalls particular precedents but does not fins the rule. The second reflects the re-mirroring; she moves on toward generalization and conceptualization: 
B': [refers to the descriptive Theory:] I still don't get it ... neither you nor I know whether [the relation] is positive or negative... all I know is what happens in reality: a newcomer CEO that replaces the software throughout the company because he is used to another software, or a CIO that avoid adopting my software because he's afraid that his users can't get used to it.

[After a pause:] OK, now I understand. In some applications, although the variation in the interface is already small, the customers still reject my solutions. Why is this? This is the power of habits.

The descriptive Theory that finally emerged is presented in figure 9.1. The "First cross-industry force" is the split of the market, between IBM and Microsoft, which restricts SOFT's activity. Four forces influence the split (from the right-hand side, clockwise):

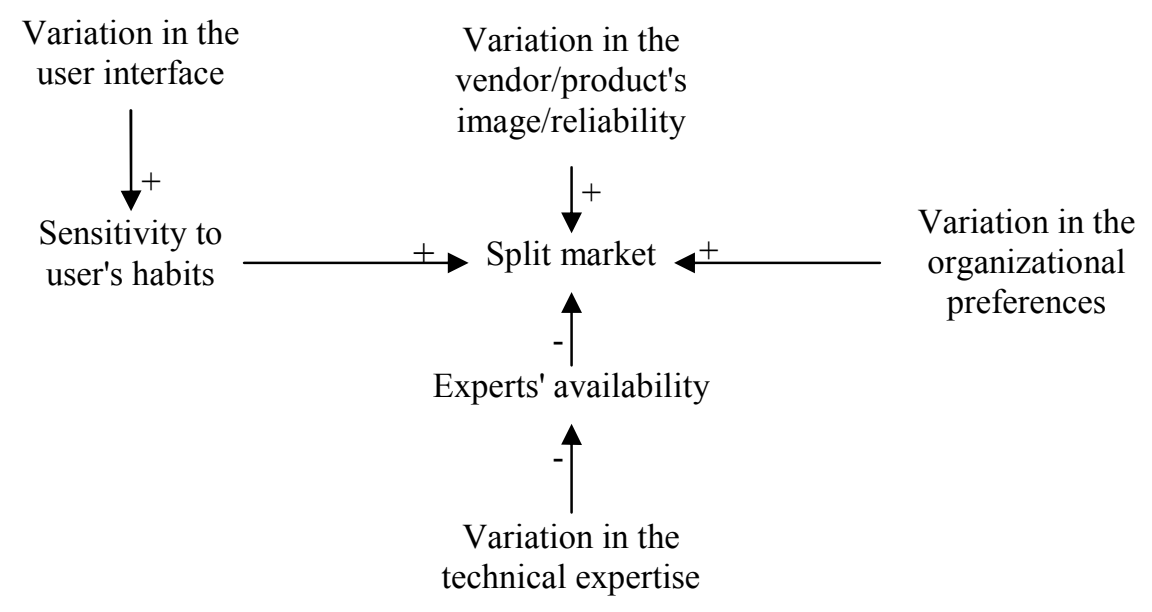

Figure 9.1. SOFT's Theory

- The variation in the organizational preferences: large firms prioritize security, reliability and scalability, whilst small firms prefer low costs and fast-reactive service. This is the demand-side restriction.

- The variation in the technical expertise required for each product prevents across-product mobility and restricts the experts' availability. This is a supply-side influence that exacerbates the former.

- $\quad$ The varied user interfaces, regardless the friendliness of each product, impeded the transfer from one product to another and posts a 
mental block (habits-driven) beyond the economical-technological considerations.

- The variation in the image/reliability of the product/vendor: IBM and its products are perceived less friendly and less sensitive to small businesses than the competition.

Of the four primary forces the Variation in the user interface is already low, therefore considered an attribute; and the Variation in the technical expertise is - in a second thought - quite marginal. Hence two primary forces remain. The emanating scenarios are described below (figure 9.2).

1. "Sold game": a monopoly-like of each vendor. High premiums, long-lasting vendor-customer relations. The incentive for new developments is low.

2. Competition: there are more competitors, no monopoly, and differential prices. The reliability is important and the vendor-customer relations last for long. The market is more diversified. There is a moderate incentive for new developments.

3. Niche market: price competition, products are adapted for niches and are more differentiated. The customer depends on the vendor.

4. Price war: tough competition around marginal features, desertion of competitors from the market. Fast transfer of customers from one vendor to another. High incentive for technological developments.

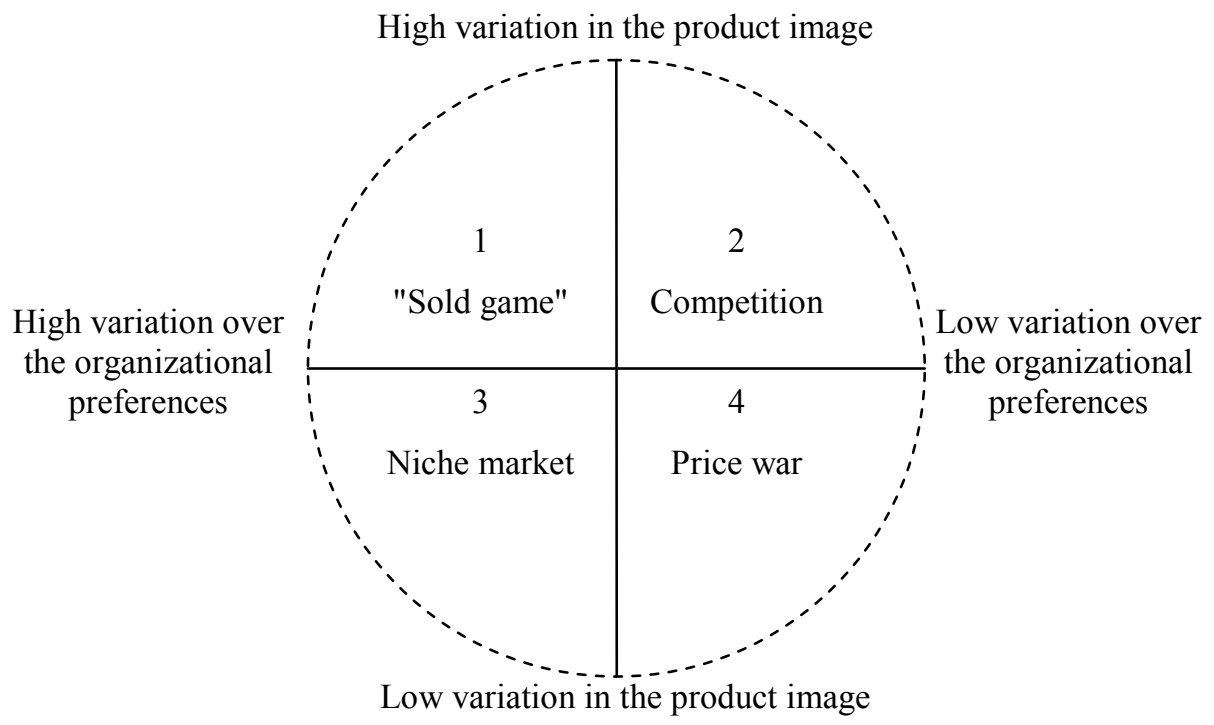

Figure 9.2. The scenarios derived in SOFT 


\section{Testing}

The first testing was conducted 10 months later (4 months beyond schedule). The initial conditions have changed remarkably enough for determining the materialized scenario - which was no. 2 ("Competition").

We compared the indicators to the environment and found the following (table 9.3):

Table 9.3. Environment vs. scenario comparison

\begin{tabular}{|c|c|}
\hline Scenario 2 - Competition & $\begin{array}{c}\text { Observed in } \\
\text { the } \\
\text { environment? }\end{array}$ \\
\hline 1. More competitors & No \\
\hline 2. No monopoly & Yes \\
\hline 3. Differential prices & Yes \\
\hline 4. The reliability is important & See below \\
\hline 5. The vendor-customer relations last for long & Yes \\
\hline 6. The market is more diversified & No \\
\hline 7. Moderate intensive for new developments & No \\
\hline
\end{tabular}

Upon the reliability is important indicator (no. 4) B' experienced a concept formation: the breakdown of the "reality" concept into three sub-concepts reliability of the product, of the vendor and of the distributer. This discovery led to another one:

Here [concerning reliability] there is some change... I don't know how to deal with it. Is it the reliability of the distributer? If so, it does not matter anymore. Let's distinguish: there is the reliability of the vendor... But then, the reliability is less important when the customer knows that he shares the same trouble with many other customers... the reliability does not stand alone, but is a consequence of another factor: the customer's self-confidence when he affiliates to the majority, even if that majority means a less reliable product.

This was the first crack in the Theory. Then we reviewed the entire list and the mismatch was conspicuous: more than half the indicators were not ob- 
served. B' immediately inferred that the Theory was falsified and started retheorizing. She discovered that the duopolistic market ceased to exist:

The Theory is incorrect... there are additional factors. You know what? Google is also a competitor, which I did not take into account. I have thought only about IBM and Microsoft, but there are more competitors. The freeware has appeared and is growing. It is a new problem for me.

It is noteworthy that (1) the "duopolistic market" assumption was a cornerstone in SOFT's strategy, and (2) B' asked herself, during the formalization, whether other competitors deserved her attention; she mentioned and negated a few, but the freeware was not among them. This is literally unawareness.

We conducted the evaluation right after the testing.

\section{Evaluation}

\section{Constructs}

There are no new insights regarding this aspect.

\section{Model}

The empirical evidence for fidelity was reconfirmed. Concerning the disagreement about the users' acceptance, SOFT took EDU's side, and commented after the testing: "I accept the model... It made me critical. I can recognize that [the reality] is unlike [the scenario], and then I wonder why: because we have failed to take that something into account".

More than that, it was already upon the formalization when B' stated: "this scenario is less probable but still is possible [according to the Theory]. These two scenarios oppose one another but both are logically possible. If we face a contradiction [between the environment and the scenario] we will know that the Theory is failed or that some factor is missing".

\section{Method}

The revised technique (Structured mirroring, explication and systematization of the Theory) is operational: it worked to extract the descriptive Theory. But simple it is not, so the mirroring requires tight facilitation. The following dialogue took place after the formalization; it demonstrates the user's alienation from the descriptive Theory, the mediation made by the researcher and the enlightenment that follows: 
$\mathrm{R}^{\prime}$ : does the method we employed, from design to description, make sense to you? Was the transformation smooth?

B': yes, but... my actions are not guided by the Theory but by the limited resources I possess. The resources determine my decisions, not the Theory.

R': but you can spend the same resources in different ways. Try to think otherwise: imagine that you have unlimited resources; will the Theory (not your decision!) change?

B': I don't know what to say... yes, you're right!

The other techniques were reemployed and were effective as before (including the worrisome Exclusive focus on the "area of net interest"), so the claim for generality holds.

It was interesting that B' (unknowingly, I guess) echoed Popper's admonishments against the conventionalist tendencies: she asserted that the Predefined hypotheses could be a double-edge sward since the user may tend to protect the predictions rather than acknowledge the falsification; she almost stumbled on this trap, she said. Just for that, she continued, the Observations of basic statements were an effective countermeasure as it confronted her with the hard evidence.

Last but not least: the cycle reaffirms the low score on the ease-of-use criterion. The researcher's assistance was required throughout the whole process.

\section{Instantiation}

The impact on the participant was immediate. The Theory's falsification was crystal clear and the participant accepted it with no reservations. Two consequences followed:

- The participant retrieved previous cues she had encountered and reinterpreted them in light of the revised Theory: "I did not react to those signals. I have never thought about it that way; but now... because of the freeware [concept], all the signals make sense".

- She instantly mirrored the Theories, this time in the design direction: "I understand that it means some [strategic] change... I have to think what I can do about it".

Later she announced her intention to reiterate the process a year later.

\section{Specifying Learning}

The agreements reached upon the first cycle were reconfirmed, concerning the constructs and the method. 
The specific hypothesis targeted in this cycle, i.e. the "Broken mirror" obstructer, was corroborated from two directions:

1. The obstructer was detected upon formalization.

2. Once the method was adapted according to that hypothesis, the disagreements encountered in the former cycle were settled.

Overall conclusions are discussed in the next and last chapter. 


\section{Discussion and Conclusions}

\section{Discussion}

An essential part of the discussion - that is, the method evaluation - was carried out at the respective phase in the research. In this section we discuss additional issues beyond strict evaluation.

\section{The applicability of the method}

All the three participants experienced difficulties during the method's implementation. The difficulties culminated toward formalization and diminished towards the testing, being the systematization the most problematic. The need for specialized facilitation was evident; even a participant as science-oriented as EDU could not handle the theorization independently. It seems unreasonable that the method can be prescribed as a recipe.

However, this is not an exception. Many management tools require professional escort and still are ubiquitous (e.g. ISO, balanced score card, or dialectic inquiry). Whilst this difficulty is surmountable, more troubling was the normative resistance that the managers demonstrated against the root idea: to pursue unknown problems. The common stance was that the already-known problems were enough.

A typical reaction in IND indicated that the problem recognition is beyond the management attention: "our thinking order is: what's the problem, to whom the problem may concern, how many profits can a solution yield, and which share of it we can seize". EDU presented a similar reaction, although not as blatant: the post-falsification strategic revision was soon halted; in the president's opinion it happened because the problem was not yet a crisis when recognized.

SOFT's CEO commented that "without a crisis managers do not check their paradigms" (she wished she was exceptional); Mintzberg et al (1976) reached the same conclusion four decades ago. The attitude (as Popper claimed) is the root obstructer and the main disabler, not the difficulty of the method.

\section{Scenarios}

The concept of scenarios is a known and popular management tool (used by $42 \%$ of the respondents to Bain \& Company's survey, $2009^{46}$ ). A by-product

\footnotetext{
${ }^{46} \mathrm{http} / /$ www.bain.com/bainweb/publications/publications_detail.asp?id=27075\&m enu url=publications\%5Fresults\%2Easp; visited April 9, 2010.
} 
of the method, beyond the falsification function, is the improvement of this tool per se.

First, in the management literature the Theory and the scenarios are interwoven and undistinguishable (this is what the mindless derivation is about). The traditional generation of scenarios is dialectic (chapter 4, p. 72) and yields a three-tenet, eclectic construct; Schoemaker (1993) counts the three: "[scenarios] may present antithetical world views. In terms of inquiring systems (Churchman, 1971), scenarios are Hegelian in their underlying philosophical premise [...] The gist of the scenario method seems that it is many things: art and science, deduction and induction, structure and fluid..." (p. 194). In contrast, the method we suggest produces scenarios with a coherent orientation: scientific, deductive and structured.

Second, the traditional method substitutes the answer for the question. Schoemaker (1995) asks and answers: "How can you determine if your final scenarios are any good? The first criterion is relevance" (p. 30). Our stance is that the relevance is the very question, and the "goodness" concerns the Theory from which the scenarios are deduced.

Third, the traditional scenarios presuppose the interactions of the firm with its environment (Schoemaker, 1995), thus are sensitive to enactment; our method enables a better distinction.

\section{The cognitive mapping}

Axelrod (1976) limits the cognitive map to represent only the causal Theory; other sorts of Theory are excluded. The virtue of the limitation is the map's unequivocalness: "The more types of images, arguments, and assertions that are allowed into the map, the less chance that the map can be coded the same way by two different coders" (Axelrod, 1976, p. 260). Since in our instance the "coder" is the Theory holder (rather than a third party), we are exempted from this limitation. In this sense we introduced the attribute, which as a constraint on causality enhances the Theory's falsifiability.

Beyond causal representation, the method promotes concept formation (recall SOFT's decomposition of "reliability"). It is a by-product of the cognitive mapping notion that extends its functionality.

\section{Evaluation of the research}

The AR principles were intended to achieve rigor in the design (table 5.6); in this paragraph we evaluate the implementation of these principles and reflect on the research as a whole.

Davison et al (2004), who conceived the CAR (canonical action research) five principles, suggest a detailed checklist for evaluation; it is annexed to this chapter. In brief all the applicable criteria were satisfied; with the first three principles speak for themselves, the last two deserve elaboration. 
The $4^{\text {th }}$ reads "The Principle of Change through Action", and the question is whether the method did cause the change "beyond a reasonable doubt". The answer rests on each of the three instances:

1. IND: it was not until the falsification that the system integrators factor, entitled "regular evolution" in hindsight, was mentioned. Recall that we entered the process shortly after a thorough strategic session and involved most of the strategic echelon; yet the omission was not noticed up to that point.

2. EDU: the daily engagement with the strategy (that was derived strictly from the Theory) has not evoked awareness of the intercollege competition for a year. The eyes were opened only upon the falsifying testing.

3. SOFT: the duopoly market assumption was questioned during the formalization, but the freeware concept was not among the potential entrees mentioned (although already existed). Just the falsification prompted the CEO to discover the factor and to reinterpret previous cues.

From the $5^{\text {th }}$ principle ("The Principle of Learning through Reflection") we elaborate on two questions: (d) "Were the results considered in terms of implications for further action in this situation?" And $(\mathrm{g})$ "Were the results considered in terms of the general applicability of CAR?" The answers are interwoven; we begin with the latter.

We explained in chapter 5 (p. 89) that although we deal with strategic management we embraced the IT version of AR because the management version is practically underdeveloped. Despite the unequal domain the method was adequate and did not necessitate amendments. So the CAR presents general applicability across domains.

However, the CAR was poor to address the attitude issue; and if we regard the attitude as "implications for further action", the method had better be altered. For instance, when French (2009/b) aimed at attitude change in strategic management, he conducted a participatory action research and found it appropriate. In this sense the applicability is purpose-sensitive rather than general.

The last reflection concerns the prevailing meaning of design science in management. Van Aken (2005) prominently advocates the use of design science in the field, but from a stance that contrasts practice with science (like Schon, 1983). In his view the relevance-rich design science has to counterbalance the rigor-only explanatory science. Van Aken opposes the unidirectional knowledge flow from explanatory science to design and calls for parallel and loosely-coupled avenues. 
Our research borrows the moderate stance of the IT literature and demonstrates a management application in which the design science maintains symbiotic relations with the explanatory science.

\section{Conclusions}

\section{The research objectives}

The research objectives were announced as follows:

1. To explicate the Popperian face of organizations in order to posit a competing theory to the inadequacy argument.

2. To corroborate the competing theory and by that to supplant the inadequacy argument.

3. To counteract the unawareness problem.

The first objective was attained through the literature review. Based on fragments of Popperian-like manners the falsification obstructers theory was introduced. Toward the second objective we derived three hypotheses from the theory and designed an organizational method aimed at their testing. The first hypothesis (twofold) concerns the environment:

H1a. The organization's environment can be theorized in a falsifiable fashion.

$H 1 b$. The right route is capable of obtaining unequivocal falsification.

This hypothesis was confirmed across both cycles. As for the second hypothesis that concerns the organization, its first version was challenged upon the first cycle. The source for the conflict was hypothesized and the pertinent technique was revised toward retesting. The essence of the update is that the "right route" is ineffective unless explicitly connected to the left route. The updated hypothesis reads:

H2. The techniques employed throughout the method overcome the "mindless derivation", the "mental irrefutability" and the "Broken mirror" falsification obstructers.

The hypothesis was tested and confirmed upon the second cycle. The ultimate objective is attained through the falsification route that $H 2$ indicates (figure 10.1). The act of re-mirroring (signified by the black dot) engenders the interface between the Popperian and the organizational conceptualizations. 


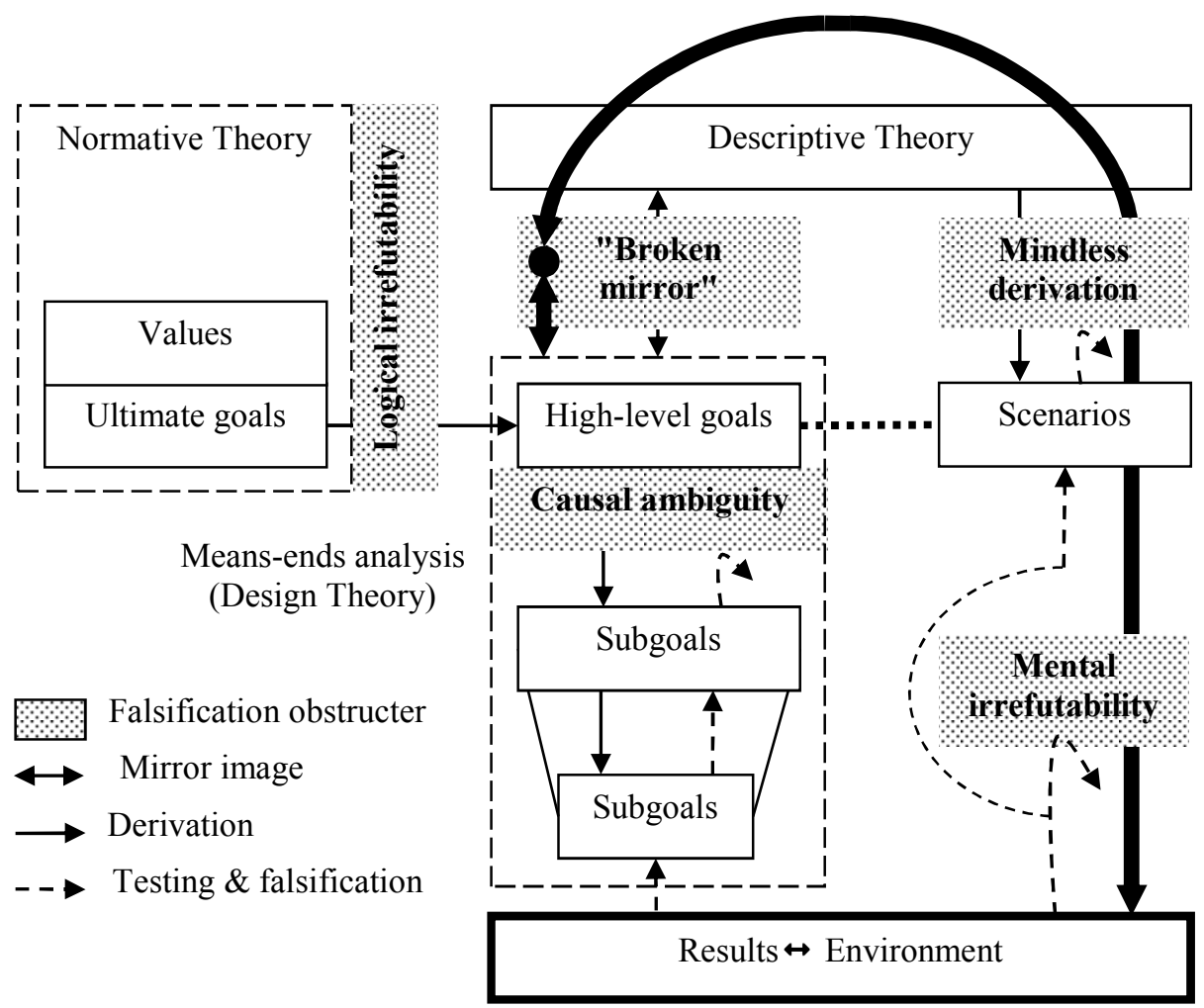

Figure 10.1. The organization's "Theoretical System" and the falsification route (marked by the thick arrow)

\section{Need for further research}

Along the research several issues for further inquiry were detected. We propose to consider the following:

1. In chapter 1 (figure 1.1, p. 7) we tried to determine the frequency (and the associated damage) caused by a false Theory, but figured out that such a category was missing. Next we stressed the poor attention paid to the unawareness problem and the parallel problem recognition phase, compared to e.g. uncertainty.

There is a need for empirical studies that specify the unawareness problem or the falsehood of the Theory as distinct categories, in order to estimate the cost of the associated damage. It is likely that large figures will draw the attention of academics and practitioners.

An example in a parallel direction is McKinsey's research effort to quantify the strategic effect of cognitive biases. The $1^{\text {st }}$-quarter2010 issue of McKinsey on Strategy Newsletter announces the mission: 
"This issue of McKinsey on Strategy highlights our recently published package on the application of behavioral economics to strategic decision making. Its articles combine new research that quantifies the benefits of "debiasing" strategic decisions with practical tools for engineering strategy processes that mitigate the effect of cognitive bias$\mathrm{es}^{47} . "$

2. Still in chapter 1 (p. 22) we concerned the scarcity of epistemological references to the organizational context. The allegation is twofold: first, the few explicit epistemological accounts overemphasize the social dimension (examples were indicated); second, most of the studies that concern the shortcomings of the organizational Theory prefer the cognitive over the epistemological perspective. Even when alternative perspectives are considered, Camerer (1985) still regards the unawareness as an issue for which the cognitive viewpoint is exclusive.

The epistemology of organizations has to be investigated beyond the socio-cultural aspects (maybe a branch entitled "philosophy of management" is necessary).

3. In chapter 4, upon criticizing the "Critical Method" (p. 82), we commented that this method addresses formal (specific-decision based) causality with methods that are suitable for efficient or final causality (associated with descriptive or design theories, respectively). Consequently, the method and the problem it targets mismatch.

Further research has to inquire whether this discrepancy harms other management methods that encounter the causality factor but fail to distinguish between its different forms.

4. In chapter 8 we experienced the limitations embedded in the cognitive map. Although they were surmountable, improvements are welcomed. The prominent weaknesses are the temporal notation and the expression of complex relationships, which are frequent in strategic context.

The quest for a better cognitive representation is accomplishable through design science, and this connects us to the next issue.

5. In the present chapter we commented about the underdevelopment of management-related design science. The IT tradition is a desirable benchmark in this sense.

47 http://www.mckinseyquarterly.com/newsletters/strategy/2010Q1.htm, visited April 7, 2010. 
6. The conventionalist attitude of managers appeared to be a significant barrier. The stream entitled "evidence-base management" (Pfeffer \& Sutton, 2006) is a counteraction in place, though induction-oriented. The question how to promote a radical attitude change is still open.

Specifically disturbing is the intensive use of case studies in management education. The case study as a teaching instrument shares many similarities with the Kuhnian "puzzle" notion (e.g. game orientation, well-defined boundaries, known end and pursue of "elegance"). The impact of this device on the students' attitude is an open question.

7. Along this study we sharply distinguished between "theory" and "Theory", holding the former as scientific and the latter as practical and the target for validation. A question in this sense is the extent to which the distinction applies, or in other words: is and to which extent the managers' Theory incorporates scientific theories? Given that scientific theories are tested as a regular manner, can a greater leaning on them enhance the validity of the Theory?

However, the science-practice integration is not straightforward. In a recent study Raymond et al (2010) discuss the difficulties associated with it in the domain of environmental management, and find significant barriers that stem from different ontologies and epistemologies held by each party. Their conclusion is the need for "a shift in science from the development of knowledge integration products to the development of problem focused, knowledge integration processes" (p. 1775; emphasis added). Hence we pose both the benefits and the applicability of incorporation as open questions.

\section{Epilogue}

There is an endless debate whether management is science or art, based on theory or experience. I believe that experience is invaluable, but at the same time we should remember that:

We do not stumble upon our experiences, nor do we let them flow over us like a stream. Rather, we have to be active: we have to "make" our experiences. It is we who always formulate the questions to be put to nature [...] for nature does not give an answer unless pressed for it (Popper, 1961, p. 280; italics in origin).

And when nature is "pressed for it" the outcome is the undesired "greatest havoc". 


\section{Annex to Chapter 10: Evaluation of the Action Re- search}

Table 10.1. The Action Research evaluation (based on Davison et al, 2004).

$\checkmark=$ satisfied; N/A = not applicable.

Principles and Criteria Check Comments

1. The Principle of the Researcher-

Client Agreement (RCA)

a. Did both the researcher and the client agree that CAR was the appropriate approach for the organizational situation?

b. Was the focus of the research project specified clearly and explicitly?

c. Did the client make an explicit commitment to the project?

d. Were the roles and responsibilities of the researcher and client organization members specified explicitly?

e. Were project objectives and evaluation measures specified explicitly?

f. Were the data collection and analysis methods specified explicitly?

2. The Principle of the Cyclical Process Model (CPM)

a. Did the project follow the CPM or justify any deviation from it?

No deviation.

b. Did the researcher conduct an independent diagnosis of the organizational situation?

c. Were the planned actions based

Also based on the 


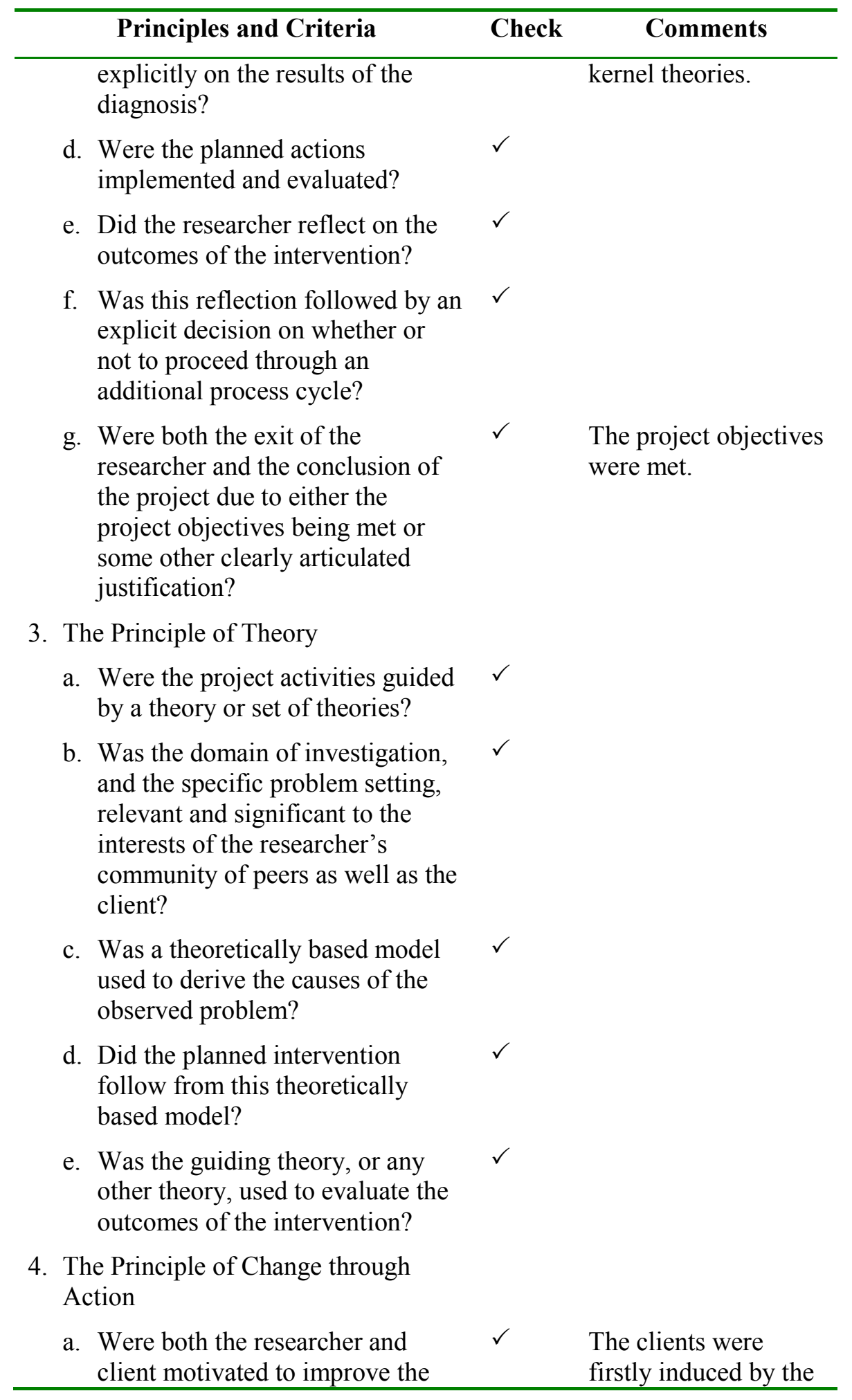




\begin{tabular}{|c|c|c|c|}
\hline & Principles and Criteria & Check & Comments \\
\hline & situation? & & $\begin{array}{l}\text { researcher and bought } \\
\text { in after the diagnosis. }\end{array}$ \\
\hline & $\begin{array}{l}\text { Were the problem and its } \\
\text { hypothesized cause(s) specified as } \\
\text { a result of the diagnosis? }\end{array}$ & $\mathrm{N} / \mathrm{A}$ & $\begin{array}{l}\text { The diagnosis } \\
\text { confirmed the pre- } \\
\text { assumed problems. }\end{array}$ \\
\hline & $\begin{array}{l}\text { Were the planned actions } \\
\text { designed to address the } \\
\text { hypothesized cause }(\mathrm{s}) ?\end{array}$ & $\checkmark$ & \\
\hline & $\begin{array}{l}\text { Did the client approve the planned } \\
\text { actions before they were } \\
\text { implemented? }\end{array}$ & $\checkmark$ & \\
\hline & $\begin{array}{l}\text { Was the organization situation } \\
\text { assessed comprehensively both } \\
\text { before and after the intervention? }\end{array}$ & $\checkmark$ & \\
\hline f. & $\begin{array}{l}\text { Were the timing and nature of the } \\
\text { actions taken clearly and } \\
\text { completely documented? }\end{array}$ & $\checkmark$ & \\
\hline \multicolumn{4}{|c|}{$\begin{array}{l}\text { 5. The Principle of Learning through } \\
\text { Reflection }\end{array}$} \\
\hline a. & $\begin{array}{l}\text { Did the researcher provide } \\
\text { progress reports to the client and } \\
\text { organizational members? }\end{array}$ & $\checkmark$ & \\
\hline & $\begin{array}{l}\text { Did both the researcher and the } \\
\text { client reflect upon the outcomes } \\
\text { of the project? }\end{array}$ & $\checkmark$ & \\
\hline & $\begin{array}{l}\text { Were the research activities and } \\
\text { outcomes reported clearly and } \\
\text { completely? }\end{array}$ & $\checkmark$ & \\
\hline & $\begin{array}{l}\text { Were the results considered in } \\
\text { terms of implications for further } \\
\text { action in this situation? }\end{array}$ & $\checkmark$ & $\begin{array}{l}\text { A major change of } \\
\text { attitude is required. }\end{array}$ \\
\hline & $\begin{array}{l}\text { Were the results considered in } \\
\text { terms of implications for action to } \\
\text { be taken in related research } \\
\text { domains? }\end{array}$ & N/A & \\
\hline & $\begin{array}{l}\text { Were the results considered in } \\
\text { terms of implications for the } \\
\text { research community (general }\end{array}$ & $\checkmark$ & \\
\hline
\end{tabular}




\begin{tabular}{lll}
\hline \multicolumn{1}{c}{ Principles and Criteria } & Check & \multicolumn{1}{c}{ Comments } \\
\hline $\begin{array}{l}\text { knowledge, informing/re- } \\
\text { informing theory)? }\end{array}$ & & \\
g. Were the results considered in & $\checkmark$ & $\begin{array}{l}\text { Positively across } \\
\text { disciplines, } \\
\text { terms of the general applicability } \\
\text { of CAR? }\end{array}$ \\
& $\begin{array}{l}\text { negatively across } \\
\text { purposes. }\end{array}$ \\
\hline
\end{tabular}




\section{References}

Agor WH (1986) How top executives use their intuition to make important decisions. Business Horizons 29 (1): 49-53

Apgar D (2006) Risk intelligence: learning to manage what we don't know. Harvard Business School Press, Boston MA

Argyris C (1976/a) Increasing leadership effectiveness. Wiley, New-York NY

Argyris C (1976/b) Single-Loop and Double-Loop Models in Research on Decision Making. Administrative Science Quarterly 21 (3): 363-375

Argyris C (1996) Unrecognized Defenses of Scholars: Impact on Theory and Research. Organization Science 7 (1): 79-87

Argyris C, Putnam R, Smith DM (1985) Action science. Jossey-Bass, San Francisco CA

Argyris C, Schon DA (1978) Organizational learning: a theory-of-action perspective. Addison-Wesley, Reading MA

Axelrod R (1976) Structure of decisions: cognitive maps of political elites. Princeton University Press, Princeton NJ

Baehr JS (2006) A Priori and A Posteriori. Internet Encyclopedia of Philosophy (http://www.iep.utm.edu/apriori/\#H2), Last updated: October 18, 2006

Barabba VP (1998) Revisiting Plato's Cave: Business Design in an Age of Uncertainty. In: Tapscott D, Lowy A, Ticoll D (Eds). Blueprint to the Digital Economy. McGraw-Hill, New-York NY (pp: 34-59)

Barr PS, Stimpert JL, Huff AS (1992) Cognitive Change, Strategic Action, and Organizational Renewal. Strategic Management Journal 13 (8): 15-36

Bar-Yosef U (2001) The Watchman Fell Asleep: The Surprise of Yom Kippur and its Sources (Hebrew, also available in English). Zmora-Bitan, Lod

Baskerville RL, Wood-Harper AT (1996) A critical perspective on action research as a method for information systems research. Journal of Information Technology 11 (3): 235-246

Baskerville RL, Wood-Harper AT (1998) Diversity in information systems action research methods. European Journal of Information Systems 7 (2): 90-107

Bazerman MH (2006) Judgment in managerial decision making. John Wiley \& Sons, New-York NY 
Ben-Israel I (1989) Philosophy and methodology of intelligence: The logic of estimate process. Intelligence and National Security 4 (4): 660-718

Berthon P, Pitt L, Katsikeas C (1999) Marketing and technical managers: An inter-functional exploration of problem perception. European Journal of Marketing 33 (7/8): 772-793

Bettis RA, Prahalad CK (1995) The dominant logic: retrospective and extension. Strategic Management Journal 16 (1): 5-14

Bohn RE (1994) Measuring and Managing Technological Knowledge. MIT Sloan Management Review 36 (1): 61-73

Bowman C (1995) Strategy workshop and top-team commitment to strategic change. Journal of Managerial Psychology 10 (8): 4-12

Boyd BK (1996) Executive Scanning and Perceived Uncertainty: A Multidimensional Model. Journal of Management 22 (1): 1-21

Brown JS, Duguid P (2000) The Social Life of Information. Harvard Business School Press, Boston MA

Bruner JS, Goodnow JJ, Austin GA (1956) A study of thinking. John Wiley \& Sons, New-York NY

Camerer C (1985) Redirecting research in business policy and strategy. Strategic Management Journal 6 (1): 1-15

Carroll PB, Mui C (2008) Seven ways to fall big. Harvard Business Review 86 (9): 82-91

Choo CW (1999) The art of scanning the environment. American Society for Information Science 25 (3): 21-24

Christensen CM (1997/b) The Innovator's Dilemma: When New Technologies Cause Great Firms to Fail. Harvard Business School Press, Boston MA

Christensen CM, Raynor M, Verlinden M (2001) Skate to Where the Money Will Be. Harvard Business Review 79 (10): 72-81

Cook SDN, Brown JS (1999) Bridging Epistemologies: The Generative Dance Between Organizational Knowledge and Organizational Knowing. Organization Science 10 (4): 381-400

Cosier RA (1981) Dialectical inquiry in strategic planning: a case of premature acceptance? Academy of Management Review 6 (4): 643-648

Courtney H, Kirkland J, Viguerie P (1997) Strategy under Uncertainty. Harvard Business Review 75 (6): 66-79

Cowan DA (1986) Developing a process model of problem recognition. Academy of Management Review 11 (4): 763-776 
Cunha PR, Figueiredo AD (2002) Action-research and critical rationalism: a virtuous marriage. Proceedings of ECIS 2002, Gdansk, Poland

Davenport TH, Beck JC (2001) The Attention Ecology. Harvard Business School Press, Boston MA

Davison RM, Martinsons MG, Kock N (2004) Principles of canonical action research. Information Systems Journal 14 (1): 65-86

Dequech D (2000) Fundamental Uncertainty and Ambiguity. Eastern Economic Journal 26 (1): 41-60

Dervin B (1999) On studying information seeking methodologically: the implications of connecting metatheory to method. Information Processing and Management 35: 727-750

Dervin B (2003) From the mind's eye of the user: The Sense-Making qualitative-quantitative methodology. In: Dervin B, Foreman-Wernet L (with Lauterbach E) (Eds). Sense-Making Methodology Reader: Selected Writings of Brenda Dervin. Hampton Press, Cresskill NJ (pp: 269-292)

Dervin B, Nilan M (1986) Information Needs and Uses. Annual Review of Information Science and Technology (ARIST) 21: 3-33

Downey HK, Ireland RD (1979) Quantitative Versus Qualitative: Environmental Assessment in Organizational Studies. Administrative Science Quarterly 24 (4): 630-637

Dubin R (1969) Theory building. Free Press, New-York NY

Duncan RB (1972) Characteristics of Organizational Environments and Perceived Environmental Uncertainty. Administrative Science Quarterly 17 (3): 313-327

Durand T, Mounoud E, Ramanantsoa B (1996) Uncovering Strategic Assumptions: Understanding Managers' Ability to Build Representations. European Management Journal 14 (4): 389-398

Durden CH (2001) The Development of a Strategic Control Framework and Its Relationship with Management Accounting. Working paper, Massey University School of Accountancy, New-Zealand

Dutton JE, Duncan RB (1987) The Creation of Momentum for Change Through the Process of Strategic Issue Diagnosis. Strategic Management Journal 8 (3): 279-295

Dutton JE, Fahey L, Narayanan VK (1983) Toward Understanding Strategic Issue Diagnosis. Strategic Management Journal 4 (4): 307-323

Ellsberg D (1961) Risk, Ambiguity, and the Savage Axioms. Quarterly Journal of Economics 75 (4): 643-669 
Ennis RH (1987) A taxonomy of critical thinking dispositions and abilities. In: Baron JB, Sternberg RJ. Teaching thinking skills: theory and practice. Freeman, New-York NY (pp: 9-26)

Erat P, Von Krogh G (2000) Intuition and strategic rationality in strategic decision-making. Presented in the 20th annual international conference, Strategic Management Society, Vancouver, Canada

Fahey L, Prusak L (1998) The Eleven Deadliest Sins of Knowledge Management. California Management Review 40 (3): 265-276

Falcon A (2008) Aristotle on Causality. The Stanford Encyclopedia of Philosophy, Edward N. Zalta (ed.), URL =

$<$ http://plato.stanford.edu/archives/fall2008/entries/aristotle-causality/>.

Faludi A (1983) Critical Rationalism and Planning Methodology. Urban Studies 20 (3): 265-278

Figueiredo AD, Cunha PR (2007) Action Research and Design in Information Systems. In: Kock N (Ed). Information Systems Action Research. Springer, Berlin (pp: 61-96)

Foss NJ, Mahnke V (1998) Strategy research and the market process perspective. Danish Research Unit for Industrial Dynamics (DRUID) working paper \# 98-29

Foster R, Kaplan S (2001) Creative destruction. Currency, New-York NY

French S (2009/a) Action research for practising managers. Journal of Management Development 28 (3): 187-204

French S (2009/b) Re-framing strategic thinking: the research aims and outcomes. Journal of Management Development 28 (3): 205-224

Freudenthal G (1977) Philosophy of Science (Unit 5; Hebrew). Open University Press, Tel-Aviv

Fuller S (2004) Kuhn vs. Popper: The Struggle for the Soul of Science. Columbia University Press, New-York NY

Gaglio CM, Katz JA (2001) The psychological basis of opportunity identification: entrepreneurial alertness. Small Business Economics 16: 95-111

Gardner H (2006) Changing minds. Harvard Business School Press, Boston MA

Garvin DA (1993) Building a learning organization. Harvard Business Review 71 (4): 78-91

Gaskill LR, Van Auken HE, Manning RA (1993) A Factor Analytic Study of the Perceived Causes of Small Business Failure. Journal of Small Business Management 31 (4): 18-31 
Goldberg P (1989) The many faces of intuition. In: Agor WH (Ed). Intuition in Organisations. Sage, Thousand Oaks CA (pp: 62-77)

Goldman A (2006) Social Epistemology. The Stanford Encyclopedia of Philosophy, Edward N. Zalta (ed.), URL = $<$ http://plato.stanford.edu/archives/fall2009/entries/epistemology-social/>

Goold M, Quinn JJ (1990) The paradox of strategic controls. Strategic Management Journal 11 (1): 43-57

Gordon LA, Naravanan VK (1984) Management accounting systems, perceived environmental uncertainty and organization structure: an empirical investigation. Accounting, Organizations and Society 9 (1): 33-47

Gregor S (2006) The nature of theory in information systems. MIS Quarterly 30 (3): 611-642

Grove AS (1999) Only the paranoid survive. Doubleday, Garden City

Hatchuel A (2005) Towards an epistemology of collective action: management research as a responsive and actionable discipline. European Management Review 2 (1): 36-47

Hedberg BLT (1981) How organizations learn and unlearn. In: Nystrom PC, Starbuck WH (Eds). Handbook of Organizational Design. Oxford University Press, Oxford NY (pp: Vol. I: 3-27)

Hedberg BLT, Jonsson S (1977) Strategy Formulation as a Discontinuous Process. International Studies of Management and Organization 7 (2): 88109

Heuer RJ (1999) Psychology of intelligence analysis. Center for the Study of Intelligence, USA Central Intelligence Agency (CIA)

Hevner AR, March ST, Park J, Ram S (2004) Design science in information systems research. MIS Quarterly 28 (1): 75-105

Hines RD (1988) Financial accounting: in communicating reality, we construct reality. Accounting, Organizations and Society 13 (3): 251-261

Hirscheim R, Klein HK, Lyytinen K (1996) Exploring the Intellectual Structure of Information Systems Development: a Social Action Theoretic Analysis. Accounting Management \& Information Technology 6 (1/2): 1-64

Huff AS (2000) Ways of mapping strategic thought. In: Paulston RG (Ed). Social cartography. Garland Publishing, New-York NY (pp: 161-190)

Huff AS, Huff JO, Barr PS (2000) When firms change direction. Oxford University Press, Oxford NY

Hult M, Lennung S (1980) Towards a definition of action research: a note and bibliography. Journal of Management Studies 17 (2): 241-250 
Hume D (1748/2008) An enquiry concerning human understanding (Hebrew edition). Resling, Tel-Aviv

Isenberg DJ (1986/a) Thinking and Managing: A Verbal Protocol Analysis of Managerial Problem Solving. Academy of Management Journal 29 (4): $775-788$

Isenberg DJ (1986/b) The structure and process of understanding: implications for managerial action. In: Sims HP, Gioia DA (Eds). The thinking organization. Jossey-Bass, San Francisco CA (pp: 238-262)

Ittner CD, Larcker DF (1997) Quality strategy, strategic control systems, and organizational performance. Accounting, Organizations and Society 22 (3): 293-314

James GE (2000) Industry-level learning and the social construction of recipes. In: Huff AS, Huff JO, Barr PS. When firms change direction. Oxford University Press, Oxford NY (pp: 148-175)

Järvinen P (2005) Action research as an approach in design science. University of Tampere, Department of Computer Sciences, Series of Publications D - Net Publications, D-2005-2. Presented in the EURAM (European Academy of Management) Conference, Munich, May 4-7, 2005

Johnson P, Duberley J (2000) Understanding management research. Sage, Thousand Oaks CA

Johnson-Laird PN (1983) Mental models: towards a cognitive science of language, inference, and consciousness. Harvard University Press, Cambridge MA

Kemmis S, McTaggart R (2000) Participatory action research. In: Denzin NK, Lincoln YS (Eds). Handbook of qualitative research. Sage, Thousand Oaks CA (pp: 567-605)

Kiesler S, Sproull L (1982) Managerial response to changing environments: perspectives on problem sensing from social cognition. Administrative Science Quarterly 27: 548-570

Kilmann RH, Mitroff II (1979) Problem defining and the consulting/intervention process. California Management Review 21 (3): 26-33

King AW (2007) Disentangling interfirm and intrafirm causal ambiguity: a conceptual model of causal ambiguity and sustainable competitive advantage. Academy of Management Review 32 (1): 156-178

Kuhn TS (1970/a) The structure of scientific revolutions (second edition). University of Chicago Press, Chicago IL

Kuhn TS (1970/b) Logic of discovery or psychology of research? In: Lakatos I, Musgrave A (Eds). Criticism and the Growth of Knowledge. Cambridge University Press, Cambridge (pp: 1-23) 
Kullven H, Mattsson J (1994) A management control model based on the customer service process. International Journal of Service Industry Management 5 (3): 14-25

Langer EJ, Moldoveanu M (2000) The Construct of Mindfulness. Journal of Social Issues 56 (1): 1-9

Langley A, Mintzberg H, Pitcher P, Posada E, Saint-Macary J (1995) Opening up decision making: the view from the black stool. Organization Science 6 (3): 260-279

Lant TK (2005) Organizational cognition and interpretation. In: Baum JAC (Ed). The Blackwell companion to organizations. Blackwell, Cambridge MA (pp: 344-362)

Lau F (1999) Toward a framework for action research in information systems studies. Information Technology \& People 12 (2): 148-175

Levinthal DA, March JG (1993) The myopia of learning. Strategic Management Journal 14 (Special issue): 95-112

Lincoln YS (1995) Emerging Criteria for Quality in Qualitative and Interpretive Research. Qualitative Inquiry 1 (3): 275-289

Lincoln YS, Guba EG (2000) Paradigmatic controversies, contradictions, and emerging confluences. In: Denzin NK, Lincoln YS (Eds). Handbook of qualitative research. Sage, Thousand Oaks CA (pp: 163-188)

Lindblom CE (1959) The Science of "Muddling Through". Public Administration Review 19 (2): 79-88

Lindgren R, Henfridsson O, Schultze U (2004) Design principles for competence management systems: a synthesis of an action research study. MIS Quarterly 28 (3): 435-472

Lippman SA, Rumelt RP (1982) Uncertain imitability: An analysis of interfirm differences in efficiency under competition. Bell Journal of Economics 13 (2): 418-438

Louis MR, Sutton RI (1991) Switching Cognitive Gears: From Habits of Mind to Active Thinking. Human Relations 44 (1): 55-76

Lyles MA (1987) Defining strategic problems: subjective criteria of executives. Organization Studies 8 (3): 263-280

Lyles MA, Mitroff II (1980) Organizational Problem Formulation: An Empirical Study. Administrative Science Quarterly 25 (1): 102-119

Lyles MA, Schwenk CR (1992) Top management, strategy and organizational knowledge structures. Journal of Management Studies 29 (2): 155 174 
Lyles MA, Thomas H (1988) Strategic problem formulation: biases and assumptions embedded in alternative decision-making models. Journal of Management Studies 25 (2): 131-145

Majone G (1980) Policies as Theories. Omega 8: 151-162

March JG, Simon HA (1958/1993) Organizations (second edition). Blackwell, Cambridge MA

March JG, Sproull LS, Tamuz M (1996) Learning from samples of one or fewer. In: Cohen MD, Sproull LS (Eds). Organizational learning. Sage, Thousand Oaks CA (pp: 1-19)

March ST, Smith GF (1995) Design and natural science research on information technology. Decision Support Systems 15 (4): 251-266

Mason RO, Mitroff II (1979) Assumptions of Majestic Metals: Strategy through Dialectics. California Management Review 22 (2): 80-88

Merchant KA (1982) The Control Function of Management. MIT Sloan Management Review 23 (4): 43-55

Midgley G (2008) Systems Thinking, Complexity and the Philosophy of Science. Emergence 10 (4): 55-73

Milliken FJ (1987) Three Types of Perceived Uncertainty about the Environment: State, Effect, and Response Uncertainty. Academy of Management Review 12 (1): 133-143

Mingers J (2008) Management knowledge and knowledge management: realism and forms of truth. Knowledge Management Research \& Practice 6 (1): $62-76$

Mintzberg H (1977) Policy as a Field of Management Theory. Academy of Management Review 2 (1): 88-103

Mintzberg H (1987/a) The strategy concept I: five Ps for strategy. California Management Review 30 (1): 11-24

Mintzberg H (1987/b) The strategy concept II: another look at why organizations need strategies. California Management Review 30 (1): 25-32

Mintzberg H, Raisinghani D, Theoret A (1976) The Structure of "Unstructured" Decision Processes. Administrative Science Quarterly 21: 246-275

Mintzberg H, Waters J, Pettigrew AM, Butler R (1990) Studying deciding: an exchange of views between Mintzberg and Waters, Pettigrew, and Butler. Organization Studies 11 (1): 1-16

Mitroff II (1973) Systems, inquiry and the meanings of falsification. Philosophy of Science 40: 255-276

Mitroff II, Mason RO (1981) The metaphysics of policy and planning: a reply to Cosier. Academy of Management Review 6 (4): 649-651 
Morris WT (1967) Intuition and relevance. Management Science 14 (4): B157-165

Morrison JL, Mecca TV (1989) Managing Uncertainty: Environmental Analysis/ Forecasting in Academic Planning. In: Smart JC (Ed). Higher Education: Handbook of Theory and Research. Agathon, New-York NY (pp: Vol. 5 334-382)

Myers MD (1997) Qualitative Research in Information Systems. MISQ Discovery, updated version, last modified: September 2, 2008, last visited: December 2, 2009 (www.qual.auckland.ac.nz/)

Nisbett RE, Ross L (1980) Human Inference: Strategies and Shortcomings of Social Judgment. Prentice-Hall, Englewood Cliffs NJ

Nonaka I (1994) A Dynamic Theory of Organizational Knowledge Creation. Organization Science 5 (1): 14-37

O'Keefe J (1985) Is consciousness the gateway to the hippocampal cognitive map? A speculative essay on the neural basis of mind. In: Oakley DA (Ed). Brain and mind. Methuem, London (pp: 59-98)

Pauchant TC, Mitroff II, Ventolo GF (1992) The dial tone does not come from God! How a crisis can challenge dangerous strategic assumptions made about high technologies: the case of the Hinsdale telecommunication outage. Academy of Management Executive 6 (3): 66-79

Peters TJ, Waterman RH (1982) In search of excellence. Warner Books, New-York NY

Pfeffer J, Sutton RI (2006) Hard Facts, Dangerous Half-Truths and Total Nonsense: Profiting From Evidence-Based Management. Harvard Business School Press, Boston MA

Polanyi M (1974) Personal knowledge: towards a post-critical philosophy. University of Chicago Press, Chicago IL

Popper K (1961) The Logic of Scientific Discovery. Science Editions, NewYork NY

Popper K (1961/a) The poverty of historicism. Harper \& Row, New-York NY

Popper K (1963/2002) Conjectures and Refutations: The Growth of Scientific Knowledge. Routledge, London

Popper K (1970) Normal science and its dangers. In: Lakatos I, Musgrave A (Eds). Criticism and the Growth of Knowledge. Cambridge University Press, Cambridge (pp: 51-58)

Popper K (1994) The Myth of the Framework: In Defence of Science and Rationality. Routledge, London 
Pounds WF (1969) The process of problem finding. Industrial Management Review 11 (1): 1-19

Prahalad CK, Bettis RA (1986) The Dominant Logic: a New Linkage Between Diversity and Performance. Strategic Management Journal 7 (6): 485-501

Rapoport RN (1970) Three Dilemmas in Action Research: With Special Reference to the Tavistock Experience. Human Relations 23 (6): 499-513

Raymond CM, Fazey I, Reed MS, Stringer LC, Robinson GM, Evely AC (2010) Integrating local and scientific knowledge for environmental management. Journal of Environmental Management 91 (8): 1766-1777

Reynolds TJ, Gutman J (1988) Laddering theory, method, analysis, and interpretation. Journal of Advertising Research 28 (1): 11-31

Rittel HWJ, Webber MM (1973) Dilemmas in a general theory of planning. Policy Sciences 4 (2): 155-169

Roberts FS (1976) The questionnaire method. In: Axelrod R (Ed). Structure of decisions: cognitive maps of political elites. Princeton University Press, Princeton NJ (pp: 333-342)

Rowland G (2004) Shall We Dance? A Design Epistemology for Organizational Learning and Performance. Educational Technology Research and Development 52 (1): 33-48

Russell B (1903/1992) The Principles of Mathematics. Routledge, London

Samuelson LA (1994) On rationales for control systems. Stockholm School of Economics (SSE/EFI) Working Paper Series in Business Administration, no. 6544

Sandelands LE, Stablein RE (1987) The concept of organization mind. In: Bacharach S, DiTomaso N (Eds). Research in the Sociology of Organizations. JAI, Greenwich CT (pp: 135-161)

Schein EH (1990) Organizational culture. American Psychologist 45 (2): 109-119

Schein EH (1992) Organizational Culture and Leadership. Jossey-Bass, San Francisco CA

Schoemaker PJH (1992) How to link strategic vision to core capabilities. MIT Sloan Management Review 34 (1): 67-81

Schoemaker PJH (1993) Multiple scenario development: Its conceptual and behavioral foundation. Strategic Management Journal 14 (3): 193-213

Schoemaker PJH (1995) Scenario Planning: A Tool for Strategic Thinking. MIT Sloan Management Review 36 (2): 25-40

Schon DA (1983) The reflective practitioner. Basic Books, New-York NY 
Schreyogg G, Steinmann H (1987) Strategic control: a new perspective. Academy of Management Review 12 (1): 91-103

Schwandt TA (2000) Three epistemological stances for qualitative inquiry: Interpretivism, hermeneutics, and social constructionism. In: Denzin NK, Lincoln YS (Eds). Handbook of qualitative research. Sage, Thousand Oaks CA (pp: 189-213)

Schwenk CR (1984/a) Cognitive Simplification Processes in Strategic Decision-Making. Strategic Management Journal 5 (2): 111-128

Senge PM (1995) The fifth discipline (Hebrew edition). Matar Publishing House, Tel-Aviv

Shane S, Venkataraman S (2000) The Promise of Entrepreneurship as a Field of Research. Academy of Management Review 25 (1): 217-226

Shapiro S, Spence MT (1997) Managerial intuition: A conceptual and operational framework. Business Horizons 40 (1): 63-68

Simon HA (1945/1997) Administrative behavior (4th edition). Free Press, New-York NY

Simon HA (1986) Rationality in psychology and economics. Journal of Business 59 (4): 209-224

Simon HA (1987) Making management decisions: the role of intuition and emotion. Academy of Management Executive 1 (1): 57-64

Simon HA (1997) Models of bounded rationality (vol. 3). MIT Press, Cambridge MA

Simon HA, and Associates (1986) Decision Making and Problem Solving. Report of the Research Briefing Panel on Decision Making and Problem Solving, http://dieoff.org/page163.htm

Simons R (1995) Levers of control: how managers use innovative control systems to drive strategic renewal. Harvard Business School Press, Boston MA

Smith GF (1988) Towards a Heuristic Theory of Problem Structuring. Management Science 34 (12): 1489-1506

Snowden DF, Boone ME (2007) A leader's framework for decision making. Harvard Business Review 85 (11): 69-76

Sobel R (1984) Car wars: the untold story. Truman Talley, New-York NY

Spender JC (1998) Pluralist Epistemology and the Knowledge-Based Theory of the Firm. Organization 5 (2): 233-256

Starbuck WH, Milliken FJ (1988) Executives' perceptual filters: What they notice and how they make sense. In: Hambrick DC (Ed). The executive ef- 
fect: Concepts and methods for studying top managers. JAI, Greenwich CT (pp: 35-65)

Staw BM (1981) The escalation of commitment to a course of action. Academy of Management Review 6 (4): 577-587

Sterman JD (2000) Business dynamics: systems thinking and modeling for a complex world. McGraw-Hill, New-York NY

Susman GI, Evered RD (1978) An Assessment of the Scientific Merits of Action Research. Administrative Science Quarterly 23 (4): 582-603

Thornton S (2006) Karl Popper. The Stanford Encyclopedia of Philosophy (Winter 2006 Edition), Edward N. Zalta (ed.), URL = $<$ http://plato.stanford.edu/archives/win2006/entries/popper/>

Tsoukas H (1996) The Firm as a Distributed Knowledge System: A Constructionist Approach. Strategic Management Journal 17 (SPI 2): 11-25

Tymon WG, Stout DE, Shaw KN (1998) Critical analysis and recommendations regarding the role of perceived environmental uncertainty in behavioral accounting research. Behavioral Research in Accounting 10: 23-46

Van Aken JE (2005) Management Research as a Design Science: Articulating the Research Products of Mode 2 Knowledge Production in Management. British Journal of Management 16 (1): 19-36

Von Krogh G, Roos J, Slocum K (1994) An essay on corporate epistemology. Strategic Management Journal 15 (1): 53-71

Wack P (1985/a) Scenarios: uncharted waters ahead. Harvard Business Review 63 (5): 347-378

Wack P (1985/b) Scenarios: shooting the rapids. Harvard Business Review 63 (6): 139-150

Wadsworth Y (1998) What is Participatory Action Research? Action Research International, Paper 2. Available on-line:

http://www.scu.edu.au/schools/gcm/ar/ari/p-ywadsworth98.html (visited 2.12.2008)

Walls JH, Widmeyer GR, El Sawy OA (1992) Building an Information System Design Theory for Vigilant EIS. Information Systems Research 3 (1): 36-59

Walsh JP, Ungson GR (1991) Organizational memory. Academy of Management Review 16 (1): 57-91

Weick KE (1969) The social psychology of organizing. Addison-Wesley, Reading MA

Weick KE (1979) The social psychology of organizing. Addison-Wesley, Reading MA 
Weick KE (1993) The Collapse of Sensemanking in Organizations: The Mann Gulch Disaster. Administrative Science Quarterly 38: 628-652

Weick KE (1995/b) Sensemaking in organizations. Sage, Thousand Oaks CA

Weick KE (1996) The nontraditional quality of organizational learning. In: Cohen MD, Sproull LS (Eds). Organizational learning. Sage, Thousand Oaks CA (pp: 163-174)

Weick KE (2004) Mundane Poetics: Searching for Wisdom in Organization Studies. Organization Studies 25 (4): 653-668

Wijnhoven F, Meertens L (2010) Hegelian Inquiring Systems and Critical Triangulation Tools for the Internet Information Slave. Research Paper, Center for Telematics and Information Technology, University of Twente

Williams T (2007) Adapting in practice: what questions might we ask? Foresight 9 (5): 3-13

Wilson TD (1999) Exploring models of information behaviour: the 'uncertainty' project. Information Processing and Management 35 (6): 839-849

Yates B (1983) The decline and fall of the American automobile industry. Empire Books, New-York NY

Zack MH (2001) If Managing Knowledge is the Solution, then What's the Problem? In: Malhotra Y (Ed). Knowledge Management and Business Model Innovation. Idea Group Publishing, Hershey PA (pp: 16-36)

Zaleznik A (1977/2004) Managers and Leaders: Are They Different? Harvard Business Review 82 (1): 74-81 


\section{Index}

\section{A}

Action research (AR), 25, 94, 95, 96, 97, $98,100,101,106,107,180,181,190$, 192, 193, 194, 195, 196

Agor WH, 41, 190, 194

Ambiguity, 3, 15, 16, 20, 56, 63, 65, 69, $79,80,83,102,118,126,131,134$, 135, 138, 168, 192, 195

Apgar D, 17, 190

Area-of-(net-) interest, 145, 171

Area-of-influence, 145, 171

Argyris C, 57, 58, 68, 74, 80, 94, 97, 190

Aristotle, 33, 38, 67, 82, 193

Assumption, 11, 55, 58, 72, 79, 103, 112, $159,176,181$

Austin GA, 19, 191

Axelrod R, 12, 78, 79, 80, 81, 84, 85, 86, $143,145,180,190,199$

\section{B}

Baehr JS, 47, 190

Barabba VP, 146, 190

Barr PS, 12, 13, 22, 37, 190, 194, 195

Bar-Yosef U, 77, 190

Baskerville RL, 94, 95, 97, 98, 190

Bazerman MH, 17, 18, 190

Beck JC, 18, 192

Ben-Israel I, 41, 74, 75, 76, 77, 78, 82, 191

Berthon P, 20, 42, 191

Bettis RA, 37, 41, 191, 199

Bohn RE, 19, 191

Boone ME, 17, 200

Bounded awareness, 17, 18, 36

Bowman C, 23, 191

Boyd BK, 16, 191

Broken mirror, 4, 67, 164, 165, 170, 172, 178,182

Brown JS, 24, 39, 110, 191

Bruner JS, 19, 22, 191

Butler R, 197

\section{C}

Camerer C, 184, 191

Carroll PB, 8, 191

Causality, 139, 193
Choo CW, 66, 191

Christensen CM, 38, 39, 59, 134, 191

Cognitive mapping, 12, 13, 78, 79, 80, $81,83,84,85,140,141,143,146$, $160,180,184,190,198,199$

Cognitive perspective, 1, 22, 23, 41

Conceptualization, 2, 15, 16, 19, 22, 44, 54, 64, 104, 131, 135, 139, 172, 175, 180

Conscious ignorance, 17, 20, 21, 58

Control, 13, 16, 30, 36, 40, 44, 45, 57, $58,63,64,65,66,69,100,105,109$, $134,138,144,145,150,163,168$, $170,192,195,196,197,199,200$

Conventionalism, 1, 29, 30, 32, 35, 39, $44,78,82$

Cook SDN, 24, 39, 191

Cosier RA, 72, 191, 197

Courtney H, 15, 16, 82, 191

Cowan DA, 42, 191

Critical Method, 74, 78, 82, 83, 184

Critical Rationalism, 1, 2, 4, 24, 26, 28, $35,42,44,45,54,87,91,96,97,107$, 192, 193, 196, 200

Cunha PR, 35, 94, 97, 99, 100, 107, 192, 193

Davenport TH, 18, 192

Davison RM, 94, 95, 97, 98, 99, 107, $180,186,192$

Decision making, 13, 20, 184, 190, 196, 200

Dequech D, 15, 192

Dervin B, 23, 42, 192

Design science, 25, 88, 89, 90, 92, 95, $96,97,98,104,181,182,184,194$, 195

Downey HK, 15, 192

Duberley J, 32, 94, 95, 195

Dubin R, 140, 192

Duguid P, 110, 191

Duncan RB, 16, 59, 192

Durand T, 24, 39, 192

Durden CH, 65, 66, 192

Dutton JE, 20, 59, 60, 61, 79, 192

\section{E}


El Sawy OA, 35, 67, 89, 201

Ellsberg D, 15, 192

Enactment, 59, 69, 80, 145, 180

Ennis RH, 82, 193

Epistemology, 23, 24, 27, 29, 34, 38, 45, 46, 63, 184, 194, 199, 200, 201

Erat P, 41, 193

Evely AC, 199

Evered RD, 95, 97, 201

\section{F}

Fahey L, 20, 60, 73, 192, 193

Falcon A, 67, 193

Falsification, 1, 2, 3, 4, 22, 24, 25, 26, $29,35,41,46,47,48,49,51,54,62$, $63,66,67,68,69,70,71,72,73,76$, $82,83,87,88,91,92,94,97,99,101$, $102,103,108,132,136,142,144$, $145,148,155,160,161,162,163$, $164,165,170,177,179,180,181$, 182, 183, 197

Falsification Obstructers (theory of), 2, 3, $4,25,26,70,71,87,88,91,92,101$, $102,103,165,170,182$

Faludi A, 41, 67, 193

Fazey I, 199

Figueiredo AD, 35, 94, 97, 99, 100, 107, 192,193

Foss NJ, 16, 193

Foster R, 38, 193

French S, 95, 181, 193

Freudenthal G, 28, 30, 32, 97, 193

Fuller S, 28, 193

\section{$\mathbf{G}$}

Gaglio CM, 16, 193

Gardner H, 22, 193

Garvin DA, 73, 193

Gaskill LR, 7, 193

Goldberg P, 41, 194

Goldman A, 27, 194

Goodnow JJ, 19, 191

Goold M, 66, 194

Gordon LA, 16, 194

Gregor S, 67, 89, 194

Grove AS, 8, 9, 14, 20, 22, 194

Guba EG, 28, 196

Gutman J, 143, 199

\section{H}

Hatchuel A, 94, 97, 194

Havoc, 5, 7, 8, 71, 185
Hedberg BLT, 5, 6, 38, 41, 57, 61, 62, 194

Henfridsson O, 95, 100, 196

Heuer RJ, 41, 194

Hevner AR, 89, 92, 93, 107, 194

Hines RD, 148, 194

Hirscheim R, 94, 194

Huff AS, 12, 37, 39, 84, 103, 190, 194, 195

Huff JO, 37

Hult M, 94, 194

Hume D, 27, 29, 34, 40, 195

Ignorance, 5, 6, 15, 17, 19

Inadequacy Argument, 2, 3, 25, 26, 42 , $44,45,58,63,70,87,88,91,92,93$, 138,182

Initial conditions, 46, 49, 50, 51, 52, 53, $54,57,60,61,63,69,82,97,102$, $103,104,113,122,133,135,139$, $140,141,142,161,167,175$

Intelligence, 74, 75, 76, 77, 78, 82, 190, 191,194

Ireland RD, 15, 192

Isenberg DJ, 37, 41, 195

Ittner CD, 65, 195

\section{J}

James GE, 39, 195

Järvinen P, 97, 98, 195

Johnson P, 32, 70, 94, 95, 195

Johnson-Laird PN, 70, 195

Jonsson S, 5, 38, 41, 194

\section{K}

Kaplan S, 38, 193

Katsikeas C, 20, 42, 191

Katz JA, 16, 193

Kemmis S, 94, 195

Kiesler S, 23, 42, 195

Kilmann RH, 42, 195

King AW, 56, 195

Kirkland J, 15, 82, 191

Klein HK, 94, 194

Knowledge, 5, 19, 20, 23, 24, 30, 36, 37, $38,39,41,42,44,46,47,53,57,59$, $66,68,73,81,89,94,96,97,98,99$, 104, 107, 109, 121, 124, 130, 133, $135,157,158,159,160,161,181$, $185,188,191,193,195,196,197$, 198, 199, 200, 201, 202 
Tacit knowledge, 21, 22, 24, 30, 36,

$57,58,146,148$

Kock N, 94, 192, 193

Kuhn TS, 1, 5, 25, 28, 29, 32, 33, 34, 35, $36,37,38,39,40,43,44,59,73,193$, 195

Kullven H, 100, 196

Laddering interview, 143, 162, 171, 199

Langer EJ, 18, 196

Langley A, 56, 196

Lant TK, 39, 196

Larcker DF, 65, 195

Lau F, 95, 196

Lennung S, 94, 194

Levinthal DA, 41, 73, 196

Lincoln YS, 28, 94, 195, 196, 200

Lindblom CE, 42, 196

Lindgren R, 95, 100, 196

Lippman SA, 56, 196

Logical irrefutability, 58, 69, 102, 103, $118,126,131,135,168$

Logical positivism, 28, 29, 46

Logical reasoning, 1, 50, 82, 195, 198

Deduction, 1, 29, 30, 36, 46, 49, 50, $53,54,55,56,58,60,61,63,65$, $68,69,72,73,77,78,79,80,82$, $92,96,97,101,132,135,139$, $141,142,144,146,148,152,158$, $161,162,167,180$

Induction, 1, 21, 29, 30, 34, 36, 37, $40,41,47,48,60,61,72,73,75$, $77,78,79,82,91,92,94,97,107$, $113,180,185$

Louis MR, 18, 196

Lyles MA, 16, 38, 39, 41, 196, 197

Lyytinen K, 94, 194

\section{M}

Mahnke V, 16, 193

Majone G, 42, 197

Management, 1, 2, 5, 13, 25, 26, 27, 28, $37,39,41,43,45,54,59,63,66,71$, $73,89,93,95,100,109,126,136$, $149,163,164,179,180,181,182$, $184,185,190,191,192,193,194$, 195, 196, 197, 198, 199, 200, 201, 202

Learning, organization/management, $2,16,24,25,37,40,43,61,62$, $85,91,190,197,202$
Management literature, 1, 2, 8, 15, 24, $25,27,28,37,39,41,42,43,44,71$, 99, 180, 182

Manning RA, 7, 193

March JG, 41, 54, 55, 56, 59, 60, 61, 73, 196, 197

March ST, 88, 89, 104, 105, 106, 194, 197

Martinsons MG, 94, 192

Mason RO, 73, 94, 197

Mattsson J, 100, 196

McTaggart R, 94, 195

Means-ends, 2, 13, 24, 43, 44, 54, 55, 56, $59,63,64,67,68,69,74,79,84,90$, $91,93,96,102,103,135,146,150$

Mecca TV, 110, 198

Meertens L, 82, 202

Mental irrefutability, 3, 4, 58, 69, 82, 83, $92,102,103,118,126,131,133,135$, $138,142,143,144,145,148,165$, 168,182

Merchant KA, 40, 63, 65, 197

Midgley G, 42, 197

Milliken FJ, 15, 16, 19, 55, 72, 197, 200

Mindless derivation, 3, 4, 69, 82, 83, 92, $102,103,112,122,131,132,135$, $136,138,142,143,147,165,180$, 182

Mindlessness, 17, 18, 59, 132

Mingers J, 23, 197

Mintzberg H, 5, 6, 16, 20, 38, 41, 56, 179, 196, 197

Mitroff II, 16, 39, 42, 73, 94, 195, 196, 197, 198

Moldoveanu M, 18, 196

Morris WT, 41, 198

Morrison JL, 110, 198

Mounoud E, 24, 39, 192

Mui C, 8, 191

Myers MD, 28, 198

myth. See Theory (of the manager)

\section{$\mathbf{N}$}

Naravanan VK, 16, 194

natural law. See Theoretical system:

Statements

Nilan M, 23, 192

Nisbett RE, 59, 198

Nonaka I, 24, 198

Objectivity, 30, 42, 65, 66, 148

O'Keefe J, 19, 198 


\section{$\mathbf{P}$}

Paradigm, 1, 5, 10, 32, 33, 34, 35, 37, 38, $39,40,41,44,59,168$

Park J, 194

Pauchant TC, 16, 198

Peters TJ, 73, 198

Pettigrew AM, 197

Pfeffer J, 39, 40, 73, 185, 198

Philosophy of science, 1, 5, 28, 32, 193, 197

Discovery, 9, 29, 30, 32, 36, 56, 61, $63,71,73,155,161,175,195,198$

Justification, 30, 32, 36, 45, 46, 54, $59,62,63,70,71,72,73,74,78$, $81,83,92,148,187$

Pitcher P, 196

Pitt L, 20, 42, 191

Polanyi M, 21, 22, 198

Popper K, 1, 21, 24, 25, 28, 29, 30, 31, $32,34,35,36,37,41,42,43,44,45$, $46,47,48,49,50,51,52,53,54,56$, $57,58,61,66,67,68,69,71,72,73$, $74,76,82,88,89,91,94,96,97,142$, $144,147,148,155,177,179,185$, 193, 198, 201

Posada E, 196

Pounds WF, 14, 20, 199

Prahalad CK, 37, 41, 191, 199

Problem recognition, 1, 14, 15, 19, 20, $31,36,41,92,107,179,183,191$

Problem solving, 1, 15, 43, 55

Prohibition, 48, 49, 50, 51, 54, 56, 61, $63,69,102,113,122,140,142,167$

Prusak L, 73, 193

Psychologism, 30

Putnam R, 94, 190

\section{Q}

Quinn JJ, 66, 194

\section{$\mathbf{R}$}

Raisinghani D, 56, 197

Ram S, 194

Ramanantsoa B, 24, 39, 192

Rapoport RN, 98, 199

Raymond CM, 185, 199

Raynor M, 38, 191

Reed MS, 199

Reynolds TJ, 143, 199

Rittel HWJ, 55, 56, 199

Roberts FS, 143, 199

Robinson GM, 199
Roos J, 24, 39, 201

Ross L, 59, 198

Rowland G, 24, 199

Rumelt RP, 56, 196

Russell B, 20, 199

\section{S}

Saint-Macary J, 196

Samuelson LA, 16, 199

Sandelands LE, 39, 199

Scenarios, 5, 61, 69, 103, 132, 141, 142, $144,147,148,154,155,159,160$, $161,175,176,180,199$

Schein EH, 38, 39, 199

Schoemaker PJH, 5, 6, 61, 180, 199

Schon DA, 42, 43, 58, 59, 67, 74, 133, $181,190,199$

Schreyogg G, 65, 200

Schultze U, 95, 100, 196

Schwandt TA, 81, 200

Schwenk CR, 38, 41, 196, 200

Self-sealing, 58, 59, 134, 145

Senge PM, 85, 200

Sense-making, 57

Shane S, 16, 200

Shapiro S, 41, 200

Shaw KN, 16, 201

Simon HA, 19, 20, 37, 41, 42, 54, 55, 56, $59,197,200$

Simons R, 63, 64, 65, 200

Slocum K, 24, 39, 201

Smith DM, 94

Smith GF, 42, 88, 89, 104, 105, 106, 190, 197,200

Snowden DF, 17, 200

Sobel R, 9, 10, 200

Social science, 24, 27, 51, 52, 54, 76, 87 , 89, 91, 94, 96

Spence MT, 41, 200

Spender JC, 39, 42, 200

Sproull LS, 23, 42, 60, 195, 197, 202

Stablein RE, 39, 199

Starbuck WH, 72, 194, 200

Staw BM, 59, 201

Steinmann H, 65, 200

Sterman JD, 85, 201

Stimpert JL, 12, 190

Stout DE, 16, 201

Strategy, 1, 5, 6, 7, 8, 12, 13, 24, 37, 38, $39,41,43,53,55,59,60,61,62,64$, $65,66,70,72,79,80,83,100,103$, $105,110,111,112,113,115,118$, $119,121,132,134,136,149,150$, $156,158,159,160,162,163,168$, $169,171,176,177,179,181,183$, 
184, 190, 191, 192, 193, 194, 195, 196, 197, 198, 199, 200, 201

Stringer LC, 199

Susman GI, 95, 97, 201

Sutton RI, 18, 39, 40, 73, 185, 196, 198

Syllogism, 50, 53, 139

Major premise, 1, 50, 53, 69, 77, 82, 92, 101, 136, 139

Minor premise, 1, 50, 82, 92, 139

Prediction, 47, 50, 51, 62, 63, 76, 81 , $89,92,102,139$

\section{$\mathbf{T}$}

Tamuz M, 60, 197

Testing (a theory), 2, 29, 30, 50, 55, 56, $58,60,61,63,66,67,68,72,75,80$, $89,93,97,99,100,101,103,104$, $106,134,136,141,142,147,149$, $154,159,160,162,163,164,171$, $175,176,179,181,182$

Theoret A, 56, 197

Theoretical system, 1, 2, 49, 69, 70, 73, $76,101,103,136$

Statements, 42, 46, 47, 48, 49, 51, 58, $67,69,82,89,100,139,143,148$, $153,162,177$

Structure, 1, 2, 47, 49, 54, 55, 57, 63, $64,65,76,102,140$

Theory (of the manager), 3, 6, 8, 12, 13, $14,17,18,19,20,21,23,24,26,27$, $31,38,42,47,56,57,60,61,62,67$, $68,69,70,71,72,74,76,77,78,80$, $82,83,88,90,91,92,101,102,103$, $104,105,112,121,131,132,133$, $134,135,136,137,139,140,142$, $143,144,146,147,148,150,151$, $152,154,155,156,157,159,160$, $161,162,163,164,167,170,171$, $172,173,175,176,177,180,181$, $183,184,185$

Theory (types of)

Descriptive theory, $32,67,89,90$, 103

Design theory, 67, 89, 90, 91, 103

Normative theory, $35,57,58,60,61$, $67,68,69,98,102,103,105,112$, $113,121,124,132,133,135,140$

Theory-of-action, 57, 58, 59, 61, 62, 63, $67,68,69,91,190$

Thomas H, 1, 16, 34, 197

Thornton S, 28, 201

Truth, 23, 24, 27, 28, 29, 30, 31, 38, 39, $46,49,94,101,105,197$

Tsoukas H, 42, 201
Tymon WG, 16, 201

\section{$\mathbf{U}$}

Ultimate goal. See Theory (types of): Normative theory

Unawareness, 1, 2, 4, 5, 6, 8, 14, 15, 16, $17,18,19,20,21,22,23,24,25,26$, $27,36,41,43,44,57,61,72,73,74$, $82,87,88,93,105,118,119,132$, $134,145,148,162,176,181,182$, 183,184

Uncertainty, 15, 190, 191, 192, 197, 198 Ungson GR, 18, 201

\section{V}

Validation, 6, 23, 24, 25, 27, 28, 29, 39, 53, 57, 62, 72, 73, 80, 81, 83, 89, 97, $101,104,106,107,155,160,161$, $163,170,185$

Van Aken JE, 7, 11, 89, 181, 193, 201

Van Auken HE, 7, 11, 89, 181, 193, 201

Venkataraman S, 16, 200

Ventolo GF, 16, 198

Verlinden M, 38, 191

Viguerie P, 15, 82, 191

Von Krogh G, 24, 39, 41, 193, 201

\section{W}

Wack P, 82, 201

Wadsworth Y, 94, 201

Walls JH, 35, 67, 89, 90, 91, 98, 104, 201

Walsh JP, 18, 201

Waterman RH, 73, 198

Waters J, 56, 197

Webber MM, 55, 56, 199

Weick KE, 6, 16, 38, 39, 40, 57, 59, 201, 202

Wicked problems, 55, 56

Widmeyer GR, 35, 67, 89, 201

Wijnhoven F, iv, 82, 202

Williams T, 73, 97, 202

Wilson TD, 42, 202

Wood-Harper AT, 94, 95, 97, 98, 190

\section{Y}

Yates B, 9, 11, 22, 39, 202

\section{Z}

Zack MH, 16, 82, 202 
A CRITICAL RATIONALIST INQUIRY OF MANAGERIAL EPISTEMOLOGY

Zaleznik A, 43, 202 